\title{
L'ÉMIGRATION SUISSE HORS D'EUROPE DANS L'ENTRE-DEUX-GUERRES (1919 à 1939)
}

\author{
Par Hermann E. Vogel
}

\section{INTRODUCTION}

Il paraît impossible d'étudier une partie quelconque de l'histoire de l'humanité sans faire intervenir le problème des migrations, c'est-à-dire des mouvements de populations ou d'individus d'une région ou d'un pays à l'autre. Le désir d'améliorer une situation économique ou sociale difficile a toujours poussé certains individus à aller s'établir dans un milieu physique et économique plus favorable.

Des événements particuliers ont largement influé sur le mouvement d'émigration, son amplitude et sa direction. Ainsi, la découverte du Nouveau-Monde inaugura l'époque des migrations transocéaniques. Toutefois, celles-ci n'ont pu tour de suite prendre une grande envergure, et elles ont eu d'abord moins d'importance que les migrations continentales.

Les pays de l'Amérique du Nord (le Mexique non compris) présentaient, en effet, un faible degré d'évolution et n'ont pu, au début, absorber qu'un petit nombre d'immigrants; la base économique d'une immigration massive a dû d'abord y être créée. En Amérique latine, par contre - qui cornaissait déjà à l'époque précoloniale des civilisations très évoluées - les conquérants espagnols et portugais ont interdit l'entrée aux ressortissants d'autres nations européennes. Enfin les communications transocéaniques, encore très imparfaites, ont constitué à leur tour un sérieux obstacle à une émigration transocéanique massive.

D'autres facteurs, dépendant du pays de provenance, se sont ajoutés à ceux-ci. D'une part, les gouvernements à conception mercantile avaient pour ambition d'accroitre autant que possible le chiffre de la population, et les migrations dépendaient pour beaucoup de l'arbitraire des pouvoirs publics. Généralement, des groupes gardant leurs caractères nationaux étaient invités par le gouvernement d'autres pays européens à venir s'y établir. Citons comme exemple la colonisation de certaines régions de la Russie par des paysans allemands sous le règne de CathÉrine II. D'autre part, les guerres, les épidémies et les famines continues décimaient les populations.

Les migrations transocéaniques ont pris une grande envergure au $19 \mathrm{e}$ et au début du 20e siècle. Les pays d'outre-mer atteignent alors un degré d'évolution économique et sociale permettant l'absorption d'un grand nombre d'immigrants. Le développement des moyens de communication (navigation maritime et fluviale, réseaux ferroviaires) permet de faire valoir leurs riches et vastes terres. Une impulsion décisive est alors donnée à l'émigration par l'accroissement de la population européenne qui, à cette époque, atteint un chiffre jusqu'alors inconnu, ainsi que par l'industrialisation rapide de l'ancien continent qui rend nécessaire l'expansion économique et démographique.

Après la première guerre mondiale, les migrations changent de caractère. Les migrations transocéaniques se réduisent parce que d'une part les vastes espaces d'outre-mer, notamment aux États-Unis, se sont peuplés, et d'autre part à cause des prescriptions prohibitives émises par les pays traditionnels d'immigration. Actuellement, elles se dirigent de plus en plus vers des pays à conditions physiques - et surtout climatériques - mo:ns favorables, mais accueillant encore les immigrants. Les mouvements continentaux prédominent et prennent, comme ils ne l'avaient jamais fait auparavant, un essor extraordinaire, notamment en Asie et dans l'Amérique du Nord. La crise mondiale a cependant provoqué une forte diminution de tous les grands courants migratoires, et certains de ceux-ci ont même été inversés.

Les facteurs régissant le phénomène de l'émigration, sont donc multiples et de nature très diverse. Il va sans dire que la géographie, et surtout la géographie humaine, occupe en cette matière une position centrale; mais pour pouvoir étudier à fond un problème de géographie humaine, on est bien obligé 
de tenir compte de questions relevant de bien d'autres sciences (histoire, droit, économie politique ou commerciale, etc.) et d'appliquer des méthodes autres que géographiques. Ainsi, des services très appréciables peuvent être rendus à la géographie par la statistique. Nous entendons faire un essai d'analyse statistique sur l'émigration suisse hors d'Europe dans l'entre-deux-guerres (1920 à 1940) en utilisant la documentation réunie par l'Office fédéral et par le Secrétariat des Suisses à l'Étranger, à Berne.

Nous avons eu recours, pour nos renseignements:

à Monsieur A. JoBin, chef de l'Office fédéral d'émigration,

à Monsieur le Dr W. Imнoof (ancien) secrétaire du Secrétariat des Suisses à l'Étranger,

à Monsieur W. Baumgartner, gérant du Service suisse de placement pour le personnel commercial, et à Monsieur A. Hablützel, gérant du Service suisse de placement des techniciens.

Nous leur manifestons nos très vifs remerciements pour l'aide précieuse qu'ils nous ont apportée.

Première Partig

\section{ANALYSE DE L'ÉMIGRATION SUISSE HORS D'EUROPE}

\section{CHAPITRE PREMIER: L'APPAREIL STATISTIQUE}

\section{A. Etendue de la recherche}

Notre étude porte sur l'émigration suisse hors d'Europe: elle embrasse la période de l'entre-deux-guerres (1920 à 1940), et considère en particulier les cinq années 1924, 1928, 1932, 1936 et 1939. Nous nous sommes contenté d'étudier l'émigration hors d'Europe ou transocéanique ${ }^{1}$ pour la raison suivante:

Tous les émigrants suisses expédiés par les agences suisses dans les pays d'outre-mer sont enregistrés dans un fichier central tenu par l'Office fédéral de l'émigration à Berne. Par contre, les émigrants se dirigeant dans un pays européen ne sont enregistrés que lorsqu'ils sont astreints au service militaire ou au payement de la taxe d'exemption; les statistiques des émigrants continentaux sont ainsi incomplètes, ne comprenant ni les femmes ni les autres personnes libérées des obligations sus-indiquées.

La distinction entre "émigration continentale" et "émigration transocéanique" reste cependant un peu artificielle, ne tenant pas compte des Suisses qui, partant pour un pays européen, y prennent par la suite un billet de passage pour un pays transocéanique. L'Union soviétique, pays à la fois européen et asiatique, n'est pas traitée, la documentation sur ces régions étant rudimentaire.

D'autre part, nous avons laissé de côté les émigrants possédant un indigénat autre que l'indigénat suisse, ce qui aurait dépassé le cadre de notre travail. Une raison analogue nous a amené à ne considérer que les années 1924, 1928, 1932, 1936, de même que l'année 1939. Le nombre des fiches, dont nous disposons pour les quatre premières années citées, se monte à 10000 environ. Si nous avions voulu étudier toutes les années, de 1920 à 1940 , le travail aurait été quintuplé. Le choix des années a été guidé par les raisons suivantes: d'une part, l'année du recensement démographique suisse, 1930, est située juste au milieu des époques prises en considération. Pour comparer les chiffres de nos statistiques d'émigration avec ceux qui concernent la population suisse globale, nous pourrons donc utiliser l'annuaire statistique de la Suisse, de l'année 1930. D'autre part, les quatre années étudiées sont, en quelque sorte, typiques des diverses phases de l'évolution économique: périodes de conjoncture normale (1924), de prospérité économique (1928), de crise (1932), de reprise économique (1936).

Le choix de l'année 1939, d'autre part, s'impose, parce que les renseignements concernant les colonies suisses d'outre-mer datent de cette époque.

\section{B. Les données statistiques}

Nous nous servirons de deux genres de statistiques se rapportant au courant de l'émigration et aux colonies suisses d'outre-mer. Ce sont:

a) les fiches personnelles des émigrants suisses au nombre de 10000 donnant des indications sur l'envergure du mouvement d'émigration en 1924, 1928, 1932, 1936;

1 Selon la définition de l'Office suisse de l'Industrie, des Arts et Métiers et du Travail, l'émigration transocéanique cmbrasse tous les pays hors d'Europe. 
b) les réponses à un questionnaire envoyé en 1939 à toutes les colonies suisses de l'étranger par le Secrétariat des Suisses à l'Étranger, qui donnent des renseignements sur la structure démographique et professionnelle de nos colonies suisses à l'étranger.

$1^{\circ}$ Le relevé des données statistiques. A l'aide de la documentation consultée, nous avons établi des fiches ${ }^{2}$ indiquant pour chaque émigrant:

a) l'année et le mois de départ,

b) le canton et la commune d'origine (c'est-à-dire la bourgeoisie),

c) le canton et la commune de résidence antérieurement au départ,

d) le continent, le pays et le lieu de destination,

e) la profession (lorsque l'émigrant exerçait lui-mème une profession),

f) la profession du chef de famille (lorsque l'émigrant n'exerçait pas d'activité économique rémunératrice),

g) l'âge,

h) l'état civil,

i) le sexe.

$2^{\circ}$ Le dépouillement. C'est l'ensemble des opérations pour compter et répartir les unités statistiques en classes homogènes. Voici les critères selon lesquels nous avons procédé. Nous avons distingué:

a) 11 catégories professionnelles: Ptoduction du sol - Alimentation - Artisanat - Industrie Technique - Commerce et Banque - Tourisme - Professions libérales - Professions féminines Carrières ecclésiastiques - Rentiers; avec leurs sous-divisions respectives (par exemple: Artisanat: bâtiment, habillement; Industrie: mécanique, textile, chimique); et les professions individuelles (par exemple: Bâtiment: maçons, menuisiers, serruriers, peintres).

b) 2 catégories économiques: Individus avec activité économique; Individus sans activité économique.

c) 8 catégories d'après le sexe et l'état civil: Hommes célibataires, mariés, veufs, divorcés; Femmes célibataires, mariées, veuves, divorcées.

d) 7 classes d'âge: 0 à 9,10 à 19,20 à 29,30 à 39, 40 à 49,50 à 59 , plus de 60 ans.

Nous avons tenu compte de ces critères en étudiant les variations dans le temps (périodes envisagées: 1924-1928-1932-1936-1939) et dans l'espace en tenant compte de la provenance et de la destination des émigrants.

\section{L'évaluation de l'intensité du mouvement migratoire}

Pour tirer certaines conclusions du phénomène de l'émigration pendant l'entredeux-guerres, quant à ses variations dans le temps et dans l'espace, et selon les différentes catégories professionnelles, économiques, suivant le sexe et d'état civil ou les classes d'âge, il faut faire intervenir d'autres opérations.

Nous avons bien entendu établi les pour-cent et pour-mille de tous les chiffres établis par dénombrement. Ainsi, la population du canton de Zurich s'élevant, en 1930, à 617706 individus, le nombre de

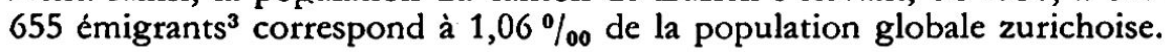

2 Par exemple la fiche ci-dessous
a) $28 \mathrm{XII}$
b) SG Balgach (100)
c) SG Heerbrugg (100)
d) Afr. Eg. Alex.
g) 47
e) -
h) $\mathrm{m}$
f) D 13
i) $f$

signifie que l'émigrant en question a quitté la Suisse en décembre 1928, qu'il était bourgeois de Balgach dans le canton de St-Gall et habitait avant de partir à Heerbrugg dans le même canton (le chiffre 100 mis entre parenthćses indique le district Unterrheintal; nous avons emprunté la numérotation des districts au "Dictionnaire géographique de la Suisse", de A. JACOT).

Il partait pour l'Afrique et gagnait Alexandrie en Egypte. Il n'exerçait pas d'activité rémunératrice, mais le chef de famille était mécanicien (D signifie industrie, D1 industrie mécanique, D13 mécanicien). L'émigrant en question avait 47 ans. Il était marié et de sexe féminin. Il s'agit donc d'une femme mariée partant probablement en compagnie de son mari ou allant le rejoindre.

${ }^{3}$ Moyenne de quatre périodes envisagées: $1924=892,1928=959,1932=235,1936=534$. 
D'autre part, le nombre total d'émigrants étant, pour le canton de Zurich, de 655, le nombre de 138 agriculteurs ${ }^{4}$ correspond à $21,06 \%$ des émigrants 5 .

De même, nous avons établi les moyennes de tous ces chiffres. Ainsi, le nombre total d'émigrants s'élevant, pour l'époque de 1851 à 1940 , à 414194 individus, la moyenne annuelle est de $4602^{6}$. Mais s'il s'agit non pas de chiffres concernant des individus, mais de pourcentages - disons, par exemple, le pourcentage d'agriculteurs par rapport au nombre total d'émigrants - et si le nombre total d'émigrants provenant des différentes régions n'est pas le même, on ne peut plus se servir de la moyenne arithmétique simple, et on doit donc faire intervenir une autre opération.

$1^{\circ}$ Les moyennes pondérées. La moyenne arithmétique pondérée tient compte non seulement de la valeur absolue des différents termes, mais encore de leur "poids»: on multiplie le pourcentage de chaque catégorie par le nombre absolu d'individus s'y rapportant, puis on divise la somme de ces produits par le nombre total d'individus. Voici, à titre d'exemple, un calcul se rapportant à l'émigration des agriculteurs. On indique:

a) les émigrants-agriculteurs de chaque canton, en nombres absolus;

b) les émigrants-agriculteurs, en pour-cent du nombre total des émigrants pour chaque canton;

c) les pour-cent d'émigrants-agriculteurs de chaque canton, multipliés par le nombre absolu d'individus.

Tableau 1. Quelques moyennes pondérées d'émigrants-agriculteurs

Canton

Argovie . . . . . . . . . . . . . . . . . . . . . . .

Appenzell Rhodes Intérieures. . . . . . . . . . . .

Appenzell Rhodes Extérieures . . . . . . . . . . . . .

Berne . . . . . . . . . . . . . . . . . . .

Bâle-Campagne . . . . . . . . . . . . . . .

Bâle-Ville . . . . . . . . . . . . . . . . . . . .

Fribourg . . . . . . . . . . . . . . . . . . .

Genc̀ve. . . . . . . . . . . . . . . . . .

Glaris . . . . . . . . . . . . . . . . . . .

Grisons . . . . . . . . . . . . . . . . . a)

173

10

61

464

74

70

23

21

22

97

7 b)

36,4

55,4

35,7

34,8

50,0

15,5

33,3

5,4

36,7

56,8 c)

6297,2

554,0

2177,7

16147,2

3700,0

1085,0

765,9

113,4

807,4

5509,6

119355,0

: 3089,0

$38,6 \%$

On multiplie donc 36,4\% par 173 (Argovie), 55,4\% par 10 (Appenzell Rhodes Intérieures), etc., additionne leurs produits $(6297,2+554,0$, etc.), établit la somme (119355) que l'on divise ensuite par le nombre total d'individus (3089) pour obtenir la moyenne arithmétique pondérée $(38,6 \%)^{8}$. On aura besoin d'elle pour calculer les écarts moyens pondérés.

$2^{\circ}$ L'écart moyen. Celui-ci permet d'établir, dans un phénomène, les domaines d'intensité supérieure, moyenne ou inférieure. On l'obtient en divisant la somme de tous les écarts élevés au carré (supérieurs ou inférieurs à la moyenne) par leur nombre et en extrayant la racine carrée.

$$
\mathrm{E}_{m}=\sqrt{\frac{\sum(\text { écart }+\mathrm{ou}-)^{2}}{\mathrm{n}}}
$$

4 Moyenne des quatre périodes envisagées.

5 On peut donc distinguer des taux d'intensité, lorsque l'on compare les émigrants à la population globale, et des taux de participation lorsque l'on compare un groupe d'émigrants au nombre total d'émigrants.

- On divise 414194 par le nombre d'années de l'époque envisagée, soit par 90; c'est le calcul de la moyenne arithmétique simple.

7 Chiffres globaux des quatre années envisagées.

${ }^{8}$ Cette moyenne pondérée n'est évidemment pas identique à la moyenne arithmétique simple, de $31,0 \%$ (voir tableau 1 ). 
Etablissons d'abord l'écart moyen simple et choisissons, à titre d'exemple, l'émigration suisse pendant la période de 1851 à 1940. On indique:

a) le nombre d'émigrants partant à une époque déterminée;

b) la différence en plus ou en moins (c'est-à-dire l'écart positif ou négatif) existant entre la moyenne arithmétique établie pour l'époque entière ${ }^{9}$ et le nombre d'émigrants valable d'une année déterminée;

c) les écarts mis au carré.

Tableau 2. Quelques écarts moyens dans le mouvement d'émigration suisse

\begin{tabular}{|c|c|c|c|}
\hline Année & a) & b) & c) \\
\hline 1851 & 6000 & +1400 & 1960000 \\
\hline 1852 & 6900 & +2300 & 5290000 \\
\hline 1853 & 5881 & +1281 & 1641000 \\
\hline 1854 & 13934 & +9334 & 87124000 \\
\hline 1855 & 4759 & +159 & 25280 \\
\hline 1856 & 2736 & -1864 & 3474500 \\
\hline 1857 & 4989 & +389 & 151320 \\
\hline 1858 & 1526 & -3074 & 9449300 \\
\hline 1859 & 1752 & -2848 & 8065600 \\
\hline 1860 & 2110 & -2490 & 6200200 \\
\hline 1940 & 1110 & -3489 & 12173000 \\
\hline & & & 679700000 \\
\hline Epoqu & 351 à 19 & ans $\rightarrow$ & $: 90$ \\
\hline & & & 7728200 \\
\hline$\forall$ & & & \\
\hline$\sqrt{7}$ & & & 2780 \\
\hline
\end{tabular}

On calcule donc les écarts (positifs ou négatifs) avec la moyenne de 4600 (en 1851: $6000-4600$ $=1400$; en 1856: $4600-2736=1864)$; on les élève au carré $\left(1400^{2}=1960000\right)$; on additionne ces carrés $(1960000+5290000+$, etc.); on établit la somme (679700000) que l'on divise ensuite par le nombre d'années (90). On obtient 7728200 et on en tire la racine, pour établir l'écart moyen (simple) de 2780 .

En ajoutant ou en déduisant ce chiffre de la moyenne de 4600 , on obtient les limites supérieure (7380) et inférieure (1820) des écarts moyens. Lorsque le nombre annuel d'émigrants dépasse ces limites en plus ou en moins, l'année en question a une forte ou faible intensité d'émigration. Ainsi, l'intensité d'émigration est faible pour les années $1858,1859 \ldots 1940$, forte pour l'année 1854.

On emploie les écarts moyens pondérés pour estimer non seulement la valeur, mais aussi le "poids» des différents termes. On multiplie les différents écarts, élevés au carré, par le nombre respectif des individus appartenant au même groupe, et en divise le produit par le nombre total des individus de tous les groupes; puis on extrait la racine du quotient. Reprenons, à titre d'exemple, l'émigration des agriculteurs. Voici le calcul. On indique:

a) le nombre absolu des émigrants-agriculteurs;

b) les émigrants-agriculteurs, en pour-cent du nombre total des émigrants de chaque canton;

c) la différence en plus ou en moins (c'est-à-dire l'écart positif ou négatif) entre la moyenne établie pour la Suisse entière ${ }^{10}$ et le pour-cent valable pour un canton déterminé;

d) on élève ces écarts au carré;

e) les écarts au carré sont "pondérés» (= multipliés) par le nombre respectif des émigrants-agriculteurs (chiffres qu'on a indiqués dans la colonne 1).

9 On a établi cette moyenne plus haut en divisant le nombre global d'émigrants de la période 1851 à 1940 (414194) par le nombre d'années de cette période ( 90 ans), et obtenu 4600 (plus précisément: 4602) individus par année en moyenne.

10 On a établi cette moyenne plus haut (tableau 1) en traitant de la moyenne pondérée; elle est de $38,6 \%$. 
Tableau 3. Quelques écarts moyens pondérés s'appliquant aux émigrants-agriculteurs Canton

\begin{tabular}{rcrr} 
a) & b) & c) & \multicolumn{1}{c}{ d) } \\
173 & 36,4 & $-2,2$ & 4,8 \\
10 & 55,4 & $+16,8$ & 286,0 \\
61 & 35,7 & $-2,9$ & 8,4 \\
464 & 34,8 & $-3,8$ & 14,4 \\
74 & 50,0 & $+11,4$ & 130,0 \\
70 & 15,5 & $-23,1$ & 540,0 \\
23 & 33,3 & $-5,3$ & 28,0 \\
$\frac{2089}{308}$ & & & \\
& & \\
$\sqrt{275,9}$ & &
\end{tabular}

e)

Argovie . . . . . . . . . 173

Appenzell Rhodes Intérieures . . . . 10

Appenzell Rhodes Extérieures . . . . . 61

Berne . . . . . . . . . . 464

Bâle-Campagne. . . . . . . . . 74

Bâle-Ville . . . . . . . . .

Fribourg . . . . . . . .

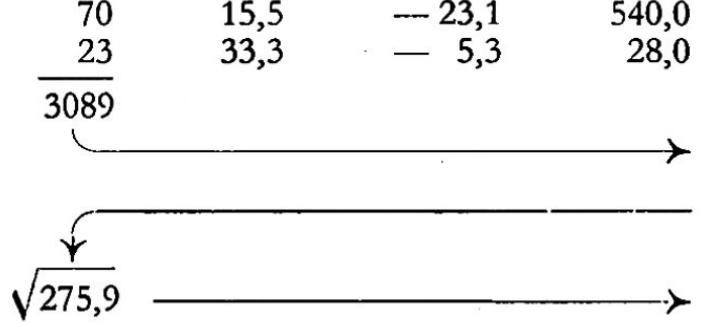

On calcule donc les écarts (positifs ou négatifs) par rapport à la moyenne de 38,6\% (Argovie $-2,2 \%$, Appenzell Rhodes Intérieures $+16,8 \%$ ), les élève au carré (Argovie 4,8), multiplie les écarts élevés au carré par le nombre respectif des émigrants-agriculteurs (Argovie 4,8 $\times 173=830$ ), additionne les produits $(830+2860+$, etc.), établit la somme (852211), la divise par le nombre total des émigrantsagriculteurs (par 3089), extrait de ce quotient de 275,9 la racine carrée et on obtient ainsi l'écart moyen pondéré de $16,6 \%$. On ajoute ou déduit celui-ci de la moyenne pondérée de $38,6 \%$ pour obtenir les limites supérieure $(55,2 \%)$ et inférieure $(22,0 \%)$ des écarts moyens pondérés.

Au-dessus de 55;2\%, l'émigration des agriculteurs est de forte intensité (par exemple Appenzell Rhodes Intérieures); de faible intensité au-dessous de 22,0\% (par exemple Bâle-Ville).

De la sorte, nous avons pu déterminer les domaines d'intensité supérieure, moyenne et inférieure du mouvement de l'émigration suisse.

\section{CHAPITRE II: ÉVOLUTION DE L'ÉMIGRATION SUISSE}

Les Alpes suisses connurent dès le moyen âge un mouvement d'émigration. If fut particulièrement intense dans les Grisons et au Tessin, où certaines classes de la population gallo-rhétienne ou lombarde allèrent s'établir de façon passagère ou permanente en Italie septentrionale ou en Vénétie pour se soustraire aux conditions de vie pénibles dues au relief, au sol et au climat de leur terre natale. Cette émigration se perpétua jusqu'en 1800, prenant alors un caractère artisanal: les Grisons partaient périodiquement pour Venise et l'Italie du Nord comme confiseurs, couteliers, cordonniers, les Tessinois pour l'Italie septentrionale et méridionale comme maçons, architectes, chapeliers, ramoneurs, vendeurs de châtaignes, etc.

Sur le versant nord des Alpes et dans le Mittelland, des famines, des disettes, des épidémies entre autres calamités provoquèrent des exodes considérables, notamment depuis le 15 e siècle, lorsque l'inégalité économique et sociale entre les villes et les campagnes commença à croître. D'autre part, l'espace restreint des terres cultivables en Suisse ne permettait de nourrir qu'un faible nombre d'habitants. L'excédent de population dut donc s'expatrier. Il en résulta l'émigration sous forme de capitulations militaires, c'est-à-dire d'un enrôlement de mercenaires à la solde de puissances étrangères. De 1472 à 1792,730000 Suisses furent engagés par la France, 190000 par d'autres États.

Le $17 \mathrm{e}$ et le début du $18 \mathrm{e}$ siècle sont caractérisés par les persécutions des anabaptistes qui, chassés de notre pays, allèrent s'établir en Amérique du Nord. En outre, des mobiles d'ordre économique provoquèrent également un mouvement d'émigration assez intense. Diverses industries familiales, exercées à domicile, s'étaient développées en Suisse; elles procuraient aux habitants des gains supplémentaires considérables et permettaient de nourrir une population plus nombreuse. Cependant, les régions montagneuses n'en profitaient pas, et les montagnards, las d'un travail pénible sur une terre peu fertile, partirent en tel nombre pour le Nouveau-Monde que le Petit Conseil de Berne, par exemple, à maintes reprises au cours du $18 \mathrm{e}$ siècle, se vit contraint de décréter des mesures restrictives contre cet exode.

\section{A. L'émigration suisse de 1800 à 1914}

L'émigration a connu quatre maxima d'intensité entre les années 1800 et 1914: à l'issue des guerres napoléoniennes, vers le milieu du $19 \mathrm{e}$ siècle, vers 1880 et au début du $20 \mathrm{e}$ siècle. Les périodes intermédiaires ne comportent que des taux d'émigration moyens ou faibles. 
De 1800 à 1820 , l'émigration suisse a été d'un caractère essentiellement colonisateur ${ }^{11}$. Le mouvement massif d'émigration à l'issue des guerres napoléoniennes résulte des faits suivants: paupérisme de larges couches de la population agricole en Suisse centrale et en Suisse occidentale dû à la disparition des capitulations militaires; misère des travailleurs à domicile en Suisse septentrionale et nord-orientale, à la suite de la concentration du travail industriel (par exemple dans l'industrie cotonnière) en certains points particuliers, dans les manufactures le long des fleuves; répercussions, jusqu'en 1820, des événements de la guerre et du blocus continental; disette générale et famine en 1816 et 1817; recrudescence de l'attraction de l'Union - notamment des riches et fertiles terres du "V'ieux Territoire du Nord-Ouest " au-delà de l'Ohio - qui n'avait pas pu s'exercer pendant la guerre.

De 1820 à 1850 , le mouvement d'émigration ne fut pas très intense ${ }^{12}$. L'industrie suisse se remettait rapidement des crises des années précédentes. Les industries textiles de la Suisse orientale (particulic̀rement celle du coton) jouirent, de 1830 à 1840 , d'une grande prospérité.

L'agriculture s'intensifia à partir de 1830 et le prix des produits agricoles augmenta.

Le second maximum d'émigration transocéanique, vers le milieu du siècle (de 1851 à 1854) - dont les premiers symptômes se manifestent déjà vers 1840 - est en grande partie dû aux faits suivants ${ }^{13}$ : les procédés d'industrialisation firent de nouveaux progrès dans le tissage du coton et privèrent le travailleur à domicile de son gagne-pain; l'agriculture traversa, de 1845 à 1855, une série d'années maigres, les récoltes furent médiocres, et les cultures de pommes de terre ravagées par la maladie; les États-Unis jouirent à cette époque d'une très grande prospérité à la suite du développement des villes industrielles de l'est et de la mise en valeur des vastes étendues cultivables du "Middle West "; d'autres États d'outre-mer dćployèrent à leur tour une vive propagande en faveur de l'immigration, notamment le gouvernement brésilien qui soutint le système de métayage du fazendeiro VerGUEIRO ${ }^{14}$, peu différent d'un véritable esclavage.

Dès le milieu du siècle, la liaison de plus en plus étroite entre l'Ancien- et le Nouveau-Monde, résultat de l'amélioration des communications continentales et transocéaniques, fit augmenter le nombre des émigrants chaque fois que la situation économique d'outre-mer devint plus prospère qu'en Suisse, et le fit diminuer, lorsque le contraire se produisit ${ }^{15}$.

Le mouvement d'émigration fut peu accusé de 1855 à 1865, car d'une part, les États-Unis traversèrent, de 1855 à 1860 , une crise économique et monétaire; les milieux ouvriers de l'industrie et de l'artisanat américains souffraient de la misc̀re. et la situation allaits'aggraver encore, lorsque la guerre de Sécession vint diviser, de 1861 à 1865 , les États-Unis en deux camps hostiles ${ }^{16}$. D'autre part, l'économie suisse passa par une période de grande prospérité gràce à la politique de librc échange ${ }^{17}$ inaugurée parl'Angleterre.

Restant moyenne de 1865 à 1869, car les perspectives outre-mer n'étaient toujours pas encourageantes (les États-Unis ćtaient encore ćbranlés par une forte crise économique due à la guerre meurtrière et à peine terminée), l'émigration redevint intense, en 1872 et 1873, à la suite d'une crise dans notre industrie cotonnière, due à l'abandon de leur politique de libre échange par les États continentaux; puis elle fléchit de 1875 à 1877, en raison de la situation prospère de l'industrie suisse.

Le troisième maximum d'émigration transocéanique, de 1881 à 1892 , résulte en grande partie d'une crise profonde de l'agriculture: Au fur et à mesure que se développaient les communications terrestres en deçà et au-delà de l'océan, de même que la navigation maritime et que les vastes étendues du "Middle West" américain devenaient prospères, la concurrence des blés transocéaniques devint plus sensible. Vers 1880 , elle devint si forte que les paysans suisses ne purent plus la soutenir. Ils abandonnèrent la culture des champs et se vouèrent désormais à celle des prés et à l'élevage, activités n'exigeant pas un nombre de travailleurs aussi grand; de la sorte, un certain nombre d'habitants furent libérés des travaux agricoles ${ }^{18}$. D'autre part, les industries suisses traversèrent une forte crise de 1885 à 1886 . On peut citer encore la crise dont souffrait la broderie en $1891^{19}$.

De 1894 à 1901, l'intensité de l'émigration fut moindre, parce que l'industrie et l'artisanat se développaient très favorablement à ce moment.

Le quatrième maximum d'émigration transocéanique (de 1902 à 1913) s'explique par le fait que: à partir de 1900, les pays européens en train de s'industrialiser, fermèrent leur marché

11 18, page 381.

1222 , page 30.1333 , page 26.

14 Grand propriétaire foncier brésilien; il suggérait au gouvernement brésilien de remplacer les esclaves noirs travaillant dans les grandes plantations de café de la région de Sào-Paulo (dont le prix d'achat allait en montant à la suite de la répression, par l'Angleterre, de la traite des Noirs d'Afrique) par des immigrants européens, auxquels on louait des terres moyennant cession de la moitié de leurs récoltes aux propriétaires fonciers. Ce système de métayage fut désastreux pour nos immigrants; la plupart d'entre eux furent bientôt chargés de dettes et tombèrent de plus en plus sous la dépendance des fazendeiros. 1522 , page 40.1818 , page 382.

17 Abolition de certaines prohibitions et de taxes sur l'entrée et la sortie des marchandises. Conclusion de traités commerciaux de réciprocité.

${ }^{18} 33$, page $54 .{ }^{10} 22$, page 54. 
aux produits suisses. L'industrie et le commerce suisses, à la recherche de nouveaux débouchés, s'intéressèrent de plus en plus aux pays neufs d'outre-mer. Pour sauvegarder leurs intérêts, ils y envoyèrent leurs représentants. D'autre part, les États néo-capitalistes d'Amérique engageaient volontiers, en tant que spécialistes, les travailleurs suisses réputés qualifiés.

En outre, les moyens de communication modernes avaient atteint un degré.de perfection assez élevé pour que le jeu international de l'offre et de la demande de main-d'œuvre s'effectuât sans grandes difficultés. Il ne s'agissait plus alors (comme au 19e siècle) d'agriculteurs s'expatriant avec la ferme volonté de s'établir de façon permanente sur les terres vierges des pays d'outre-mer, mais de manœuvres agricoles, d'ouvriers industriels, d'artisans, de techniciens, de commerçants, qui partaient offrir leurs services là où ils seraient le mieux rétribués. Par temps de crise dans les pays transocéaniques, ils rentraient fréquemment en Suisse. A partir de 1911, l'économie européenne pressentait déjà la conflagration mondiale: les industries étaient en stagnation, le marché financier traversait une forte crise. L'Amérique, par contre, jouissait d'une grande prospérité, ce qui incita un certain nombre de Suisses à s'y rendre.

\section{B. L'émigration suisse après 1914}

Pendant la première guerre mondiale, l'émigration transocéanique fut très peu intense. Un grand nombre de Suisses furent appelés sous les armes, et les conditions de passage d'Europe en Amérique n'étaient pas de nature à encourager les émigrants.

La grande prospérité dont jouirent les États-Unis, à la suite des fortes commandes de la part des pays belligérants, et la demande accrue de main-d'œuvre industrielle qui en résulta, ne purent donc pas avoir de répercussions sur notre pays.

Après la première guerre mondiale, la situation se cristallisa de la façon suivante: la guerre avait contraint les pays d'outre-mer à s'industrialiser rapidement. Par des mesures de protection douanière, ils se hâtèrent de consolider cette nouvelle position. Les peuples européens, par contre, épuisés par la guerre, subirent de fortes crises. Les travaux de reconstruction dans les régions dévastées ne furent qu'un palliatif qui, par la demande de matières premières, de produits de consommation et d'ouvriers qualifiés, provoqua en Suisse une prospérité de courte durée, sans base sérieuse.

Par ailleurs, une crise qui en Suisse fut d'abord sensible dans les industries d'exportation (textile et horlogerie surtout) et se communiqua ensuite aux industries travaillant pour le marché intérieur, éclata simultanément en Angleterre, en France et aux États-Unis. La crise industrielle fut accompagnée d'une crise de l'agriculture, due à la baisse des prix. Tous ces facteurs contribuèrent à rendre défavorable la situation économique de la Suisse et à accroître les tendances à l'émigration.

En effet, un maximum d'intensité dans l'émigration se note en 1920. Cependant, une bonne partie de ces émigrants étaient des commerçants, des techniciens, des employés d'hôtel qui avaient été retenus en Suisse pendant la guerre et qui allaient maintenant à l'étranger compléter leur préparation professionnelle; il est très probable qu'ils seraient partis, même si la situation économique de la Suisse avait été plus favorable. Le nombre d'individus partant effectivement à cause de la crise, n'était donc pas très élevé. D'autre part, le point culminant de la crise ne fut atteint qu'en 1922; on compta en cette année 100000 chômeurs. Le nombre des émigrants aurait donc dû en 1922/23 dépasser largement les chiffres de 1920.

En réalité, il fut moins élevé, pour la raison suivante: le 21 mai 1921, les États-Unis avaient introduit "the Emergency law", qui limitait l'immigration des ressortissants non-américains; les autres pays d'outre-mer réservaient à leur tour le marché du travail à leur ressortissants.

De 1924 à 1925, les affaires reprirent dans toutes les branches économiques, et le mouvement migratoire se maintint en position moyenne. De 1926 à 1929, l'économie suisse fut prospère, à l'exception de certaines branches de l'industrie textile et de l'agriculture. L'exportation des produits agricoles notamment (lait, bétail) subit une crise à la suite de l'institution, par l'Allemagne et l'Angleterre, de droits de douane élevés. Le nombre d'émigrants fut relativement élevé à cette époque; il nous faudra donc vérifier, si cet accroissement est dû à une forte participation d'émigrants-agriculteurs.

De 1930 à 1935 , la Suisse subissait une forte crise économique. On aurait pu s'attendre à voir l'intensité du mouvement d'émigration considérablement accrue. Mais comme cette crise embrassait le monde entier et que les pays transocéaniques souffraient des mêmes difficultés, ils ne pouvaient pas absorber nos travailleurs en chômage. Cette crise économique mondiale - qui devint apparente lors de la catastrophe financière de New-York en automne 1929 et dont les débuts remontaient à la guerre était due pour sa plus grande part au déséquilibre croissant entre l'expansion industrielle et les possibilités d'absorption du marché mondial.

De nouvelles industries, établies outre-mer, firent concurrence à celles du continent. D'autre part, la culture du sol, intensifiée et élargie durant la guerre, n'arriva plus à écouler ses produits, et la baisse des prix des produits agricoles réduisit la puissance d'achat des pays qui en vivent. 
La crise économique qui en résulta, s'étendit à tous les pays et à toutes les branches d'activité. La crise agricole fut aggravée par une crise industrielle; puis vint s'ajouter, en 1931 à 1932, une crise financière dont la conséquence fut la congélation des capitaux dans les pays débiteurs. La production mondiale se réduisit de 37,0\%, de 1929 à 1932 , tandis que le commerce faillit de $2 / 3$ financièrement, de $1 / 3$ quantitativement.

Terminée à l'étranger en 1932 déjà, grâce aux mesures de dévaluation (Livre anglaise, Dollar, etc.), la crise dura en Suisse jusqu'au 26 septembre 1936, date de la dévaluation du franc. Elle sc limita d'abord aux industries d'exportation (horlogerie, textiles, métallurgie), mais à partir de 1933, elle envahit aussi les branches travaillant pour le marché intérieur.

En 1932, les constructions civiles absorbèrent encore un grand nombre de chòmeurs provenant des industries d'exportation. La situation devint également très défavorable pour l'agriculture (le prix des produits agricoles ayant baissé plus que celui des produits manufacturés et que les salaires des ouvriers) et pour le tourisme (le nombre des étrangers ayant diminué de deux tiers de 1929 à 1936). Le chiffre minimum de l'émigration de cette période n'est donc pas l'indice d'une faible disposition à l'expatriation, mais bien plus la conséquence du trouble économique mondial paralysant les échanges en produits et en individus.

De 1936 à 1939, l'émigration reprit en intensité. Au premier abord, cela parait étrange, puisqu'à la suite de la dévaluation de septembre 1936, l'économie nationale devait voir des jours meilleurs. Mais cette dévaluation, réadaptant notre standard de vie aux conditions du marché mondial, profita surtout aux industries d'exportation. Le nombre des émigrants augmenta en mème temps que les exportations, car nos produits durent être réintroduits sur les marchés d'outre-mer par des spécialistes, aptes à sauvegarder les intérêts de nos industries nationales. D'autre part, l'industrie du bâtiment comptait en 1937 encore un grand nombre de chômeurs, et les conditions du marché du travail continuèrent à rester défavorables. Nous verrons par la suite, quelles ont été les répercussions de ce phénomène sur la structure professionnelle du courant de l'émigration.

En résumé, le calcul des écarts moyens permet de distinguer, dans l'époque de 1851 à 1940, des périodes de forte et de faible intensité d'émigration. Le domaine d'intensité moyenne correspondant à un chiffre annuel d'émigrants de 1820 à $7380^{20}$, les années suivantes sont des périodes de forte intensité: 1854, 1881-1885, 1887-1892, 1920 et des périodes dé faible intensité: $1858-1859,1861-1863,1875-1877,1916$ à 1918, 1931-1935, 1940.

Figure 1. L'émigration suisse de 1850 à 1940

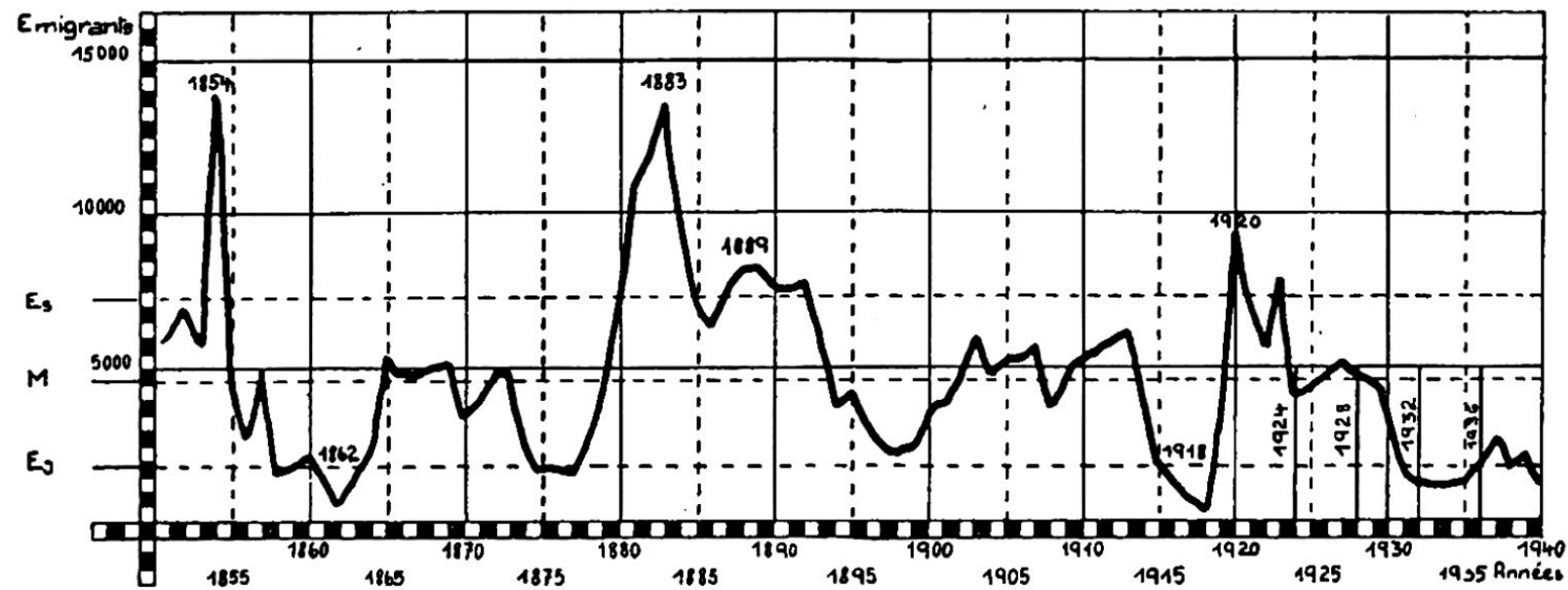

Ordonnée: Nombre annuel d'émigrants. Abscisse: Périodes décennales de 1850 à 1940 . $E_{S} / E_{J}$ : Limites supérieure et inférieure des écarts moyens. M: Moyenne.

Maxima d'émigration:

1854: Changement de la structure agricole et crise agricole en Suisse, prospérité et propagande des pays d'outre-mer.

1881-1885: Crise profonde de l'agriculture européenne.

1887-1892: Crise dans l'industric (surtout textile). 1920: Crise industrielle et agricole.
Minima d'émigration:

1858-1859: Crise économique aux États-Unis. 1861-1863: Prospérité en Suisse, guerre aux États-Unis.

1875-1877: Prospérité en Suisse.

1916-1918: Première guerre mondiale.

1931-1935: Crise économique mondiale.

1940-1945: Seconde guerre mondiale.

20 On a calculé ce chiffre dans le chapitrc premier, page 5. 
Le mouvement de l'émigration est devenu donc inteinse chaque fois que la situation outre-mer était plus prospère qu'en Suisse, et il s'est rédıit, lorsque le phénomène contraire s'est produit. Il est certain qu'un grand nombre des émigrants de l'avant-guerre s'expatriait aux moments, où une crise profonde rendait instable la situation dans la mère-patrie, ou bien parce que les pays d'outre-mer jouissaient d'une situation prospère, et ils restaient en Suisse, lorsque la situation y était plus encourageante que hors d'Europe.

Dans l'entre-guerres, la siluation paraît considérablement modifiée. La première guerre ayant provoqué un dévelóppement énorme des moyens de communication et une interdépendance croissante des différents États, les ébranlements économiques et sociaux (et d'autre part les pé-iodes de prospérité) ont pris de plus en plus un caractère universel. Les crises éconoıniques s'étendant désormais au monde entier, on ne peut plus échapper à une situation économique défavorable dans la mère-patrie en se déplaçant vers les pays transocéaniques.

C. L’émigration transocéanique daris les années $1924,1928,1932,1936$

Le mouvement de.l'émigration transocéanique suisse porte, en chiffres absolus, sur 3454 individus en 1924, 4057 individus en 1928, 915 individus en 1932, 1576 individus en 1936. Ceci correspond, par rapport à la population globale, à une intensité d'émigration de $0,85 \%$ en $1924,1,00 \%$ en $1928,0,23 \%$ en $1932,0,39 \%$ en 1936 .

Afin de pouvoir déterminer pour quelles raisons ces taux d'émigration diffèrent les uns des autres, nous examinerons brièvement la situation économique et sociale de la Suisse, caractéristique aux quatre années en question:

1924: Reprise dans toutes les branch.es économiques. Toutefois, les conséquences des lois restrictives de l'immigration, mises en vigueur outre-mer, se font encore ressentir.

1928: Prospérité de l'économie suisse, à l'exception de certaines branches de l'industrie textile et de l'agriculture, notamment en ce' qui concerne l'exportation de produits agricoles.

1932: Forte crise dans les industries d'exportation (horlogerie, textiles, métallurgie) de même que dans l'agriculture et le tourisme. Situation encore relativement stable dans les constructions civiles.

1936: Reprise économique, due à la dévaluation monétaire, surtout dans les industries d'exportation. Crise dans le bâtiment.

Toutefois, comme on a pu le constater, un mcuvement d'émigration intense ne signifie plus, dans l'entre-deux-guerres, que la situation soit critique dans la mère-patrie et prospère outre-mer, un chiffre d'émigrants minimum ne veut plus dire que la Suisse jouit d'une situation stable, tandis que les pays transocéaniques traversent une crise. Par contre, on peut prétendre que les possibilités de placement de main-d'œuvre et les déplacements d'individus d'un pays à l'autre ont augmenté chaque fois que le monde passait par une période de prospérité. C'est pour cette raison que le chiffre d'émigrants a été en 1924 et surtout en 1928 plus grand qu'en 1932 et en 1936.

\section{CHAPITRE III: LA COMPOSITION DE L'ÉMIGRATION}

Afin de pouvoir vérifier la nature de certains problèmes particuliers qui interviennent dans le phénomène de l'émigration, nous allons passer à l'étude approfondie de la structure du courant d'émigration, en déterminant d'abord les diverses formes de ce mouvement et en examinant ensuite de quelle façon, et en quelle mesure, celui-ci est influencé, au cours des années 1924, 1928, 1932, 1936, par la structure économique et sociale de la Suisse d'une part, par l'économie mondiale d'autre part.

A. La structure professionnelle du courant migratoire et la participation des différentes professions à l'émigration

$1^{\circ}$ Participation des diverses catégories professionnelles à l'émigration. Si nous considérons le tableau 4, nous constatons que: le nombre des émigrants-agriculteurs est beaucoup plus élevé que celui des autres c atégories d'éimgrants. 
Le commerce, la technique, le tourisme, le bâtiment, l'art ménager sont de moyenne importance pour l'émigration.

La plupart des 33 catégories professionrelles sont pour le mouvement de l'émigration d'une importance numérique réduite. 16 catégories présentent des taux de participation inférieurs à $1,0 \%, 5$ catégories des taux inférieurs à $2,0 \%$ du mouvement d'émigration global.

Tableau 4. Les catégories professionnelles; leur participation au mouvement d'émigration

\begin{tabular}{|c|c|c|c|c|c|c|c|c|}
\hline No & Professions & $\mathrm{ABC}^{1}$ & $1924^{2}$ & $1928^{2}$ & $1932^{2}$ & $1936^{2}$ & $\Sigma 3$ & $\Sigma+$ \\
\hline 1 & Agriculture. & A & 30,0 & 37,7 & 10,6 & 31,8 & 31,0 & 1 , \\
\hline 2 & Industrie laitière & $\mathrm{C}$ & 1,0 & 0,7 & 0,5 & 1,2 & 0,9 & 0,7 \\
\hline 3 & Profession compl. (meuniers, etc.) & C & 0,2 & 0,2 & 0,2 & 0,0 & 0,2 & a \\
\hline 4 & Horticulture . . . . . & B & 1,3 & 2,6 & 1,4 & 2,2 & 2,0 & U, \\
\hline 5 & Mines et carrières. . . . . . & C & 0,1 & 0,1 & 0,0 & 0,3 & 0,2 & 0 \\
\hline 6 & Alimentation (artisans) & B & 2,2 & 2,0 & 3,8 & 2,5 & 2,3 & \\
\hline 7 & Industrie alimentaire. & $\mathrm{C}$ & 0,0 & 0,0 & 0,1 & 0,3 & 0,1 & 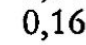 \\
\hline 8 & Habillement & C & 0,2 & 0,4 & 1,3 & 0,4 & 0,4 & 0, \\
\hline 9 & Soins du corps. & C & 0,2 & 0,5 & 1,1 & 0,6 & 0,6 & \\
\hline 10 & Horlogerie, Arts graphiques & C & 1,3 & 1,8 & 2,2 & 1,2 & 1,5 & \\
\hline 11 & Bâtiment, Ameublement. . & A & 4,9 & 4,3 & 3,6 & 6,8 & 5,0 & \\
\hline 12 & Arts massifs (forgerons). & C & 1,0 & 0,4 & 1,0 & 0,1 & 0,7 & \\
\hline 13 & Industrie mécanique et métallurgique & B & 3,9 & 3,2 & 3,1 & 3,8 & 3,5 & \\
\hline 14 & Industrie textile..... & $\mathrm{C}$ & 1,1 & 0,8 & 1,4 & 1,1 & 0,8 & \\
\hline 15 & Industrie chimique... & C & 0,7 & 0,6 & 0,8 & 0,8 & 0,7 & \\
\hline 16 & Technique... . & A & 5,8 & 6,2 & 9,5 & 9,5 & 7,0 & \\
\hline 17 & Banque & C & 0,8 & 0,6 & 1,0 & 0,1 & 0,4 & \\
\hline 18 & Assurance & C & 0,0 & 0,0 & 0,1 & 0,2 & 0,1 & $(?$ \\
\hline 19 & Commerce & A & 17,3 & 15,5 & 19,6 & 15,8 & 16,5 & \\
\hline 20 & Trafic & C & 1,0 & 0,7 & 0,3 & 0,8 & 0,8 & \\
\hline 21 & Tourisme & A & 6 , & 5,9 & 7,6 & 3,4 & 6,0 & \\
\hline 22 & Carrières d'État. . . . . & C & 0,7 & 0,5 & 0,9 & 0,3 & 0,6 & \\
\hline 23 & Droit et économie & C & 0,5 & 0,4 & 0,5 & 0,5 & 0,5 & \\
\hline 24 & Enseignement . . & B & 1,3 & 1,6 & 3,1 & 1,5 & 1,6 & \\
\hline 25 & Médecine . & C & 1,1 & 0,7 & 1,5 & 0,7 & 0,9 & \\
\hline 2 & Sciences & C & 0,2 & 0,3 & 0,3 & 0,3 & 0,3 & \\
\hline 27 & Beaux-Arts & C & 0,9 & 0,8 & 1 , & 1 , & 1,0 & \\
\hline 20 & Ménage (domestiques, etc.) & A & 7,5 & 3,2 & 5,6 & 2,2 & 5,0 & \\
\hline 25 & Professions féminines à domicile & $\mathrm{C}$ & 1,5 & 1,1 & 1,6 & 1,1 & 1,3 & \\
\hline 32 & Éducation & B & 1,5 & 2,6 & 5,1 & 1,6 & 2,4 & \\
\hline 3 & Assistance & C & 0,8 & 1,1 & 1,3 & 1,0 & 1,0 & \\
\hline 促 & Carrières ecclésiastiques . . . . & B & 1,4 & 1,8 & 4,8 & 2,1 & 2,0 & \\
\hline 3. & Rentiers, particuliers ... & B & 3,6 & 2,7 & 6,1 & 4,1 & 3,6 & \\
\hline
\end{tabular}

1 Les lettres de la trolsième colonne indiquent les catégories professionnelles de première importance (A : de 5 à $31 \%$ ), de seconde importance (B : de 1,5 à $5 \%$ ), de troisic̀me importance ( $C:$ de 0,1 à $1,5 \%$ ).

Taux de participation - en pour-cent du nombre total des émigrants - au mourement d'émigration des annécs 1924, 1928, 1932, 1936.

3 Moyenne de ces qúatre taux de participation.

- L'émigratıon suisse rapportćc à l'effectif global des diverses catégorics professionnelles. En pour-mille de la population globale.

L'année 1924 indique en majorité des taux de participation moyens. L'année 1928 se distingue par un taux élevé d'émigrants-agriculteurs. L'année 1932 indique des taux élevés d'émigrants provenant des industries d'exportation (textile et horlogerie), la technique, les affaires bancaires, le commerce, le tourisme, les carrières libérales, feminines et ecclésiastiques, des taux peu élevés d'individus appartenant à l'agriculture et au bâtiment. L'année 1936 se caractérise par des taux élevés d'ouvriers du bâtiment, des industries mécanique et textile, de la technique.

L'année 1924 étant une année de prospérité moyenne pour toutes les branches économiques, les taux de participation à l'émigration d'autre part étant moyens dans leur majorité, nous n'en pouvons pas tirer des conclusions quant aux facteurs du mouvement d'émigration. Par contre, il nous est possible de faire certaines déductions pour les autres périodes considérées. 
En 1928, l'exportation des produits agricoles (lait, bétail) subit une crise à la suite de l'institution, par l'Allemagne et l'Angleterre, de droits de douane élevés. Simultanément, le nombre des émigrants-agriculteurs s'élève. Il existe donc une relation entre la politique économique de certains pays européens, la situation économique d'une branche d'activité suisse et le mouvement d'émigration outre-mer. Une situation favorable de l'agriculture outre-mer aurait pu avoir les mêmes effets, mais l'agriculture américaine était en grosses difficultés déjà durant cette époque de "high prosperity». Néanmoins, il n'est pas exclu que la situation défavorable de l'agriculture américaine ait pu provoquer un mouvement d'émigration intense d'agriculteurs, si, par hasard, ces émigrants allaient occuper des places que les Américains avaient quittées pour l'industrie. C'est une hypothèse qui met en relation certains pays d'outre-mer avec nos émigrants; elle suppose que nos émigrants subissaient l'attraction des pays transocéaniques.

En 1932, la crise économique mondiale a été chez nous très sensible dans les industries d'exportation, le commerce, le tourisme, l'agriculture. Les taux de participation élevés des émigrants provenant des industries d'exportation, de la technique, du commerce, du tourisme, sont donc l'expression d'une situation économique précaire de ces branches d'activité. De même, le taux peu élevé d'émigrants provenant du bâtiment, témoigne de la situation encore prospère à cette époque des chantiers de construction. Nous sommes donc en présence d'un mouvement d'émigration dû à la situation économique précaire dans la mère-patrie.

L'agriculture, par contre, qui souffrait à son tour de fortes difficultés, indique un nombre d'émigrants minimum. D'autres professions aussi ont en 1932 des taux inférieurs à ce que leur situation précaire aurait pu laisser prévoir.

Essayons de préciser le fait en comparant les taux de participation de l'année 1932 aux taux des trois autres périodes envisagées. On divise dans ce but les moyennes respectives des quatre années en question par les taux de l'année 1932, et on obtient, pour 14 professions de 1 re et $2 \mathrm{e}$ importance, les taux suivants ${ }^{21}$ :

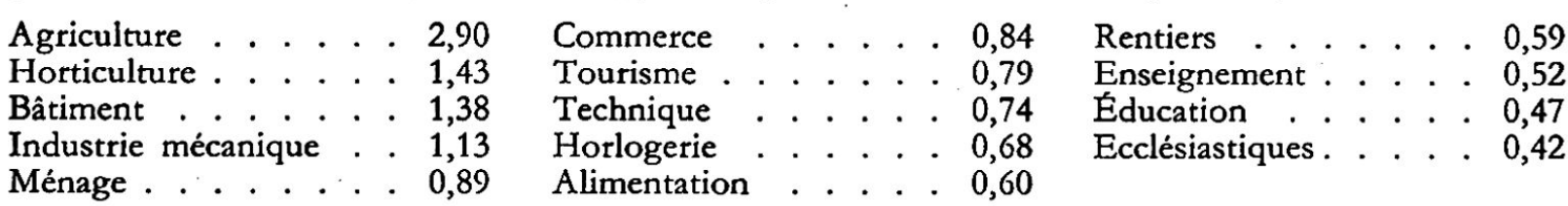

Ces chiffres indiquent, en quelle mesure le mouvement d'émigration des différentes professions a été déprimé par l'insécurité économique des années de crise. Les professions manuelles s'en ressentent il est facile de le constater - bien davantage que les professions non manuelles.

Cette situation particulière des professions manuelles est le résultat de deux phénomènes différentes: d'une part, les professions manuelles développent une mentalité plus conservatrice que les professions non manuelles; ceci s'exprimait par un sentiment d'hésitation vis-à-vis de l'émigration pendant ce temps de crise. D'autre part, la situation outre-mer contribuait encore à réduire l'émigration de la première catégorie d'individus.

En 1936, notre standard de vie est réadapté aux conditions du marché mondial à la suite de la dévaluation du franc, et nos industries sont remises en état de combattre la concurrence étrangère. Il n'est pas surprenant de constater (fig. 2) que le nombre des émigrants appartenant à l'industrie mécanique et à la technique augmente en même temps que les exportations, puisqu'il a fallu des spécialistes pour réintroduire nos produits et le commerce sur les marchés d'outre-mer. Pour une raison bien différente, le bâtiment indique également des taux de participation élevés: c'est parce que cette branche d'activité comptait en 1936 encore un grand nombre de chômeurs et que les conditions du marché du travail continuent après cette date à rester défavorables. La participation intense au mouvement d'émigration est donc, en 1936, due à des circonstances diverses: d'une part à une politique expansionniste de certaines industries suisses en vue de la reconquête des marchés d'outre-mer, d'autre part à la situation écono-

${ }^{21}$ On divise, par exemple, dans l'agriculture, $31,0 \%$ (moyenne des quatre taux de participation) par 10,6\% (taux de participation de l'année 1932); on obtient un taux de 2,90 . 
mique précaire d'une autre branche d'activité suisse travaillant en particulier pour le marché intérieur.

Les phénomènes que nous venons de décrire, peuvent d'ailleurs s'observer sur la représentation graphique suivante:

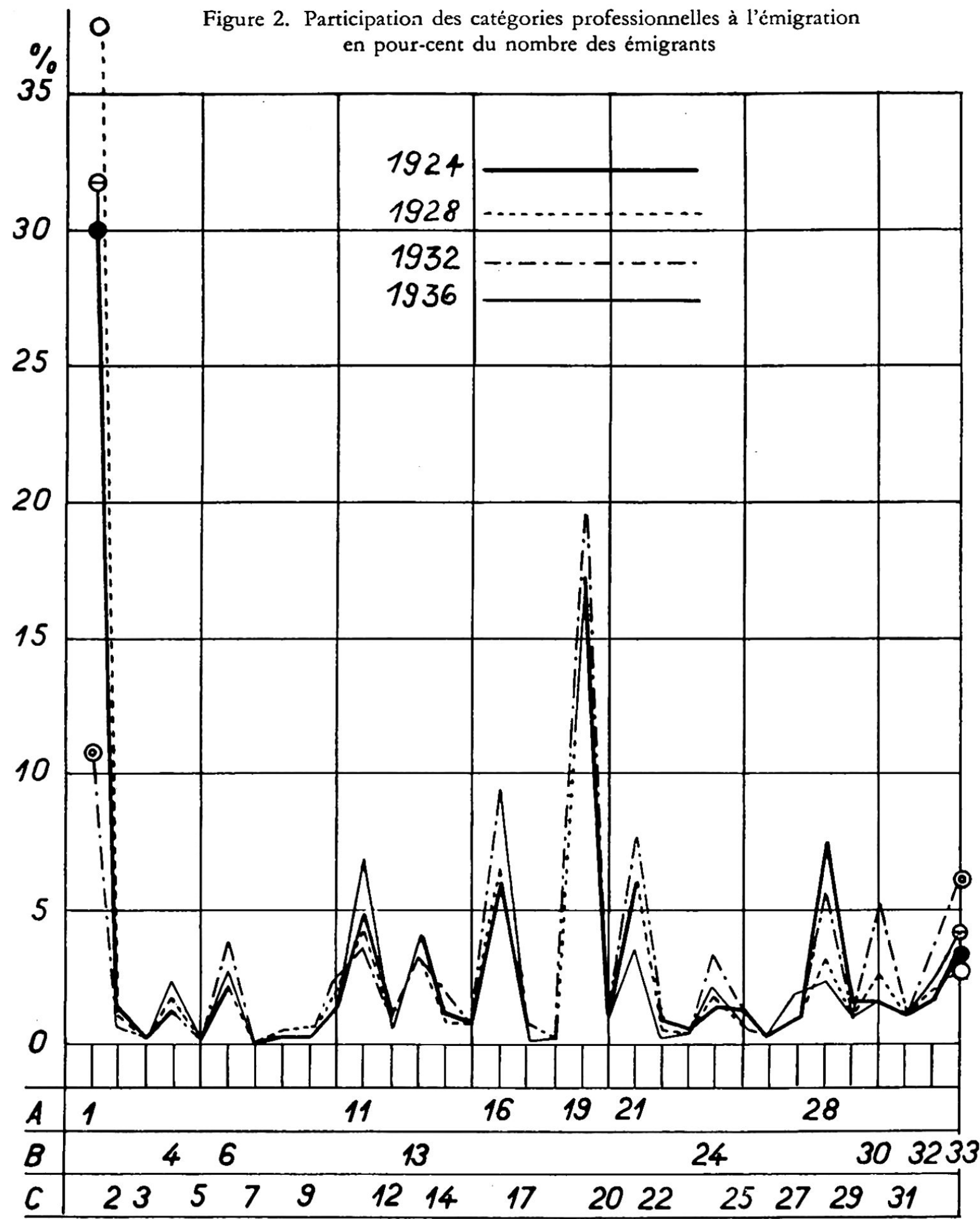

En ordonnée: Nombre d'individus pour-cent, appartenant à une catégorie professionnelle déterminée. En abscisse: Les différentes catégories professionnelles. Pour les autres indications, voir la légende du tableau 4.

Les agriculteurs (1) représentent de 38 à $11 \%$ du nombre total des émigrants; en outre participent activement les artisans du bàtiment (11), les techniciens (16), les commerçants (19), le tourisme (21), le ménage (28) en 1924 ct 1932, l'éducation (30) en 1932. 
$2^{\circ}$ L'émigration suisse rapportée à l'effectif global des diverses catégories professionnelles. Le taux de participation, en pour-cent du nombre total des émigrants, ne nous montre pas dans quelle mesure chaque catégorie professionnelle de la population suisse a été touchée par l'émigration.

Nous constatons, à l'aide du tableau 4, colonne 9, que certaines professions libérales et la technique sont fortement sujettes à l'attraction du mouvement de l'émigration. Celle-ci est moins forte pour l'agriculture, le commerce, le tourisme. Elle est encore plus faible pour l'enseignement, le ménage. Elle est très faible pour les arts et métiers. On peut supposer que les individus appartenant aux professions non manuelles (professions libérales, techniciens, commerçants, employés d'hôtel) se déplacent avec plus de facilité que les travailleurs appartenant aux professions manuelles. Le taux d'intensité plu̧s ou moins élevé est donc le résultat d'une structure professionnelle particulière. Exception doit être faite pour l'agriculture qui, malgré son appartenance aux professions manuelles, indique un taux d'intensité relativement élevé.

Une autre observation pourrait aussi retenir notre attention: certaines professions libérales, et notamment l'éducation et les carrières ecclésiastiques, trouvent à l'étranger un champs d'activité plus étendu et plus intéressant qu'en Suisse, puisque chez nous la demande en spécialistes de ce genre est assez réduite.

L'émigration suisse de l'entre-guerres est donc une émigration de qualité bien que, quantitativement, le nombre des émigrants manuels, notamment des agriculteurs, soit assez élevé.

Les phénomènes que nous venons de décrire, s'observent bien sur la représentation graphique qui suit.

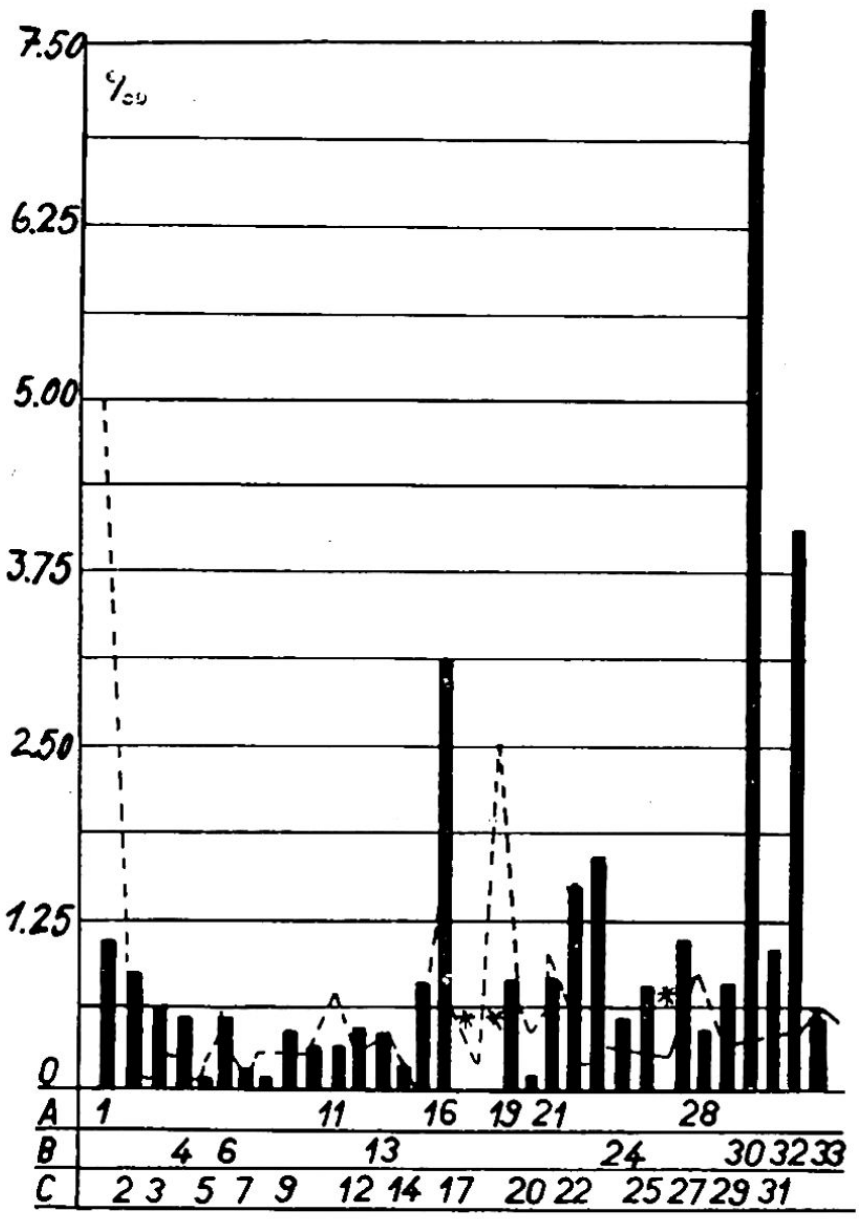

Figure 3. Participation des catégories professionnelles à l'émigration en pour-mille de l'effectif global de chaque catégorie

En ordonnée: Fraction en millièmes de la popuiation globale appartenant à telle ou telle profession touchée par l'émigration. En abscisse: Les différentes catégories professionnelles.

La ligne pointillée indique le taux de participation au mouvement d'émigration de chaque catégorie professionnelle.

Importance relative de l'émigration des gouvernantes (30), des ecclésiastiques (32), des techniciens (16). Bien que les agriculteurs (1) fournissent le gros des émigrants (voir fig. 2), ils ne représentent qu'une minime fraction des agriculteurs suisses.

$3^{\circ}$ L'émigration en fonction des subdivisions des catégories professionnelles. Si enfin nous envisageons la composition du courant d'émigration à l'intérieur des différentes catégories professionnelles (Annexe I, pages 86/87), nous 
constatons que plus du $90 \%$ des émigrants-agriculteurs sont des paysans indépendants, moins de $10 \%$ des manœuvres agricoles ${ }^{22}$, que dans l'industrie mécanique, l'industrie textile, le commerce, le nombre de travailleurs subordonnés diminue, en 1932, par rapport aux individus avec fonction dirigeante. Ainsi, dans l'industrie mécanique, le taux des mécaniciens descend au profit des contre-maîtres et directeurs. Le même phénomène s'observe dans l'industrie textile pour les fileurs, tisseurs, brodeurs, par rapport aux techniciens et directeurs. De même, en technique, les ingénieurs et techniciens gagnent, en 1932, par rapport aux monteurs et dessinateurs techniques. Aussi dans l'activité bancaire et dans le commerce, les taux des individus à fonction dirigeante ont, à cette époque, augmenté, ceux des personnes à position subordonnée diminué.

La crise mondiale déprimait done davantage l'émigration des personnes à position subordonnée que celle des individus à fonction dirigeante. Or, ainsi que nous le verrons dans la troisième partie, comme les pays d'outre-mer limitaient à cette époque l'immigration d'individus dont ils disposaient eux-mêmes en surabondance, c'est-à-dire des travailleurs moins qualifiés, ils ont appliqué les restrictions moins rigoureusement aux personnes bien qualifiées qui malgré la crise pouvaient être d'un certain intérêt pour leur économie.

Et vice versa, la prospérité dont jouissaient les pays d'outre-mer en 1928, favorisait en Suisse l'émigration d'un nombre élevé de personnes à position subordonnée. Il paraît donc que des temps de prospérité outre-mer favorisent, en particulier, l'émigration de personnes à position subordonnée, que des temps de crise la contrarient.

En 1936, le taux des individus à fonction dirigeante est plus élevé encore qu'en 1932 dans les activités bancaires, le commerce et le tourisme. Or, nous avons pu constater que la dévaluation du franc en 1936 a mis la Suisse en mesure d'entrer en concurrence sur le marché mondial avec les autres pays, et, pour sauvegarder nos intérêts, nous avons dû envoyer à l'étranger des hommes expérimentés et qualifiés. Voilà donc pourquoi en 1936 le pourcentage des individus à fonction dirigeante a été plus élevé (relativement!) que celui des personnes à position subordonnée.

$4^{\circ}$ Les individus avec ou sans activité économique ${ }^{23}$. Le tableau 5 nous renseigne sur la participation à l'émigration des individus avec ou sans activité économique, les premiers l'emportant de beaucoup sur les seconds.

Tableau 5. Emigrants avec ou sans activité économique

\begin{tabular}{|c|c|c|c|c|c|c|}
\hline Catégories économiques & $1924^{1}$ & $1928^{1}$ & $1932^{1}$ & $1936^{1}$ & 2 & is \\
\hline${ }_{10}$ & 72,0 & 81,0 & 71,0 & 60,0 & 74,0 & \\
\hline onnes $s$ & 28,0 & 19,0 & 29,0 & 40,0 & 26,0 & \\
\hline
\end{tabular}

1 Taux de participation - en pour-cent du nombre total des émigrants - au mouvement d'emigration des annécs 1924, 1928, 1932, 1936.

2 Moyenne arithmétique pondéréc de ces quatre taux de participation.

3 Mesure dans laquelle la population suisse - appartenant à telle ou telle catégoric économique - a ćté touchéc par l'úmigrałisın. F:n pour-mille de la population globale.

${ }^{22}$ L'agriculture en Suisse souffre toujours d'un certain défaut de main-d'œuvre, parce que les conditions d'engagement, de travail et de vie de cette classe de travailleurs sont insuffisantes: La journée de travail est très longue, le travail fatigant, le salaire peu élevé. D'autre part, le marché du travail agricole, déterminé par le cycle saisonnier, offre en été un nombre de places vacantes excédant le nombre des manœuvres disponibles, tandis qu'en hiver, la situation est inverse. De même, le genre d'exploitation foncière en Suisse - la petite exploitation - ne permet pas aux ouvriers agricoles de fonder un foyer. Voilà pourquoi même des fils de paysans, ne voyant pas la possibilité d'acquérir une ferme, préférent quitter leur terre, choisir une autre profession et, le cas échéant, s'expatrier plutôt que de se loucr comme ouvriers agricoles. D'autre part, les émigrants-agriculteurs proviennent en principe de régions ne connaissant pas les exploitations agricoles occupant plusieurs manœuvres; par conséquent, le nombre de travailleurs de ce genré y est rare et ne peut donner lieu à une forte émigration.

${ }^{23}$ On appelle personnes sans activité économique des personnes à la charge des émigrants. 
Figure 4. Individus avec ou sans activité économique par catégories professionnelles

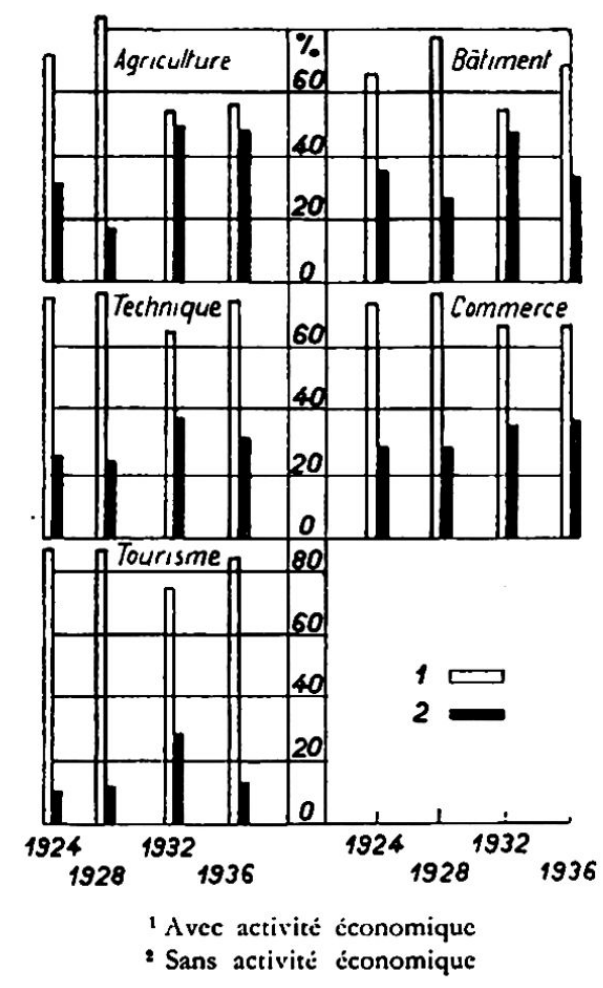

En ordonnée: Individus sur cent avec ou sans activité économique. En abscisse: Les deux catégories en 1924, 1928, 1932, 1936.

Dans toutes les catégories, le taux de participation des individus avec activité économique est maximum en 1928, celui des individus sans activité économique maximum en 1932 (sauf pour le commerce).

Dans l'agriculture, le bâtiment, les professions techniques, le commerce et le tourisme, le taux de participation des individus avec activité économique est maximum en 1928, celui des individus sans activité est maximum en 1932. Les époques de prospérité paraissent donc favoriser l'émigration des individus ayant une activité économique; celle des personnes sans activité acquiert plus d'importance en temps de crise. Les pays d'immigration éprouvent, en temps de prospérité, un besoin accru de travailleurs de toute sorte et réussissent plus facilement à absorber les individus avec activité économique qu'en temps de crise. En temps de crise, en effet, chaque immigrant constitue pour les travailleurs indigènes une concurrence dangereuse, dès qu'il exerce une profession. La catégorie des individus ayant une activité économique est donc, manifestement, plus sensible aux oscillations économiques que celle des personnes sans activité; et ces oscillations dépendent surtout de la situation des pays d'outre-mer.

Enfin, de quelle façon les différentes professions participent-elles à l'émigration des individus avec ou sans activité économique? Le pourcentage des individus ayant une activité économique est très élevé dans les professions qui obligent les travailleurs à vivre avec leur employeur ${ }^{24}$. Tel est le cas pour les gouvernantes (Éducation), ménagères, employés d'hôtel (Tourisme), boulangers et bouchers (Alimentation). Le type même de leur profession interdit à ces individus de se faire accompagner par des personnes à leur charge. Le taux des individus actifs est également élevé dans les carrières ecclésiastiques.

On sait qu'il s'agit de religieuses ct religieux catholiques n'ayant évidemment pas de charge de famille, et de missionnaires partant, dans la plupart des cas, pour des régions tropicales malsaines ou dangereuses interdisant aux femmes et aux mineurs un séjour prolongé. L'agriculture, l'horticulture, le bâtiment comportent des taux relativement élevés de personnes sans activité économique. Dans ces professions, il est bon, en effet, d'avoir des enfants, le fils pouvant rapidement assister le père dans son travail; d'autre part, ces catégories de travailleurs manuels partent en majorité pour des pays à climat tempéré favorables à l'immigration de femmes et d'enfants, donc de personnes sans activité ćconomique.

24 Intensité de la participation à l'ćmigration, dans chaque profession, des individus avec activité économique:

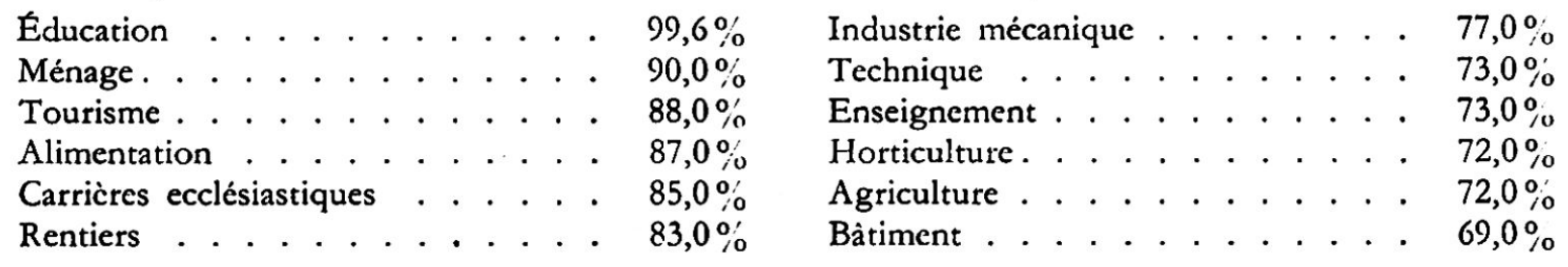




\section{B. L'émigration suivant le sexe et l'état civil}

Le tableau 6 met en évidence la participation à l'émigration des individus de s€xe masculin ou féminin, des célibataires, mariés, veufs ou divorcés.

Tableau 6. L'émigration en fonction du sexe et de l'état civil

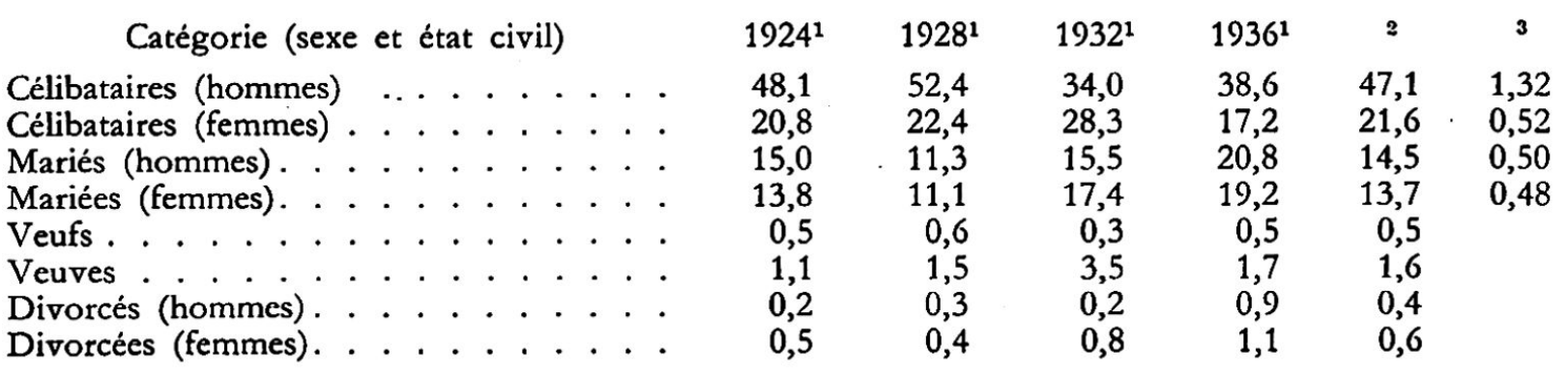

1 Taux de participation - en pour-cent du nombre total des émigrants - au mouvement de l'émigration des années 1924, 1928, 1932, 1936.

- Moyenne arithmétique pondérée de ces quatre taux de participation.

3 Mesure dans laquelle la population suisse - appartenant à telle ou telie condition de sexe et d'état civil —a ćté touchée par l'émigration. En pour-mille de la population globale.

Les célibataires de sexe masculin occupent, dans le mouvement d'émigration, une position importante. Ils sont suivis de loin par les femmes célibataires.

La comparaison entre le nombre des émigrants et le chiffre de la population suisse globale fait ressortir en quelle mesure les différentes catégories d'état civil ont été touchées par l'émigration. Ainsi, nous apercevons que les taux d'intensité pour les femmes célibataires, les hommes et femmes mariés sont à peu près égaux, mais restent bien au-dessous du taux pour les hommes célibataires.

Figure 5. L'émigration en fonction du sexe et de l'état civil

Le groupe des célibataires de sexe masculin parait donc plus enclin à l'émigration que les trois autres catégories. D'autre part, il semble plus sensible aux variations économiques, puisque son taux de participation à l'émigration varie considérablement au cours des années: en période de prospérité (1928), il est très élevé; en période de crise (1932), il se maintient à une position inférieure. Le célibataire paraît donc émigrer de préférence aux époques de prospérité, et il semble, plus que les autres, sensible aux difficultés économiques mondiales. C'est d'ailleurs un phénomène bien explicable. En 1928, en raison de la grande prospérité dont ils jouissaient, les pays d'outre-mer ont pu facilement absorber un grand nombre de travailleurs étrangers. En 1932, par contre, lorsqu'ils ont commencé à souffrir de la crise, ils ont restreint autant que possible le nombre des immigrants. Ces mesures prohibitives de même que la situation économique instable atteignaient en premier lieu les individus les moins qualifiés. Or, les émigrants célibataires sont, en général, jeunes et ne disposent pas encore d'expérience professionnelle suffisante.

Le phénomène inverse s'observe pour les

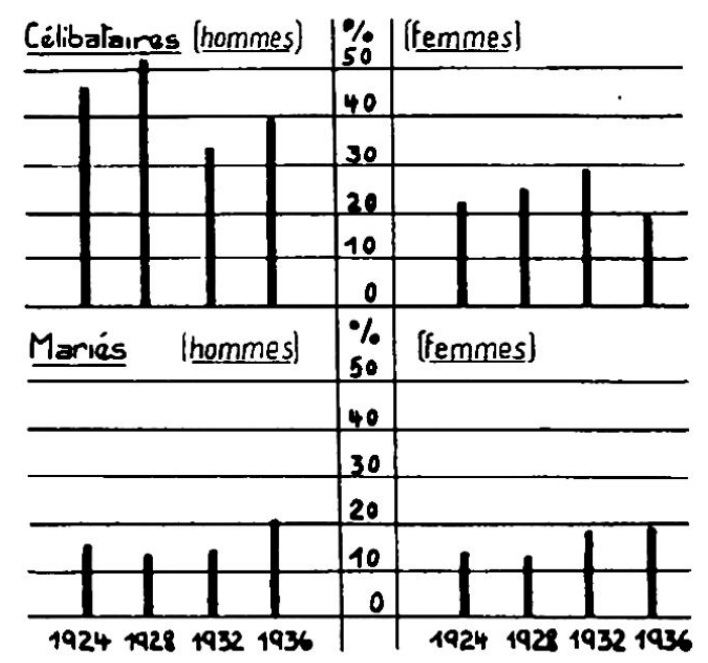

Les hommes célibataires occupent dans le mouvement d'émigration une position importante. Ils sont suivis de loin par les femmes célibataires. hommes mariés. Ceux-ci indiquent des taux de participation élevés en 1932, car ce sont en principe des individus d'un certain âge et d'une certaine expérience professionnelle, qui même en temps de crise sont appréciés par l'économie d'outre-mer.

Cependant, en 1936, le taux des émigrants mariés est encore plus élevé qu'en 1932, et nous pensons que ce phénomène est dû à certaines répercussions favorables de la dévaluation du franc: Les industries d'exportation pouvant reprendre leur lutte contre la concurrence étrangère, en vue de la reconquête des marchés perdus, notamment dans les pays transocéaniques, éprouvaient un grand besoin d'individus 
expérimentés et qualifiés. Il va sans dire qu'ils préféraient des travailleurs d'un certain âge, c'est-à-dire des individus dont un pourcentage relativement élevé était marié25.

Etendons notre étude et constatons, de quelle façon les individus de telle ou telle condition d'état civil ont participé au mouvement d'émigration de telle ou telle profession. Voici d'abord les taux moyens des quatre années en question:

Tableau 7. Composition des professions en fonction du sexe et de l'état civil

Professions

Agriculture . . . . . . . . . .

Bâtiment . . . . . . . . . . .

Technique ............

Commerce . . . . . . . . . . .

Tourisme. . . . . . . . . . .

Horticulture . . . . . . . . . . .

Alimentation . . . . . . . . . . .

Industrie mécanique . . . . . . . . . .

Enseignement . . . . . . . . . .

Ménage $^{2}$. . . . . . . . . . .

Éducation . . . . . . . . . . .

Carrières ecclésiastiques . . . . . . . . . .

Rentiers .............. . .

1 Restes se rapportant aux hommes ct aux femmcs veufs et divorcćs.

2 Les 5,6\% de célibataircs représentent des garçons au-dessous de 15 ans, sans activité économique, voyageant en compagnic de leur mère qui exerce le métier de mćnagère.

Ce tableau statistique fait ressortir que les célibataires des deux sexes réagissent d'une manière toute différente à l'attraction du mouvement de l'émigration. Le taux de participation des célibataires de sexe masculin est élevé dans les professions manuelles; il est moindre pour les professions libérales. Pour les célibataires de sexe féminin, le phénomène est inverse: les professions non manuelles acquièrent une très grande importance, tandis que les professions manuelles sont parfois à peine représentées. Pour les individus mariés, la situation n'apparaît pas aussi nette. En principe, on peut dire que les professions manuelles et la technique présentent des taux plus élevés d'hommes mariés que les professions non manuelles ${ }^{26}$.

Les oscillations économiques ont de fortes répercussions sur la composition selon l'état civil dans le cadre des professions suivantes: agriculture, bâtiment, technique, commerce, tourisme. L'époque de prospérité (1928) fait monter le taux des célibataires, la période de crise (1932) la fait descendre.

En 1936, le bâtiment indique des taux élevés de célibataires alors qu'il souffre de la crise. Puisque les célibataires comprennent un plus grand nombre de jeunes manœuvres, ils sont davantage soumis aux péripéties d'une situation économique instable et se sentent plus disposés à l'émigration que les hommes mariés. En technique, par contre, nous observons des taux élevés d'hommes mariés, car nos industries d'exportation, qui profitent de la reprise économique résultant de la dévaluation monétaire, ont, pour sauvegarder leurs intérêts outre-mer, surtout besoin d'individus de grande expérience professionnelle, soit donc plutôt d'hommes mariés que de célibataires.

25 Le taux de participation des femmes mariées augmente et diminue selon l'accroissement ou la diminution du taux des hommes mariés. Il existe donc une relation de cause à effet entre le mouvement migratoire des hommes mariés et celui des femmes mariées. Toutefois,en 1932, le nombre des femmes mariées est sensiblement plus élevé que celui des hommes mariés. La crise économique mondiale freinait donc en 1932 non seulement l'émigration des célibataires, mais aussi, bien qu'en moindre mesure, celle des hommes mariés. Ses répercussions furent moins sensibles pour les femmes mariées, car il s'agissait là en majorité de personnes sans activité économique, qui souvent allaient rejoindre leur mari établi déjà dans un pays d'outre-mer.

${ }_{26}$ Toutefois, dans l'enseignement (profession non manuelle), la catégorie des individus mariés atteint des taux de participation élevés, tandis que cette participation est faible pour les agriculteurs. On peut se demander si cela ne tient pas à une question d'âge, puisque les agriculteurs émigrent certainement plus jeunes que les instituteurs qui doivent d'abord achever leurs études. 


\section{L'émigration suivant l'âge}

$1^{\circ}$ Les différentes classes d'âge et l'émigration. Le tableau 8 et la figure 6 nous renseignent sur la composition selon l'âge du courant d'émigration:

Tableau 8. Participation des différentes classes d'âge à l'émigration

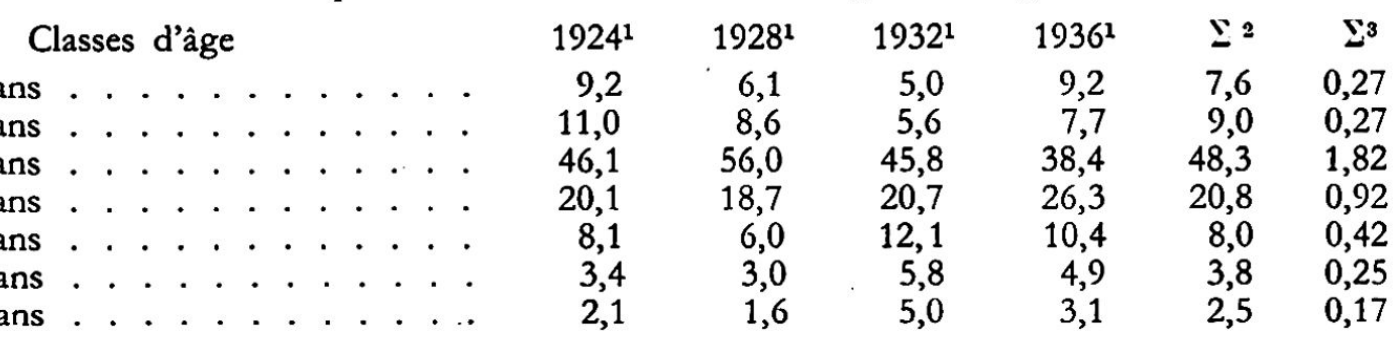

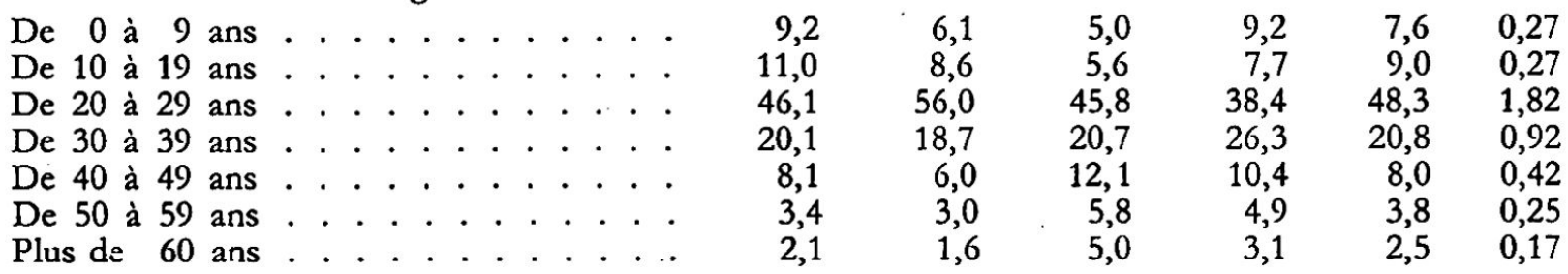

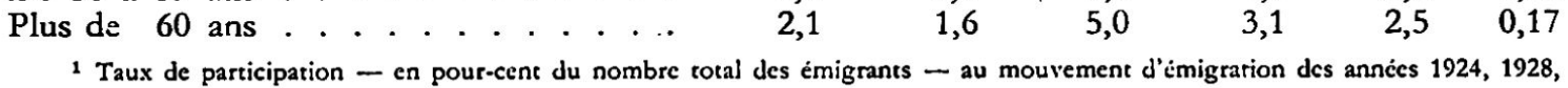
$1932,1936$.

2 Moyenne arithmétique pondérée de ces quatre taux de participation.

3 Mesurc dans laquelle la population suisse - appartenant à telle ou telle classe d'àge - a été touchée par l'émigration en pourmille de la population globale.

Figure 6. Les différentes classes d'âge et l'émigration

On constate que la grande majorité des émigrants s'expatrient à l'âge de 20 à 40 ans. Notamment les classes d'âge de 20 à 30 ans indiquent un mouvement d'émigration intense. La plus grande fréquence s'observe pourtant à l'âge de 22 à 26 ans. Rapportés à l'effectif global de la population, les taux d'intensité sont maximum à l'âge de 20 à 30 ans.

Regardons, de quelle façon les oscillations économiques se répercutent sur la structure parâges du courant d'émigration. La période de prospérité (1928) fait augmenter le taux des individus de 20 à 29 ans, diminuer le taux des personnes de 0 à 19 et de 30 à 60 ans. L'année de crise (1932) est caracté-

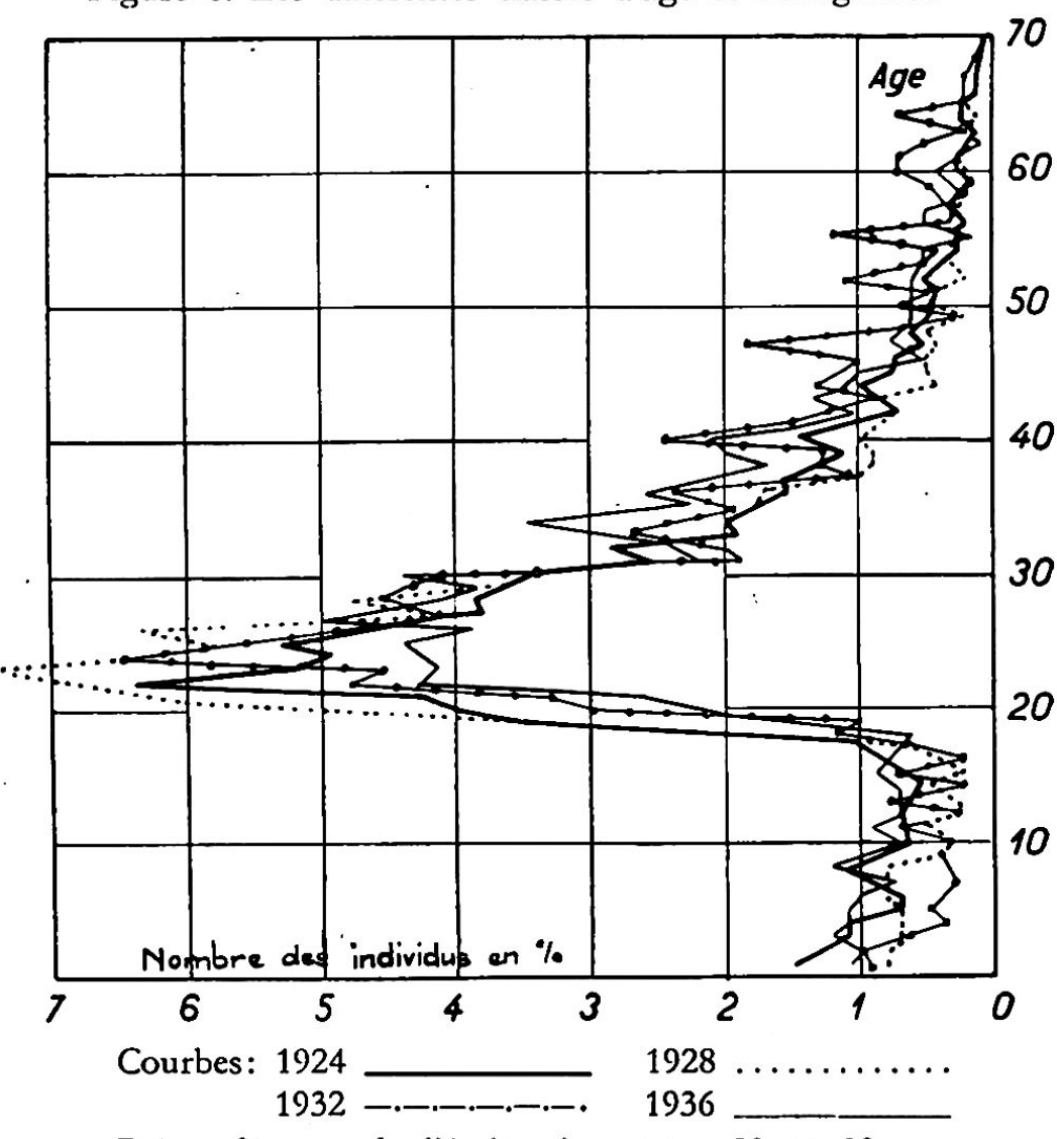

Prépondérance de l'émigration entre 20 et 30 ans risée par un pourcentage relativement élevé d'individus de 40 à 60 ans. En 1936, les enfants jusqu'à 9 ans, les adultes de 30 à 60 ans occupent une forte position dans le mouvement de l'émigration, les jeunes gens de 20 à 30 ans une faible position.

Voici les conclusions qu'on peut en tirer: La prospérité de l'année 1928 favorisait surtout l'émigration de jeunes gens de 20 à 29 ans, qui, comme on l'a déjà constaté, ont été attirés par la prospérité d'outre-mer. La crise de l'année 1932 déprimait l'émigration des jeunes travailleurs peu qualifiés et peu expérimentés, tandis qu'elle frappait en moindre mesure le déplacement outre-mer de personnes plus âgées. D'une part, ces émigrants étaient des hommes expérimentés, représentant même en temps de crise une certaine valeur pour les pays transocéaniques, d'autre part, il s'agissait de femmes mariées qui allaient rejoindre leurs maris établis outre-mer et qui, n'exerçant pas de profession, ne constituaient pas de concurrence pour les travailleurs indigènes des pays transocéaniques. 
En 1936 (période d'expansion économique des industries d'exportation), les émigrants ont été notamment des individus d'un certain âge (plus de 30 ans) capables de représenter les intérêts des industries nationales à l'étranger. Comme ils étaient souvent accompagnés par leurs enfants, le taux de participation de la classe d'âge de 0 à 9 ans fut également élevé2 ${ }^{2}$.

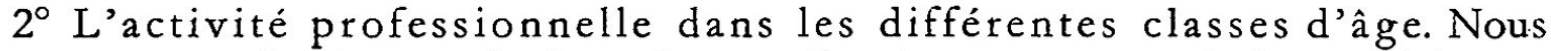
tenons compte de cinq professions de première importance: agriculture, bâtiment, technique; commerce, tourisme:

Figure 7. L'activité professionnelle dans les différentes classes d'àge

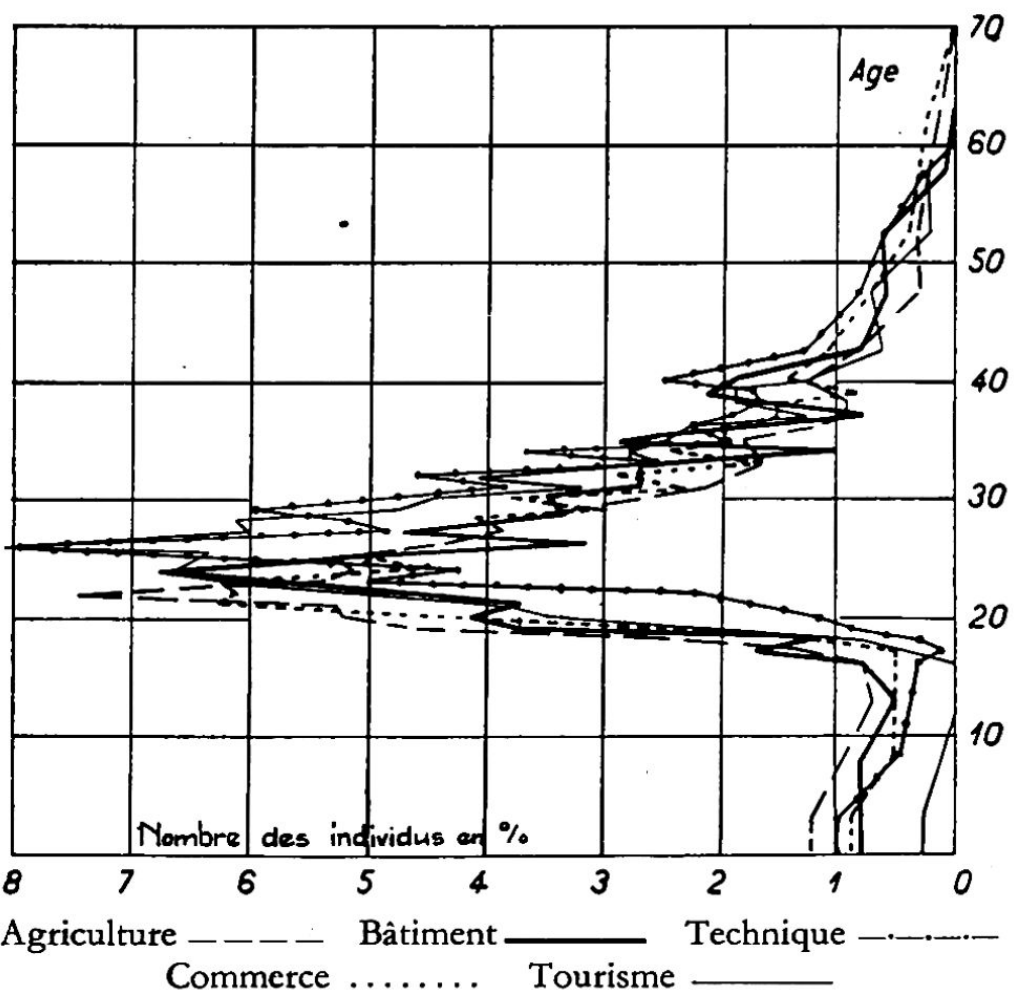

Emigration des agriculteurs et des commerçants à un âge jeune, des techniciens et des employés d'hôtel à un âge plus avancé. Contingent d'enfants relativement élevé dans l'agriculture, le bâtiment, le commerce, peu élevé en technique et dans le tourisme.
On constate que la structure par âge n'est pas la même pour les cinq professions envisagées. Les agriculteurs émigrent de préférence à un âge jeune; leur fréquence maximum s'inscrit à 22 ans. D'autre part, leur contingent d'enfants de moins de 10 ans est le plus important des cinq professions envisagées.

Pour les travailleurs en bâtiment, la fréquence maximum est à 24 ans, des fréquences de moindre importance à 28,33 , 40 ans. Le nombre d'enfants y est également relativement élevé.

Les techniciens émigrent plus tard, de préférence vers 27 ans, puis de nouveau vers 32 et vers 40 ans. Le nombre d'enfants y est peu élevé. Un grand nombre de commerçants s'expatrient déjà assez tôt, mais ils participent aussi à

l'émigration des âges moyens. Le nombre d'enfants parmi les émigrants-commerçants est relativement élevé. Les employés d'hôtel indiquent une fréquence maximum à l'âge de 28 ans; le nombre d'enfants y est peu élevé.

27 A part ces modifications dues aux oscillations économiques dans le temps, nous constatons un autre fait: L'âge de la plus grande fréquence se déplace, au cours du temps, dans la pyramide des âges vers le haut. Tandis qu'en 1924 elle s'inscrit à 23 ans; elle est à 24 ans en 1928, à 26 ans en 1932. En 1936, il n'y a pas même de fréquence maximum manifeste à l'âge de 20 à 30 ans, les pour-cent qui auraient dû la constituer étant répartis sur les âges moyens ( 30 à 40 ans) et supérieurs (40 à 60 ans). Ce phénomène est-il l'indice du fait que les jeunes gens n'émigrent qu'après une préparation professionnelle plus longue? Résulte-t-il plutôt du fait que la structure professionnelle du courant d'émigration a subi des modifications au cours du temps? Voilà la question qui se pose. Nous tenons à affirmer plutôt la valeur de la seconde hypothèse, puisque nous avons pu constater que la participation des professions non manuelles est beaucoup plus importante en 1932 et 1936 qu'en 1928, et certes les individus appartenant à cette première catégorie professionnelle partent outre-mer à un âge plus avancé que les personnes faisant partie des professions manuelles. C'est un problème qu'on peut d'ailleurs facilement résoudre en envisageant brièvement la question de l'âge en rapport avec d'autres aspects particuliers du phénomène d'émigration. 
Cette différence de structure par âge des différentes professions qui participent à l'émigration, est due à une structure particulière de chaque branche d'activité de notre économie nationale. En principe, un très grand nombre d'individus émigrent après avoir terminé leur préparation professionnelle. Certaines professions demandent une plus longue période de préparation; il en résulte une différence de plusieurs années entre les fréquences maximum des différentes professions.

D'autre part, les chances de réussite dans un pays outre-mer ne sont pas, au mème âge, les mêmes pour toutes les professions. Un agriculteur, qui doit labourer la terre, ne verra pas aussi vite les fruits de son travail qu'un technicien ou un employé d'hòtel, qui peuvent changer de position sans compromettre leur carrière; il aura donc un plus grand intérèt à émigrer jeune, tandis que les techniciens sont surtout appréciés en outre-mer, lorsqu'ils disposent déjà d'une certaine expérience.

Le contingent plus ou moins considérable d'enfants est aussi le résultat de la structure particulière des différentes branches d'activité. Les employés d'hôtel, par exemple, indiquent un taux d'enfants peu élevé, parce que ceux-ci constitueraient pour les émigrants dans cette profession, pour des raisons que nous avons déjà expliquées (nécessité de loger auprès du patron, etc.), un certain embarras. De même, on pourrait prétendre que le contingent des enfants est variable suivant que les travailleurs des différentes professions émigrent pour des pays à climat tempéré ou tropical. C'est une question que nous aurons à examiner dans la troisième partie.

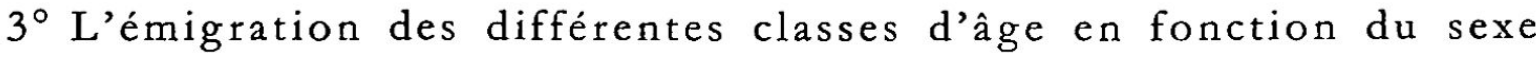
et de l'état civil.

On constate, d'après la pyramide extérieure, que si l'époque de prospérité 1928 favorise l'émigration des jeunes gens entre 20 et 30 ans, la période de crise de 1932 la contrecarre. Cependant, il s'agit notamment de jeunes hommes dont la participation à l'émigration subit les plus grands changements. Ils occupaient une position prédominante en 1928; en 1932, par contre, leur supériorité numérique diminue et se répartit d'une part entre les hommes d'un âge plus élevé, d'autre part les femmes indépendamment de l'âge. L'année 1936 se caractérise par des taux de participation élevés d'hommes et de femmes d'un âge moyen et avancé.

La pyramide intérieure nous indique la façon dont les individus mariés participent au mouvement d'émigration des différents âges. Nous constatons d'une part que l'importance numérique des individus mariés est beau-
Figure 8. L'émigration des différentes classes d'âge en fonction du sexe et de l'état civil
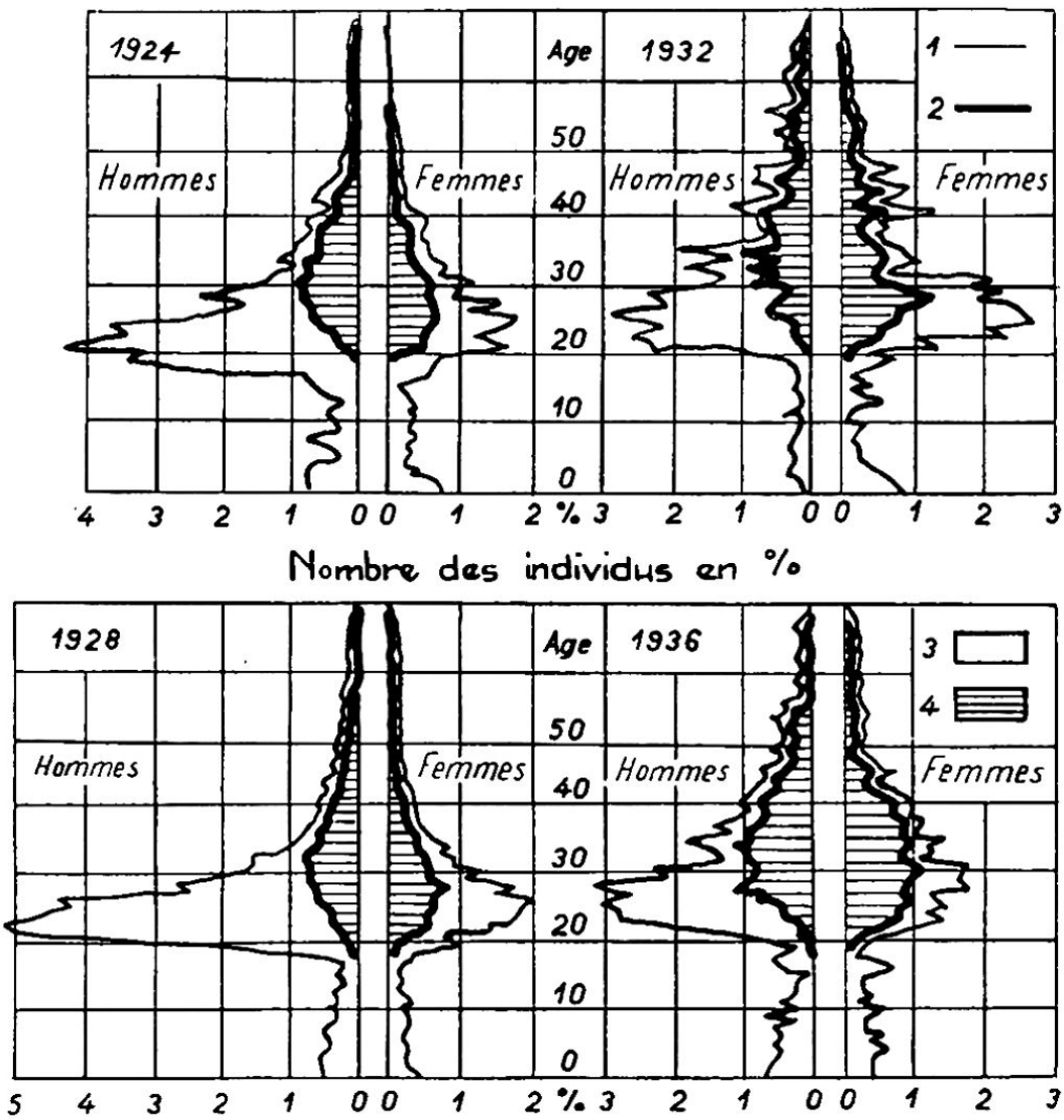

1 Courbe cxtéricure: Émigrants masculins ct féminins de tel ou tel àge.

2 Courbe intérieure: Émigrants mariés (masculins ou féminins) de tel ou tel àge.

3 Célibataires des deux sexes.

- Hommes et femmes marićs.

Position prédominante en 1928 des jeunes gens de sexe masculin entre 20 et 30 ans. Participation relativement forte en 1932 et 1936 des hommes d'un âge plus élevé et des femmes des différents âges (voir pyramide extérieure). Importance numérique des individus mariés plus élevée dans les âges supérieurs. Participation élevée en 1932 et 1936 (voir pyramide intérieure). 
coup plus grande dans les âges supérieurs, qu'elle est d'autre part plus grande en 1932 et surtout en 1936 qu'en 1928. C'est aussi une observation que nous avons déjà faite auparavant.

$4^{\circ}$ Émigrants avec ou sans activité économique par classes d'âge Figure 9. Émigrants avec ou sans activité économique par classes d'àge
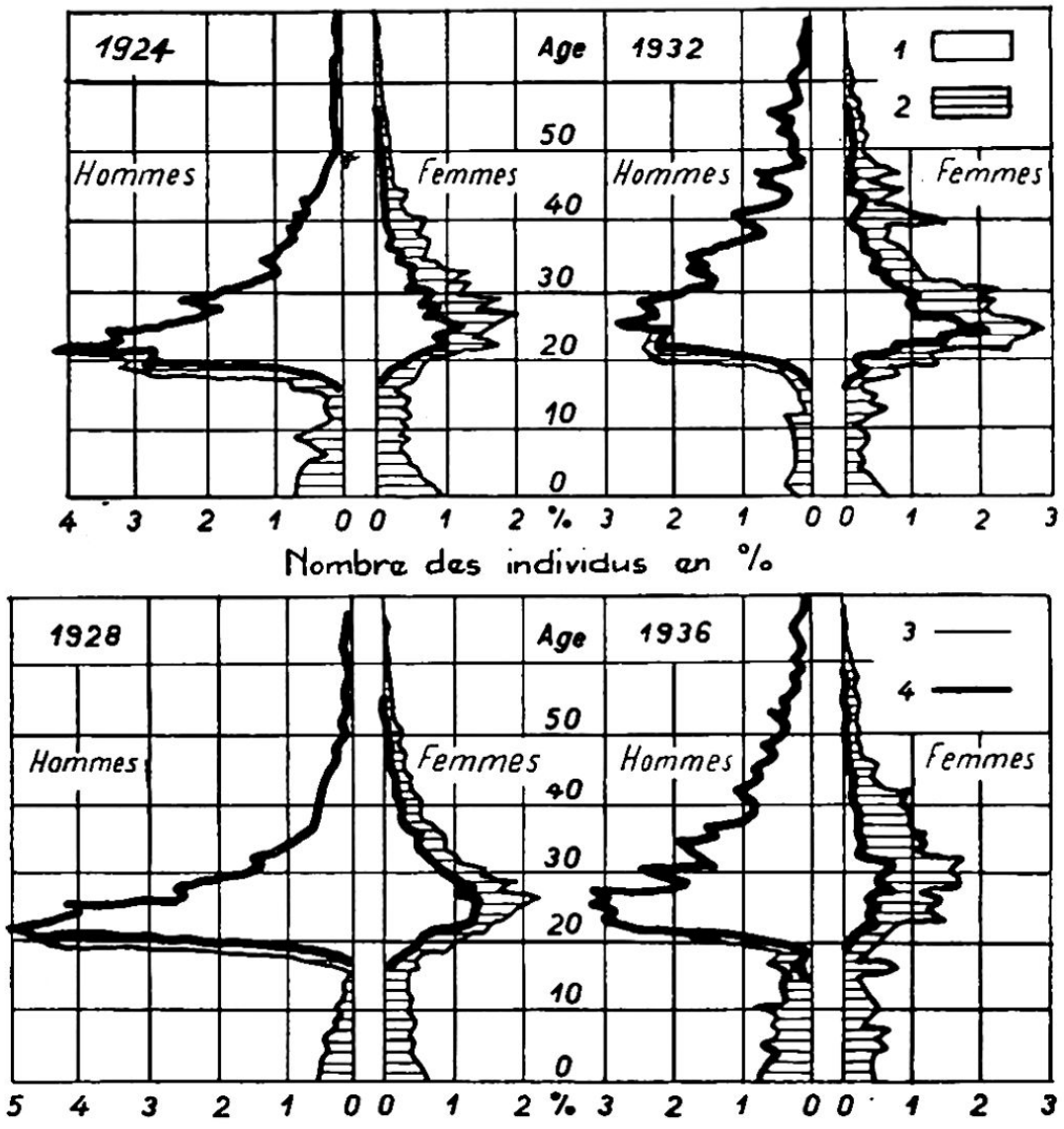

Individus avec activité économiquc. 2 Individus sans activité économique.

3 Courbe cxtérieure: Émigrants de sexe masculin ou féminin de tel ou tel àge.

- Courbe intéricurc: Émigrants de tcl ou tel àge (hommes ou femmes) exerşant unc activité économiqục.

Les individus sans activité économique sont des mineurs et des adultes de sexe féminin. Le nombre des femmes sans activité économique est plus élevé en 1932 et 1936 qu'en 1928.
De nouveau, nous distinguons deux espèces de pyramides d'âge:

a) une pyramide extérieure considérant le nombre total des émigrants,

b) une pyramide intérieure (en blanc) tenant compte des individus avec activité économique.

La première des deux pyramides correspondant exactement à celle que nous venons de traiter dans le paragraphe précédent, nous n'avons plus à nous occuper que de la seconde pyramide.

Nous constatons queles émigrants-mineurs n'exercent pas encore d'activité économique, et dans les classes d'âge de plus de 20 ans, les personnes sans activité économique sont toutes de sexe féminin. Il s'agit là, pour la plupart, de femmes mariées qui accompagnent ou vont rejoindre leurs maris.

Quant aux répercussions des oscillations économiques dans le temps, le nombre des femmes sans activité économique est beaucoup plus élevé en 1932, et plus encore en 1936, qu'en 1928. Ce phénomène ejt certainement dû aux conditions économiques particulières de chaque année en question, conditions que nous avons exposées à maintes reprises: en 1928, la prospérité outre-mer favorise l'émigration d'individus actifs, sans charge de famille, et le taux des personnes sans activité économique est réduit.

En 1932, l'émigration des individus actifs, notamment des jeunes travailleurs, est contrecarrée par la crise outre-mer; les personnes sans activité économique s'en ressentent moins.

En 1936, la reprise économique dans les industries d'exportation favorise l'émigration de techniciens et notamment d'individus expérimentés et d'un certain âge, qui, grâce à leur position relativement élevée, sont en mesure de se faire accompagner par leur épouse. 


\section{L'ÉMIGRATION TRANSOCÉANIQUE AU DÉPART DE LA SUISSE}

\section{CHAPITRE IV: \\ RÉPARTITION DES ÉMIGRANTS PAR UNITES ADMINISTRATIVES}

\section{A. Intensité de l'émigration transocéanique}

Les cantons suisses ne participent pas tous de la même façon au mouvement d'émigration transocéanique des années 1868 à 1940. Les cantons appartenant aux Alpes ou au Jura présentent plus souvent des taux d'intensité d'émigration élevés que les cantons faisant partie du Mittelland ${ }^{28}$. Ce sont notamment les cantons de la Suisse centrale (Schwyz, Obwald, Uri, Glaris) et le Tessin qui, de façon presque permanente, participent à un mouvement d'émigration intense, et, en outre, le demi-canton transjurassien de Bâle-Ville. Dans les autres cantons montagnards (Valais, Grisons, Appenzell Rhodes Extérieures, St-Gall), de même que dans les cantons appartenant au Jura, cette participation élevée se limite à l'époque antérieure à 1895. Les cantons appartenant au Mittelland, ont presque toujours une intensité moyenne ou faible. Cependant, les particularités suivantes distinguent les cantons du Mittelland septentrional de ceux du Mittelland méridional:

Les cantons septentrionaux (Argovie, Zurich, Thurgovie) présentent d'une manic̀re générale une intensité d'émigration moyenne, et ils participent, de 1880 à 1884, à un mouvement d'émigration intense. La position du canton de Berne ne ressort pas clairement, car ce canton s'étend sur les trois régions principales de la Suisse, de sorte que le mouvement migratoire intense de 1880 à 1895 peut provenir de l'une ou de l'autre de ces régions. Dans les cantons méridionaux (Genève, Vaud, Fribourg, Lucerne, Zoug), l'émigration est le plus souvent de faible intensité. Ils ne participent pas, à l'époque de 1880 à 1884, au mouvement migratoire intense.

Pendant la période de 1930 à 1935, la plupart des cantons indiquent un mouvement d'émigration minime, cx zepté les cantons de Bâle, Genève et Zurich (cantons à grandes agglomérations urbaines), où elle est d'intensité moyenne.

Nous constatons donc dès l'abord des oppositions entre: les Alpes, le Mittelland, le Jura; les cantons de la Suisse centrale et le Tessin, d'une part, et les autres cantons montagnards, d'autre part; le Mittelland septentrional et le Mittelland méridional; les cantons à grandes agglomérations et le reste de la Suisse.

Ces oppositions se retrouvent en 1924, 1928, 1932, 1936.

B. Intensité de l'émigration transocéanique dans les différentes zones de départ en 1924, 1928, 1932, 1936

$1^{\circ}$ L'intensité de l'émigration par districts. L'examen du mouvement d'émigration par districts fait bien ressortir les particularités des différentes zones

28 Taux d'intensité migratoire des cantons suisses:

\section{Cantons}

Argovie

Appenzell Rhodes Intérieures

Appenzell Rhodes Extérieures

Berne.

Bâle-Ville ' . . . . $\cdot 1,30$

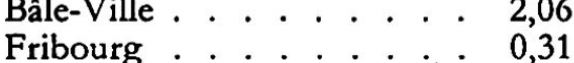

Genève . . . . . . . . . 1,16

Glaris. . . . . . . . 3,00

Grisons . . . . . . . . . 1,24

Lucerne . . . . . . . . . . 0,66

Neuchâtel . . . . . . . 1,26

Nidwald

$\begin{array}{lll}1,10 & 1,91 & 0,61 \\ 0,39 & 0,42 & 0,37 \\ 1,25 & 1,52 & 1,04 \\ 1,64 & 2,60 & 0,94 \\ 1,30 & 2,18 & 0,75 \\ 2,06 & 3,57 & 1,44 \\ 0,31 & 0,50 & 0,20 \\ 1,16 & 1,23 & 1,10 \\ 3,00 & 5,20 & 1,09 \\ 1,24 & 1,98 & 0,73 \\ 0,66 & 0,66 & 0,67 \\ 1,26 & 1,70 & 0,92 \\ 0,77 & 0,75 & 0,79\end{array}$

\begin{tabular}{|c|c|c|c|c|c|c|c|c|c|c|}
\hline \multirow{2}{*}{\multicolumn{2}{|c|}{ Obwald }} & \multicolumn{6}{|c|}{ Cantons } & 1 & 2 & 3 \\
\hline & & & & & & & & 2,75 & 3,88 & 2,12 \\
\hline St-Gall: & & & & & & & & 1,35 & 1,67 & 1,13 \\
\hline Schaffhc & buse & e. & . . & . & . & & & 2,17 & 4,10 & 0,92 \\
\hline Soleure & & & . . & . & 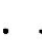 & & & 0,98 & 1,98 & 0,57 \\
\hline Schwyz & & & & 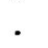 & & & & 1,93 & 2,12 & 1,77 \\
\hline Thurgo & vie & & . & . & & & & 0,83 & 1,05 & 0,68 \\
\hline $\sin$ & . & . . & . & . & & & & 3,40 & 4,84 & 2,44 \\
\hline Ur & 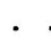 & . . & . . & . & & & & 1,77 & 2,85 & 1,25 \\
\hline Vaud. & & . . & . & & & & & 0,62 & 0,75 & 0,55 \\
\hline Valais & . & • & $\cdot$ & . & 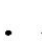 & & & 1,38 & 2,43 & 0,66 \\
\hline 70 & $\theta^{\circ}$ & 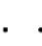 & . & . & • & & & 1,22 & 1,37 & 1,10 \\
\hline $\mathrm{ch}$ & 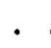 & . . & . & & & & & 1,50 & 1,74 & 1,33 \\
\hline
\end{tabular}


de départ, et l'étude de la figure $10^{29}$ permet de retrouver certains faits particuliers qu'on a déjà relevés au paragraphe précédent.

Ainsi, dans le Mittelland, les taux d'intensité migratoire augmentent du sud-ouest au nord-est. Il est de 0,00 à $0,15 \%$ dans le Plateau suisse romand, de 0,15 à $0,30 \%$ dans le Plateau bernois et lucernois, de 0,30 à $0,45 \%$ dans le Plateau argovien, le nord du Plateau zurichois, la Thurgovie. Pourtant, ce phénomène de localisation des taux d'émigration ne s'applique pas partout.

$\mathrm{La}$ région de Genève et les districts vaudois de Nyon [166] et d'Aubonne [157], situés à l'extrémité sud-ouest du Mittelland, ainsi que les districts vaudois, riverains méridionaux du lac de Neuchâtel, indiquent des taux plus élevés que le reste du Plateau suisse romand. Dans les trois premières contrées, cette intensité est due certainement à la plus grande proximité du Jura.

Une bande de districts s'étendant le long de la rive droite de l'Aar, du pied des Alpes à Thoune jusqu'au pied du Jura $[49,35,37,22,30]$, a une intensité supérieure à celle des régions qui les prolongent vers le nord-est.

Dans la région du Napf [district de Trachselwald 50], l'intensité d'émigration est également supérieure à celle des districts environnants, en raison de son relief plus accidenté.

D'autre part, on observe des centres de forte émigration, d'une extension relativement restreinte, répartis dans les diverses régions du Mittelland. En principe, ces centres se trouvent localisés dans les grandes agglomérations urbaines ou industrielles ${ }^{30}$.

Dans les Alpes septentrionales également, les taux d'intensité augmentent vers le nord-est, atteignent un maximum dans l'Oberhasle [42], le demi-canton d'Obwald [89], les districts de Lucerne [79], de Küssnacht [113] et de Schwyz [115], se réduisent quelque peu dans les cantons d'Uri [142] et de Glaris [62], reprennent dans les régions méridionales des Alpes thuranaises (districts st-gallois d'Obertoggenbourg [95], Untertoggenbourg [101], Wil [103], Gossau [92], district appenzellois de Hinterland [12]), pour ensuite atteindre un nouveau maximum à l'extrémité nord-orientale des Alpes thuranaises.

Malgré cet accroissement des taux d'intensité du sud-ouest au nord-est dans les Alpes septentrionales, particulièrement dans leur secteur occidental, les intensités migratoires élevées ne s'y rencontrent cependant pas partout. Certaines régions comportent des taux inférieurs. L'Entlebuch [77] a la même intensité que les régions du Mittelland qui forment sa continuation vers le nord et l'ouest. La partie supérieure de la vallée du Rhin st-gallois ainsi que la vallée de la Seez, du lac de Wallenstadt, du Gaster et de la March, situées à une altitude moins élevée et jouissant d'un climat relativement favorable, ont des taux moins élevés que les régions environnantes. Les districts st-gallois d'Alt- et de Neutoggenbourg $[90,93]$, qui sont la continuation du district thurgovien de Münchwilen [139] en direction sud-est et présentent certains aspects physiques analogues (relief relativement peu accidenté par rapport à celui du Toggenbourg supérieur, etc.), ont la même intensité que cette région du Mittelland.

Dans le Jura enfin, on constate également, comme dans le Mittelland et les Alpes septentrionales, un accroissement des taux d'intensité en direction nord-est. Ils sont de 0,00 à $0,15 \%$ dans le district de I a Vallée [172], de 0,15 à $0,30 \%$ dans les districts d'Orbe [167], de Grandson [161], du Val de Travers [87], de 0,30 à 0,45\% dans les districts Du Locle [84], de La Chaux-de-Fonds [83], de Courtelary [28], de Moutier [38], de 0,45 à $0,60 \%$ dans les districts de Waldenbourg [19] et de Gösgen [120], supérieurs à $0,60 \%$ en certaines parties du canton de Schaffhouse. Nous tâcherons d'expliquer ce phénomène dans le chapitre II.

${ }^{29} \mathrm{La}$ liste détaillée des districts suisses et de leurs taux d'intensité migratoire se trouve à l'annexe, page 87.

Les chiffres en crochets ([]) dans la deuxième partie signifient "numérotage des districts suisses".

30 Parfois, le centre d'intensité élevée ne dépasse pas le proche voisinage de l'agglomération. Telle est la situation des villes de Genève, Bienne, Soleure, Berne, Baden. Parfois, le centre d'intensité élevé est entouré d'une zone intermédiaire d'intensité inférieure à celle du centre même, mais supérieure à celle des régions environnantes. Ainsi, les centres de Lausanne et de Montreux sont reliés par une semblable zone intermédiaire. De même, le centre de Winterthour est entouré d'une zone analogue. La ville de Zurich forme, avec toute la partie méridionale du Plateau zurichois (la région de Zoug comprise) toute une zone d'intensité élevée. A l'intérieur de cette zone, les districts d'Uster et de Horgen sont d'une intensité supérieure à celle des districts de Hinwil, de Meilen et d'Affoltern a. A. 


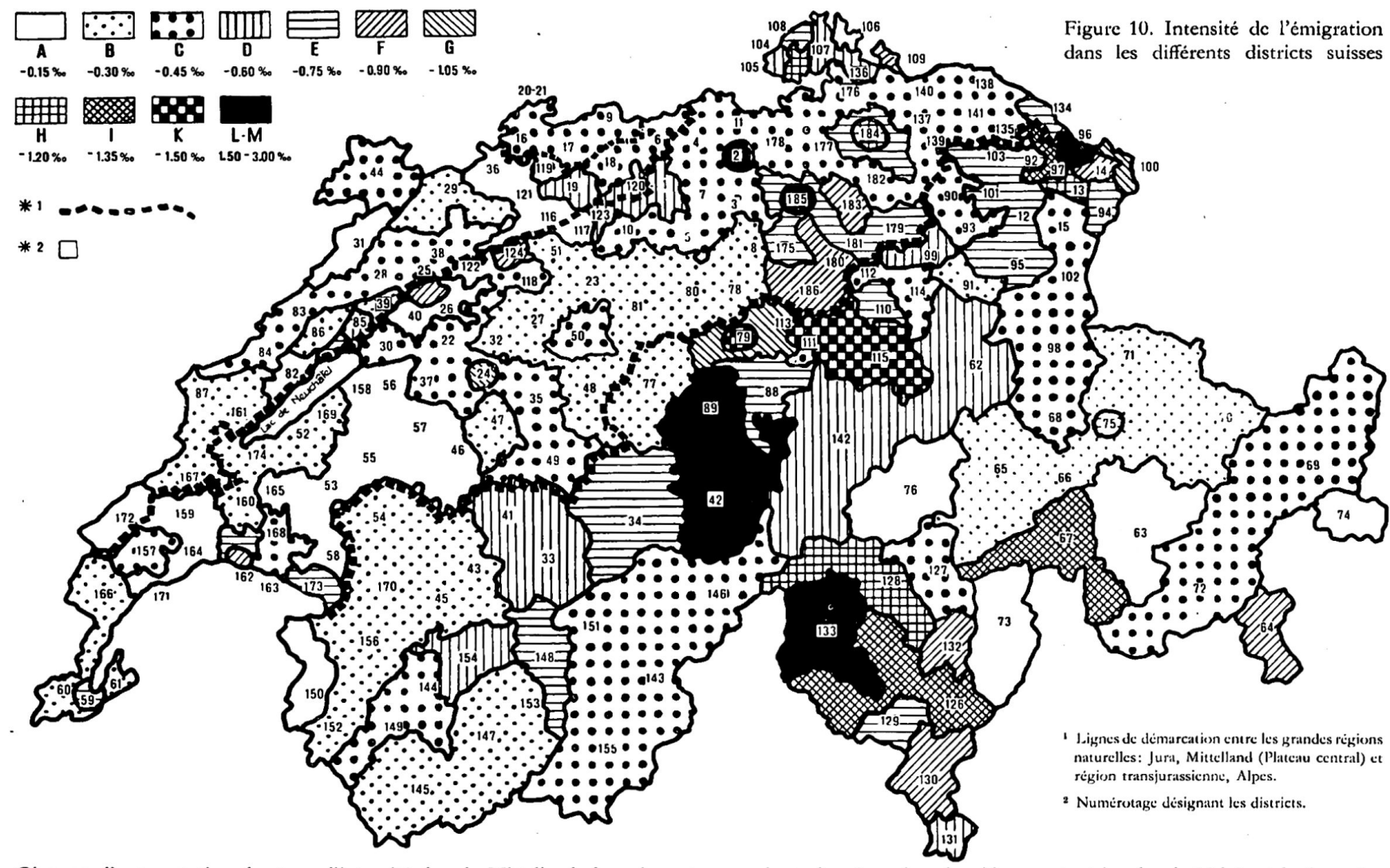

Observer l'augmentation des taux d'intensité dans le Mittelland, du sud-ouest au nord-est, de méme dans les Alpes septentrionales, le Valais et le Jura. Les agglomérations urbaines sont des centres de forte intensité d'émigration. L'intensité d'émigration est plus élevée dans les Alpes et dans le Jura que dans le Mittelland. Dans le Tessin, l'émigration augmente du sud au nord. 
Dans certains districts riverains des lacs de Neuchâtel et de Bienne, les intensités sont inférieures à celle des régions situées en plein Jura. Les districts de Delémont [29], Laufon [36], Kriegstetten [121], Balsthal [116], indiquent des taux plus faibles que les régions environnantes. Les districts de Dorneck [119], de Sissach [18] et de Laufenbourg [6] prennent les intensités de la région transjurassienne qui les touche au nord-ouest, inférieures à celles des autres districts jurassiens de cette région.

A part quelques exceptions, on peut dire que les régions alpestres et jurassiennes ont des taux supérieurs aux régions du Mittelland auxquelles elles touchent. On s'en rend compte à l'examen de la carte, par exemple le long de l'axe unissant les districts 41, 46, 57, 82, 83.

Les différentes régions des Alpes au sud du Rhône-Rhin antérieur semblent trop disparates pour pouvoir être envisagées ensemble. Nous distinguons donc trois régions différentes:

a) Le Valais: Ici également, les taux d'intensité augmentent de l'ouest vers l'est. Cet accroissement est plus remarquable sur le versant nord de la vallée principale. Tandis que dans le secteur méridional les taux sont de 0,00 à $0,15 \%$ dans le district de Monthey [150], de 0,15 à 0,30\% dans les districts de St-Maurice [152], Entremont [145], Hérens [147] et dans le Val d'Anniviers, de 0,30 à $0,45 \%$ dans le Valais supérieur, le secteur septentrional indique les taux suivants: 0,30 à $0,45 \%$ dans les districts de Martigny [149] et Conthey [144], 0,45 à $0,60 \%$ dans le district de Sion [154], 0,60 à $0,75 \%$ dans la district de Loèche [148].

b) Le Tessin: On peut y constater un accroissement d'intensité au fur et à mesure qu'on remonte du sud au nord, vers la haute montagne. Tandis que le Mendrisiotto [131] est d'une intensité de 0,45 à $0,60 \%$, les taux sont de 0,75 à $0,90 \%$ dans le Luganese [130], de 1,20 à $1,35 \%$ dans le district de Bellinzona [126], de même que dans les vallées de Verzasca, Centovalli, Onsernone [district de Locarno 129], de plus de 1,50\% dans le Vallemaggia [133]. Dans la vallée principale du Tessin, l'accroissement n'est pas aussi rapide. Le district de Riviera [132] indique des taux de 0,75 à $0,90 \%$, la Léventine [128] 1,05 à 1,20\%. D'autre part, la région de Locarno [129] riveraine du lac Majeur est d'une intensité inférieure, de 0,60 à $0,75 \%$. Tout à fait hors de règle est le taux d'émigration du Val Blenio [127]; il est de 0,30 à $0,45 \%$.

c) Les Grisons: Les taux d'intensité de ce canton ne sont pas uniformes, puisque des régions à forte intensité sont voisines de districts de faible intensité. Toutefois, on reconnaît les faits suivants: L'intensité est la même dans les deux districts de l'Engadine (Maloja et Inn). Dans la partie des Grisons appartenant au système fluvial du Rhin, le district de Hinterrhein, zone de peuplement des Valses, est d'intensité d'émigration élevée, moyenne dans les autres régions de langue allemande, faible dans les districts de langue rhéto-romane.

L'étude que nous venons d'entreprendrc, nous permet d'entrevoir divers centres d'émigration: les centres de forte émigration provenant surtout des Alpes septentrionales, du Tessin, du district de Hinterrhein ainsi que des centres urbains; une faible émigration provenant des Grisons, du Valais, des Préalpes romandes, du Mittelland; une faible ou moyenne émigration provenant du Jura ${ }^{31}$.

Sans doute, l'intensité migratoire élevée que nous venons d'observer pour certains districts suisses est-elle caractéristique aussi des communes qui s'y trouvent. En effet, d'après le tableau 9, certaines communes se signalent par des taux particulièrement élevés.

31 Tenant compte de la commune d'origine, on retrouve, dans le mouvement de l'émigration, certaines uniformités qu'on a déjà constatées pour le lieu de résidence. Dans le Mittelland, les taux d'intensité augmentent du sud-ouest au nord-est; les centres urbains indiquent souvent des taux d'intensité élevés, et certaines parties des Alpes septentrionales ont un mouvement d'émigration intense, par rapport aux régions du Mittelland avoisinantes. D'autres régions, par contre, notamment les districts de La Vallée [172], Orbe [167], Bienne [25], Soleure [124], Signau [48], Oberrheintal [94], Maloja [72], indiquent, pour la bourgeoisie, des intensités supérieures à celles du lieu de résidence, tandis que nous ne connaissons qu'un seul cas caractéristique [Oberhasle 42], où l'intensité est beaucoup plus élevée pour le lieu de résidence que pour la commune d'origine. 
Tableau 9. Participation de certaines communes suisses au mouvement d'émigration.

Moyenne des quatre années envisagées: en pour-mille de la population globale.

Communes qui sont situées dans une des grandes régions naturelles suivantes Le Jura

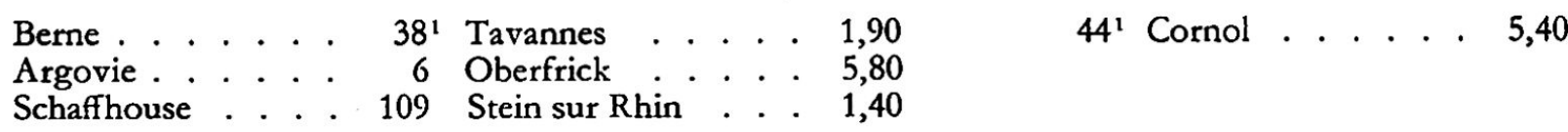

\section{Le Mittelland}

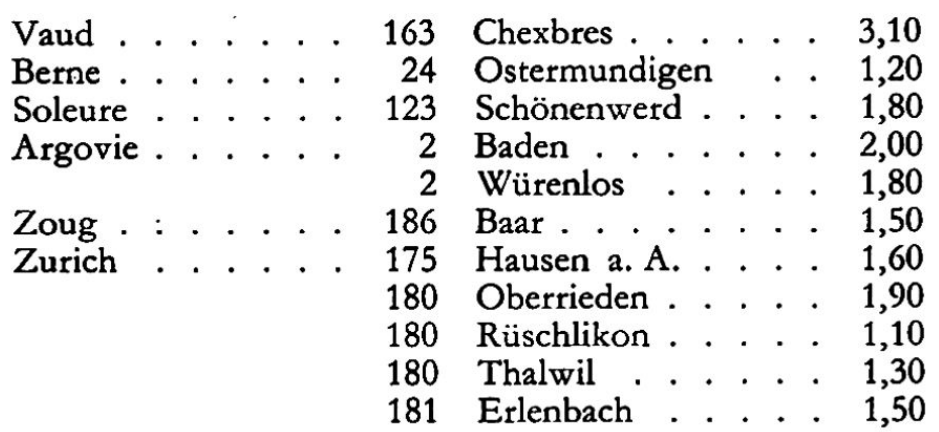

\begin{tabular}{|c|c|c|c|}
\hline 10 & Aarbourg & & \\
\hline 11 & Klingnau & & \\
\hline 186 & Menzingen & & \\
\hline 181 & Zollikon & & \\
\hline 183 & Dübendorf & & \\
\hline 18 & Winterthour. & & \\
\hline 18 & Affoltern-Zch. & & \\
\hline 185 & Zurich & & \\
\hline
\end{tabular}

Les Alpes septentrionales

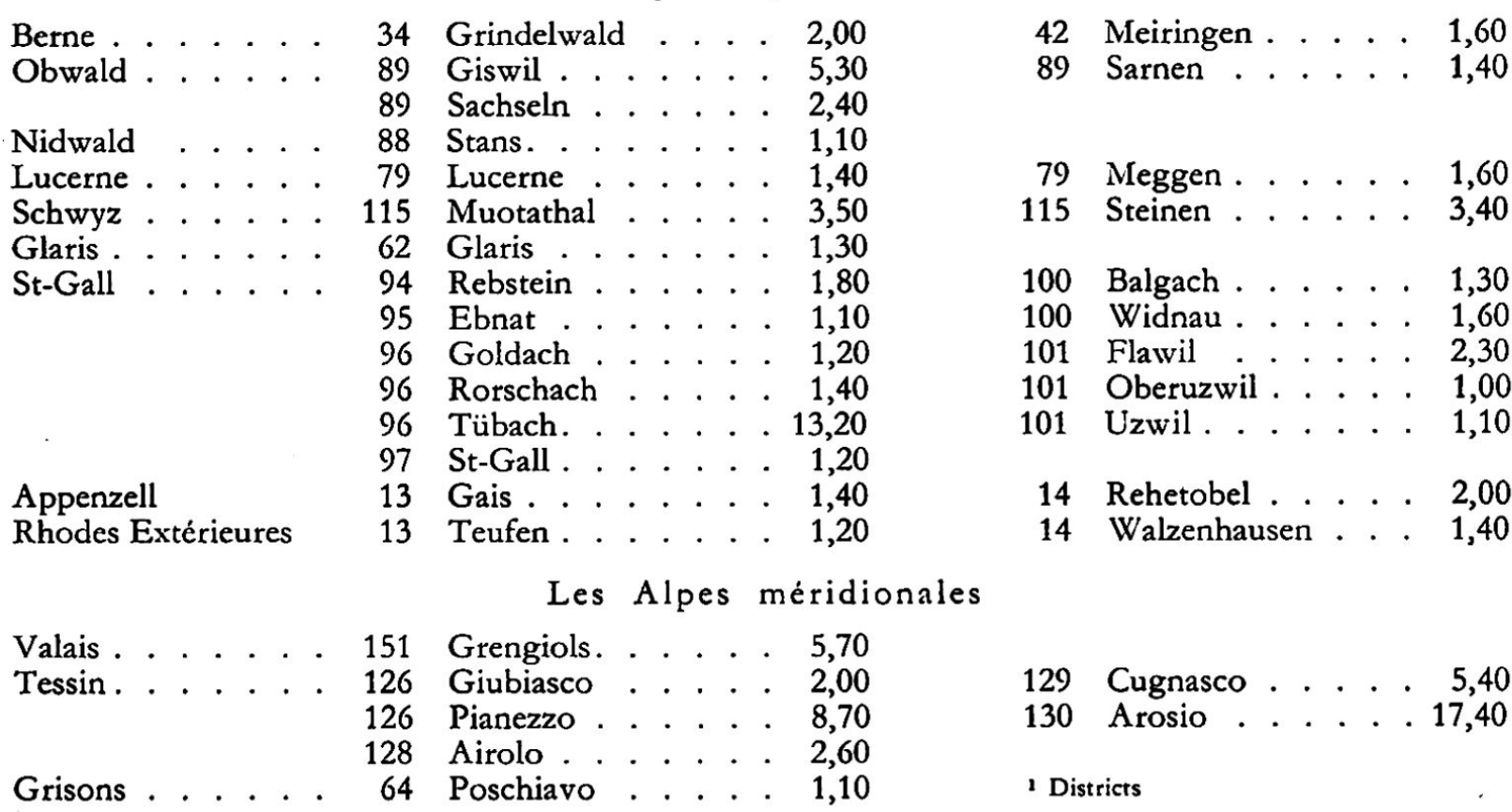

Ces communes se trouvent en majorité dans des régions de forte intensité. Dans le Mittelland, elles se concentrent dans la partie méridionale du canton de Zurich; les quelques communes qui se trouvent dans les autres parties du Mittelland, sont en règle générale situées dans les environs de centres urbains ou industriels: Ostermundigen près de Berne, Schönenwerd près d'Olten, Würenlos près de Baden.

Dans les Alpes septentrionales, ces communes à taux élevés sont réparties un peu parţout, mais se rencontrent en plus grand nombre dans les régions à forte intensité des canton's de St-Gall et d'Appenzell. Dans les Alpes méridionales, on les trouve surtout dans le Tessin. Dans le Jura, elles ne se rencontrent que dans le secteur nord ${ }^{32}$.

${ }^{32}$ Du point de vue de la commune d'origine, les centres de forte émigration correspondent, dans leurs grandes lignes, aux centres envisagés en fonction du lieu de résidence, mais certaines parties du secteur oriental du Mittelland bernois viennent s'y ajouter:

a) La région de l'Emmental et du Napf [48 et 50 ].

b) La région intermédiaire entre l'Emmental et le centre urbain de Berne [35]. 
L'examen de l'intensité de l'émigration par district et par commune permet de tirer d'intéressantes conclusions sur le phénomène migratoire général dans les différents centres de départ. Par contre, en raison du faible nombre d'émigrants, ces unités administratives sont trop petites pour pouvoir servir de base à l'étude des variations du mouvement migratoire dans le temps. Le choix de plus grandes unités s'impose donc.

$2^{\circ}$ L'intensité de l'émigration par cantons. La participation aux mouvements d'émigration des années 1924, 1928, 1932, 1936 n'est pas la même pour tous les cantons suisses, et les différentes régions à forte émigration réagissent de façon bien différente aux changements de la situation économique au cours des quatre années envisagées. L'année 1924, période de conjoncture moyenne, est d'intensité migratoire supérieure dans les Alpes septentrionales (à l'exception du canton d'Uri, de Nidwald, des Préalpes lucernoises et d'Appenzell Rhodes Intérieures), dans le Tessin, dans les Plateaux zurichois et thurgovien et dans tous les grands centres urbains.

L'année 1928, époque de grande prospérité, connaît un mouvement d'émigration intense provenant des Alpes septentrionales (à l'exception du canton de Glaris, d'Appenzell Rhodes Intérieures, de Nidwald, des Préalpes lucernoises), du Tessin, du Plateau zurichois (Zoug compris) et des grands centres urbains.

Le mouvement d'émigration intense de l'année 1932 (période de crise) se limite, dans les Alpes septentrionales, au demi-canton de Nidwald et aux cantons de St-Gall et d'Appenzell Rhodes Extérieures et, en outre, au Tessin, au Plateau zurichois et aux grands centres urbains.

En 1936 (période de reprise économique) on ne retrouve qu'un petit nombre de régions traditionnelles de forte émigration. Il s'agit d'Appenzell Rhodes Extérieures et des grands centres urbains. Le mouvement d'émigration intense s'est déplacé vers les cantons d'Argovie, de Bâle-Campagne et de Bâle-Ville, de Schaffhouse et vers le Plateau lucernois.

On peut en tirer les conclusions suivantes:

a) Les grands centres urbains, foyers de l'émigration urbaine, participent fortement à l'émigration pendant les quatre périodes envisagées.

b) Le Plateau zurichois, les Alpes thuranaises (St-Gall, Appenzell) et le Tessin ont une émigration intense pendant trois époques: les périodes de conjoncture moyenne (1924), de prospérité (1928), de crise (1932).

c) Les secteurs central et occidental des Alpes septentrionales ne connaissent un mouvement migratoire intense qu'aux périodes de conjoncture moyenne (1924) et de prospérité (1928).

d) L'époque de reprise économique (1936) provoque une forte émigration en certaines régions du Mittelland septentrional qui n'y participent pas aux autres époques.

Le mouvement d'émigration paraît donc permanent dans les grands centres urbains, intense aux époques de prospérité et de crise dans le Plateau zurichois, les Alpes thuranaises, le Tessin, intense uniquement aux temps de prospérité dans les secteurs central et occidental des Alpes septentrionales, à l'époque de reprise économique 1936 dans la partie nord-occidentale du Mittelland, dans les cantons de Schaffhouse et d'Appenzell Rhodes Extérieures ${ }^{33}$.

Au lieu d'envisager les changements d'intensité du mouvement migratoire au cours des années 1924, 1928,1932, 1936 on peut traiter ses variations au cours des différentes saisons de l'année. Tandis que les régions du Mittelland présentent un mouvement d'émigration relativement intense pendant tous les mois de l'année, l'émigrant montagnard ne se met en route qu'à la mauvaise saison, c'est-à-dire pendant l'automne et l'hiver.

33 Sous l'aspect de la commune d'origine, la zone d'intensité migratoire élevée est plus étendue, et la participation des régions traditionnelles d'émigration est souvent plus manifeste. Toute la Suisse nord-orientale et le canton de Schwyz participent, au moins à trois époques, à un mouvement d'émigration intense. Dans les Alpes également, la zone d'intensité élevée est plus étendue. Les Grisons participent en forte mesure à l'émigration de l'année 1928 (région de l'Inn) et de l'année 1936 (régions du Rhin grison), les Préalpes romandes à celle de l'année 1932. Certaines parties du Jura également indiquent parfois des taux d'intensité élevés, le Jura bernois en 1928 et 1932, le Jura vaudois en 1932. Les régions qui restent de faible intensité pour toutes les quatre époques, sont le Plateau suisse romand, bernois, lucernois, le Jura neuchâtelois, soleurois et bâlois, les Alpes valaisannes. 
L'examen de l'intensité ne suffit pas à expliquer les particularités du mouvement migratoire dans les différentes zones de départ. Pour compléter notre recherche, il faut passer à l'étude de sa composition.

C. La composition du mouvement migratoire dans les différentes zones de départ

$1^{\circ} \mathrm{La}$ participation des différentes professions à l'émigration. La profession des émigrants est un élément de toute première importance dans la détermination de la nature du mouvement migratoire et peut fournir des indices intéressants sur les motifs qui le provoquent. D'après la figure 11, la participation des différentes professions au mouvement d'émigration subit de fortes modifications suivant les régions.

Figure 11. Structure professionnelle du courant d'émigration par régions de départ

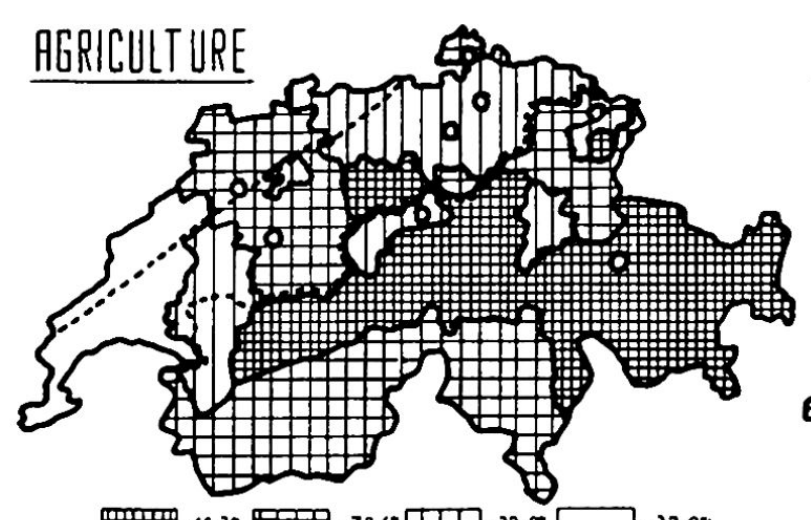

曲.55.22
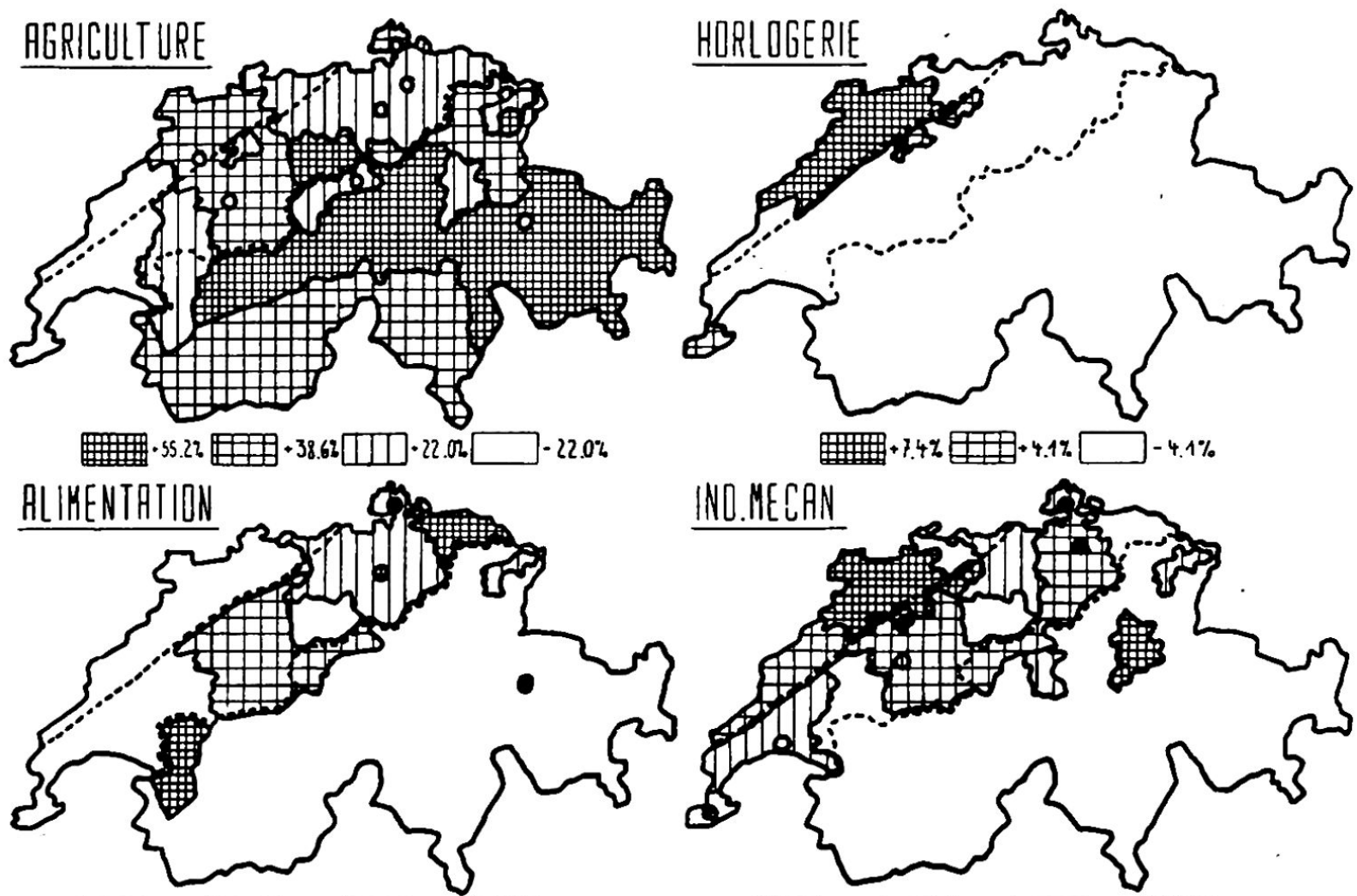

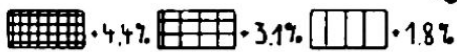
$-1.8 \%$

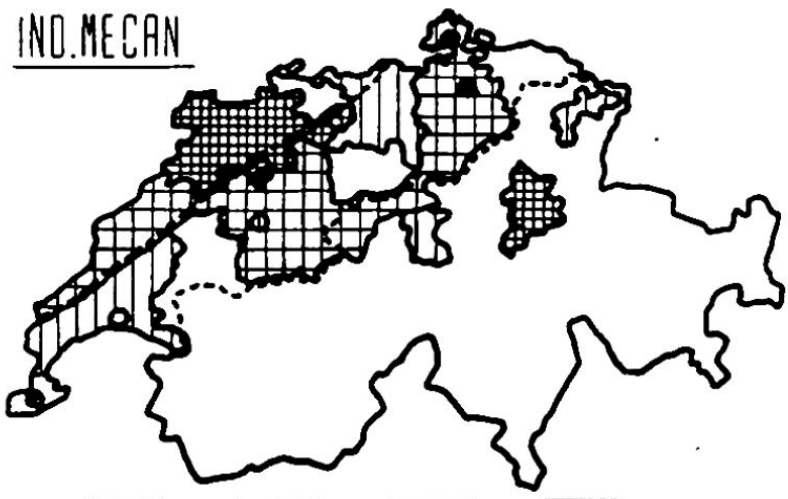

\section{BRTIMENT}

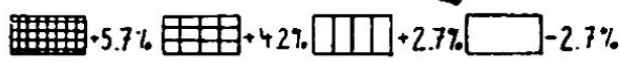
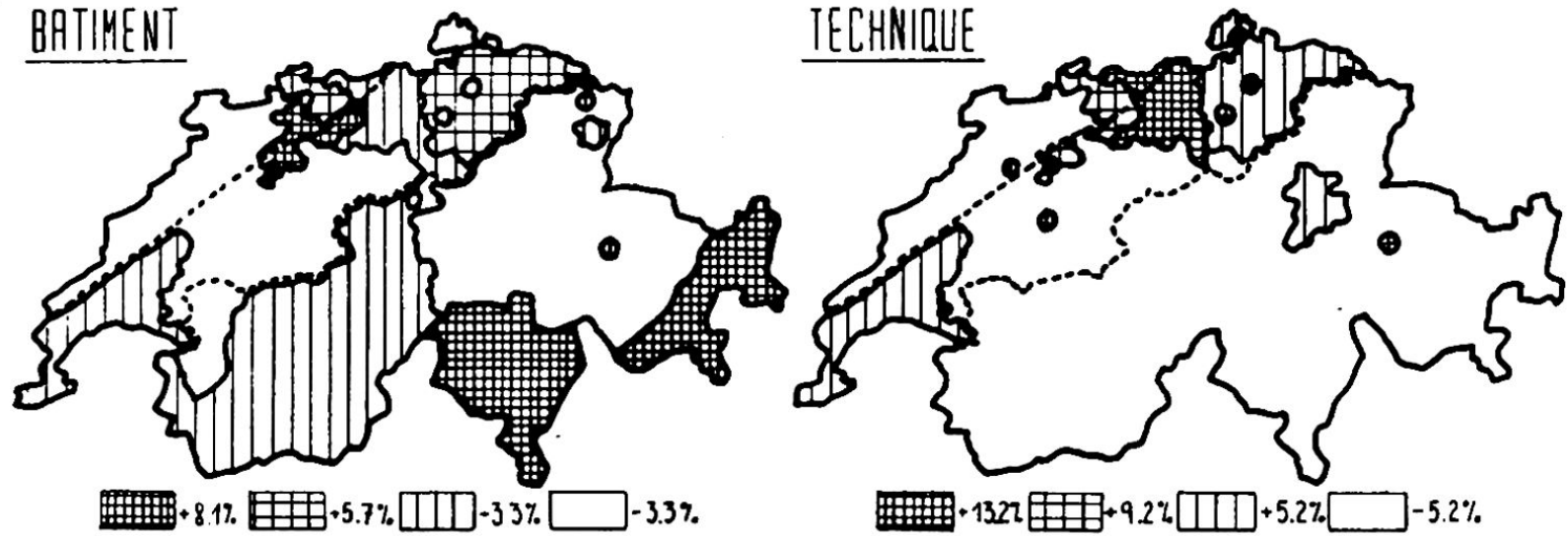

- - - Lignes de démarcation entre le Jura, le Mittelland ct les Alpes. 
Le mouvement d'émigration des agriculteurs est élevé dans les secteurs central et occidental des Alpes septentrionales, dans les Grisons, en Appenzell Rhodes Intérieures et sur le Plateau lucernois, moyen en presque toutes les autres régions des Alpes, sur le Plateau bernois, dans le Jura bernois et schaffhousois. Il se maintient moins élevé dans le reste du Mittelland de langue alémanique, sur le Plateau fribourgeois et dans les
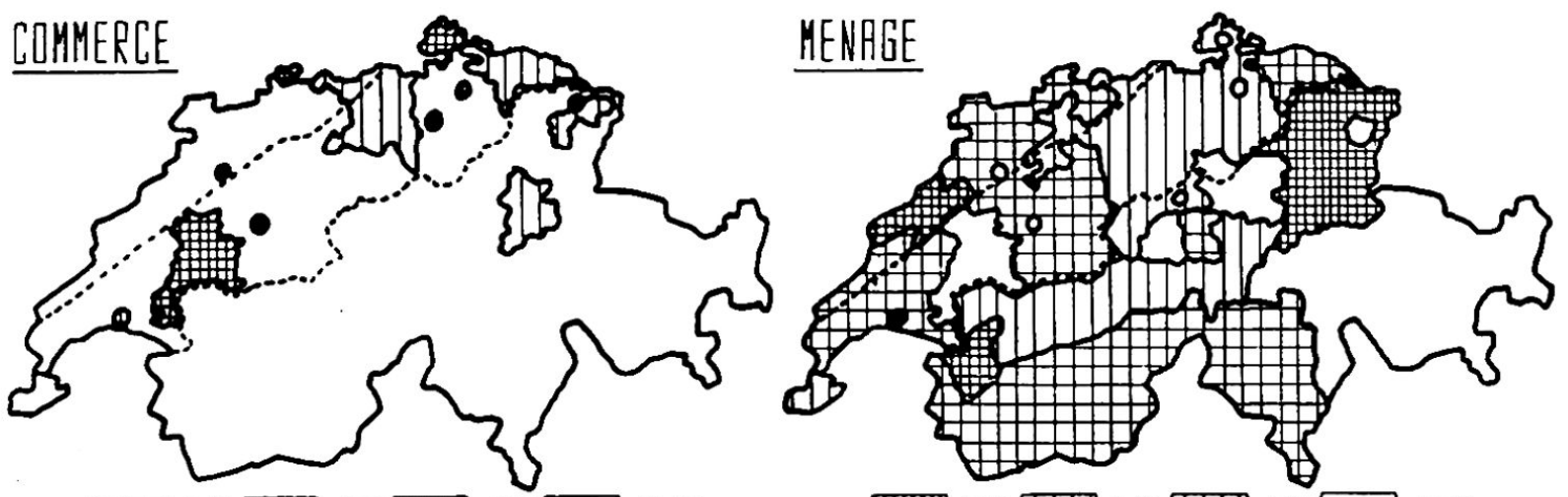

冊+2424 +18.67 .

TOURISME

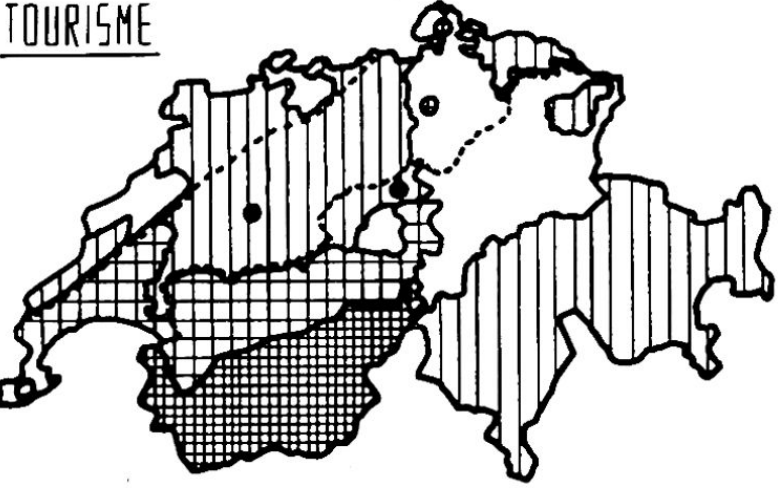

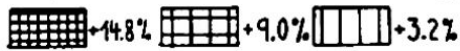

$-3.2 \%$

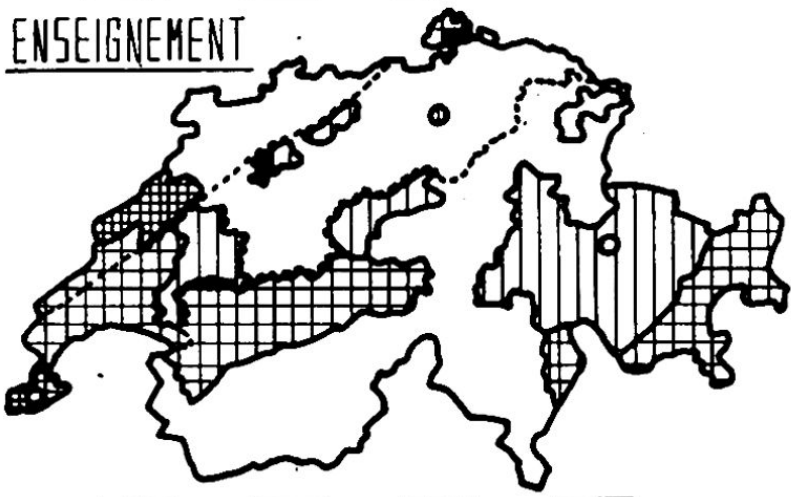

册+6.1\%. -11\%

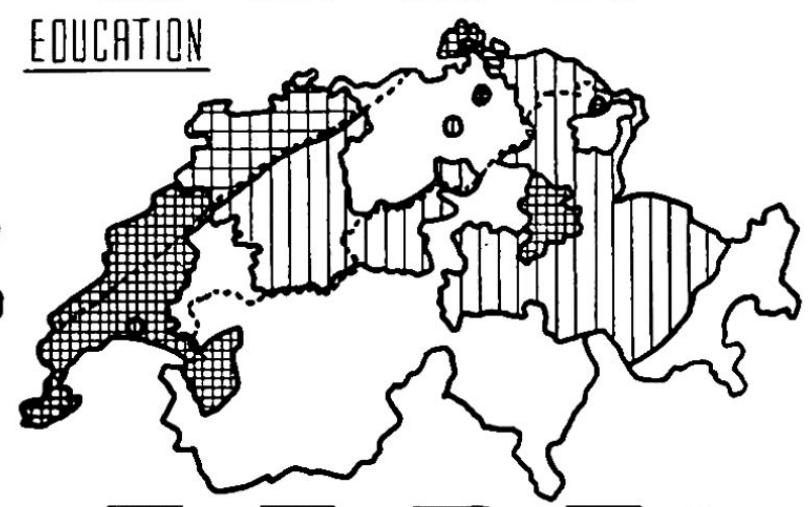

进+3.8.

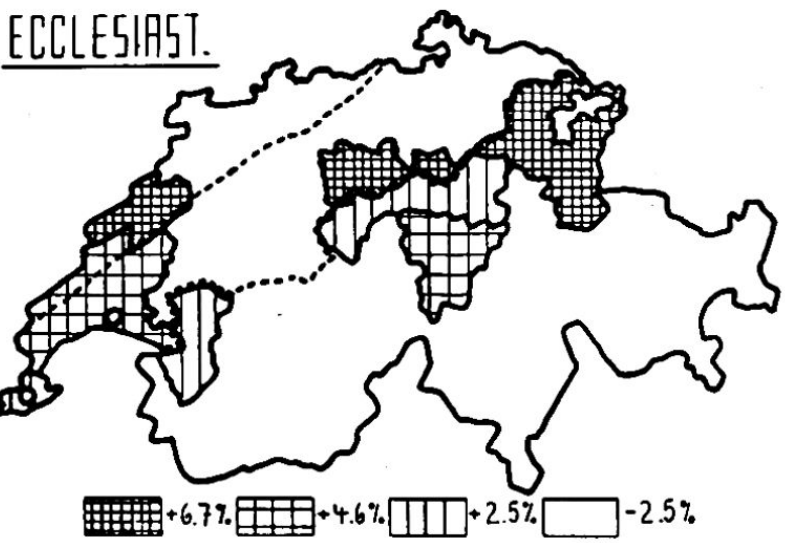

Préalpes romandes; il est de très faible intensité dans les centres urbains, dans la région de Genève, dans le canton de Vaud et dans le Jura vaudois et neuchâtelois. L'émigration des agriculteurs est donc surtout un phénomène propre aux régions de montagne.

Les artisans de l'alimentation (bouchers, boulangers, etc.) proviennent surtout de la Thurgovie et des Préalpes romandes; leur taux de participation est moyen sur le Plateau bernois et dans les Préalpes lucernoises. L'exode de gens de ce métier se limite donc à certaines régions du Mittelland et des Préalpes.

Le mouvement d'expatriation des artisans du bâtiment est caractéristique d'une part du Tessin et des régions méridionales des Grisons, d'autre part, bien qu'en moindre mesure, des cantons de Soleure, de Bâle-Ville et Bâle-Campagne, de la Thurgovie et 
du Plateau zurichois à l'exclusion des centres de Zurich et de Winterthour. Les émigrants-artisans du bâtiment sont donc bien probablement en grande partie d'origine montagnarde, de nos Alpes méridionales et sud-orientales. Tandis que les uns partent directement de leur lieu d'origine, les autres vont d'abord travailler en Suisse alémanique septentrionale.

Les émigrants-horlogers proviennent presque tous du Jura neuchâtelois $\epsilon$ t bernois; la région de Genève et le Plateau soleurois participent à ce mouvement en moindre mesure.

L'industrie mécanique participe à une forte émigration dans le canton de Glaris, les agglomérations de Winterthour et de Schaffhouse, le canton de Soleure et le Jura bernois. Ce mouvement est un peu moins important dans le Jura vaudois et neuchâtelois, sur les Plateaux bernois et zurichois, dans les Préalpes lucernoises. Ce genre d'émigration est donc caractéristique d'une bonne partie du Mittelland et du Jura de même que du canton alpestre de Glaris.

L'émigration des techniciens se trouve concentrée en Suisse septentrionale, notamment dans le canton d'Argovie, de Bâle-Campagne et les centres urbains de Zurich, Winterthour et Schaffhouse. Le Plateau zurichois, la région de Schaffhouse, la Thurgovie, le canton de Glaris, d'une part, les centres de Berne et de Bienne, le Plateau vaudois et la région de Genève, d'autre part, y participent en moindre mesure.

Le mouvement d'émigration des commerçants est surtout un phénomène caractéristique des grands centres urbains: Genève, Berne, Bienne, Bâle, Zurich, Winterthour, Schaffhouse, St-Gall.

Le tourisme indique un mouvement migratoire intense dans les Alpes valaisannes, bernoises, dans le demi-canton de Nidwald, au centre urbain de Lucerne, dans les Préalpes et le Plateau romand. Ce genre d'émigration est donc typique pour le secteur occidental de nos Alpes et pour la région du lac Léman.

Les émigrants-instituteurs proviennent surtout de la Suisse romande, notamment du canton de Neuchâtel, de l'Oberland bernois et des secteurs méridionaux des Grisons.

Le mouvement migratoire des ménagères est très accentué dans les Alpes thuranaises (St-Gall, Appenzell Rhodes Extérieures), dans les Préalpes romandes, dans la ville de Lausanne et dans le Jura neuchâtelois. Il est moyen en Valais et dans le Tessin, sur le Plateau et le Jura vaudois et bernois et en Thurgovie. Par contre, la plupart des grands centres urbains n'y participent que faiblement. Ce genre d'émigration se trouve donc répandu sur une grande partie du territoire des Alpes et du Jura et dans les régions de campagne du Mittelland, mais fait défaut dans la plupart des grands centres urbains.

Les gouvernantes émigrent de préférence de la Suisse romande et du Jura tout entier; on les rencontre, en outre, en plus grand nombre dans les centres de Winterthour, de Schaffhouse et de St-Gall et dans le canton de Glaris.

On reconnaît deux foyers d'émigration intense pour les carrières ecclésiastiques, se trouvant l'un en Suisse romande protestante, l'autre en Suisse centrale et nord-orientale catholique.

En conclusion, on peut dire que le mouvement d'émigration des agriculteurs et des employés d'hôtel est surtout caractéristique de certaines parties de nos Alpes. Celui des artisans du bâtiment, des ménagères et des ecclésiastiques se rencontre en même temps dans les Alpes et dans le Mittelland; celui de l'industrie mécanique et de la technique est localisé en certaines parties du Mittelland ou du Jura. L'émigration des commerçants est caractéristique des grands centres urbains, et celle des activités pédagogiques (instituteurs et gouvernantes) est surtout un phénomène particulier à la Suisse romande.

$2^{\circ}$ L'émigration en fonction du sexe et de l'état civil. L'examen du sexe et de l'état civil explique aussi certaines causes du mouvement migratoire et la façon dont elles se manifestent dans les différentes zones de départ; il complète donc le paragraphe précédent concernant la profession. 
Figure 12. Composition du courant d'émigration (sexe et état civil) par régions de départ
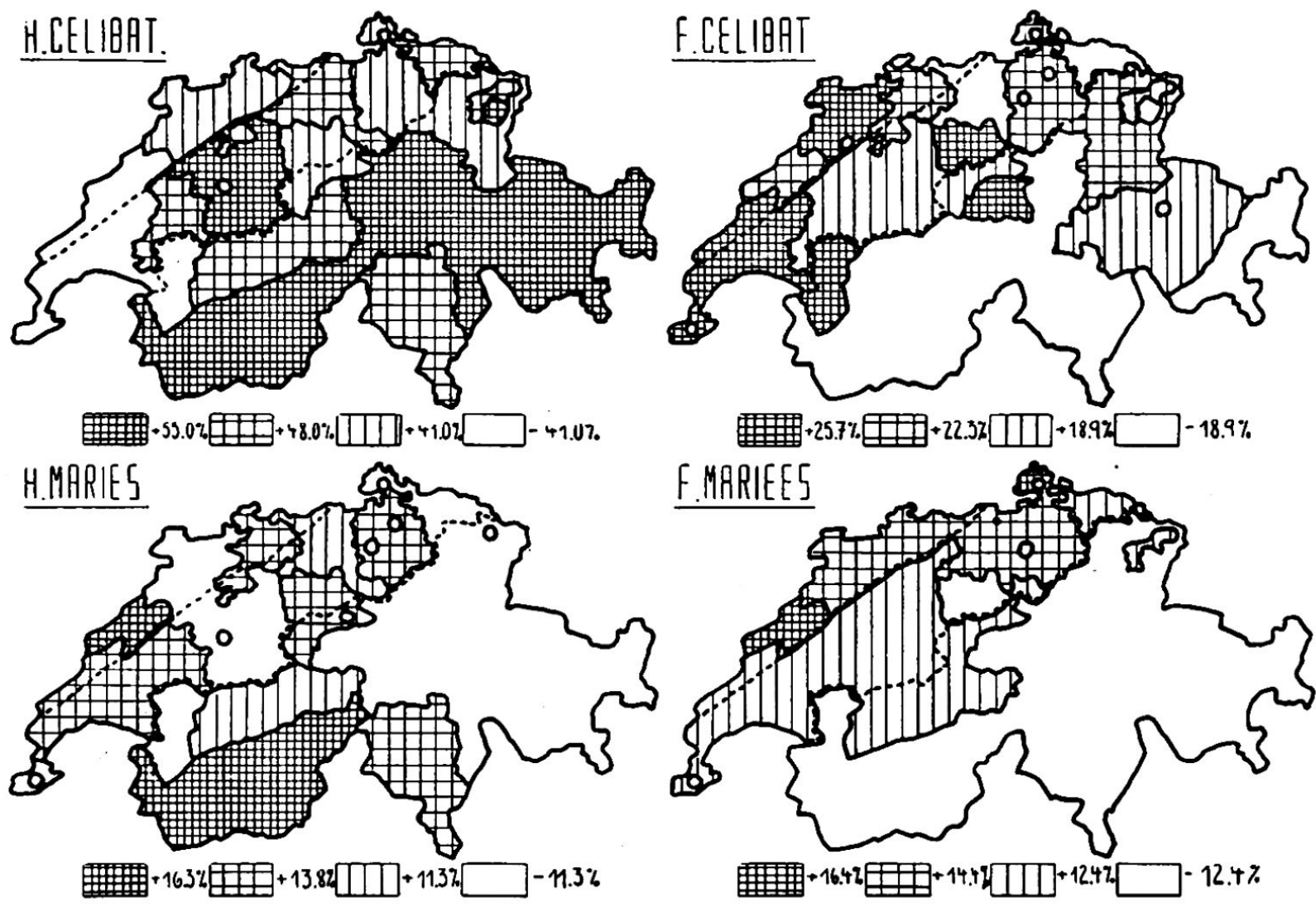

L'émigration des célibataires de sexe masculin intéresse surtout les Alpes. Les femmes célibataires proviennent notamment du Jura et de la Suisse romande, les hommes mariés du Valais et du Tessin, les femmes mariées du Jura et de la Suisse septentrionale.

L'émigration des célihataires de sexe masculin est maximum dans le Valais, aux Grisons, en Suisse centrale, dans le Plateau bernois et en Appenzell Rhodes Intérieures; elle acquiert une certaine importance dans le Tessin, dans l'Oberland bernois, en Appenzell Rhodes Extérieures, dans les Plateaux fribourgeois et argovien et en Thurgovie. Ce genre d'émigration est donc surtout caractéristique d'une bonne partie du territoire de nos Alpes, notamment ses secteurs central, sud-oriental et sud-occidental. Ce phénomène est dû en partie à la structure économique particulière des régions alpestres, car les hommes célibataires éprouvent en bien plus forte mesure l'instabilité de l'agriculture, activité principale de ces contrées, due à son caractère saisonnier.

Les femmes célibataires participent en forte mesure au mouvement d'émigration provenant des cantons de Vaud, de Genève, du Jura neuchâtelois, bernois, soleurois et bâlois, du Plateau lucernois et du demi-canton d'Obwald. Un centre de moindre intensité se trouve en Suisse nord-orientale. Il s'agit là en grande partie de gouvernantes ou d'ecclésiastiques.

Le mouvement migratoire des hommes mariés est un phénomène propre aux grands centres urbains et au Jura neuchâtelois; certaines parties du Mittelland y participent en plus faible mesure. Tandis qu'un autre foyer de forte participation se trouve en Valais ${ }^{34}$, ce genre d'émigration reste peu élevé dans les secteurs central et oriental des Alpes.

Les femmes mariées proviennent surtout du Jura et de la Suisse septentrionale. Ce sont le plus souvent des femmes de techniciens et de commerçants. Dans les Alpes, ce mouvement migratoire est insignifiant.

Dans le chapitre premier, on a déterminé l'intensité et la composition du courant d'émigration dans les différents centres de départ. Dans le chapitre II, on utilisera les conclusions obtenues, et on mettra les données statistiques en rapport avec le milieu physique, économique et social des différentes zones de départ.

34 Une explication détaillée en est donnée dans le chapitre II, page 45. 


\section{A. Régions alpestres à forte intensité d'émigration}

Une grande partie du territoire de nos Alpes indique des taux d'intensité de l'émigration supérieurs à ceux du Mittelland. Sans doute, cette intensité élevée s'expliquet-elle en première ligne par les caractères physiques de la région au relief accidenté, au climat ingrat, soumise à la menace permanente des éléments: avalanches, eaux torrentielles, vents violents, etc. De là des répercussions évidentes sur la vie économique et sociale des populations montagnardes. L'influence des facteurs physiques sera renforcée ou amoindrie par des facteurs d'ordre économique ou social qui, venant du dehors, ne sont pas soumis en aussi forte mesure à l'influence du milieu régional.

Analyser le jeu réciproque de ces éléments hétérogènes et faire ressortir leurs conséquences sur le phénomène migratoire, sera notre tâche dans les paragraphes qui suivent.

$1^{\circ}$ L'Oberland bernois. Dans l'Oberland bernois, l'intensité du mouvement de l'émigration augmente, suivant la règle générale constatée dans la majeure partie de la Suisse, de l'ouest vers l'est. Tandis que les districts de Gessenay [Saanen 45] et du Simmental supérieur [43] font preuve d'une faible intensité, celle-ci devient moyenne dans le Simmental inférieur [41] et dans le district de Frutigen [33], supérieure dans le district d'Interlaken [34], très élevée dans l'Oberhasle [42].

Il est incontestable qu'ici les facteurs physiques interviennent de façon déterminante. L'altitude des communes appartenant aux districts occidentaux, est en général peu élevée; elle varie entre 500 et $1000 \mathrm{~m}$. La température permet encore une exploitation de la terre assez intensive.

Dans le Simmental inférieur, le climat est doux, parce que la région est protégée contre les vents du nord par la chaîne du Stockhorn. Ainsi, la contrée de Weissenbach-Latterbach appartient aux régions les plus favorisées de l'Oberland bernois, au point de vue climatique. Le relief y est à son tour favorable au peuplement, puisque la surface improductive n'y embrasse que $15,3 \%$ du territoire total ${ }^{35} 36$. Le Simmental supérieur et le pays de Gessenay ont un caractère physique peu différent de celui du Simmental inférieur ${ }^{37}$. La commune de la Lenk, par exemple, se trouvant tout au fond du Simmental supérieur, présente encore bien des aspects propres à la montagne de moyenne altitude ${ }^{\mathbf{3 8}}$.

D'un tout autre caractère sont les districts orientaux. L'altitude y est plus élevée; elle dépasse $1000 \mathrm{~m}$. et va jusqu'à $3000 \mathrm{~m}$. et au-dessus. Les bords des lacs de Thoune et de Brienz font exception; ils jouissent d'un climat relativement doux grâce à une forte insolation et grâce aux deux lacs fonctionnant comme régulateurs de température qui adoucissent la rigueur de l'hiver ${ }^{39}$. Pour le mouvement de l'émigration, cette contrée est de moindre importance. Comparé à l'effectif global de la population, le plus grand nombre des émigrants de ce district proviennent de communes situées dans les hautes Alpes. La vallée de Lauterbrunnen, avec ses pentes abruptes, et Grindelwald se trouvant au-dessus de $1000 \mathrm{~m}$. d'altitude, ont toujours subi les répercussions du relief fort accidenté et du manque de terres fertiles, et ils ont de tous temps présenté un mouvement d'émigration intense. Déjà vers 1799 , lorsque la population de la vallée de Lauterbrunnen (les communes de Wengen et Mürren comprises) ne comptait que 1186 personnes, un grand nombre d'individus furent poussés à l'expatriation ${ }^{40}$.

Le mouvement migratoire de ce district est élevé encore de nos jours; il atteint plus de $2,0 \%$ à Grindelwald, en raison des conditions physiques que nous venons d'indiquer.

Le caractère physique de l'Oberhasle est encore plus alpin. Dans la commune de Guttannen, par exemple, le pourcentage de terres improductives atteint $66,8 \%$ de la surface totale, et le Haslital, en raison de conditions orographiques et climatériques

${ }^{35}$ En comparaison: Surface improductive, des autres districts de l'Oberland bernois: Simmental supérieur $22,3 \%$, Gessenay $18,8 \%$, Frutigen $35,0 \%$, Interlaken $40,0 \%$, Oberhasle $67,0 \%$.

${ }^{36} 6$, page $391 . \quad{ }^{37} 6$, page $395 . \quad 383$, page $59 . \quad{ }^{38} 6$, page 362. 
particulièrement ingrates, est une des régions alpestres les moins favorisées qui soient de nos jours encore habitées de façon permanente. Les habitants doivent soutenir une lutte permanente contre les éléments: avalanches, torrents, vents violents ${ }^{41}$, il n'est donc pas surprenant de voir les habitants quitter une région si peu hospitalière. En effet, la seule commune de Guttannen souffre d'une régression de population qui, même pour la région des Alpes, est extraordinaire; le nombre des habitants est tombé de 505 personnes en 1860 à 302 personnes en 1930, et le nombre des émigrants transocéaniques est de 332 personnes pour la période $1850-1927^{42}$.

Il est évident que ces conditions physiques particulières ont eu des effets sur la structure économique et sociale de la région prédestinée au pâturage et où les autres branches économiques n'ont pu facilement se développer. Seul le tourisme a pu acquérir à son tour une importance remarquable. Il n'est donc pas surprenant que les émigrants provenant de cette contrée, soient surtout des agriculteurs et des employés d'hôtel, encore que la disposition à l'émigration soit plus accentuée parmi les premiers que parmi les seconds.

La mesure dans laquelle l'Oberland bernois participe à l'émigration durant les quatre années envisagées, est une conséquence de l'absence de grandes industries. Le mouvement migratoire y est élevé en 1924 et en 1928, époques pendant lesquelles la participation des agriculteurs à l'émigration est considérable. En 1932 et en 1936, par contre, il est insignifiant, puisque ces périodes connaissent surtout l'émigration de spécialistes des différentes industries, du commerce et des carrières libérales.

L'industrie n'existe, en effet, dans l'Oberland, que sous forme d'activité à domicile ${ }^{43} 4$, et encore celle-ci n'a-t-elle plus la même extension qu'auparavant, en raison de la concurrence des grandes fabriques du Mittelland. La région de Brienz est un centre de l'industrie de la sculpture sur bois, l'Oberhasle ${ }^{45}$ et Frutigen connaissent la tisseranderie à main, Lauterbrunnen la dentellerie ${ }^{46}$. Ces métiers sont exercés exclusivement par des femmes. Ce fait se manifeste à notre avis aussi dans le mouvement migratoire: les émigrants de l'Oberland bernois sont surtout des célibataires de sexe masculin, tandis que les femmes célibataires font complètement défaut.

On pourrait objecter qu'il existe à Frutigen la fabrication des boîtes d'alumettes, dans l'Oberhasle le métier de sculpteur sur bois, et qu'en raison de ce fait, le mouvement migratoire des jeunes hommes célibataires aurait dû être de moindre importance par rapport aux autres catégories d'état civil. Pour le district de Frutigen, ce phénomène s'explique de la façon suivante: cette contrée qui, en raison de son caractère montagnard assez accentué, aurait dû avoir un taux d'intensité migratoire élevé, indique un mouvement d'émigration peu considérable en raison des possibilités de travail procurées par l'industrie sus-indiquée ${ }^{47}$. Dans la détermination des taux de participation des différentes catégories professionnelles et d'état civil pour l'Oberiand bernois tout entier, elle n'intervient donc que d'une façon secondaire. L'existence d'une industrie de sculptures sur bois dans l'Oberhasle, par contre, est réduite d'une part (comme le prouve le cas de la commune de Guttannen), parce que l'organisation de la vente des articles fabriqués a été défectueuse, d'autre part (comme l'association pour la colonisation à l'intérieur et pour l'agriculture industrielle a pu le constater, dans une de ses enquêtes) ${ }^{48}$, parce que les jeunes gens ne montrent plus assez d'intérêt pour ce genre de travail.

En résumé, nous relevons encore une fois les faits suivants: grâce à un climat et un relief relativement favorables, le Simmental et le pays de Gessenay indiquent un mouvement d'émigration peu élevé. Dans le district de Frutigen, l'existence d'une industrie à domicile occupant des hommes (soit la catégorie d'état civil la plus sensible à l'attraction de l'émigration) neutralise les répercussions néfastes du milieu montagnard et empêche un mouvement d'expatriation massif.

Le district d'Interlaken et surtout les vallées de la Lütschine, ont déjà une plus forte intensité, bien que dans ces contrées, le tourisme ait freiné le mouvement migratoire.

41 3, page 218. 42 6 , page 371. 43 6, page 365. 44 56 . 45 6 , page 373 . 46 56.

$4736,0 \%$ des 4753 habitants de Frutigen (en 1930) travaillent dans les arts et métiers et dans l'industrie, $32,0 \%$ seulement dans l'agriculture.

48 , page $218,221$. 
Dans l'Oberhasle, moins touristique, l'emigration est plus forte. Toutefois ici, un certain nombre d'émigrants ne sont pas des indigènes. La construction du bassin d'accumulation du Grimsel a attiré des travailleurs provenant d'autres régions de la Suisse ${ }^{49}$, lesquels, les travaux terminés, ont dû quitter la région et parfois participer à l'émigration transocéanique. Ainsi s'explique que le nombre des émigrants du district d'Oberhasle soit plus élevé dans le classement par lieux de résidence que dans le classement par communes d'origine, phénomène qui est en général inverse dans les régions montagnardes.

$2^{\circ}$ Le lac des Quatre-Cantons et ses environs ${ }^{\mathbf{5 0}}$. Le mouvement d'émigration des régions du lac des Quatre-Cantons et de ses environs est surtout d'intensité moyenne ou supérieure. Toutefois, la différence de taux est souvent assez sensible d'un district à l'autre. Les taux sont très élevés dans le demi-canton d'Obwald [89] et dans le district de Schwyz [115], élevés dans le district de Lucerne [79] et de Küssnacht [113], moyens dans le demi-canton de Nidwald [88] et dans le district d'Einsiedeln [110], faibles dans les districts d'Entlebuch [77], de Gersau [111], de Höfe [112] et de March [114].

Cette diversité de taux exprime dans une certaine mesure la variété considérable des conditions climatiques et de relief des contrées envisagées. Par exemple dans la partie extérieure du canton de Schwyz, le caractère préalpin n'est pas prononcé dans les districts de Höfe [112] et de March [114], voisins du Plateau zurichois et faisant en réalité partie du Mittelland. Ces régions profitant du climat tempéré des bords du lac de Zurich, la participation au mouvement d'émigration y est peu élevée.

Dans une position climatérique encore plus favorisée se trouve le district de Gersau [111]: Exposé au fœhn, il jouit d'un climat très doux permettant la culture de plantes méridionales. Par conséquent, l'intensité migratoire s'y trouve réduite à un taux minimum.

Le demi-canton de Nidwald est également exposé au fœhn et jouit d'un climat assez doux. Le fond de ses vallées, formé d'alluvions, est donc assez fertile. Toutefois, l'altitude moyenne y est plus élevée et l'anœcumène ${ }^{51}$ plus étendue que dans les districts précédents, et cette circonstance contribue à y maintenir le mouvement d'émigration un peu plus élevé.

En raison de son climat assez rude, surtout en hiver ${ }^{52} 53$, de son relief plus accidenté et.de son altitude plus élevée, le district d'Einsiedeln présente une intensité migratoire supérieure ${ }^{54}$. Dans le district de Schwyz, de forte émigration, on distingue deux foyers d'intensité maximum. Le premier foyer (la commune de Steinen), situé dans le bassin de Schwyz, est protégé contre les vents du nord; la région est très fertile et jouit d'une position favorisée due à l'insolation et à la proximité du lac des Quatre-Cantons ${ }^{55}$.

$\mathrm{Si}$ les raisons de ce mouvement migratoire intense n'y sont pas très manifestes, elles ressortent davantage dans le second foyer qui se trouve dans la commune de Muotathal, au fond de la vallée de la Muota. C'est une région entourée de hautes montagnes, peu accessible au trafic en raison de son caractère de cul-de-sac et du défilé barrant l'entrée ${ }^{57}$. Elle ne possède que des terres peu fertiles, parfois dépourvues d'eau, le sous-sol calcaire étant d'une grande perméabilité. En hiver, les avalanches provoquent de grands ravages, et l'homme y dépend encore fortement de son milieu physique, puisque la surface improductive embrasse plus du $53,0 \%$ du territoire total-de la commune ${ }^{58}$.

Dans le demi-canton d'Obwald, le taux d'intensité est très élevé; il est à Sarnen de $1,40 \%$ de la population globale, à Sachseln $2,40 \%$, à Giswil $5,30 \%$, et n'est pas dû à la défaveur des conditions physiques, mais résulte du fait que les paysans de la partie supérieure du demi-canton d'Obwald, à cause de l'exhaussement du lac de Lun-

49 3, page 218-221.

50 Nous entendons par "régions du lac des Quatre-Cantons et de ses environs" les contrées à prédominance préalpine de la Suisse centrale: demi-cantons d'Obwald et de Nidwald, Préalpes lucernoises, canton de Schwyz. Les régions extérieures du canton de Schwyz, orientées vers le lac de Zurich, mais appartenant encore aux Préalpes, y sont comprises. Le canton d'Uri, faisant partie des Grandes Alpes, n'y figure pas.

51 Surface improductive dans les districts: Höfe 2,4\%, March 6,7\%, Gersau 4,2\%; dans le demicanton de Nidwald $12,4 \%$.

526 , page 314 .

53 Température moyenne du mois de janvier: à Einsiedeln $-4,0^{\circ} \mathrm{C}$., à Oberiberg $-3,7^{\circ} \mathrm{C}$., 'à Schwyz $-1,2^{\circ} \mathrm{C}$., à Gersau $+0,2^{\circ} \mathrm{C}$., à Sarnen $-1,7^{\circ} \mathrm{C}$., à Lucerne $-1,3^{\circ} \mathrm{C} .5^{56}$.

${ }_{54}^{54} 60.556$, page $320 . \quad{ }^{56} 20.5742 .586$, page 323. 
gern, ont perdu leurs terres ${ }^{59}$. Le district de Lucerne a une intensité supérieure, bien qu'il jouisse d'un climat tempéré. Cette particularité peut certes être attribuée en partie au fait que ce district entoure un grand centre urbain, où les facteurs physiques ne s'excercent plus directement. La faible intensité du district d'Entlebuch reste pour le moment assez énigmatique, cette contrée souffrant, au moins dans sa partie supérieure, d'un climat et d'un relief assez ingrats.

Les conditions physiques des environs du lac des Quatre-Cantons prédisposent à la culture des prés et au pâturage. Même dans le canton d'Obwald, relativement pauvre en pluie par rapport aux autres contrées envisagées, la culture des céréales a disparu depuis des siècles ${ }^{60}$. Le pâturage et la culture des prés, travail extensif, ne peuvent pas absorber un grand nombre d'individus. Ceux-ci participaient donc très activement au mouvement d'émigration, en majorité intense, des années 1868 à 1930 et encore aujourd'hui, les émigrants sont pour la plupart des agriculteurs, conformément au caractère à prédominance agricole des régions en question. Seules les Préalpes lucernoises font exception: En raison de l'évolution industrielle assez avancée du district de Lucerne (filatures et usines de construction à Kriens, fabrique de viscose Emmenbrücke S.A. à Littau), le taux de participation à l'émigration des agriculteurs se trouve réduit, celui des travailleurs de l'industrie mécanique, par contre, est renforcé.

Dans les autres régions qui nous intéressent, les industries n'ont jamais pris une grande extension et ne se sont développées qu'aux centres de communication. Ainsi, Schwyz est devenu siège de quelques établissements de coton et de soie. D'autres lieux connaissent une industrie à domicile. Dans la commune de Muotathal se trouve un atelier de couture occupant surtout des femmes. Le demi-canton d'Obwald est un ancien centre d'industrie à domicile. Grâce à la production d'articles en paille, la contrée a joui de grande prospérité à maintes reprises au cours du 19e siècle. Centralisée en 1910 en fabrique par Meyer \& Cie, cette branche d'activité passe par une nouvelle époque de prospérité, de 1925 à 1929, puis tombe en décadence à la suite d'une forte concurrence et de la crise économique mondiale ${ }^{61}$. Les tissages de la soie et les filatures de coton, qui firent travailler, vers 1887, 300 métiers à tisser, avaient déjà avant la première guerre mondiale subi de fortes diminutions et n'avaient plus grande importance dans l'entredeux-guerres ${ }^{62}$. Par contre, la fabrication de mobilier et de chalets procure encore aujourd'hui un certain gain, surtout à la population masculine. Ces différentes activités à domicile n'ont pas pu réduire l'intensité de l'émigration, mais elles ont pu donner à ce mouvement un caractère particulier s'exprimant, par exemple, dans sa composition par sexe et par état civil.

Dans le canton de Schwyz, où le travail à domicile occupe surtout des femmes, l'émigration se limite aux seuls hommes célibataires.

Dans le demi-canton d'Obwald, la participation à l'émigration des célibataires masculins est moins prononcée, celle des femmes plus accentuée, puisque les hommes sont occupés pour la plupart à la fabrication de mobilier, tandis que les activités féminines (de soie et de coton, etc.) subissaient les contre-coups des crises économiques. Les Préalpes lucernoises constituent un cas particulier. Le pourcentage relativement élevé d'hommes mariés est certainement dû à des travailleurs industriels qualifiés qui partent outre-mer pour représenter leurs industries nationales.

Le mouvement d'émigration des quatre années envisagées nous donne d'ailleurs certaines indications à ce propos: les Préalpes lucernoises ne participent de façon accrue à l'émigration qu'en 1936, année de reprise économique de nos industries d'exportation; les autres régions en question, par contre, connaissent surtout un mouvement migratoire en 1924 et en 1928 , en relation avec leur caractère à prédominance agricole ${ }^{63}$.

Le tourisme n'est pas d'une grande importance pour l'émigration. Cette branche d'activité s'est développé un peu partout autour du lac des Quatre-Cantons ${ }^{64}$, et selon $\mathrm{PESCH}^{65}$, ses répercussions sur

505 , page 169 . ${ }^{60} 54 . \quad{ }^{61} 54 . \quad 623$, page 204.

${ }^{63}$ Ces particularités de la structure économique s'expriment aussi dans l'intensité migratoire des différentes saisons: aux cantons de Schwyz et d'Unterwald, le mouvement d'émigration est réduit pendant le printemps et l'été, saisons dans lesquelles le travail ne manque point aux paysans montagnards. Dans l'Oberland bernois, il n'a lieu qu'en été; cette extension au printemps de la période de calme dans le mouvement d'émigration du lac des Quatre-Cantons prouve que ces contrées se trouvent à des altitudes moins élevées, où l'alpage du bétail et les travaux agricoles commencent plus tôt. Les Préalpes lucernoises, par contre, indiquent des taux migratoires élevés tant au printemps qu'en été.

${ }^{64} \mathrm{La}$ ville de Lucerne constitue un cas particulier; elle est le siège de l'importante association hòtelière "Union Helvétia » qui chaque année envoie un assez grand nombre d'employés d'hôtel à l'étranger. 6552. 
l'économie régionale ont été favorables. Le taux peu élevé de participation à l'émigration du tourisme signifierait donc, comparé à l'intènsité élevée du mouvement migratoire global, que le tourisme absorbe en Suisse centrale un certain nombre d'habitants, mais ne réussit pas, en raison de son envergure limitée, à supprimer son émigration ${ }^{68}$.

$3^{\circ}$ Les Alpes uranaises et glaronaises. L'intensité de l'émigration est moyenne dans les cantons d'Uri et de Glaris, bien que le caractère physique de ces deux régions eût pu faire prévoir un mouvement migratoire plus élevé. Ces deux régions sont situées entièrement dañs les Grandes Alpes. Toutes les deux sont constituées d'une vallée principale incisée dans la haute montagne, limitée à l'Ouest et à l'Est par les pentes abruptes des montagnes ${ }^{67} .70 \%$ de ces territoires sont situés au-dessus de $1500 \mathrm{~m}$. et sont très pluvieux. Les habitations y sont menacées par des avalanches, des eaux torrentielles, de violentes tempêtes et des éboulements. Le sol est peu productif et les terres fertiles se limitent au fond étroit des vallées ${ }^{68} 69$.

Toutefois, les températures y sont plus élevées que ne le voudrait l'altitude, et sous l'influence du fœhn, la vallée inférieure de la Reuss jouit d'un climat particulièrement doux ${ }^{70}$, même pendant les mois d'hiver ${ }^{71}$ 72. Par contre, la vallée d'Urseren souffre pendant l'hiver de températures très basses. Presque dépourvue de forêts, elle ne dispose que de $56,0 \%$ de terres productives, et elle est exposée aux avalanches ${ }^{73}$.

La vallée supérieure de la Linth forme un cul-de-sac; entourée de pentes abruptes, elle est fortement exposée au fœhn.

Les taux d'émigration, d'intensité moyenne, valables dans l'entre-deux-guerres, n'expriment donc point les conditions physiques difficiles de ces contrées ${ }^{\mathbf{7 4}}$. Par contre, le mouvement d'émigration y fut supérieur dans le passé, au cours du 19e siècle, et ce n'est qu'au début du $20 \mathrm{e}$ siècle qu'il commença à fléchir. Il faut donc découvrir les causes de cette diminution.

Les conditions physiques de ces régions de haute montagne imposent presque partout un système de pâturages et de prés. Ce genre d'activité n'occupant qu'une partie de la population, le reste a dû chercher une occupation autre que le travail de la terre, ou quitter la région. Le problème a été résolu dans chaque contrée de manière différente. Le canton d'Uri, profitant de sa position favorisée au point de vue des communications, a développé le trafic.

Avant 1880, la vallée d'Uri tout entière bénéficiait du trafic routier, les villages le long de la route du Gothard en nourrissant et logeant les voyageurs, la population des vallées transversales grâce à ses livraisons de fourrage pour les chevaux de trait. Le trafic n'a pu toutefois faire vivre la population entière et l'intensité du mouvement d'émigration est restée élevée. Elle est devenue maximum lors de l'ouverture du trafic ferroviaire, qui a réduit un certain nombre de possibilités de gain, mais une fois le premier choc passé, les villages le long de la ligne ferroviaire se sont développés rapidement ${ }^{75}$, tandis que les contrées à l'écart du trafic (vallées de Maderanen, de Meien, etc.) tombaient en décadence et commençaient à voir diminuer leur population ${ }^{76} 77$. D'autre part, certaines industries venaient d'être introduites au fond de la vallée: à Altdorf des fabriques de munition, de caoutchouc, de fil de fer, à Isleten une fabrique de dynamite, en d'autres communes des usines métallurgiques, des entreprises alimentaires et d'habillement. Ces nouvelles activités ont constitué de nouvelles possibilités de travail et ont donc contribué à diminuer la nécessité de s'exiler.

Pour échapper aux conditions de vie pénibles imposées par le caractère inhospitalier de leur pays, les Glaronais s'expatriaient périodiquement autrefois et parcouraient l'Europe entière comme vendeurs de tables d'ardoise et de fromages verts. Puis, au $18 \mathrm{e}$ siècle, vint s'y installer l'industrie cotonnière ${ }^{78}$.

66 Pour terminer, portons notre attention sur la question de la bourgeoisie des émigrants. Dans le territoire entier du lac des Quatre-Cantons, sauf dans les Préalpes lucernoises, les émigrants partent directement de leur commune d'origine, ou bien ils proviennent d'une autre commune du même canton. Mais tandis que dans le canton de Schwyz le nombre d'émigrants correspond, en fonction du lieu de résidence, à peu près au nombre valable pour la commune d'origine ou est même un peu inférieur, il est bien supérieur dans le canton d'Obwald. Ce phénomène peut être expliqué de la façon suivante: En 1921, on construisit un barrage exhaussant le lac de Lungern. Les individus qui y avaient afflué pour participer aux travaux ne purent pas y rester, les travaux terminés, et durent quitter la région. Une partie d'entre eux partait outre-mer.

${ }^{67} 6$, page 342.

${ }^{68}$ Surface improductive de la vallée de la Reuss inférieure: $48,0 \%$. ${ }^{69} 50$.

70 Température moyenne du mois de janvier: Altdorf $+0,1^{\circ} \mathrm{C}$; ; en comparaison: Schwyz $-1,2^{\circ} \mathrm{C}$.

${ }^{71} 53 .{ }^{72} 6$, page $348 .{ }^{73} 3$, page 201. ${ }^{74} 6$, page $301 .{ }^{75} 42 .{ }^{76} 50 .{ }^{77} 53 .{ }^{78} 6$, page 302. 
Chaque fois que cette branche d'activité passait par une crise, les conditions physiques défavorables reprenaient toute leur importance et poussaient grand nombre d'habitants à l'émigration ${ }^{79}$.

Dans l'entre-deux-guerres, la situation de cette industrie est assez précaire en raison du changement de mode vestimentaire, des droits de douane élevés et de la concurrence étrangère accrue. Toutefois, certaines industries nouvelles (entreprises alimentaires, d'habillement, d'appareils, de machines) allaient se développer. Offrant du travail à un cinquième environ de la population active, elles contribuent à maintenir le taux d'émigration relativement peu élevé.

La structure économique particulière des deux contrées en question se reflète dans la composition par professions du courant migratoire: Le canton d'Uri connait surtout l'émigration d'agriculteurs venus des régions agricoles se trouvant à l'écart des lignes de communication, qui, en majorité (plus de $90 \%$ du nombre total des émigrants uranais), ont émigré vers les États-Unis. L'émigration industrielle y est insignifiante, puisque les industries uranaises travaillent en majorité pour le marché intérieur et sont donc peu soumises à l'influence des changements économiques internationaux.

Dans le canton de Glaris, la situation se présente autrement: Tandis que l'agriculture occupe, dans le mouvement d'émigration, une place tout à fait secondaire, l'industrie mécanique, l'industrie textile, le ménage et l'éducation y participent de façon accrue. Ce phénomène doit être attribué aux faits suivants: un certain contingent d'émigrants (notamment des travailleurs spécialisés des deux industries orientées vers le marché extérieur) partent outre-mer pour représenter leurs fabriques. D'autres individus partent tout simplement dans l'espoir de pouvoir se créer une nouvelle existence. Parmi eux, les ménagères et gouvernantes sont vraisemblablement en partie d'anciennes travailleuses textiles.

La structure économique des régions envisagées s'exprime aussi dans la composition du courant d'émigration par sexe et par état civil. Tandis que le canton d'Uri ne connaît que l'émigration des célibataires masculins, le canton de Glaris y fait participer aussi les femmes célibataires.

Aussi l'émigration envisagée par années fait-elle ressortir les particularités des régions étudiées. Les Glaronais s'expatrient surtout en 1924, lorsque l'industrie textile souffre toujours de certaines difficultés résultant de la crise d'après-guerre. Les Uranais, par contre, participent au mouvement d'émigration à prédominance agricole de l'année 1928.

$4^{\circ}$ Les Alpes thuranaises ${ }^{80}$. Le mouvement d'émigration provenant des Alpes thuranaises, ne présente pas de caractère uniforme. Il est faible dans le Gaster [91], dans la région du lac de Wallenstadt et dans la vallée de la Seez [district de Sargans 98], dans la vallée supérieure du Rhin st-gallois [district de Werdenberg 102], en Appenzell Rhodes Intérieures [15] et dans le secteur occidental du Toggenbourg inférieur [districts d'Alttoggenbourg 90 et de Neutoggenbourg 93], d'intensité moyenne dans le district du lac [Seebezirk 99], d'intensité supérieure dans le Toggenbourg supérieur [Obertoggenbourg 95], au secteur oriental du Toggenbourg inférieur [Untertoggenbourg 101, Wil 103], en Appenzell Rhodes Extérieures [12, 13, 14], dans la région

79 La crise de l'industrie cotonnière des années 1840 et suivantes fait émigrer grand nombre de Glaronais; ils se créent une nouvelle existence à New-Glaris (Wisconsin). Le processus de rationalisation des années 1872 à 1878 provoque un nouveau maximum de l'émigration glaronaise.

${ }^{80}$ On entend, selon J. FrüH, par "Alpes thuranaises" l'ensemble des régions suivantes différant les unes des autres par leurs conditions climatiques et de relief:

a) la ville de St-Gall, ses environs, la vallée de St-Gall-Uzwil;

b) le pays des deux Appenzell et le massif du Säntis;

c) le Toggenbourg;

d) la vallée du Rhin st-gallois;

e) les massifs du Speer et des Churfirsten et la vallée de la Seez;

f) la région du lac de Wallenstadt et le groupe de montagnes de la Sardona. Cette dernière contrée appartient plutôt aux Alpes glaronaises, mais fait partie du district st-gallois de Sargans. 
des villes de St-Gall [97] et de Rorschach [96] et dans la partie inférieure de la vallée du Rhin st-gallois [Ober- et Unterrheintal 94 et 100].

Essayons de déterminer la relation entre le mouvement d'émigration et les conditions physiques locales. Le district de Gaster est composé de la plaine de Gaster, aujourd'hui très fertile, située à moins de $500 \mathrm{~m}$. d'altitude, et de la région d'Amden, située à plus de $900 \mathrm{~m}$. d'altitude, mais jouissant de bonnes conditions d'insolation. L'intensité d'émigration peu élevée de cette contrée est donc l'expression de conditions physiques favorables.

Le bassin du lac de Wallenstadt se trouve dans une situation analogue ${ }^{81}$. Le climat est très doux sous l'influence du fœhn ${ }^{82}$ (la flore y est parfois méridionale); le mouvement d'émigration n'est donc pas considérable. Aussi la vallée de la Seez et la partie supérieure de la vallée du Rhin st-gallois, profitant à leur tour du climat tempéré dû au foehn ${ }^{83}$, indiquent-elles de faibles taux migratoires. Dans toutes ces régions, les dégâts causés par les éléments, sont peu importants: tandis que le district de Werdenberg est parfois exposé aux inondations venues du Rhin, les incendies de villages entiers, fréquents autrefois et dûs au fohn, sont devenus rares actuellement.

Dans le Toggenbourg, le taux d'intensité varie en fonction directe de l'altitude: dans la vallée supérieure, plus rude et moins favorisée au point de vue climatique, le mouvement migratoire est plus considérable que dans la partie inférieure.

Une relation aussi manifeste entre le mouvement d'émigration et les conditions physiques du pays ne peut pas être constatée pour les autres régions.

L'intensité migratoire est maximum dans les districts de Rorschach, de St-Gall, de Vorder- et Mittelland et d'Unterrheintal, donc en des contrées différant considérablement par l'altitude, la température annuelle moyenne, le relief, la fertilité du sol.

Ainsi, le district de Rorschach et notamment celui d'Unterrheintal sont situés à de basses altitudes et jouissent de conditions de climat et de sol relativement favorables. Le district de St-Gall, par contre, souffre en hiver d'un climat assez rude, en raison de son altitude plus élevée et de son exposition aux vents. Les Vorder- et Mittelland se trouvent à une altitude encore plus élevée, mais indiquent une intensité migratoire plus faible.

Encore plus frappant est le mouvement d'émigration, de moyenne ou faible intensité, du district de Hinterland et du demi-canton des Rhodes Intérieures, ces contrées étant en majorité situées au-dessus de $1000 \mathrm{~m}$. d'altitude. Le phénomène de l'inversion de température 8485 ne suffit pas à expliquer l'absence d'un mouvement migratoire important. D'autre part, l'intensité maximum du district d'Unterrheintal se trouve en opposition avec un certain nombre de conditions physiques: altitude peu élevée, grande fertilité du sol, conditions climatiques assez favorables.

Pour une bonne partie du territoire des Alpes thuranaises, le mouvement migratoire doit done avoir d'autres causes que celles qui résultent de conditions purement physiques: Les conditions physiques défavorables, notamment la forte pluviosité, poussaient déjà vers le 15e siècle la population à abandonner la culture des champs et à se vouer uniquement à l'exploitation des prés. Celle-ci n'absorbant pas la population entière, un grand nombre d'individus sont allés chercher du travail dans l'industrie qui, sous forme de métiers à domicile, puis parfois de fabriques, s'était développée un peu partout sur territoire st-gallois et appenzellois.

Il s'agit dans la ville de St-Gall et dans ses environs des industries linière et cotonnière et de la broderie, dans les deux Appenzell des industries du lin, du coton, de la soie et surtout de la broderie, dans le Toggenbourg des industries de la soie, du coton et de la broderie ${ }^{88}$, dans la vallée du Rhin st-gallois surtout de la broderie.

A l'exception de l'industrie linière (qui déclinait déjà au milieu du 18e siècle), ces activités industrielles ont joui d'une grande prospérité au cours du $19 \mathrm{e}$ et au début du $20 \mathrm{e}$ siècles. Elles ont absorbé tout l'excédent de la population agricole et ont même procuré à un grand nombre d'agriculteurs des gains accessoires. Les périodes de crise furent peu fréquentes pendant cette époque, et chaque fois, les industries se remettaient rapidement.

815 , page $177 .{ }^{82} 6$, page $285 .{ }^{83} 6$, page 251.

84 Température moyenne d'hiver relativement élevée par rapport à l'altitude, due à l'absence de brouillard et à la forte insolation.

Température moyenne du mois de janvier à Trogen $\left(900 \mathrm{~m}\right.$.) $-2,0^{\circ} \mathrm{C}$.; en comparaison: Einsiedeln $(910 \mathrm{~m}$. $)-4,0^{\circ} \mathrm{C}$., Elm $(963 \mathrm{~m}$. $)-3,4^{\circ} \mathrm{C}$. Nombre de jours avec brouillard au mois de novembre: Trogen 6,0, Einsiedeln 10,5.

85 51. 8840 . 
En raison de ces conditions économiques prospères, le mouvement d'émigration st-gallois et appenzellois fut peu intense; dans la seconde moitié du siècle, il ne devînt fort que pendant la crise cotonnière vers 1890 . La situation allait se modifier après la première guerre mondiale, lorsque l'appauvrissement des anciens États belligérants, les droits de douane élevés, les changements survenus dans le domaine de la mode, la concurrence chinoise travaillant à très bon compte, et l'invention d'automates de broderie aux États-Unis provoquèrent, avec le coût de production élevé en Suisse, une crise aiguë dans les industries principales st-galloises et appenzelloises. La broderie surtout, qui avait été, par son chiffre d'affaire, la plus importante industrie suisse d'exportation avant 1914, a vu se réduire ses exportations à un dixième du volume d'avant-guerre ${ }^{87}$. Une fois ces industries paralysées, la population n'y a plus trouvé de moyens d'existence suffisants, et la sensible réduction de la forte densité démographique en a été une conséquence inévitable. Aussi, la population appenzelloise (Rh. Ext.) baisse-t-elle de 57973 habitants en 1910 à 55354 en 1920, à 48877 en 1930, à 44756 en 1941.

Les répercussions sur l'émigration de ce changement de structure économique sont sensibles sur le territoire entier des Alpes thuranaises de 1920 à 1923; aux périodes ultérieures (1924-1928-1932-1936), le mouvement d'émigration intense se concentre en certains districts, tandis que d'autres régions sont moins touchées. Parmi ces dernières, on remarque des contrées moins industrialisées, donc moins touchées par la crise, où l'agriculture, en raison du climat et du relief plus favorables, réussit plus facilement à offrir à la population des moyens d'existence suffisants: Gaster, vallée du lac de Wallenstadt, vallée de la Seez, partie supérieure de la vallée du Rhin st-gallois.

En d'autres contrées, l'économie régionale, à cause de sa structure particulière, ne souffre pas tellement de la crise. Ainsi, la broderie à main surfine se trouve localisée dans le demi-canton des Rhodes Intérieures ${ }^{88}$; elle est moins touchée par la crise d'aprèsguerre. Dans cette industrie travaillent d'ailleurs exclusivement des femmes (les hommes gagnent leur vie dans l'agriculture), la sensibilité à la crise y est donc réduite et explique le faible taux d'intensité du mouvement d'émigration.

Dans les Rhodes Extérieures, l'intensité du mouvement migratoire est plus élevée dans le district du Mittelland que dans celui du Vorderland. Dans la première des deux contrées, hommes et femmes pratiquent la broderie à main ordinaire et le tissage du coton. La seconde région connaît, en outre, le tissage de soie superfine (Seidenbeuteltuch) dont les articles font toujours l'objet sur le marché d'une certaine demande ${ }^{89}$. Cette activité accessoire freine donc le mouvement migratoire.

Dans le district de Rorschach, l'activité industrielle ne se limite pas à la seule branche textile: Rorschach même est le siège de fabriques de soie artificielle, d'aluminium, de conserves, d'ateliers mécaniques. Ces entreprises travaillent en majorité pour le marché extérieur, et la forte intensité migratoire est donc en partie la conséquence de leur situation précaire pendant la crise économique mondiale. D'autre part, les environs de Rorschach connaissent un genre d'émigration intense tout particulier. Il s'agit de religieuses provenant de Schloss Wartensee et de Tübach. Cette dernière commune connaît, en effet, un taux migratoire correspondant à $13,2 \%$ de la population globale.

Dans la partie inférieure de la vallée du Rhin st-gallois, de conditions physiques analogues, le mouvement d'emigration est bien plus intense dans le district d'Unterrheintal que dans celui d'Oberrheintal: cela est dû au fait que ces deux contrées ont fortement développé l'industrie textile, et qu'elles ont donc été gravement atteintes par les crises d'après-guerre et la crise économique mondiale. Dans le district d'Oberrheintal ont été crées, par la suite, d'autres industries, ou au moins elles prirent un plus grand essor. On peut indiquer la grande tuilerie et l'atelier pour instruments optiques à Heerbrugg, une fabrique de viscose à Widnau, des établissements de transport à Altstätten, etc. La création de nouvelles industries y a donc réduit l'intensité de l'émigration.

La composition du courant d'émigration résulte en grande partie de la structure physique et économique particulière des Alpes thuranaises. L'émigration st-galloise est forte en 1924-1928-1932: elle fait partie des mouvements migratoires des années 1924 et 1928 en raison du caractère montagnard du pays, à l'émigration de l'année 1932 à cause de la crise de l'industrie textile. Le mouvement migratoire du demi-canton

876 , page 268. 8851.

89 Ainsi, les meuniers achctent des bluteaux. 
de Rhodes Extérieures est, en outre, de forte intensité en 1936, au moment où la broderie va reconquérir une partie des marchés perdus, et envoie dans ce but ses représentants également outre-mer. Ce mouvement d'expatriation s'étend d'ailleurs aussi aux St-Gallois, lorsqu'on envisage les communes d'origine. Bien qu'ils ne résident plus dans leur canton d'origine, ils sont atteints par cette expatriation pour 1 a reconquête du marché extérieur.

Quant aux professions, on remarque des taux de participation à l'émigration relativement élevés d'agriculteurs sur territoire st-gallois et des Rhodes Intérieures, de travailleurs textiles dans toutes les régions envisagées, de ménagères dans les cantons de St-Gall et de Rhodes Extérieures, d'ecclésiastiques dans les cantons de St-Gall et de Rhodes Intérieures. L'émigration des agriculteurs est due aux conditions physiques défavorables et à la situation difficile de l'industrie textile, celle des travailleurs textiles et des ménagères ${ }^{90}$ seulement au dernier fait. Le mouvement migratoire des ecclésiastiques est la conséquence de l'existence d'un certain nombre d'institutions religieuses à fonction missionnaire outre-mer (couvents de Tübach, Schloss Wartensee, etc.).

La répartition de l'émigration par sexes est également en rapport avec la structure économique particulière des régions envisagées. Du canton de St-Gall partent surtout des femmes célibataires, parce que l'industrie en crise occupait une forte main-d'œuvre fémininè. Dans les Rhodes Extérieures, les deux catégories sont touchées par la situation peu favorable de l'industrie textile en 1932. Aux Rhodes Intérieures, les femmes célibataires ne participent pas à l'émigration, la broderie à main surfine jouissant d'assez bonnes conditions (relativement aux autres secteurs de la broderie) même pendant la crise. Le taux de participation des hommes et femmes mariés reste insignifiant: en effet, le tisseur st-gallois et appenzellois étant souvent en même temps agriculteur, les pères et mères de famille restent au pays pour cultiver leur petit domaine agricole.

$5^{\circ}$ Le Tessin. Le mouvement d'émigration tessinois, de tous temps très vif, est d'intensité moyenne ou très forte dans la période d'entre-guerres. Minimum dans le district de Mendrisio [131], il gagne d'importance au fur et à mesure que l'on avance vers les Alpes, et atteint un maximum dans la vallée de la Maggia [133]. Cet accroissement d'intensité n'est pourtant pas uniforme. Les bords du lac Majeur, appartenant au district de Locarno [129], fournissent moins à l'émigration que le district de Lugano [130] situé plus au sud. De même l'intensité migratoire du district de Blenio [127], situé tout au nord, est peu accentuée. Comparée aux régions montagnardes du versant septentrional des Alpes, l'émigration tessinoise paraît cependant active.

Les conditions physiques sont ici en cause. Les taux d'émigration varient avec les changements de climat. Au fur et à mesure qu'on gagne en altitude et avance vers les Alpes, ils s'élèvent. La forte déclivité des montagnes tessinoises, les vallées profondément encaissées ${ }^{91}$, le manque de replats étendus et de bandes de terrains fertiles dans les vallées limitent l'établissement de l'homme et paraissent maintenir élevé le mouvement d'émigration ${ }^{92}$. Seul le district de Blenio connaît des alpages étendues ${ }^{93}$; sa faible - intensité migratoire doit donc être en partie attribuée à cette particularitée 94 . D'autre part, les terres alluviales tessinoises sont caractérisées par un mouvement d'émigration relativement faible. Ainsi, le Mendrisiotto [131] doit sa faible émigration à son caractère orographique peu accidenté et à la grande fertilité de la Campagna Adorna entre Stabio et Mendrisio ${ }^{9596}$.

Dans le district de Lugano, le fond des vallées et les bords des lacs se trouvent à des altitudes peu élevées et sont gratifiés de conditions climatiques très favorables (par exemple la grande chaleur) permettant, dans des lieux bien abrités contre les vents du nord (par exemple à Gandria) de cultiver l'olivier à côté de la vigne, le maïs, le mûrier, le tabac, etc. Les terres d'alluvions n'y sont pourtant pas très éten-

${ }^{90}$ Certainement d'anciennes travailleuses textiles. Nos fiches n'indiquent pas s'il s'agit d'épouses d'émigrants ou de servantes.

01 6, page 500. ${ }_{92}^{92} 5$, page $151 . \quad{ }^{93} 6$, page 507.

94 Terres agricoles et alpestres en pour-cent de la superficie: districts de Blenio 61,5\%, de Vallemaggia $37,0 \%$; cantons: Valais $42,0 \%$, Uri $42,0 \%$, Grisons $49,0 \%$.

${ }_{95} 6$, page 540 . $\quad{ }^{96} 48$. 
dues $^{97}$. Les régions situées aux altitudes plus élevées (certaines parties du Malcantone), les vallées latérales et les parties supérieures des vallées principales (par exemple la vallée de Colla, etc.) présentent un tout autre caractère physique: le relief y est plus accidenté, le sol moins fertile, et les cultures, en raison du fort déboisement pratiqué au 19e siècle, sont souvent ravagées par des torrents. Les conditions physiques y favorisent donc le dépeuplement et impliquent un mouvement d'émigration élevé pour le district de Lugano tout entier ${ }^{98}{ }^{99}$.

Dans le district de Bellinzone aussi, où l'intensité d'émigration est encore plus forte, un grand nombre d'émigrants proviennent de régions de montagne, notamment du Val Morobbia, des communes de Pianezzo, St. Antonio, etc. ${ }^{100}{ }^{101}$.

Dans le district de Locarno, on distingue nettement deux régions de caractère physique très différent: la plaine de Magadino et les bords du lac Majeur, favorisés par la grande fertilité des terres d'alluvions et par une forte réverbération du lac, sont de moindre intensité d'émigration ${ }^{102}$.

Celle-ci, par contre, est très élevée dans les vallées de Verzasca, de Centovalli et d'Onsernone. Ceci doit être attribué aux faits suivants: La vallée de Verzasca, séparée de la vallée principale par une gorge de raccordement, présente un caractère physique nettement montagneux ${ }^{103}$. Les pentes abruptes des montagnes y rendent les terres productives peu nombreuses; situées au fond de la vallée, elles sont menacées par l'inondation des torrents et ravagées en hiver par des avalanches ${ }^{\mathbf{1 0 4}}$.

Des conditions physiques analogues se rencontrent dans les vallées de Centovalli et d'Onsernone: leur relief est fort accidenté, et les vallées sont profondément enfoncées dans la montagne. Les terres productives y sont peu nombreuses et la couche de terre végétale mince et rudimentaire, surtout à des altitudes plus élevées ${ }^{105}$.

Dans le district de la vallée Maggia [133], également, le taux d'intensité migratoire maximum est la conséquence naturelle des conditions physiques défavorables. Celles-ci sont encore plus accentuées que dans les vallées de Centovalli et d'Onsernone, notamment dans la vallée de Lavizzara et de Bavona qui n'est, par conséquent, pas habitée l'hiver. Le fond de la vallée principale est une gavière ${ }^{106}$.

Le mouvement d'émigration reste moindre dans le district de Riviera, en raison de son climat doux dû à l'altitude peu élevée et grâce à la fertilité et l'extension relativement grande des terres d'alluvions accumulées par le Tessin.

Il est de forte intensité dans le district de la Leventina, d'altitude plus élevée, de relief plus accidenté, de conditions climatiques moins favorables, où pourtant il y a des pâturages et des replats. L'émigration y est plutôt une habitude ancestrale; d'abord hivernale, elle devient définitive.

La structure physique particulière du Tessin influe aussi sur la composition professionnelle du courant d'émigration. Depuis le moyen âge, la région alpestre du Sopraceneri ${ }^{107}$ a toujours été une réserve de main-d'œuvre peu spécialiséc, et l'émigration la plus typique y était celle des agriculteurs, des rôtisseurs de châtaignes, des valets d'écurie. Les régions préalpines du Sottoceneri et les bords du lac Majeur connaissent depuis des siècles le mouvement migratoire des maçons, gypsiers, stucateurs, tailleurs de pierre ${ }^{108}$.

Aussi dans l'entre-deux-guerres, les deux catégories professionnelles des agriculteurs et des travailleurs en bâtiment sont-elles prédominantes pour l'émigration tessinoise ${ }^{\mathbf{1 0 9}}$.

L'émigration industrielle est insignifiante, le Tessin ne disposant pas de grandes industries en raison de sa position excentrique par rapport à la Suisse intérieure, ce qui implique des frais de transport élevés. Toutefois, l'existence d'une industrie locale a pu parfois réduire l'intensité du mouvement d'émigration. Ainsi, une fabrique de chocolat se trouvant à Dongio-Torre, procure du travail à une bonne partie de la population du district de Blenio ${ }^{110}$. De même, le trafic de marchandises et de voyageurs sur la ligne du

97 Il s'agit des plaines d'Agno, de Lugano et du delta de la Magliasina.

98 La petite commune d'Arosio, qui fait partie de la partie montagneuse du Malcantone, présente, par exemple, un taux annuel d'intensité de $17,40 \%$ de la population globale.

${ }^{99} 6$, page 530. $10061 . \quad 1016$, page 511. $\quad 1026$, page $525 . \quad{ }^{103} 6$, page $512 . \quad 1043$, page 255.

105 Rapport des terres agricoles et alpestres à la superficie: communes de Brione (Verzasca) 31,0\%,

Gerra (Verzasca) 36,5\%, Palagnedra (Centovalli) 33,0\%, Russo (Onsernone) 24,0\%.

10636.

107 Sopraceneri: Leventina, Blenio, Vallemaggia, Riviera, Bellinzone, Locarno.

Sottoceneri: Lugano, Mendrisio.

10861.

109 L'émigration considérable des ménagères est, à notre avis, liée à celle des agriculteurs.

1106 , page 510. 
Gothard est une source de travail pour les habitants de la Leventina; le taux migratoire de ce district est donc bien inférieur à celui du Vallemaggia ${ }^{111}$. Le trafic ferroviaire favorise d'autre part la migration périodique vers la Suisse intérieure, ce qui réduit automatiquement l'émigration transocéanique des régions participant à la migration intérieure. Ainsi, la vallée de Blenio, qui débouche à Biasca dans la Leventina, de faible émigration outre-mer, indique un mouvement migratoire périodique assez considérable ${ }^{112}$.

La structure économique du Tessin s'exprime aussi par la participation plus ou moins intense à l'émigration des quatre années envisagées: Celle-ci est élevée en 1924, 1928, 1932, faible en 1936. Les émigrants des années 1924 et 1928 sont surtout des agriculteurs et des travailleurs en bâtiment qui partent, attirés par la prospérité outre-mer et par le manque de manœuvres dans l'agriculture américaine ${ }^{113}$.

L'année 1932 connaît, en outre, l'émigration de ménagères qui vont rejoindre leurs maris. En 1936, le mouvement migratoire tessinois reste faible en raison du défaut de grandes industries d'exportation qui auraient pu envoyer leurs représentants hors d'Europe.

L'agriculture et le bâtiment sont toutes deux des activités saisonnières, offrant un maximum de travail en été. L'émigration tessinoise devient donc particulièrement forte dans la période morte, en automne et en hiver. Ce mouvement migratoire ne s'effectue en règle pas par familles entières. Les pères de familles et les jeunes hommes s'expatrient et sont absents pendant des années ${ }^{114}$, tandis que les femmes et filles continuent de labourer la terre. Cette circonstance (qui peut d'ailleurs s'observer sur notre figure 12 concernant l'état civil et le sexe) implique souvent une désagrégation des propriétés rurales et devient, par conséquent, à son tour la cause d'un nouveau mouvement d'émigration.

Retenons, pour terminer, que la forte émigration tessinoise est en bonne partie l'expression de conditions physiques défavorables. Le défaut de grandes industries y participe en moindre mesure, mais contribue quand même à maintenir élevée l'intensité migratoire.

\section{B. Régions alpestres à faible intensité d'émigration}

$1^{\circ}$ Les Grisons. Les Grisons sont le siège d'une émigration moyenne ou faible. Seuls les districts de Hinterrhein ${ }^{115}$ [67] et de Bernina [64] ont des taux migratoires plus élevés, bien que le canton entier soit situé dans les Grandes Alpes. Les parties supérieures des vallées sont, en général, de plus forte intensité que les régions situées à une altitude moins élevée (aspect de la commune d'origine). Ainsi, dans la vallée d'Engadine, le district de Maloja [72], d'altitude plus élevée, indique un taux d'émigration bien supérieur à celui du district de l'Inn [69] situé à plus faible altitude. Le même phénomène s'observe dans le Prättigau, avec les deux districts d'Oberlandquart [70] et d'Unterlandquart [71], et également dans la région de Hinterrhein, où les taux migratoires du district de Hinterrhein [67] dépassent largement ceux du district de Heinzenberg [66]. L'intensité de l'émigration y augmente donc en raison directe de l'altitude. La région de Vorderrhein fait exception à cette règle, le taux du district de Vorderrhein [76] étant inférieur à celui du district de Glenner [65] situé à une moindre altitude.

Les faibles taux d'émigration d'une grande partie du territoire grison s'expliquent en partie par certaines coñditions physiques particulières à ce canton. Les contrastes de relief n'y sont pas aussi prononcés qu'au Tessin. Les pentes des montagnes sont moins abruptes, les hautes vallées pourvues de

$11161 . \quad 1123$, page 251.

$11359,0 \%$ du nombre total des émigrants tessinois des années 1924, 1928, 1932, 1936 partent pour les États-Unis, 16,4\% pour l'Argentine, 3,1\% pour l'Uruguay et le Paraguay, 3,8\% pour le Pérou et l'Équateur.

114 Le phénomène des "golondrinas" a été plutôt caractéristique pour certaines parties de l'Italie. Les émigrants partant, par exemple, pour l'Argentine, revenaient chaque année au pays. Aujourd'hui, les lois d'immigration de ce pays ont mis fin à ce mouvement migratoire.

11558. 
pâturages relativement riches et étendus ${ }^{118}$, et elles sont souvent liées entre elles par des cols bien accessibles $^{117}$. Quant au climat, les hautes stations se distinguent par la sécheresse de l'air, la faible précipitation, la forte insolation, la grande chaleur du sol, facteurs qui favorisent l'établissement de l'homme et qui font défaut aux régions de même altitude du versant septentrional des Alpes. Le district de Hinterthein [67] fait exception; il doit son intensité migratoire maximum en grande partie à des conditions physiques peu favorables: son relief est accidenté, sa pluviosité élevée par rapport aux autres régions grisonnes ${ }^{118}$; la contrée est peu accessible, séparée du reste du monde par des défilés étroits (Viamala, Averser Gasse, etc.), et une bonne partie des habitations humaines y sont situées à des altitudes élevées (Avers-Cresta à $1949 \mathrm{~m}$., Juf à $2133 \mathrm{~m}$.) ${ }^{119}$. Les autres régions grisonnes sont presque toutes favorisées par des conditions physiques plus favorables et indiquent, par conséquent, des taux d'émigration moins élevés: Les vallées du Vorderrhein et du Prättigau [76,65/71,70] sont protégées contre les vents du nord par les Alpes glaronaises ${ }^{120}$, respectivement par la chaine du Rhéticon ${ }^{121}$. Le climat y est donc relativement tempéré et permet, dans des lieux bien abrités, de cultiver des arbres fruitiers.

Dans le district de Heinzenberg [66], le relief est peu accidenté, et ses vastes et fertiles hauts-plateaux ne sont pas hostiles à l'établissement de l'homme ${ }^{122}$. Dans l'Engadine également, jouissant d'une forte insolation $^{123}$, les conditions physiques ne réussissent pas à provoquer une émigration extraordinaire.

Néanmoins, toutes ces régions ont connu des mouvements migratoires considérables, puisque les ressources de la terre ne suffisaient pas à la longue à garantir à la population accrue un niveau d'existence suffisant. Le district de Maloja a connu depuis des siècles une émigration continentale périodique, d'abord vers l'Italie du Nord, puis vers presque tous les pays d'Europe ${ }^{124}$. En certaines zones de dépeuplement, le mouvement migratoire se dirigeait de préférence vers d'autres régions du même canton et vers d'autres cantons de la Suisse, et ce n'est que vers $1880-1890$, lors de la crise de l'agriculture provoquée par la concurrence américaine, que l'émigration transocéanique grisonne a atteint une intensité supérieure à la moyenne.

Ce mouvement migratoire intérieur persiste aussi dans l'entre-deux-guerres. Les districts de Münster [74] et de Moësa [73] le connaissent; dans le premier cas, les émigrants vont s'établir de préférence dans le district de Maloja, et dans le second cas, ils se dirigent vers la Suisse septentrionale.

Les émigrants partant directement des Grisons, sont surtout des agriculteurs. Le caractère de haute montagne de ce canton s'oppose, en effet, malgré certaines conditions de relief et climatiques relativement favorables, à toute activité humaine, particulièrement à la culture du sol. Les industries et le commerce n'alimentent pas le mouvement migratoire grison, parce que trop faibles pour pouvoir envoyer de représentants outre-mer. Par contre, des industries locales ont été introduites en divers endroits, et leurs répercussions sur l'économie régionale ont été favorables. Elles ont aussi contribué à maintenir le mouvement d'émigration dans des limites basses. Ainsi, le district de Vorderrhein [76] doit sa faible intensité migratoire à l'existence d'une manufacture de tissus ${ }^{125}$. Pour cette raison, le taux d'émigration du district de Vorderrhein est inférieur à celui du district de Glenner [65], de moindre altitude.

$\mathrm{La}$ faiblesse du mouvement d'émigration est, d'autre part, une conséquence de la place prise par le tourisme dans l'économie grisonne. Cette branche d'activité a pu retenir nombre d'agriculteurs qui avaient quitté leur sol. Notamment les centres de Davos et d'Arosa et ceux de l'Engadine supérieure ont pris un énorme développement et ont complètement changé de structure économique ${ }^{126}{ }^{127}$.

Jouissant d'une bonne prospérité, les employés d'hôtel ne participent pas d'une manière considérable à l'émigration.

L'influence du tourisme ne se limite pas aux seuls employés d'hôtel et aux grands centres touristiques. Elle est sensible en d'autres professions et en d'autres régions.

116 Rapport des terres agricoles et alpestres à la superficie dans les districts grisons: Albula 53,0\%, Bernina 45,0\%, Glenner $63,0 \%$, Heinzenberg $67,0 \%$, Imboden $45,0 \%$, Inn $47,0 \%$, Ob́erlandquart $57,0 \%$, Unterlandquart 54,0\%, Maloja $32,0 \%$, Moësa 34,0\%, Münstertal 54,0\%, Plessur $64,0 \%$, Hinterrhein 53,0\%, Vorderrhein $54,0 \%$.

1175 , page $158 . \quad 1186$, page 449. 1183 , page $162 . \quad 1206$, page $430 . \quad 1216$, page 418. 1226 , page 444.1236 , page 467.124 44. 1253 , page 161.

128 Rapport des différentes branches économiques en pour-cent de la population active totale. Davos: agriculture $9 \%$, arts, métiers et industrie $24,3 \%$, commerce et tourisme $31,2 \%$. Arosa : agriculture $1,1 \%$. Engadine supérieure: agriculture 6,8\%, arts, métiers et industrie 31,3\%, commerce et tourisme $40,4 \%$. St-Moritz: agriculture $1,3 \%$, arts, métiers et industrie $30,1 \%$, commerce et tourisme $51,3 \%$. 12758. 
Dans le district d'Alvaschein [63], l'intensité d'émigration a diminué depuis qu'une ligne ferroviaire a relié cette contrée au monde extérieur et l'a fait devenir zone de pas-

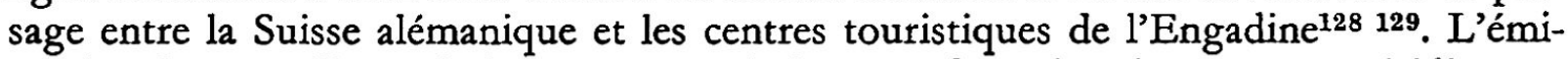
gration des travailleurs du bâtiment est relativement forte dans les secteurs méridionaux des Grisons. Ils proviennent surtout des districts de Moësa, de Bregaglia, de Poschiavo, soit de contrées de langue italienne, où ce genre d'activité est assez répandu.

La structure particulière de l'économie, et notamment de l'agriculture grisonne, s'exprime dans la composition du courant d'émigration par sexes et en fonction de l'état civil. Dans les régions grisonnes touchées par le dépeuplement (par exemple le district de Hinterrhein), la jeune génération, et surtout les jeunes hommes, sont les premiers à abandonner leur terre; pour cette raison, les émigrants grisons sont surtout des jeunes hommes célibataires ${ }^{130}$.

$2^{\circ}$ Le Valais. Les taux d'émigration augmentent, dans le Valais, de l'ouest à l'est: Ils sont très faibles dans le district de Monthey [150], s'élèvent un peu dans les districts de St-Maurice [152], d'Entremont [145], d'Hérens [147] et dans le secteur méridional (Val d'Anniviers) du district de Sierre [153], pour atteindre une valeur moyenne-inférieure dans la partie supérieure du Valais, dans les districts de langue allemande de Viège [155], Rarogne [151], Brigue [143] et Conches [146]. La même tendance s'observe sur le versant nord de la vallée principale; l'intensité migratoire est petite dans les districts de Martigny [149] et de Conthey [144], moyenne-inférieure dans le district de Sion [154], moyenne dans le district de Loèche [148].

Cet accroissement d'intensité de l'émigration signifie que certaines conditions physiques empirent au fur et à mesure que l'on avance en cette direction: l'altitude moyenne est plus grande, le relief plus accidenté, la température plus basse.

Bien qu'appartenant pour la plus grande partie aux Grandes Alpes, le Valais témoigne d'une intensité d'émigration relativement faible. Ce phénomène s'explique par le caractère physique et la position géographique particuliers de toute la région. Séparé du reste du monde, par les deux puissantes chaînes des Alpes bernoises et pennines, le Valais est protégé contre les vents froids du nord et contre la forte pluviosité qui sévit dans le Tessin ${ }^{131}$. Il jouit, dans sa partie centrale, d'une forte insolation et, par conséquent, d'une température annuelle moyenne relativement élevée ${ }^{\mathbf{1 3 2}}$, permettant de cultiver dans la vallée principale du Rhône le maīs, la vigne, les pommes, les poires, les pêches, les abricots, les asperges, dans les vallées latérales la vigne et le noyer jusqu'à $1200 \mathrm{~m}$. d'altitude (près de Visperterminen), le pommier, l'orge, la pomme de terre, le lin à $1500 \mathrm{~m}$., le cerisier à $1800 \mathrm{~m}$., le seigle à $2100 \mathrm{~m}$. (à Findelen au-dessus de Zermatt) ${ }^{133}$. La faible pluviosité est à son tour un facteur favorisant la culture de la terre.

Il n'en est pas de même dans le secteur oriental du Valais, dans la vallée de Conches. Cette région reçoit des précipitations de 1600 à $2000 \mathrm{~mm}$. de pluie annuelle ${ }^{135}$, et d'autres facteurs physiques défavorables viennent s'ajouter. Située à une altitude de 1000 à 1800 m., la vallée de Conches souffre d'un

128 La région d'Oberhalbstein, située dans le même district, fut vers 1880-1890 une zone d'un important dépeuplement, lorsque l'ouverture de la ligne du Gothard allait détourner le trafic des cols grisons. Dans l'entre-deux-guerres, elle s'est remise de ce coup, et le trafic routier par-dessus le Julier constitue pour la population régionale une nouvelle source de gain.

12958.

130 Pour terminer, répétons le fait suivant: Le mouvement d'émigration est peu important, lorsqu'on l'envisage selon le lieu de résidence. Il est d'une plus grande envergure d'après la commune d'origine. Grand nombre de Grisons partent donc d'autres cantons de la Suisse; ce mouvement étant assez important en 1936, ces émigrants exercent une profession autre que l'agriculture, puisque cette année est surtout caractéristique pour l'émigration des spécialistes de nos industries d'exportation. Déracinés dans les zones de dépeuplement, ils ont abandonné la profession d'agriculteur, quitté la région, appris un autre métier en d'autres cantons de la Suisse; puis, ils sont partis outre-mer. On ne peut pourtant pas constater, si ce mouvement d'expatriation est une conséquence ultérieure des mobiles qui ont poussé les émigrants grisons à quitter leur région d'origine.

1315 , page 143.

132 Température annuelle moyenne: Leukerbad (Loèche-les-Bains) (1405 m.) 4,5 C., Grächen

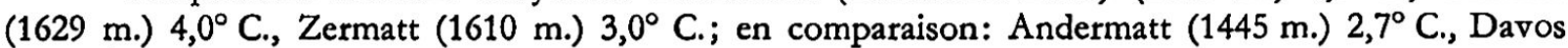
(1561 m.) $2,7^{\circ}$ C., Bevers (1710 m.) $1,3^{\circ}$ C. ${ }^{134}$.

1336 , page $558 . \quad 13420.1356$, page 551. 
climat rude. La plaine marécageuse du Haut-Conches ne porte que de médiocres prairies. Les cultures sont confinées sur une zone étroite qui longe le pied de la montagne; encore y sont-elles exposées, au printemps, aux gels tardifs, toute l'année à des vents violents soufflant de la Furka et du Grimsel. Les inondations, les eaux torrentielles, les avalanches dessinent un réseau de lignes dangereuses ${ }^{136}$. Compte tenu de tous ces faits, le district de Conches [146] devrait indiquer une intensité d'émigration bien supérieure.

En effet, la région a connu un mouvement migratoire considérable, d'abord sous forme de migration des Valses ${ }^{\mathbf{1 3 7}}{ }^{\mathbf{1 3 8}}$, puis sous forme d'émigration continentale et transocéanique (vers le Brésil, par exemple). La perte de population fut même si grande que des villages tout entiers se dépeuplaient, de sorte que, par exemple vers 1870 déjà, le dernier des hameaux entourant Ulrichen et les villages de Gehrensdorf, Zumloch, Zur Rottenbrücke, Richelsmatt, Wyler, Zeit, Sechshäusern cessaient d'être habités. La faible participation à l'émigration du district de Conches s'explique par son degré avancé de dépeuplement.

Dans la partie centrale du Valais, le système économique archaiqque de la population agricole ${ }^{139}$ contribue à maintenir le mouvement migratoire à une valeur peu élevée. Vivant la plus grande partic de l'année dans des vallées latérales dont l'accès à partir de la vallée principale est difficile à cause de défilés ou de fortes pentes terminales, les habitants des Vals d'Anniviers ${ }^{140}$, d'Hérens, de Bagnes ne sont pas encore trop touchés par la civilisation. Faisant souvent encore eux-mêmes leurs vêtements et vivant de leur économie agricole complexe les menant, au cours de l'année, de $550 \mathrm{~m}$. à $2700 \mathrm{~m}$. d'altitude, ils conservent un genre de vie autarcique ${ }^{\mathbf{1 4}}$.

L'excédent de ces populations montagnardes est absorbé par certaines industries de la vallée principale. Les Anniviards vont travailler à l'usine d'aluminium de Chippis ${ }^{142}$, les habitants du Val d'Hérens aux caves et en d'autres entreprises de Sion, ceux du Val de Bagnes et d'Entremont aux entreprises chimiques de Monthey. S'appropriant les us et coutumes modernes, ils deviennent plus accessibles à l'attraction du mouvement d'émigration. Ainsi s'expliquent les taux d'émigration telativement élevés de la population de résidence des districts de Sion et de Loèche, ainsi que le mouvement migratoire, plus élevé selon la commune d'origine que d'après le lieu de résidence, du district d'Hérens.

Les répercussions du tourisme sur l'émigration ne paraissent pas défavorables. En tout cas, aux centres d'industrie hôtelière, à Zermatt, Saas-Fee, etc., le mouvement migratoire est peu intense; cette branche d'activité a donc pu absorber une bonne partie de l'excédent de la population agricole.

Des facteurs de nature diverse ont donc contribué à maintenir peu élevé le mouvement migratoire valaisan pendant les quatre époques envisagées. Les industries n'y étant que d'im. portance locale, la plupart des émigrants sont des agriculteurs et des employés d'hôtel.

Dans le mouvement d'émigration, les hommes célibataires dominent, fait qui est d'ailleurs bien expliquable.

Tandis que les femmes et les filles s'occupent des travaux agricoles, les hommes vont souvent travailler en fabrique, où ils sont exposés aux sollicitations du temps moderne, ce qui les rend plus sensibles à l'attraction du mouvement d'émigration. Le déplacement alternatif, journalier ou hebdomadaire, entre le village de montagne et le lieu de travail au fond de la vallée principale, aboutit donc à une émigration permanente. Le travail industriel éloigne les hommes des labours et en donne la charge principale aux femmes. Les hommes ne sont plus nécessaires aux travaux agricoles et s'expatrient pour aller chercher fortune outre-mer.

$3^{\circ}$ Les Préalpes romandes (Préalpes fribourgeoises et vaudoises). Le mouvement d'émigration des Préalpes romandes est d'intensité faible dans tous ses districts [Gruyère 54, Pays-d'Enhaut 170, Aigle 156]. La structure physique de la région est de caractère essentiellement préalpin. L'altitude n'y est pas très élevée, le relief moins accidenté qu'en d'autres parties des Alpes. Le pourcentage de terres pro-

$13638 . \quad 1373$, page 72 .

138 Un fort accroissement démographique dans un milieu géographique peu favorable a pendant des siècles poussé la population de la vallée des Conches à l'émigration. Les émigrants se sont établis dans des régions montagnardes à conditions physiques et économiques analogues, d'abord à l'est et au sud du massif du Mont-Rose, dans la vallée de la Toce, puis en certaines parties des Grisons (Rheinwald, etc.) et enfin dans le Vorarlberg.

${ }^{139} 6$, page $568 . \quad{ }^{140} 6$, page $573 . \quad 1415$, page $148 . \quad{ }^{142} 6$, page 573. 
ductives y est assez élevé, et les alpages sont fertiles et étendus. La pluviosité s'y maintient à une valeur moyenne, et toute la région profite de la durée d'insolation relativement longue. Le Pays-d'Enhaut est presque dépourvu de brouillard ${ }^{\mathbf{1 4 3}}$. La région des Ormonts a toutefois un caractère orographique plus accidenté que le reste des Préalpes romandes: d'où un taux d'émigration de 0,45 à $0,60 \%$ dans le district d'Aigle.

Ces conditions physiques favorables permettaient autrefois d'y cultiver des céréales. La concurrence des blés étrangers devenant trop forte vers $1860^{144}$, les paysans des Préalpes romandes se sont donc spécialisés dans la production laitière, qui, dans le district de Gruyère, est aujourd'hui en fort excédent et exportée ou utilisée pour la fabrication de fromage et de chocolat Cailler S.A. à Broc.

En d'autres régions, surtout dans les Préalpes vaudoises, les paysans ont su se procurer un gain accessoire en louant, à des étrangers, pendant la saison d'alpage, leurs appartements pour les vacances. Le milieu physique et les conditions économiques des agriculteurs des Préalpes romandes ne sont donc pas propres à favoriser une émigration agricole considérable, et, en effet, les paysans n'y participent que dans une faible mesure au mouvement d'émigration.

L'industrie hôtelière proprement dite s'est développée en divers endroits des Préalpes romandes, à Leysin, Château-d'Oex, Diablerets, Villars, etc. Ses répercussions sur l'économie régionale ne paraissent pas défavorables: La participation relativement élevée des employés d'hôtel au mouvement d'émigration s'explique par le taux d'intensité et le nombre absolu peu élevé d'émigrants; elle n'est pas la conséquence d'une situation précaire du tourisme.

Les taux de participation de l'enseignement, de l'éducation et du ménage sont relativement élevés à cause de la langue, les instituteurs, gouvernantes et ménagères de langue française trouvant plus facilement un engagement à l'étranger que leurs collègues de langue allemande. La participation à l'émigration des artisans de l'alimentation est à notre, avis assez élevée, parce que les confiseurs ont travaillé dans la fabrique de chocolat de Broc et gagnent une de ses succursales outre-mer.

D'autres industries n'ont pu se développer dans les Préalpes romandes. Le mouvement d'émigration des travailleurs industriels est donc insignifiant.

L'importance relativement élevée pour l'émigration des gouvernantes et ménagères s'exprime aussi dans la composition du courant migratoire par sexe et par état civil, les taux de participation des femmes célibataires étant assez élevés.

\section{L'émigration jurassienne}

Le milieu physique de la plus grande partie du territoire jurassien est moins rude que dans les Alpes, mais plus défavorable que dans le Mittelland. Les taux d'intensité de l'émigration jurassienne se tiennent entre les taux des Alpes et les taux du Mittelland.

$1^{\circ}$ Le Jura vaudois et neuchâtelois. Le Jura neuchâtelois et vaudois est parcouru du sud-ourest au nord-est par des chaînes parallèles qui le divisent en trois régions bien distinctes, complètement différentes d'aspect et de climat. Il s'agit, dans le canton de Neuchâtel, des régions suivantes ${ }^{\mathbf{1 4 5}}$ :

a) les montagnes, constituées par les vallons élevés de $\mathrm{La}$ Chaux-de-Fonds, du Locle, de la Sagne, des Ponts, de la Brévine, des Verrières, de la Côte-aux-Fées, entre 900 et 1050 m. d'altitude;

b) les vallées, c'est-à-dire le Val de Travers et le Val de Ruz, de 700 à 900 m. d'altitude;

c) le Vignoble, compris entre 430 et $700 \mathrm{~m}$. d'altitude.

Le Jura vaudois comprend de son côté:

a) la Vallée de Joux, Ste-Croix, le Chasseron;

b) la Vallée de l'Orbe;

c) le Piedmont subjurassien et la Béroche ${ }^{146}$.

Les régions de la Montagne sont caractérisées par leur relief accidenté, le sol calcaire d'une grande perméabilité, donc peu fertile et sec, par l'altitude élevée (1000 m.), par un climat rigoureux surtout en

1436 , page 402.

144 Dans ces régions de montagne, elle fut sensible plus tôt que dans le Mittelland, où la crise agricole date de 1880 .

1456 , page $61 . \quad 1466$, page 78. 
hiver, par des vents violents, par des neiges abondantes jusqu'au mois d'avril, par une forte pluviosité pendant les autres saisons de l'année atteignant plus de $2000 \mathrm{~mm}$. au Mont Risoux ${ }^{14}$.

Les régions du Piedment subjurassien, de la Béroche et du Vignoble sont en comparaison favorisées par une altitude moins élevée, un climat plus doux, des précipitations moins fortes ${ }^{\mathbf{1 4 8}}$, une forte insolation sur les rives des lacs de Neuchâtel et de Bienne ${ }^{149}$.

Dans le canton de Neuchâtel, les répercussions du milieu physique sur l'émigration sont manifestes. Dans le district de Boudry [82], dans la région du Vignoble, les taux d'intensité sont minimum; ils augmentent quelque peu dans les districts des Vals de Ruz [86] et de Travers [87] et deviennent de 0,30 à 0,45\% dans la Montagne [districts de La Chaux-de-Fonds 83 et du Locle 84$]^{150}$.

Dans le Jura vaudois, le phénomène ne ressort pas d'une façon aussi claire. Il y faut tenir compte de la commune d'origine pour découvrir une liaison de cause à effet entre le milieu physique et le mouvement d'émigration. Ainsi, les districts de La Vallée [172] et d'Orbe [167] ont une intensité migratoire de 0,90 à $1,20 \%$, tandis que celle-ci se maintient entre 0,45 et $0,60 \%$ dans le district d'Yverdon ${ }^{151}$ [174: Piedmont subjurassien], dont une partie appartient au Jura, le reste au Mittelland.

Le caractère physique peu hospitalier d'une grande partie du Jura a amené les habitants déjà très tôt à introduire certains arts et métiers. Dans le Vignoble seulement, la production du sol est encore de première importance, surtout sous forme de viticulture. Ces régions n'ayant qu'une faible émigration, la participation des agriculteurs au mouvement migratoire est donc très réduite.

L'industrie horlogère s'est surtout développée dans le Jura neuchâtelois. Cette branche d'activité a passé, sous forme de travail à domicile, par un temps de prospérité dans la première moitié du 19e siècle. La forte concurrence américaine provoque, vers 1885 à 1890, une sensible crise dans l'industrie suisse qui provoque un mouvement d'émigration considérable.

L'équilibre se rétablissant par l'introduction de la machinisation, l'intensité migratoire redevient moyenne ou faible. En 1920, la politique protectionniste des États-Unis amène une nouvelle crise dans l'industrie horlogère suisse et a pour conséquence un nouveau maximum d'émigration. Dans l'entredeux-guerres, le mouvement migratoire neuchâtelois est réduit; le taux de participation élevé des horlogers résulte donc du nombre absolu peu élevé d'émigrants et n'est pas un signe de la situation économique précaire de cette profession.

L'industrie mécanique s'est surtout développée aux environs de la ville de Neuchâtel. Ainsi, à Serrières, se sont installées des forges, des scieries et d'autres entreprises industrielles. La fabrique de chocolat Suchard S.A. envoie ses spécialistes (aussi des mécaniciens) dans ses succursales d'outre-mer. Ainsi s'explique le taux de participation à l'émigration relativement élevé des travailleurs de l'industrie mécanique.

Le Jura vaudois également est industrialisé: Les établissements Paillard S.A. ${ }^{152}$ construisent des appareils de radio et des machines à écrire. Vallorbe est le centre des importantes Forges d'Eterpas ${ }^{153}$ et d'une grande fabrique de ciment. Ces établissements travaillant en majorité pour le marché extérieur, ils se font représenter outre-mer par des travailleurs expérimentés, et, par conséquent, la participation à l'émigration des travailleurs industriels y est relativement élevée.

Toute la région étant de langue française, l'émigration des instituteurs, des gouvernantes ct des ménagères y acquiert une importance particulière pour des raisons que nous avons déjà expliquées. D'autre part, l'émigration ecclésiastique paraît y être devenue tradition dans certaines familles.

La prédominance, dans le mouvement d'émigration, de ces genres d'activité implique une participation particulièrement forte d'hommes maries (comme travailleurs industriels qualifiés, instituteurs et missionnaires), de femmes célibataires et mariées (institutrices, gouvernantes, ménagères, missionnaires, etc.).

$2^{\circ}$ Le Jura bernois et soleurois. Le Jura bernois et soleurois offre en partie des caractéristiques analogues à celles du Jura neuchâtelois et vaudois: l'altitude rela-

1476 , page 65.

148 Sur le versant sud-est du Jura, la chute de pluie diminue rapidement en raison inverse de l'altitude et atteint un minimum de $900 \mathrm{~mm}$. à Payerne, dans le Plateau suisse romand.

1496 , page 75 .

150 Dans le centre urbain de Neuchâtel, l'émigration obéit à d'autres lois.

15125 , page 376.1526 , page 88.1536 , page 83. 
tivement élevée, le climat ingrat, le sol peu fertile et sec, dépourvu d'eau, les fortes précipitations et les chutes de neiges abondantes, le climat continental de certains bassins ${ }^{154}$.

Les sept chaînes parallèles qui coupent ses diverses régions prêtent au Jura bernois et soleurois une diversité de climat considérable. Ainsi, le climat du Val de St-Imier [Courtelary 28] est assez fioid, la récolte du blé s'y fait en général 15 jours après celle du Mittelland. Les hauteurs environnantes sont pauvres en eau superficielle, et les sources n'apparaissent qu'au fond des vallées. Les Franches-Montagnes [31], situées à $1000 \mathrm{~m}$. d'altitude, exposées aux vents, indiquent une forte pluviosité et des chutes de neige abondantes. Les hivers y sont longs et durs, les étés très chauds, et la région manque de cours d'eau. Le climat est relativement doux dans le district de Moutier [38: vallée de la Birse supérieure], continental dans le district de Delémont [29] ${ }^{155}$, la forme en bassin de cette région a pour résultat une forte accumulation d'air chaud pendant le jour et d'air froid pendant la nuit. Le sol y est assez fertile grâce aux sédiments molassiques accumulés, comme d'ailleurs aussi dans le bassin de Laufon [36] ${ }^{156}$ et de Breitenbach [Kriegstetten 121]. Dans la vallée du Doubs, dominée par trois chaines de montagne, les étés sont très chauds, les hivers nébuleux ${ }^{157}$. L'Ajoie est exposée aux vents du nord et de l'ouest; les hivers y sont donc souvent rudes ${ }^{158}$. La région est connue par sa pauvreté en eau. Un tout autre caractère climatique caractérise la région de Bienne et de Neuveville [39]. Située sur le versant sud-est du Jura, elle constitue une zone intermédiaire entre les régions jurassiennes et le Flateau ternois, et tcute la contrée jouit d'un climat favorable grâce à la réverbération du lac et à l'exposition la plus favorable de la pente aux rayons du soleil.

Les régions du Jura bernois et soleurois les plus favorisées au point de vue physique sont d'une part les bassins de Laufon et de Breitenbach (terres fertiles, étés chauds en raison du climat continental), d'autre part le versant sud-oriental du Jura, notamment la région de Neuveville. Leurs taux d'émigration sont, par conséquent, inférieurs à ceux des districts de Courtelary, de Moutier et de Porrentruy 159.

Comparé à d'autres régions suisses de caractères physiques semblables, le mouvement d'émigration du Jura bernois et soleurois reste peu élevé, l'ingratitude du sol et du climat y étant neutralisée par la forte industrialisation de toute la région. Ainsi, l'industrie horlogère occupe une grande partie de la population. Le taux maximum de participation à l'émigration des horlogers n'est donc pas un indice d'une situation précaire de cette branche d'activité, car le nombre des émigrants-horlogers, en comparaison de l'effectif global de la population, n'est pas assez élevé; il n'est qu'une simple manifestation de la situation privilégiée de l'horlogerie dans l'économie jurassienne ainsi que de l'intérêt vital des marchés étrangers pour cette industrie d'exportation.

A côté de l'industrie horlogère se sont développées, dans cette partie du Jura, certaines entreprises de l'industrie mécanique et métallurgique qui, travaillant aussi pour le marché extérieur, envoient également leurs représentants outre-mer. Ainsi s'explique le taux relativement élevé des travailleurs de l'industrie mécanique participant à l'émigration (figure 11).

Certains districts ont gardé un caractère à prédominance agricole; ces régions, et notamment le district de Porrentruy, sont les foyers d'un mouvement d'émigration agricole relativement élevé dû à l'ingratitude du climat.

Grâce à leur langue maternelle française, les gouvernantes et ménagères du Jura bernois trouvent facilement engagement à l'étranger; elles occupent donc une assez forte position dans le mouvement migratoire de cette contrée (figure 11 et 12$)^{100}$.

1546 , page 33. 1556 , page 47. 1586 , page 49.1576 , page 52.1586 , page 53.

159 Selon la commune d'origine, le district de Porrentruy disposant également de terres fertiles assez étendus, fait partie de la zone de moindre intensité des bassins septentrionaux.

${ }^{160}$ Selon le lieu de résidence, l'émigration du Jura bernois et soleurois est de faible intensité pendant les quatre périodes envisagées. D'après la commune d'origine, elle est de forte intensité en 1928 et en 1932. Les Jurassiens émigrent donc à l'époque de prospérité 1928 favorisant surtout l'expatriation d'agriculteurs, et pendant la période de crise propre surtout à l'émigration de travailleurs spécialisés. Toutefois, ils ne partent pas directement de leur lieu d'origine; le procédé de concentration qui, depuis le début de ce siècle, fait diminuer la population des grands villages des régions intérieures du Jura bernois, a amené également nos émigrants aux grands centres de l'industrie horlogère, Bienne, Soleure, La Chaux-de-Fonds, etc., et c'est de ces endroits qu'ils sont partis pour l'étranger. Ainsi s'expliquent les taux d'émigration des districts du Jura bernois, plus élevés d'après la commune d'origine que selon le lieu de résidence ${ }^{161}$.

1616 , page 39. 
$3^{\circ}$ Le Jura bâlois et argovien. Le demi-canton de Bâle-Campagne appartenant en majorité au Jura, est parcouru, dans sa partie occidentale, par une chaìne de $878 \mathrm{~m}$. d'altitude (Blauen) qui s'abaisse rapidement vers le nord et se perd en petites collines dans la plaine du Haut-Rhin. Dans sa partie orientale, la longue chaîne du Jura se dresse comme un puissant remport, se dirigeant du sud-ouest au nord-est sur une longueur de $25 \mathrm{~km}$. environ, avec une altitude de 700 à $1160 \mathrm{~m}$. Protégées contre les vents du nord par la Forêt Noire, les régions situées plus au nord, à une altitude moins élevée, aux bords du Rhin, sont favorisées par un climat particulièrement doux ${ }^{162}$, par une faible pluviosité ${ }^{163}$ et par des terres fertiles assez étendues.

Sur les pentes et au sommet de la longue chaîne jurassienne, la température est moins élevée en raison de la plus grande altitude et la région est plus exposée aux vents froids du nord et du nord-est.

Le sous-sol calcaire, très perméable, est moins fertile, et le relief est plus accidenté: En relation avec ces faits, les districts méridionaux [Waldenbourg 19, Gösgen 120] indiquent des taux d'émigration supérieurs à ceux des districts de moindre altitude se trouvant dans le nord [Arlesheim 16, Liestal 17, Sissach 18, Rheinfelden 9, Laufenbourg 6].

L'intensité migratoire du Jura bâlois dépasse d'ailleurs celle du Jura bernois et soleurois ${ }^{165}$, bien que les conditions physiques y soient moins défavorables. Les causes de ce mouvement d'émigration relativement important ne tiennent donc pas au milieu physique, mais à la structure économique régionale.

Depuis des siècles, le Jura bẩlois est industrialisé. L'industrie de la soie, introduite au 16e siècle à Bâle par des réfugiés huguenots, s'est répandue dans toute la région sous forme de passementerie et d'activité à domicile procurant aux agriculteurs des gains accessoires, sans toutefois leur garantir, à elle seule, un niveau de vie suffisant. En effet, lors de la forte crise agricole des années 1880 à 1885 , due à la concurrence écrasante des blés transocéaniques, nombre d'agriculteurs bâlois ont été contraints d'abandonner leur terre; ainsi s'explique le maximum d'intensité migratoire bâloise de cette époque.

Dans l'entre-deux-guerres, la situation se présente autrement. C'est maintenant au tour de la passementerie de souffiir d'une forte crise résultant du changement de la mode, de droits de douane élevés et de l'appauvrissement des peuples belligérants ${ }^{168}$. L'agriculture, à elle seule, ne peut pas nourrir ces paysans-artisans qui souvent, en raison des possibilités de gains accessoires offertes par la passementerie, n'ont labouré qu'un lot de terre peu étendu. Ainsi s'explique l'intensité d'émigration. relativement élevée du Jura bâlois au moment, où ce gain accessoire vient à manquer.

De la même manière s'explique le taux de participation à l'émigration des agriculteurs, des ménagères et des gouvernantes, qui tous, auparavant, ont travaillé dans la passementerie. D'autre part, le pourcentage assez élevé des techniciens tient à l'existence de nombreux établissements industriels se trouvant dans la plaine de la Birse près de Bâle et dans la région de Sissach. Ce dernier taux n'est donc pas, à la différence des taux précédents, l'indice d'une situation économique précaire de l'industrie en question, puisque les émigrants-techniciens vont représenter leurs entreprises dans les pays transocéaniques.

La structure professionnelle particulière du mouvement migratoire implique une plus forte participation des hommes mariés (ce sont des artisans-agriculteurs, qui ont perdu leurs moyens d'existence, et des techniciens expérimentés), des femmes célibataires et mariées (gouvernantes et ménagères).

Le mouvement d'émigration est d'intensité supérieure en 1936, année de reprise économique pour les industries d'exportation. Il s'agit donc surtout de spécialistes des branches d'exportation ainsi que de travailleurs du bâtiment, cette dernière catégorie

${ }_{182}$ Température annuelle moyenne: Bâle $9,5^{\circ} \mathrm{C}$., Liestal 8,7 $7^{\circ} \mathrm{C}$

163 Précipitations annuelles moyennes: Bâle $829 \mathrm{~mm}$., Liestal $901 \mathrm{~mm} .{ }^{164}$

16420.

165 Elle est de 0,45 à $0,60 \%$ dans les trois districts de Waldenbourg [19], d'Olten [123] et de Gösgen [120]. 16634. 
souffrant à cette époque d'une sensible crise qui oblige, par exemple, le gouvernement bâlois à fermer son marché du travail aux travailleurs en bâtiment provenant d'un autre canton. L'émigration des agriculteurs-artisans s'y répartit sur les quatre périodes envisagées, la crise en passementerie, de caractère chronique, s'étendant sur un grand nombre d'années.

\section{L'émigration dans le Mittelland}

Le mouvement d'émigration du Mittelland augmente d'intensité au fur et à mesure que l'on avance du sud-ouest au nord-est. Minimum sur le Plateau suisse romand, il gagne un peu d'importance sur le Plateau bernois et lucernois, s'élève encore un peu plus en Suisse septentrionale et devient moyen $(0,60$ à $0,75 \%$ aux approches des Alpes thuranaises. Cette modification des taux d'émigration est due en grande partie au changement des conditions orographiques et surtout climatiques (exemple: augmentation des chutes annuelles moyennes, etc.). Les facteurs qui déterminent le mouvement d'émigration en provenance des grands centres industriels sont de toute autre nature. Il importe donc de traiter à part ce genre particulier d'émigration.

$1^{\circ}$ Le Plateau suisse romand. Deux conditions climatiques ont donné un aspect tout particulier à l'économie régionale du Plateau suisse romand, et notamment à la contrée comprenant le Haut-Plateau romand proprement dit (Plateau d'OutreVenoge, Gros de Vaud, vallée supérieure de la Broye) et à la dépression subjurassienne (plaine de l'Orbe, rives des lacs de Neuchâtel et de Morat, vallée inférieure de la Broye) ${ }^{\mathbf{1 6}}$. Ce sont d'abord les précipitations pluvieuses peu abondantes ${ }^{\mathbf{1 6 8}}$, les crêtes du Jura absorbant la majeure partie de l'humidité; c'est ensuite le climat plus océanique apportant le maximum de pluies en automne, en contraste avec la Suisse nord-orientale, de climat plus continental, où ce maximum est en été ${ }^{169}$. Le climat y est donc assez sec et favorise la culture des céréales et surtout du froment.

Ce genre d'activité demandant une somme de travail relativement élevée, il absorbe la plus grande partie de la population. Le mouvement d'émigration y est, par conséquent, très peu élevé pendant toute la période envisagée (de 1880 à 1940). Même la forte crise de l'agriculture des années 1880 à 1885 n'y est point sensible, ou en tout cas n'y provoque pas un mouvement d'émigration accru. Grâce à un climat sec garantissant un rendement de blé suffisant, les paysans vaudois continuent, dans l'entredeux-guerres encore, à cultiver les céréales. Ainsi s'expliquent les taux d'émigration peu élevés du Plateau suisse romand. Le minimum d'intensité migratoire s'observe pourtant dans la vallée de la Broye. La culture des céréales n'y étant pas aussi étendue que dans le Gros de Vaud, l'excédent de la population est absorbé par le travail dans les plantations de tabac (figure 11).

Les bords du lac Léman sont encore plus favorisés, au point de vue climatique. Jouissant d'une forte insolation, de la fonction régulatrice de température du lac et parfois d'une situation protégée contre les vents froids du nord, les habitants de ces contrées se sont spécialisés dans la culture de la vigne qui, demandant de très grands soins, occupe la majorité de la population ${ }^{170}$. Pour cette raison, le mouvement migratoire est minimum dans les districts de Rolle [171] et de Morges [164]. Il est un peu plus élevé dans les districts de Nyon [166] et d'Aubonne [157] qui s'approchent du Jura. Il est de 0,60 à $0,75 \%$ au secteur oriental de la rive suisse du lac Léman, notamment dans les districts de Lausanne [162] et de Vevey [173] qui sont fortement industrialisés. L'intensité migratoire accrue y est donc l'indice d'un développement industriel plus avancé.

1676 , page 214.

168 Précipitations annuelles moyennes: Valeyres-sous-Rances $928 \mathrm{~mm}$.

169 Maximum de pluies: Valeyres-sous-Rances en octobre (108 mm.); Zurich: du mois de juin au mois d'août (133 mm. par mois).

1706 , page 231. 
Exception faite de cette région riveraine du lac Léman, le Plateau suisse romand est dépourvu de grandes industries. Le tourisme, par contre, a pris une envergure considérable aux bords du lac Léman; il est d'une importance locale sur le Haut-Plateau romand. Le mouvement d'émigration indique donc un pourcentage relativement élevé d'employés d'hôtel.

D'autre part, en raison du nombre absolu peu élevé d'émigrants, la participation à l'émigration des instituteurs, des missionnaires, des gouvernantes et des ménagères ressort davantage. Les individus appartenant à ces professions sont d'ailleurs favorisés, par leur langue, dans la recherche d'un engagement à l'étranger (figure 11).

La participation relativement forte de ces professions implique des pourcentages élevés d'hommes mariés (instituteurs et missionnaires) et de femmes célibataires (gouvernantes, employés d'hôtel, ménagères) (figure 12).

$2^{\circ}$ Le Plateau bernois et soleurois. On distingue, dans le Plateau bernois, une partie supérieure (le Haut-Plateau bernois) comprenant le pays de montagne du $\mathrm{Napf}^{171}$, le Plateau de l'Argovie supérieure, l'Emmental, les vallées de l'Aar et de la Gürbe entre Berne et Thoune, et le pays montagneux de Schwarzenbourg et une partie inférieure (la dépression bernoise) comprenant la région de Wangen sur Aar, la plaine de l'Emme inférieure, le Plateau entre Emme et Sarine et le Seeland.

Dans l'Emmental, les vallons sont nombreux et profondément encaissés; ils découpent un massif de montagnes en un grand nombre de crêtes qui se rejoignent dans la région du Napf. L'Emmental est un pays caractéristique de montagne, ne présentant aucune plaine étendue. Il pénètre, dans sa partie supérieure, dans la zone des Préalpes bernoises (Hohgant $2260 \mathrm{~m}$. d'altitude) et présente, avec ses magnifiques pâturages, des caractères nettement préalpins ${ }^{172}$.

Le pays de montagne de Schwarzenbourg est moins découpé; il est, dans sa partie centrale, relativement plat et dispose de vastes et fertiles étendues ${ }^{173}$. La vallée de l'Aar, de Thoune à Berne, située à $550 \mathrm{~m}$. d'altitude, est large et fertile, tandis que le Plateau de l'Argovie supérieure est couvert de collines de 500 à $700 \mathrm{~m}$. d'altitude.

Dans la dépression bernoise, moins élevée, le caractère de plateau ressort davantage; ces contrées sont en principe constituées de terres d'alluvions ${ }^{174}$.

Tandis que la température annuelle moyenne diminue avec l'altitude, les précipitations sont faibles dans le Seeland, moyennes dans les autres parties de la dépression bernoise, élevées dans les pays de montagne de l'Emmental et de Schwarzenbourg ${ }^{175}{ }^{176}$.

D'après le lieu de résidence, les facteurs physiques n'interviennent pas de façon déterminante dans le mouvement d'émigration. Seule la région du Napf [Trachselwald 50] exprime, par son intensité migratoire relativement élevée $(0,30$ à $0,45 \%)$, son caractère orographique compliqué. Le reste de l'Emmental [Signau 48] et le pays de Schwarzenbourg [46], régions de montagne, indiquent des taux d'émigration minimum, et ceux-ci sont plus élevés dans la vallée de l'Aar [Thoune 49, Konolfingen 35] et dans le Seeland [Laupen 37, Aarberg 22] situés à bien moindre altitude et jouissant de conditions de relief et de climat plus favorables.

Les répercussions du milieu physique sont un peu plus apparentes selon la commune d'origine. L'Emmental supérieur [Signau 48] indique un taux d'émigration maximum. Toutefois, cette intensité migratoire élevée n'est qu'une conséquence indirecte des conditions physiques; elle est directement déterminée par le caractère particulier de la loi de succession patrimoniale emmentaloise qui à son tour est dans une certaine mesure influencée par le milieu physique: aux temps passés, la population de l'Emmental a occupé successivement toutes les terres cultivables; les fils aînés se sont approprié les terres situées sur les hauteurs, et le cadet a pris la succession de la ferme paternelle. Lorsque toutes les terres disponibles ont été occupées, les fils aînés ont dû aller chercher une nouvelle existence autre part, le caractère montagneux de l'Emmental ne permettant pas, sans le risque de surpeuplement, une division ultérieure des propriétés agricoles ${ }^{177}$.

Des paysans d'origine emmentaloise se sont donc établis un peu partout dans le Mittelland, du Plateau romand jusqu'à la Thurgovie; ils ont également pénétré dans le Jura bernois ${ }^{179}$. Ils y ont gardé leur taux de reproduction élevé, de sorte que certains de leurs enfants, à la recherche de travail, se sont ex-

1716 , page 178. $\quad 17241 . \quad{ }^{173} 6$, page 197. $\quad 174$ 49. 17537.

176 Précipitations annuelles moyennes: Aarberg $936 \mathrm{~mm}$., Burgdorf $1066 \mathrm{~mm}$., Schwarzenbourg $1172 \mathrm{~mm}$., Langnau i. E.: $1360 \mathrm{~mm}$., Eggiwil $1442 \mathrm{~mm} .{ }^{178}$

17725 , page $376 . \quad 17820 . \quad 17939$. 
patriés et sont allés s'établir outre-mer. Ainsi s'explique le taux d'émigration, élevé seulement selon la commune d'origine, des ressortissants emmentalois, qui persiste encore dans l'entre-deux-guerres.

Les autres régions du Plateau bernois ont connu un maximum d'émigration de 1880 à 1890, lorsqu'à la suite de la forte crise agricole les paysans bernois ont dû changer de production, abandonner la culture des céréales et se spécialiser dans la culture des prés absorbant un nombre plus faible de travailleurs. Encore dans l'entre-deux-guerres, certaines régions à prédominance agricole indiquent des taux d'intensité d'émigration supérieurs à ceux de contrées à évolution industrielle plus avancée. Voilà l'explication des taux relativement élevés de la vallée de l'Aar de Thoune à Berne, du Seeland bernois et de la région de Bucheggberg [118]. Ces contrées sont faiblement industrialisées, tandis que dans l'Emmental inférieur et dans le Plateau de l'Argovie supérieure se sont établies des industries textiles (laine, coton), mécanique et céramique (Langenthal).

Le taux minimum du pays de Schwarzenbourg peut être le résultat de son exposition orientée en partie vers le sud, ainsí que de son caractère isolé à cause du cañon du Schwarzwasser qui le sépare du reste du Plateau bernois ${ }^{\mathbf{1 8 0}}$.

En fonction de sa structure économique particulière, le Plateau bernois participe de façon supérieure à la moyenne à l'émigration des agriculteurs et des travailleurs de l'industrie mécanique. Les artisans d'alimentation (bouchers, etc.) et les ménagères indiquent également des pourcentages relativement élevés. La forte participation des agriculteurs implique des taux considérables d'hommes célibataires (figures 11 et 12).

$3^{\circ}$ Le Plateau argovien et lucernois. Le Plateau argovien et lucernois, situé entre 400 et $500 \mathrm{~m}$. d'altitude, est un pays de collines peu élevées aux croupes arrondies. Le climat est tempéré, et la pluviosité s'y maintient presque partout entre 1000 et $1200 \mathrm{~mm} .{ }^{\mathbf{1 8 1}}$.

Les caractéristiques physiques des différentes contrées ne sont pas assez diverses pour provoquer de grandes variations dans l'intensité d'émigration. Néanmoins, le Plateau argovien, situé plus au nord, indique des taux migratoires supérieurs à ceux du Plateau lucernois. Les causes de ces différences. ne résident donc pas dans le milieu physique et doivent être cherchées autre part:

La structure de la propriété rurale n'est pas la même dans les deux cantons. Au début du $19 \mathrm{e}$ siècle, les paysans argoviens et lucernois ont, à côté de l'agriculture, développé certaines industries à domicile, notamment les industries cotonnière, de la soie et de la paille. Ces activités ont pourtant pris un bien plus grand essor en territoire argovien, et les gains accessoires réalisés y ont permis de morceler davatage la propriété foncière. Vers 1850 , les industries qui, jusqu'alors, ont été réparties par toute la campagne argovienne sous forme d'activité à domicile, vont se concentrer en manufactures et fabriques le long des fleuves, et le paysan argovien, dépourvu des gains accessoires, ne trouve plus désormais de quoi vivre sur son petit lopin de terre ${ }^{182}$. Le paysan lucernois est bien moins touché par cette évolution; le moindre développement des industries à domicile implique un moindre morcellement de sa propriété rurale et lui permet de rester sur sa terre.

Dans l'entre-deux-guerres encore, le Plateau lucernois est une région à prédominance agricole. Cette contrée indiquant d'ailleurs, dans la période de 1850 à 1900, un décroissemment de population moyen de $15 \%$, les taux d'émigration restent également peu élevés.

Dans le canton d'Argovie, les individus libérés des travaux agricoles sont absorbés par les industries qui se sont installées sur tout le Plateau argovien, mais surtout dans les régions de Baden (Brown, Boveri \& Cie), Brougg et Aarau. L'intensité migratoire y reste donc également d'une importance réduite sans toutefois tomber au minimum caractéristique du Plateau lucernois.

La structure économique particulière des deux Plateaux s'exprime aussi dans la composition professionnelle du courant d'émigration. Tandis que le Plateau lucernois

18037.1816 , page $160 . \quad 18257$. 
est caractérisé par l'émigration d'agriculteurs, le Plateau argovien indique surtout des pourcentages élevés de techniciens, qui, en majorité, vont représenter à l'étranger Brown, Boveri \& Cie.

Le Plateau lucernois connaît, en outre, l'émigration religieuse. C'est pour cette raison que la participation à l'émigration des femmes célibataires (religieuses) y est élevée.

Le mouvement d'émigration est de faible intensité, sur le Plateau lucernois, pendant les quatre périodes envisagées. Sur le Plateau argovien, en raison de l'orientation vers le marché extérieur des industries mécaniques, les taux d'intensité sont supérieurs en 1936, année de reprise économique pour les branches d'exportation.

$4^{\circ}$ Le Plateau zurichois. On distingue, sur le Plateau zurichois, les régions suivantes:

a) l'Unterland, comprenant la région au nord de Winterthour, et la vallée de la Glatt;

b) les bords du lac de Zurich, Zurich-Ville, la vallée de la Limmat;

c) le Plateau entre Albis et Reuss;

d) l'Oberland et la vallée supérieure de la Töss.

L'Unterland, situé au nord du canton, à une altitude moyenne de $450 \mathrm{~m}$., est essentiellement plat. Les précipitations y sont peu élevées, de 800 à $1200 \mathrm{~mm}$. Elles augmentent vers le sud, vers les Préalpes, avec l'altitude des montagnes molassiques, et atteignent un maximum dans la vallée supérieure de la Töss' ${ }^{183}$.

Les conditions orographiques et du sol sont bien moins favorables dans l'Oberland que dans l'Unterland et dans la région du lac de Zurich. Cette dernière contrée est favorisée par des températures moyennes relativement élevées, résultant de la forte insolation des rives du lac ${ }^{184}$.

La région la moins favorisée du Plateau zurichois, au point de vue physique, est donc l'Oberland; l'Unterland, par contre, est plus favorisé par la configuration physique et la somme des précipitations pluvieuses.

On pourrait donc s'attendre à voir les taux d'émigration maximum dans l'Oberland, minimum dans l'Unterland. En effet, le mouvement migratoire de l'Oberland [Hinwil 179] est bien plus intense que celui de l'Unterland [Andelfingen 176, Bülach 177, Dielsdorf 178 ${ }^{185}$. Toutefois, les centres d'émigration maximum se trouvent localisés autour des grandes agglomérations urbaines de Zurich [185] et de Winterthour [184], dans la vallée supérieure de la Glatt [Uster 183] et sur les bords du lac de Zurich [Horgen 180, Meilen 181].

Le mouvement migratoire n'est donc pas partout en première ligne déterminé par le caractère du milieu physique, mais son influence sur l'économie régionale ne peut pas être complètement niée. Ainsi, les faibles précipitations impliquent, dans l'Unterland, une extension relativement grande de la culture des céréales. Ce genre d'agriculture demandant une somme de travail assez élevée, il absorbe une grande partie de la population; le nombre d'individus poussés à l'émigration, y est donc relativement petit. La culture de la vigne, sur les bords du Rhin et de la Thur, contribue à le maintenir peu élevéér ${ }^{186}$.

Également dans la zone de très forte intensité, les contrées aux meilleures conditions physiques indiquent des taux migratoires inférieurs à ceux des régions moins favorisées. Ainsi s'explique la moindre intensité migratoire de la rive droite du lac de Zurich [Meilen 181] et du district d'Affoltern [175] ${ }^{187}$ qui tous deux sont favorisés par une forte insolation permettant, dans le district de Meilen, la viticulture qui exige de grands soins et absorbe la majeure partie de la population. Les autres districts de la zone d'intensité maximum sont fortement industrialisés et travaillent en grande partie pour le marché extérieur, soit dans la branche mécano-métallurgique (Winterthour, vallée de la Limmat), soit dans le textile (districts d'Uster ${ }^{\mathbf{1 8 8}}$, de Horgen, etc.). Ceci implique aussi l'envoi d'un grand nombre de spécialistes dans les pays transocéaniques.

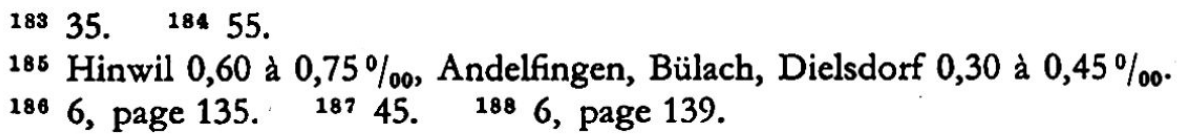


La majeure partie des émigrants provenant des régions industrialisées du Plateau zurichois, la participation à l'émigration est particulièrement forte parmi les travailleurs industriels; elle atteint, en outre, un pourcentage élevé parmi les travailleurs du bâtiment qui, certes, s.ont en grande partie originaires d'autres cantons suisses, et surtout des régions alpestres. Attirés, dans les premières années qui suivent la première guerre mondiale, vers les centres industriels zurichois par une activité accrue des entreprises du bâtiment, ils souffrent ensuite de la stagnation de cette activité. Ils émigrent donc pour une toute autre raison que la plupart des travailleurs de l'industrie mécanique qui, souvent, avant de partir, ont déjà un engagement en perspective.

Le mouvement d'émigration zurichois se maintient élevé pendant au moins trois des quatre périodes envisagées en raison de l'orientation très accentuée des industries mécano-métallurgiques (Sulzer, Maschinenfabrik Oerlikon, Bührle, Escher-Wyss, etc.) vers le marché extérieur.

$5^{\circ}$ La Thurgovie. Le mouvement d'émigration de la Thurgovie se maintient moyen ou peu élevé pendant toute l'époque de 1868 à 1940 . Il est de 0,30 à $0,45 \%$ dans l'entre-deux-guerres sur la plus grande partie de son territoire, car ses caractères physiques sont assez favorables.

La Thurgovie appartient entièrement au Mittelland; son caractère orographique est peu compliqué, sauf dans son secteur méridional [Hinterthurgau, district de Münchwilen 139] dont le relief est un peu plus accidenté. On y reconnaît deux régions naturelles distinctes, séparées l'une de l'autre par la chaîne du «Seerücken»: d'une part les régions riveraines du lac de Constance, d'autre part la vallée de la Thur. Les deux contrées sont situëes entre 400 et $500 \mathrm{~m}$. d'altitude; le Seerücken s'élève jusqu'à $700 \mathrm{~m}$. Le sol y est très fertile en raison des dépôts et alluvions de l'époque glaciaire. Le climat est relativement tempéré, et les chutes d'eau y sont peu considérables ${ }^{189} 190$.

Ces facteurs physiques ont favorisé l'agriculture et notamment la culture des pommes. La Thurgovie est ainsi devenue la région suisse la plus riche en pommes ${ }^{\mathbf{1 9 i}}$. L'industrie laitière est aussi d'une importance considérable pour l'économie régionale. D'autre part, les bords ensoleillés de la vallée de la Thur et les rives du lac de Constance connaissent la culture de la vigne. L'excédent de la population agricole est absorbé par certaines industries, surtout de la branche textile (coton, broderie, etc.). Le faible taux d'émigration de la Thurgovie s'explique donc d'une part par la faveur du milieu physique, d'autre part par la co-existence de productions agricole et industrielle.

Le plus important centre d'agglomération industrielle du canton se trouve dans le nord-est, au district d'Arbon [134] ${ }^{193}$. Il s'agit des industries métallurgiques (Saurer \& $\mathrm{Cie}$, automobiles) et de la broderie, qui, travaillant de préférence pour le marché extérieur, envoient leurs représentants à l'étranger, et qui, par conséquent, contribuent à maintenir plus élevé le mouvement migratoire de ce district. Dans le reste du territoire thurgovien, les émigrants dont le taux de participation est relativement élevé, sont des artisans de l'alimentation et des travailleurs du bâtiment; ils appartiennent donc à des professions de moindre importance numérique. Cette absence des professions de majeure importance dans l'émigration est à notre avis un indice de leur situation économique prospère.

$6^{\circ}$ Les grands centres urbains. Le mouvement d'émigration des grands centres urbains [Genève 59, Lausanne 162, Neuchâtel 85, Bienne 25, Soleure 124,

18943.

190 Température annuelle moyenne: Frauenfeld $8,1^{\circ} \mathrm{C}$. Chutes d'eau annuelles moyennes: Frauenfeld $896 \mathrm{~mm}$.

${ }^{191}$ Plus de $50 \%$ de tous les arbres fruitiers y sont des pommiers ${ }^{192}$.

18220.

1936 , page 107. 
Berne 24, Lucerne 79, Baden 2, Zurich 185, Winterthour 184, Schaffhouse 107, St-Gall 97] est, en général, d'intensité élevée pendant au moins trois des quatre périodes envisagées. Il est certain que les facteurs physiques n'y interviennent que dans une très faible mesure. Par contre, la question se pose de savoir si ce mouvement migratoire intense est la conséquence d'une trop grande densité démographique provoquant l'appauvrissement et le paupérisme de larges couches de la population, ou bien s'il est plutôt l'indice d'un rythme économique accéléré nécessitant l'envoi outre-mer de représentants de nos industries d'exportation et éveillant, chez d'autres, le désir d'éprouver leurs qualités professionnelles et humaines sur le champ plus étendu des pays transocéaniques. On a déjà démontré, dans la première partie, que notre émigration est une émigration de qualité et que les fonctions subordonnées (ouvriers non qualifiés) participent faiblement à l'émigration.

Presque tous les centres urbains participent par des taux relativement élevés au mouvement migratoire des commerçants comprenant un grand nombre d'individus indépendants ou à fonction de dirigeants, les centres industriels égal ment à l'émigration des techniciens qui à leur tour occupent une position sociale assez élevée (figure 11).

On peut donc constater que le milieu physique est pour l'émigration d'une importance primordiale. L'influence du milieu est moins manifeste, lorsque certaines industries viennent suppléer aux insuffisances de l'agriculture, mais elle reprend toute sa vigueur, lorsque ces industries passent par une crise. L'intensité migratoire élevée des régions de montagne s'explique par l'ingratitude du milieu physique, la médiocre accessibilité et le manque d'industries. Une amélioration des méthodes d'exploitation rurale et l'introduction de nouvelles industries y sont donc susceptibles de ralentir l'émigration. Le mouvement migratoire intense des villes, par contre, n'est qu'une manifestation toute naturelle de leur rythme économique accéléré.

Troisième Partie

\section{LES ZONES DE DESTINATION DE L'ÉMIGRATION TRANSOCÉANIQUE}

\section{CHAPITRE VI: \\ LA REPARTITION GÉOGRAPHIQUE ¿DE L'EMIGRATION OUTRE-MER}

A. Variations de l'intensité de l'émigration suivant la destination

Les émigrants se dirigent en majeure partie vers les deux Amériques; ils y choisissent de préférence les États-Unis et les pays de la Plata (Argentine, Uruguay, Paraguay [tableau $\left.10^{194}\right]$ ). Le Canada au nord, le Brésil au sud indiquent à leur tour des taux de participation au mouvement migratoire global relativement élevés. L'envergure du courant d'émigration se dirigeant vers les pays andins et vers les pays de l'Amérique centrale, est en comparaison bien moindre. Les trois autres continents (Afrique, Asie, Australie) comportent des chiffres d'émigrants suisses qui, mis en rapport avec l'effectif global des populations autochtones, sont encore plus réduits. Ils s'élèvent (moyenne des quatre années envisagées) à 475 individus pour l'Afrique, à 184 pour l'Asie, à 96 pour l'Australie.

La répartition, entre les différents pays transocéaniques, du mouvement migratoire suisse varie, toutefois, au cours du temps.

194 En 1928 51,0\% des émigrants vers les U.S.A., en 1936 31,5\% vers l'Argentine, l'Uruguay. le Paraguay. 
Tableau 10: Le courant d'émigration en 1924, 1928, 1932, 1936 vers les différentes destinations

Pays de destination

En nombres absolus

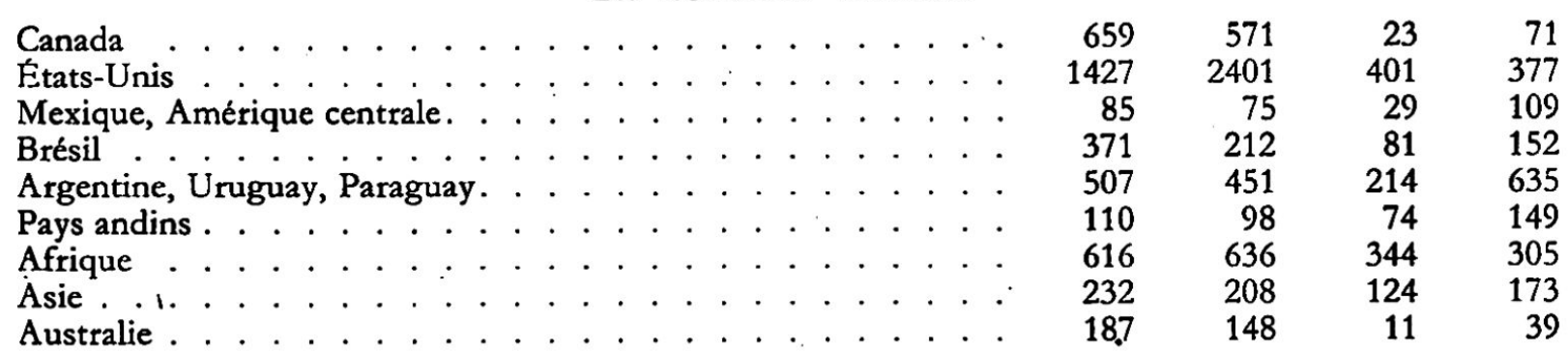

En pour-cent du total annuel des émigrants

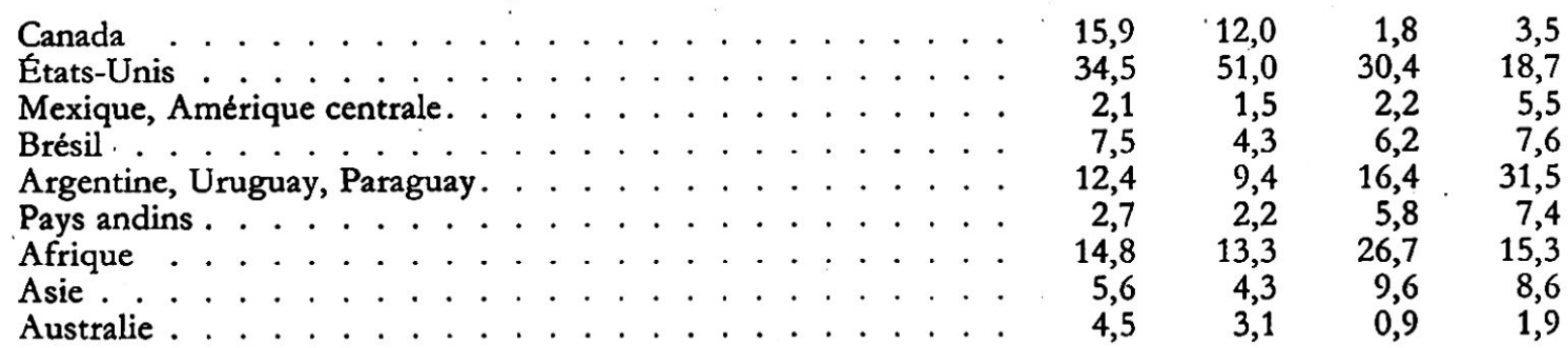

Ainsi, le chiffre d'émigrants partant pour les États-Unis, est maximum à l'époque de prospérité, en 1928; il devient moyen durant la période de crise (1932) et tombe à un minimum en 1936. Dans le Canada également, la réduction du taux de participation est très sensible de 1928 à 1932. Par contre, l'Argentine et le Brésil regagnent, en 1932, par rapport à d'autres États, la position perdue en 1928 en raison de l'orientation trop unilatérale vers les États-Unis; ils la consolident encore en 1936. Le mouvement migratoire dirigé vers les pays de l'Amérique centrale et les pays andins subit une semblable évolution. Le centre d'attraction de l'émigration suisse, situé aux États-Unis en 1928, à l'époque de la prospérité, se déplace de plus en plus vers l'Amérique centrale et l'Amérique du Sud, lesquelles jouent en 1936, époque de reprise économique de nos industries d'exportation, un rôle de premier plan dans le mouvement migratoire suisse. En Afrique et en Asie, le taux de participation est maximum en 1932. La réduction du chiffre absolu des émigrants y étant moins accentuée qu'en d'autres régions, ces deux continents sont moins sensibles à la crise économique mondiale. Ils participent également dans une moindre mesure à la reprise du mouvement d'émigration de l'année 1936. Alors, en effet, des travailleurs expérimentés sont envoyés outre-mer pour regagner à notre économie nationale les marchés extérieurs perdus par la crise, et l'Afrique, l'Asie ne sont pas en mesure d'absorber des travailleurs industriels étrangers en raison de leur évolution économique moins avancée.

Quel est, en 1939, le nombre de nos ressortissants habitant les circonscriptions suisses d'outre-mer?

Tableau 11. Nombre des ressortissants suisses habitant, en 1939, les circonscriptions suisses d'outre-mer

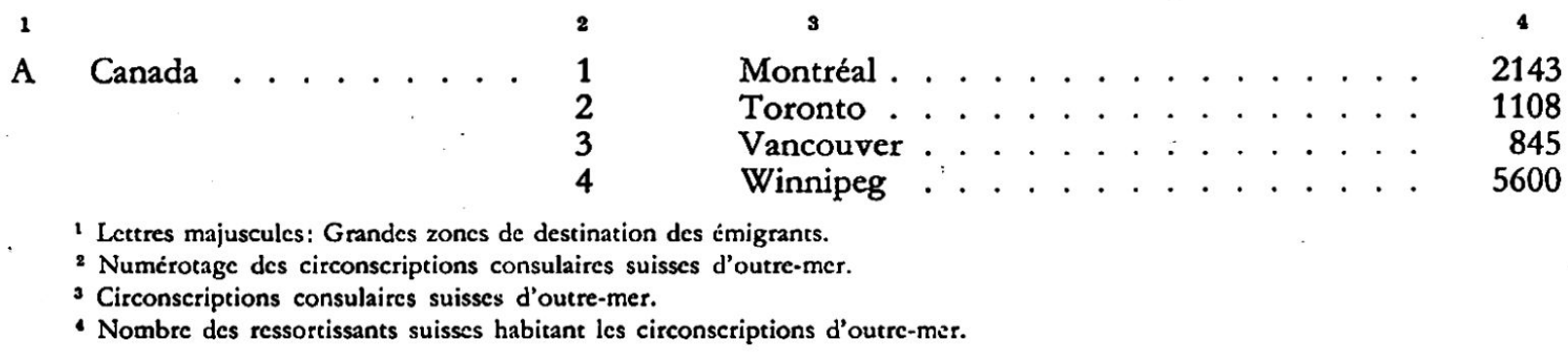


Cincinnati . . . . . . . . . 50000

Denvers . . . . . . . . . . 6822

Los Angeles . . . . . . . . . . . . . 5954

New-Orléans . . . . . . . . . . . 2100

New-York . . . . . . . . . . . . . . . 28877

Philadelphia $^{6}$. . . . . . . . 10000

San-Francisco . . . . . . . . . . . 40000

St-Louis ${ }^{7}$. . . . . . . . . . . . . . . 35521

Seattles. . . . . . . . . . . 26436

Washington . . . . . . . . 1446

C Mexique . . . . . . 15

Guadalajara . . . . . . . . . . . . 80

Mexico-City . . . . . . . . . . . . 680

Tegucigalpa (Honduras) . . . . . . . . 40

Amérique centrale. . . . . 17

Panama (Panama) . . . . . . . . . 150

San-Miguel (Salvador) . . . . . . . . . . . . 124

La Havane (Cuba) . . . . . . . . . . . . 150

Indes occidentales . . . . 20

Port-au-Prince (Haīti) . . . . . . . . . . 57

Ciudad-Trujillo (St-Domingue) . . . . . 29

D Brésil . . . . . . 23

Bahia . . . . . . . . . . . . . 190

Curityba . . . . . . . . 700

Pernambouc . . . . . . . . . 200

Rio-Grande-do-Sul ${ }^{10}$. . . . . . . . . . 500

Sâo-Paulo . . . . . . . . . . . . . . 1800

Santa-Catharina . . . . . . . . . 500

E Argentine ...... 29

Buenos-Aires . . . . . . . . . . 10000

Rosario de Santa-Fé11 . . . . . . . 4000

Montevideo ${ }^{12}$. . . . . . . . . . . 600

Uruguay ...... 31

Paraguay. . . . . . 32

F Chili ....... . 33

Asunçion . . . . . . . . . 680

Santiago . . . . . . . . . . . . 900

Valdivia . . . . . . . . . . 1000

La Paz . . . . . . . . . . . . . . . . . 200

Lima. . . . . . . . . . . . . . . . . 694

Guayaquil . . . . . . . . . . 237

Bogotà . . . . . . . . . . . 520

Caracas. .......... 300

Venezuela . . . . . . . . 39

Alexandrie . . . . . . . . . . . 722

Le Caire . . . . . . . . . . . . . . 840

Alger (Algérie) . . . . . . . . . . 3200

Casablanca $^{13}$. . . . . . . . . . . . . 1950

Dakar (Sénégal) . . . . . . . . . . . 300

Accra (Côte d'Or) . . . . . . . . . . . 390

Léopoldville (Congo belge) . . . . . . . . 323

Capetown . . . . . . . . . . 330

Johannesburg . . . . . . . . . . . . . 1100

Tanga (Afrique orientale). . . . . . . . 430

Tananarive (Madagascar) . . . . . . . 88

- Denver indique un mouvement démographique régressif. Le nombre de Suisses s'y ćlève en 1937 à 7278, en 1938 à 7050 .

- Lorsqu'on tient compte des Suisses nés en Suisse et de ccux qui sont nés aux États-Unis, le nombre s'élève à 17000 .

7581 individus nés en Suisse: domiciliés à Nebraska 1364, Kansas 1594, Missouri 3578, Illinois 1045;

27940 individus nés aux Êtats-Unis: domiciliés à Nebraska 5131, Kansas 7328, Missouri 12806, Illinois 2675.

88650 nés Suisses, dont 3578 à Tacoma, 4034 à Orégon, 1038 à Idaho;

17786 descendants de Suisses, dont 7067 à Tacoma, 7537 à Orćgon, 3183 à Idaho.

- Nous ne disposons pas de données statistiques conccrnant la circonscription consulaire de Rio de Janciro.

10 On prétend qu'il existe plus de 1200 descendants des 15 familles suisses, immigrées vers 1875, originaires du Valais.

11 Il est très difficile de faire des remarques concernant les Suisses non immatriculés, ces derniers étant généralement ignorés du consulat. Le nombre des Suisses habitant la campagne, cst probablement beaucoup plus élevé qu'il ae l'a été indiqué. Ainsi, la colonic suisse de Romang comptc 50 familles suisses, dont à peine six immatriculés.

12 Selon une estimation du correspondant du consulat de Nueva Helvecia, cette seule région, avec quelques 10000 habitants, compterait environs 4000 descendants de Suisses.

12 Il y faut ajouter un certain nombre de légionnaires. 
Jaffa (Palestine) . . . . . . . . . . 230

Beyrouth (Liban-Syrie)

Bagdad (Irak) . . . . . . . . . . . . . 27

Téhéran (Iran) . . . . . . . . . 151

Bombay . . . . . . . . . . . . 152

Indes ... 55

Calcutta . . . . . . . . . . 153

Colombo (Ceylan) . . . . . . . . . 35

Singapour (Malaisie britannique) . . . . . 121

Insulinde ....... 58

Medan (Sumatra) . . . . . . . . 210

Batavia (Java) . . . . . . . . . . 475

Manille (Philippines) . . . . . . . . . . 332

Bangkok (Siam) . . . . . . . . . . . . . $\quad 39$

Saigon (Indochine française) . . . . . . 160

Canton. . . . . . . . . . 43

Shanghaì . . . . . . . . . 418

Tokio . . . . . . . . . . 285

Japon ....... 66

Melbourne (Australie) . . . . . . . 844

Sydney (Australie) . . . . . . . . . . . 1000

Wellington (Nouvelle-Zélande) . . . . $\quad 647$

Monde entier . . . . . . . . . . . . . . . . . . . ca. 260000

Les grandes colonies suisses d'outre-mer sont toutes situées dans les zones de climat tempéré (tableau 11, figure 13). En certaines circonscriptions consulaires, notamment aux États-Unis et en Argentine, l'effectif de ressortissants suisses dépasse largement 10000 , et dans les deux Amériques il existe peu de circonscriptions situées au nord du tropique du Cancer ou au sud du tropique du Capricorne, où il soit inférieur à 1000 . Cette règle s'applique avec de petites restrictions ${ }^{\mathbf{1 9 5}}$ également à l'Australie et à l'Afrique. Par contre, les colonies situées entre les tropiques sont toutes assez restreintes. Rarement l'effectif des ressortissants suisses d'une circonscription y dépasse le nombre de 500 . Une situation analogue se rencontre en Asie, où partout cet effectif reste au-dessous de 500 individus. Toutefois, dans ce continent, le nombre de Suisses est peu élevé, même dans les circonscriptions du nord du tropique du Cancer, en des zones à climat tempéré.

La conclusion est que des facteurs d'ordre climatique contrarient l'émigration des Suisses vers des zones tropicales et y interdisent l'existence de colonies suisses importantes. Mais dans la zone tempérée on distingue les pays des deux Amériques, de l'Afrique et de l'Australie, ayant de grandes colonies suisses, et les pays de l'Asie, où l'élément suisse n'est pas aussi fortement représenté. L'effectif des colonies suisses d'outre-mer n'est donc pas déterminé par le seul climat; il dépend encore d'autres facteurs.

L'examen de l'intensité de l'émigration ne suffisant pas à expliquer le phénomène migratoire, il faut passer à l'étude de sa composition et envisager notamment les problèmes de la profession et de l'état civil de nos ressortissants outre-mer.

\section{B. Variations dans la composition de l'émigration suivant la desti- nation}

$1^{\circ}$ Les professions. La structure professionnelle de nos colonies transocéaniques n'est pas partout la même (Annexe 3, page 90).

Les agriculteurs occupent la première place ou une place moyenne dans l'émigration à destination des zones tempérées de l'hémisphère occidental, de même qu'en NouvelleZélande. Le taux de participation de cette catégorie est particulièrement élevé dans les circonscriptions consulaires de la prairie et de la côte pacifique canadiennes [Winnipeg 4,

195 Le nombre des ressortissants suisses n'atteint pas 500 dans la circonscription de Capetown. Cela est dû au fait que ce port a une situation économique moins favorable que l'intérieur du pays (circonscription de Johannes, burg). 
Figurc 13. Le courant d'émigration suissc des années 1924, 1928, 1932, 1936 et les colonies suisses d'outre-mer en 1939

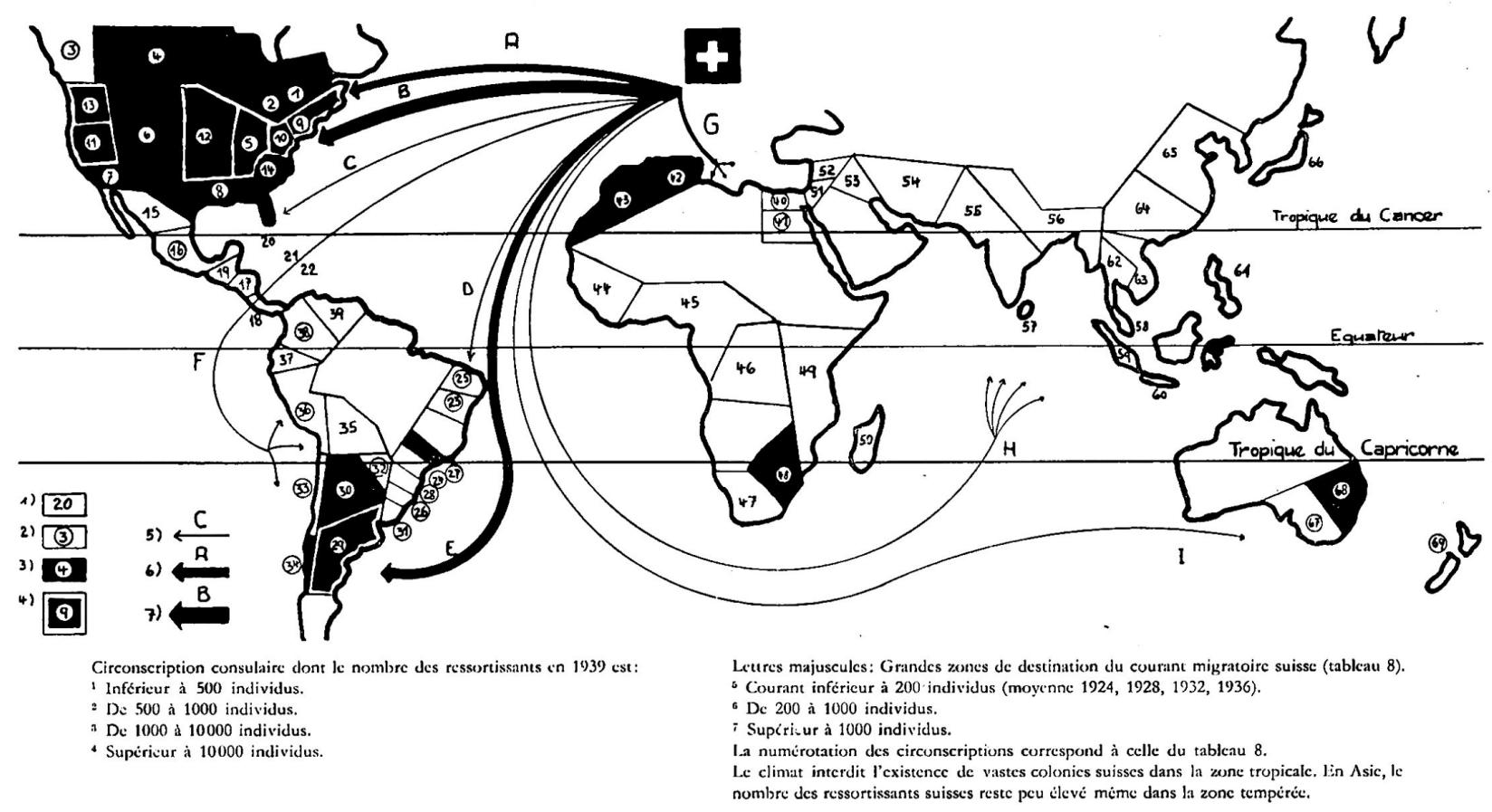


Vancouver 3] ${ }^{196}$, dans l'État brésilien de Santa-Catharina [28], au Paraguay [32] et en Nouvelle-Zélande [69] (figure 13 et annexe 3). Le climat implique donc deux genres différents d'exploitation de la terre: l'agriculture dans les zones tempérées des deux Amériques et en Nouvelle-Zélande, les plantations ${ }^{197}$ entre les deux tropiques, notamment en Amérique centrale, en Afrique occidentale [44-46] et orientale [49], à Ceylan [57], en Insulinde [58-61] et en Indochine [62-63]. Les zones tropicales de l'Amérique du Sud et les Indes britanniques [55--56] y participent en moindre mesure. En revanche, les circonscriptions de Los Angeles [7], de Beyrouth [52] et de Sydney [68], situées dans la zone tempérée, indiquent à leur tour des taux de participation relativement élevés. Il s'agit là de maraîchers. Les zones tempérées de l'Afrique et de l'Asie ne participent en forte mesure ni à l'une ni à l'autre de ces deux accivités.

Les horlogers suisses sont répartis un peu partout sur le globe terrestre, aussi bien dans les zones tempérées que dans la zone tropicale, quoiqu'en nombre peu élevé. Aux États-Unis et au Canada, ils se rencontrent surtout dans les grands ports [NewYork 9, Montréal 1], de même en Amérique centrale et en Amérique du Sud, où ils habitent de préférence les régions côtières. Ils manquent presque complètement en Afrique tropicale, mais sont plus nombreux aux Indes britanniques et en Indochine.

Les travailleurs du bâtiment sont très répandus dans les deux Amériques et en Australasie (Australie, Nouvelle-Zélande), mais ils font complètement défaut en Afrique et en Asie. Horlogers et travailleurs du bâtiment subissent donc la loi du climat dans une mesure moindre que les agriculteurs. Par contre, les travailleurs du bâtiment sont exclus de l'Afrique et de l'Asie, où se recrute une forte main-d'œuvre de couleur.

Les travailleurs de l'industrie mécanique se rencontrent également un peu partout outre-mer. Aux États-Unis et au Canada, ils sont plus nombreux sur les côtes atlantique et pacifique, où les industries sont plus développées, qu'à l'intérieur du pays.

Les techniciens se répartissent sur le globe entier, en particulier en Amérique centrale, dans les pays des Andes, dans le Moyen- et l'Extrême-Orient. Le facteur climatique n'intervient donc pas ici de façon déterminante, et la faible absorption des pays de l'Afrique et de l'Asie joue moins pour les techniciens que pour les travailleurs de l'industrie mécanique (mécaniciens, etc.).

L'émigration des commerçants, universelle aussi, n'est pas très sensible aux influences climatiques.

Les employés d'hôtel se rencontrent un peu partout, sauf évidemment dans les régions tropicales' de l'Afrique dépourvues de grandes agglomérations urbaines.

L'enseignement occupe un rang moyen ou élevé en toutes les zones climatiques des deux Amériques; en Afrique et en Asie, son importance est réduite dans la zone tropicale, dans des régions qui, en raison de leur climat défavorable, sont néfastes à la santé des enfants blancs pendant la puberté.

Les ecclésiastiques affrontent, par contre, le climat tropical; on les rencontre de préférence dans la zone tropicale (Amérique centrale, Afrique, Asie) et dans les pays à faible absorption de l'Asie, où ils vont évangéliser les populations primitives.

Les ménagères sont nombreuses particulièrement aux États-Unis et au Canada (notamment au «Middle West» et «Far West» des deux États), ainsi qu'en Afrique du Nord et en Égypte. En Amérique du Nord, il s'agit en majeure partie de sœurs et de filles d'agriculteurs qui les ont accompagnés outre-mer. Dans les pays neufs des Amériques centrale et du Sud, de l'Afrique du Sud, de l'Australie, dans la zone tropicale de

190 Les chiffres en crochets [] dans la troisième partie signifient unumérotage des circonscriptions suisses d'outre-mer ".

197. En agriculture, les immigrants eux-mêmes labourent la terre, cultivent des champs, des prés, des arbres fruitiers ou élèvent du bétail. Dans les plantations, où l'on cultive des plantes tropicales (thé, tabac, coton, caoutchouc, sisal, etc.), les grands travaux manuels sont exercés par des indigènes, et les Européens ont des charges de surveillance et d'administration. 
tous les continents et dans les pays à faible absorption de l'Asie, les ménagères font presque complètement défaut.

Le domaine des gouvernantes est un peu plus étendu, puisqu'elles partent seules et sont donc, dans le choix de leur résidence, plus indépendantes. On les trouve en particulier dans les régions côtières de l'Atlantique du Canada et des États-Unis, aux Indes occidentales, en Afrique du Nord, en Égypte et en certains pays de l'Asie. Par contre, elles sont plus rares dans presque toute la zone tropicale et dans les pays neufs de l'hémisphère austral.

$2^{\circ}$ Le sexe et 1'âge. Aussi le sexe de nos ressortissants est partiellement conditionné par les particularités du milieu physique et économique des pays d'outre-mer.

Figure 14. Sexe et âge des ressortissants suisses habitant nos colonies d'outre-mer

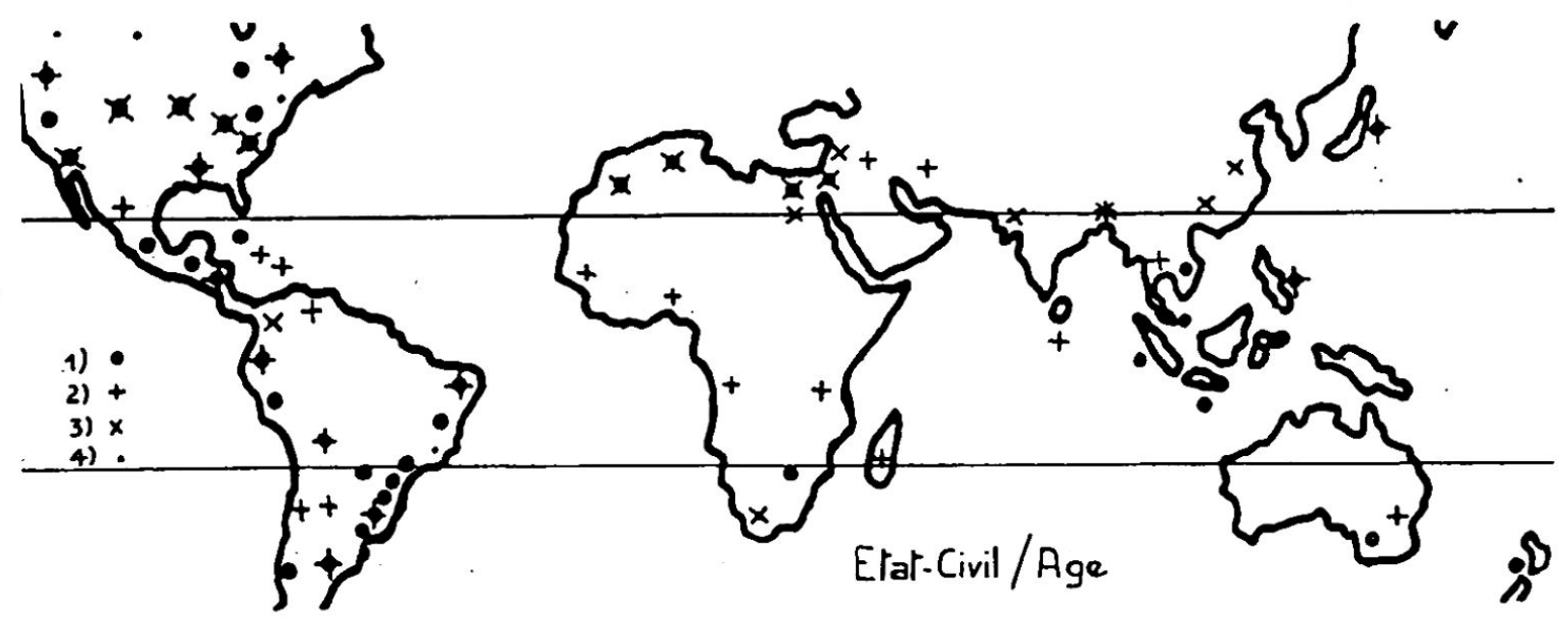

1 Enfants et adolescents, sans distinction de sexe, représcntant plus de 15,7\% (moyenne suissc) du nombre total des ressortissants suisses.

2 Hommes adultes représentant plus de $50,4 \%$.

3 Femmes adultes représentant plus de 33,9\%.

- Circonscriptions pour lesquelles nous ne possédons pas de donnécs concernant le scxe et l'àge.

Les femmes adultes, les enfants et adolescents des deux sexes, plus sensibles à un climat malsain, sc rencontrent moins fréquemment que les hommes àdultes dans les pays tropicaux dépourvus de grandes agglomérations urbaincs.

Les enfants et les adolescents des deux sexes sont relativement nombreux dans les deux Amériques, en Afrique du Nord et du Sud, dans l'Insulinde et en Indochine, au Japon et en Australie; ils le sont moins, par contre, dans les zones tropicales de l'Afrique et dans les autres pays asiatiques de faible absorption. Les adultes de sexe masculin prédominent dans presque tous les pays tropicaux; les femmes surtout aux États-Unis, en Afrique du Nord et du Sud et en certains pays asiatiques. Femmes adultes d'une part, enfants et adolescents d'autre part sont plus sensibles aux effets d'un climat défavorable et se rencontrent, par conséquent, moins fréquemment sous les tropiques que les hommes adultes (figure 14).

Il faut donc distinguer, suivant les facteurs qui favorisent le développement des différentes catégories d'émigrants classés suivant la profession ou l'état civil: la zone tempérée (pays à économie différenciée, pays neufs et pays à faible absorption), la zone tropicale.

\section{CHAPITRE VII: LES ZONES DE DESTINATION: LES PAYS TEMPÉRÉS ${ }^{198}$}

L'homme de race blanche est, on le sait, mieux préparé à vivre dans la zone tempérée que dans la zone tropicale. Il n'y est pas exposé à l'influence néfaste du climat humide et chaud ou aride, à une diminution de ses capacités physiques et psychiques lui interdisant tout travail manuel fatigant. Il y est, en outre, moins menacé par des maladies

198 Parmi les pays tempérés, on a été obligé d'indiquer certaines régions à climat déjà tropical comme l'Ile du Nord de la Nouvelle-Zélande, Sydney, Natal, etc. 
endémiques ou épidémiques (malaria, fièvre jaune, typhus, choléra, etc.). Les grandes agglomérations de la race blanche se sont donc développées de préférence dans la zone tempérée. Elles y offrent de meilleures possibilités de vie et de gain et ont attiré la majorité des émigrants suisses. Aussi les colonies de ces derniers sont-elles plus étoffées dans la zone tempérée que dans la zone tropicale.

Certains pays de la zone tempérée, notamment en Asie (Moyen-Orient, Chine, Japon), possèdent cependant peu d'immigrants européens en raison de la forte densité de leur population indigène. Le degré d'évolution économique et sociale. intervient également suivant qu'il s'agit d'États à économie différenciée et de pays neufs, de pays à grande ou à faible capacité d'absorption.

\section{A. Pays à économie différenciée et pays neufs}

$1^{\circ}$ L'Amérique. Dans cette catégorie, où il est difficile de séparer les pays neufs des autres, nous rencontrons d'abord les États-Unis.

Les États-Unis. Depuis des siècles, les États-Unis sont un pays d'immigration suisse. Dans l'entre-deux-guerres, en 1924, 1928, 1932, 1936, l'effectif annuel moyen des immigrants suisses y a été supérieur à 1000 individus, et le total des ressortissants suisses dépasse 10000 personnes dans 6 sur 10 circonscriptions consulaires (tableau 11, figure 13). Seules les circonscriptions de Washington, New-Orléans, Denver et Los Angeles n'atteignent pas ce chiffre.

Les États-Unis appartiennent, en effet, en dehors du "Sud", à la zone tempérée, mais à la zone tempérée à climat continental. La différence entre les maxima et les minima de température est plus prononcée qu'en Europe. Seule la côte atlantique, la dépression du Mississipi - jusqu'à St-Louis au nord, jusqu'au 97e méridien à l'ouest - et une étroite bande de terre le long de la côte pacifique jouissent d'un climat réellement tempéré. La vallée inférieure du Mississipi et les côtes du golfe de Mexique à l'est de son embouchure appartiennent entièrement à la zone de climat tropical. Les températures d'été y sont très élevées, et la grande humidité de l'air les rend parfois presque insupportables ${ }^{199}$. La forte chaleur, la grande humidité de l'air y ont donc contrarié l'immigration massive de travailleurs agricoles de race blanche et ont favorisé l'emploi de la main-d'œuvre noire. Voilà pourquoi le nombre de ressortissants suisses est médicore dans la circonscription de la New-Orléans (tableau 11, No 8). D'autre part, le Grand Bassin situé dans les Montagnes Rocheuses constitue en été un foyer de températures très élevées, de 30 à $40^{\circ} \mathrm{C}$., les Cordillères empêchant le passage des vents tempérés de l'ouest. Ces régions sont d'ailleurs très pauvres en pluie, et la zone de faible pluviosité s'étend également sur le versant Est des Montagnes Rocheuses, dans la région appelée "the Great Plains". La rareté des chutes de pluie a pour résultat un climat aride qui a interdit pendant longtemps la colonisation agricole et qui oblige de nos jours le paysan à appliquer un système agricole particulier, le "dry farming "200.

Aussi la densité démographique n'y est-elle pas très élevée, d'où la faiblesse de la colonie suisse de la circonscription de Denver (tableau 11, No 6). Dans la circonscription de Los Angeles (No 7), le nombre des Suisses reste limité pour une raison analogue. A l'exception d'une étroite bande le long de la côte du Pacifique, le climat y est très $\mathrm{sec}$, et les précipitations n'atteignent même pas $250 \mathrm{~mm}$. dans la vallée du Colorado. Les autres régions des États-Unis sont plus favorables à l'établissement des Suisses. La rigueur de l'hiver, plus accentuée qu'en Europe, parce que les régions septentrionales de l'Union sont exposées, en cette saison, aux courants froids venant de la baie d'Hudson, n'intervient pas de façon déterminante: les grands travaux agricoles s'effectuent, en effet, en d'autres saisons de l'année (céréales du printemps).

L'étendue des États-Unis, son relief parfois accidenté (Appalaches, Montagnes Rocheuses), l'évolution historique du pays ${ }^{201}$, ont eu pour conséquence la mise en valeur successive des États de l'Est (côtes de l'Atlantique, vieux territoire du Nord-Ouest [Ohio]), du "Middle West" (vallée du Mississipi, Prairies, Great Plains) et du "Far West" (Montagnes Rocheuses, côtes du Pacifique). Au-

19928 , page 201.

200 On cherche à emmagasiner l'humidité en empêchant l'écoulement superficiel de l'eau ainsi que l'evaporation par un labour très profond.

201 Affluence accrue, vers 1880 à 1900, d'immigrants prov. des pays du Sud et de l'Est de l'Europe. 
jourd'hui encore, le développement économique et industriel plus ou moins avancé des différentes régions est en grande partie la conséquence de cette évolution. Ainsi, les $\hat{E}$ tats du Nord-Est sont depuis longtemps fortement industrialisés, tandis que les régions du "Middle West" et du "Far West ", nommées autrefois "the wide open spaces $》$, sont toujours à prédominance agricole ${ }^{202} 203$.

Ainsi s'expliquent la prédominance des agriculteurs suisses dans les circonscriptions occidentales (St-Louis, Denver, Seattle, San-Francisco), leur infériorité numérique dans les circonscriptions de l'Est (New-York, Philadelphia, Washington, Cincinnati). En Californie et en Orégon, il s'agit surtout d'une forte immigration de Tessinois, de Schwyzois et de Bernois spécialisés dans la production laitière ${ }^{204}$.

Pour la même raison, les travailleurs de l'industrie mécanique ${ }^{205}$ atteignent des taux de participation élevés dans l'Est (New-York, Philadelphia, Cincinnati), moins élevés dans le «Middle West» (St-Louis, Denver) et dans le secteur septentrional du "Far West» (Seattle), tandis que la participation à cette branche d'activité est de nouveau plus accentuée parmi les Suisses de San-Francisco, en raison de son importance maritime.

La prédominance de l'agriculture dans les circonscriptions occidentales explique également que les ménagères ${ }^{206}$, sœurs et filles d'agriculteurs, y soient relativement nombreuses.

Les travailleurs suisses du bâtiment ${ }^{207}$ sont répandus sur le territoire entier des États-Unis, y trouvant partout un travail bien rétribué, puisque le bâtiment y est particulièrement favorisé pendant le temps de "high prosperity» de l'époque Hoover. Les commerçants ${ }^{208}$ y sont rares partout en raison des possibilités de gain réduites. Les salaires des employés de commerce sont peu élevés, un aide-comptable gagnant dans l'entre-deux-guerres $\$ 15$. - à 18.-, un secrétaire en langue anglaise de $\$ 20$. à 25.-, en plusieurs langues $\$ 30 .-$ par semaine, tandis que le coût mensuel de la vie s'élève au minimum à $\$ 80$. - pour un célibataire.

Éducation et enseignement ${ }^{209}$ occupent un rang plus élevé dans les grandes villes de l'Est, tandis que le taux des ecclésiastiques suisses est partout insignifiant, les ÉtatsUnis, pays chrétien, n'ayant pas besoin de missionnaires.

${ }_{202}$ Pour-cent des agriculteurs: Cincinnati 13,8 \%, Denver 26,5\%, Los Angeles 5,8\%, New-Orléans 25,0\%, New-York 4,6\%, Philadelphia 8,8\%, San-Francisco 49,2\%, St-Louis 37,5\%, Seattle 52,5\%, Washington 5,7\% ; dont des agriculteurs indépendants: Los Angeles 3,0\%, New-York 70,0\%, Philadelphia $81,5 \%$, St-Louis $84,5 \%$, Seattle $99,7 \%$. A Los Angeles (pour-cent très élevé de manœuvres agricoles par rapport aux effectifs d'agriculteurs: $97,0 \%$ ), la plupart des agriculteurs suisses sont des Tessinois, à Seattle (pour-cent très élevé d'agriculteurs indépendants: 99,7\%), des Bernois et des Schwyzois.

20330 , page 3.

204 Pour-cent des laitiers et des fromagers par rapport au chiffre total des Suisses: Cincinnati 7,4\%, Denver 3,0\%, Los Angeles 18,0\%, St-Louis 5,5\%.

205 Pour-cent des travailleurs de l'industrie mécanique: Cincinnati 17,1\%, Denver 5,5\%, Los Angeles $7,3 \%$, New-Orléans 10,0\%, New-York 6,1\%, Philadelphia 19,0\%, San-Francisco 8,5\%, St-Louis $5,1 \%$, Seattle 3,2\%; dont de mécaniciens et de machinistes: Los Angeles 56,8\%, New-York 89,4\%, Philadelphia 42,0\%, St-Louis 45,1\%, Seattle 40,9\%; de manœuvres industriels: Los Angeles 34,6\%, New-York 5,4\%, Philadelphia 39,7\%, St-Louis 31,4\%, Seattle 50,0\%.

${ }^{206}$ Pour-cent des ménagères: Cincinnati 5,6\%, Denver 8,0\%, Los Angeles 5,0\%, New-Orléans 7,5\%, New-York 6,3\%, San-Francisco 11,6\%, St-Louis 11,4\%, Seattle 26,8\%, Washington 12,4\%.

207 Pour-cent des travailleurs en bâtiment par rapport au nombre total des Suisses: Cincinnati $13,4 \%$, Denver 17,0\%, Los Angeles 4,2\%, New-Orléans 10\%, New-York 2,7\%, Philadelphia 10,3\%, San-Francisco $8,6 \%$, St-Louis $8,2 \%$, Seattle 3,2\%, Washington $1,9 \%$.

208 Pour-cent des commerçants: Cincinnati 11,1\%, Denver 25,5\%, Los Angeles 7,9\%, New-Orléans $15,0 \%$, New-York 16,7\%, Philadelphia 14,0\%, San-Francisco 4,6\%, St-Louis 3,5\%, Seattle $2,5 \%$, Washington $12,4 \%$.

209 Pour-cent de l'enseignement: Cincinnati 3,0\%, Denver 3,0\%, Los Angeles 1,2\%, New-Orléans 10,0\%, New-York 2,4\%, Philadelphia 5,1\%, San-Francisco 1,2 \%, St-Louis 1,1\%, Seattle 0,1\%, Washington 12,4\%. Pour-cent de l'éducation: Cincinnati 1,9\%, Los Angeles 1,1\%, New-York 8,2\%, Philadelphia 4,1\%, San-Francisco $1,7 \%$, St-Louis $0,7 \%$, Seattle $0,3 \%$, Washington $13,4 \%$. 
Le changement survenu dans le nombre absolu des émigrants à destination des États-Unis au cours des années 1924,1928, 1932, 1936 et dans le taux de participation au mouvement migratoire global, est un indice du degré de prospérité variable de ce pays. Ainsi, l'époque de 1923 à 1929 est caractérisée par une grande prospérité atteignant, vers 1928, un niveau jusqu'alors inconnu, et le nombre d'immigrants suisses qui, par l'«Emergency law» ${ }^{210}$ du 21 mai 1921, a été sensiblement réduit, se fixe en 1928 à 2401 individus ou à $51,0 \%$ du nombre global des émigrants suisses.

La crise économique qui a débuté au mois de septembre 1929 a fait tomber l'embauche dans l'industrie de $97,5 \%$ en 1929 à $64,6 \%$ en 1933 ; l'indice des salaires est descendu de $100,0 \%$ à $44,0 \%$ et le nombre des chômeurs s'est élevé à 15 millions ${ }^{211}$. Le nombre des immigrants suisses s'abaisse dès lors en 1932 à 401 ; il ne correspond plus qu'à 30,4\% du chiffre global des émigrants suisses. Malgré la remise en marche en 1933, par le président RoOsEvELT, de l'économie paralysée, le nombre des immigrants suisses diminue encore et ne comporte plus en 1936 que 377 individus, soit 18,7\% du total.

Retenons donc que l'émigration à destination des États-Unis, bien que favorisée par le caractère physique favorable de ce pays, est contrariée dans l'entre-deux-guerres et notamment dans la seconde moitié de la période, par le haut degré d'évolution et la situation économique particulière de la grande république américaine.

Le Canada. Les colonies suisses du Canada ne sont pas comparables par leurs effectifs à celles des États-Unis. Tandis que le nombre de nos ressortissants se maintient entre 1000 et 6000 dans les circonscriptions de Montréal, Toronto et Winnipeg, il n'atteint pas même 1000 individus dans la circonscription de Vancouver. Toutes ces colonies se situent d'ailleurs près de la frontière des Etats-Unis.

Le fait résulte, pour une bonne part, des conditions climatiques et orographiques particulières à ce pays. A l'exception du sud de l'Ontario et de la Colombie, le Canada est un pays de climat rigoureux, parce que soumis à l'influence de l'océan Arctique. Le pays est largement ouvert aux vents froids du nord, et les Montagnes Rocheuses interdisent l'irruption des vents humides et tempérés de l'ouest.

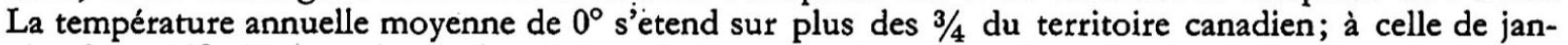
vier de $-10^{\circ}$ n'échappent que les régions de l'ouest et du sud-est. Seule la côte du Pacifique jouit d'un hiver d'une température moyenne égale ou supérieure à $0^{\circ}$. Toutefois, la rigueur de ces températures annuelles moyennes et hivernales n'est pas aussi décisive pour l'économie du pays qu'on pourrait le croire, car l'été, période de grande activité agricole, est caractérisé par des températures relativement élevées et une durée d'insolation assez prolongée. Le Quẻbec méridional, l'Ontario, et notamment les provinces de la Prairie, la partie méridionale du système fluvial du Mackenzie, ont des étés très chauds, fait qui résulte à la fois de leur latitude et de leur position continentale. En comparaison, les Rocheuses canadiennes (Colombie britannique) sont moins favorisées, malgré leurs hivers doux, leurs étés frais, mais sans gelées néfastes, à cause du relief plus accidenté et moins accessible. Il est donc compréhensible que la circonscription de Vancouver [tableau 11, No 3, Colombie britannique] indique un nombre moins élevé de Suisses que les trois autres circonscriptions canadiennes ${ }^{212}$. Le nord du pays est complètement dépourvu de colonies suisses en raison des conditions climatiques très défavorables. Dans le "Clay belt" (nord des forêts laurentiennes) le sol est assez fertile, mais les cultures sont toujours menacées par les gelées d'été. Les immigrants pourront s'y spécialiser dans l'élevage du bétail, l'industrie laitière, sans que.pourtant le potentiel d'absorption de ces contrées puisse jamais dépasser une certaine limite. Plus au nord encore, dans les "Barren Grounds", le climat est rigoureux, l'hiver dure neuf mois, le sol est en grande partie perpétuellement gelé ou saturé d'eau glacée 213 .

$\mathrm{Au}$ point de vue économique et malgré l'ancienneté de ses origines historiques, le Canada présente encore à l'issue de la première guerre mondiale les caractères classiques des pays neufs : abondance de ressources naturelles et faible densité de population. Seules les provinces de Québec et d'Ontario ont atteint undegréd'industrialisation relativement élevé.

Les autres régions canadiennes sont toujours essentiellement agricoles. La Prairie du "Middle West " canadien en particulier (Manitoba, Saskatchewan, Alberta) est devenue un grand marché de blé de printemps. Ainsi s'explique la forte densité d'agriculteurs ${ }^{214}$ parmi les ressortissants suisses de la circonscription de Winnipeg. Ils y dépassent $90 \%$ du nombre total des Suisses. Les circonscriptions de Montréal et de Toronto, par contre, en raison de leur industrialisation relativement avancée, comptent une forte proportion de travailleurs de l'industrie mécanique ${ }^{215}$, une proportion d'agriculteurs moyenne (Toronto) ou faible (Montréal).

21030 , page 327. 21130 , page $361 . \quad 212$ 28, page $366 . \quad 21328$, page 383.

214 Pour-cent des agriculteurs: Montréal 13,0\%, Toronto 36,8\%,Vancouver $92,0 \%$, Winnipeg $97,0 \%$.

215 Pour-cent des travailleurs en industrie mécanique: Montréal 8,3\%, Toronto 6,4\%. Pour-cent des techniciens: Montréal $6,0 \%$, Toronto $11,6 \%$. 
Pays neuf, le Canada est très sensible à toute oscillation de l'équilibre économique mondial. De 1920 à 1929, il jouit d'une assez grande prospérité, et le nombre d'immigrants suisses y est relativement élevé; il est en 1924 de 659, en 1928 de 571 individus, ou bien, en pour-cent du nombre global des émigrants, de 15,1, respectivement $12,0 \%$. La faible réduction de l'année 1928 est la conséquence de l'attraction accrue exercée sur les émigrants par les États-Unis. La crise économique mondiale porte un coup terrible à l'économie canadienne, car sa production ne comporte que peu d'articles très demandés sur le marché mondial (blé, fourrures, bois, produits de l'élevage du bétail). En relation avec cette situation défavorable, le nombre des immigrants suisses se réduit en 1932 à un minimum de 23 individus, soit 1,8\% de l'effectif global. En 1936, il ne s'était pas sensiblement accru, parce que l'économie canadienne, et surtout l'agriculture, traversaient à cette époque encore une période difficile.

En résumé, l'immigration suisse au Canada est limitée par l'ingratitude du climat boréal, par le caractère de pays neuf de cet État, par l'orientation unilatérale de son économie, fortement soumise aux oscillations de l'économie mondiale.

Les États de la Plata. L'Argentine, l'Uruguay et le Paraguay sont en grande partie situés dans la zone des climats tempérés, mais ceux-ci sont très variés.

La plaine argentine comprend trois grandes provinces végétales répondant à des climats distincts ${ }^{216}$ : la forêt au Nord-Est; la brousse (Monte) à l'Ouest; la prairie (Pampa) au Sud-Est. Dans la Pampa, le climat prend vers l'intérieur de plus eṇ plus un caractère continental. La hauteur des pluies diminue régulièrement du Nord-Est au Sud-Ouest: elle atteint $1200 \mathrm{~mm}$. sur le Parana inférieur, de 400 à $600 \mathrm{~mm}$. sur la bordure occidentale de la Pampa. Le climat pampéen est caractérisé avant tout par l'égalité de la distribution des pluies pendant l'année et par le défaut d'une saison sèche rigoureuse. Vers l'intérieur, le climat prend de plus en plus un caractère continental; les étés deviennent plus chauds, et les précipitations se concentrent de plus en plus sur la période chaude. Dans l'Argentine nord-occidentale, région intermédiaire entre la dépression du Rio de la Plata et les Andes, règne un climat aride accidenté. La .hauteur des pluies y est pourtant très inégale, les vallées et les bassins intérieurs étant beaucoup moins arrosés que la Puna à la frontière bolivienne.

L'Uruguay est un pays de prairies; les pluies sont réparties assez également pendant l'année. Au Paraguay, par contre, l'humidité augmente vers l'Est et contribue à expliquer l'étendue et la richesse des forêts dans le bassin du Parana.

Le Chaco forme une région à part. Le climat proprement tropical, avec sa longue saison sèche en hiver, y règne sans partage à l'Ouest et s'atténue à l'Est ${ }^{217}$.

Le climat de la steppe patagonienne est rude. Les vents violents soufflent l'année entière, et la température se réduit rapidement vers le sud, de sorte que les céréales ne mûrissent pas au sud du Chubut ${ }^{218}$.

La région la plus favorisée, au point de vue climatique, est donc la Pampa. Aussi la circonscription de Buenos-Aires appartenant entièrement à cette zone indique un nombre de ressortissants suisses élevé, plus de 10000 individus ${ }^{219}$.

La circonscription de Rosario de Santa-Fé s'étendant simultanément sur la Pampa et sur la région aride de l'Argentine nord-occidentale, le nombre de Suisses y est moins élevé; il s'établit autour de 4000 individus. Les conditions physiques sont encore moins favorables dans la circonscription d'Asunçion comprenant le Gran Chaco et une zone tropicale au nord: le nombre de nos compatriotes n'y atteint pas 1000 individus. De même la Patagonie se prête mal à l'établissement humain, et, par conséquent, les colonies suisses y font complètement défaut.

En raison de son caractère physique et surtout climatique favorable, la région du Rio de la Plata connaît depuis longtemps l'immigration suisse. On distingue dans ce mouvement migratoire quatre périodes de forte intensité autour de 1850 à 1860 , de 1870,1880 et $1910^{220}$. Toutefois, la colonisation des vastes Pampas argentines a été pendant longtemps contrariée, d'abord par le manque de communications ferroviaires, ensuite par l'instabilité économique résultant des fréquentes révolutions et "pronunciamientos" et des invasions des Indiens. Grâce aux efforts du président Avellanedo, la situation

216 14, page 403.21714 , page 411. 21814 , page 398.

219 L'Uruguay jouit des mêmes conditions climatiques favorables, mais en raison de la petite étendue de son territoire, et à cause de la trop forte attraction exercée sur les émigrants par l'Argentine voisine, le nombre de Suisses s'y maintient au-dessous de 1000 individus.

22033 , page 33. 
économique et sociale se stabilise à partir de 1875, la construction d'un réseau ferroviaire permet de mettre en valeur les terres fertiles des Pampas occidentales. L'Argentine devient un pays d'exportation de froment et de viande, mais reste économiquement dépendante des grandes puissances européennes et des États-Unis. Son économie, fondée exclusivement sur la culture du froment et l'élevage du bétail, se montre extrêmement sensible aux oscillations de la vie économique du globe.

La première guerre mondiale y apporte certaines modifications ${ }^{221}$ : les nations belligérantes ne pouvant pas satisfaire la demande en machines et en produits manufacturés, l'Argentine fait de grands efforts pour introduire chez elle de nouvelles industries. La crise économique accentue encore cette tendance. On introduit l'industrie du coton, la fabrication de conserves de viande, de ciment, de chaussures, de papier et de caoutchouc. L'Argentine est donc un pays en pleine éyolution. Ce fait s'exprime dans nos données statistiques: le taux de l'émigration suisse dans ce pays passe, entre 1928 et 1936, de 9,4\% à $31,5 \%$.

L'Argentine n'est donc plus tout à fait un pays neuf. Les arts et métiers, l'industrie et le commerce s'y sont développés, et, pour cette raison, les agriculteurs sont passés au second plan ${ }^{222}$ parmi les immigrants suisses. Leur taux reste élevé dans la seule circonscription d'Asunçion, le Paraguay n'ayant pas participé à l'évolution économique de l'Argentine 223 .

Quant aux travailleurs du bâtiment ${ }^{224}$, de l'industrie mécanique ${ }^{226}$ et les techniciens ${ }^{227}$, ils sont principalement installés dans les circonscriptions de Buenos-Aires, de Rosario et de Montevideo. Tandis que les travailleurs de l'industrie mécanique se rencontrent surtout dans la région de Rosario, les techniciens, les travailleurs du bâtiment se concentrent plutôt près des grandes agglomérations de Buenos-Aires et de Montevideo, phénomène qui s'observe du reste également pour les commerçants ${ }^{228}$.

Selon les informations du Service suisse de placement des techniciens, les techniciens trouvent des engagements comme architectes, comme ingénieurs et techniciens dans l'industrie du sucre, chimistes dans les ateliers de teinturerie, ingenieurs et techniciens de construction en béton dans les constructions civiles. Un monteur-électricien auprès d'une société d'électricité engagé en qualité de tourneur-mécanicien, est devenu chef d'une usine électrique avec dix employés sous ses ordres, des ingénieurs ont été employés comme spécialistes en moteurs Diesel dans la culture du riz à Corrientes.

Retenons donc que les pays du Rio de la Plata, et surtout l'Argentine, sont, par leurs caractères physiques, favorables à l'immigration suisse et que leur évolution économique y accroît encore les possibilités d'établissement des ressortissants suisses.

Toutefois, les avis sur les possibilités futures d'engagement sont partagés. L'Argentine a besoin de spécialistes tant pour l'industrie que pour l'artisanat, mais la marche de l'industrie dépend du résultat de la récolte, et une mauvaise récolte oblige le gouvernement à se décharger des obligations contractées envers les établissements civils. D'autre

221 1, page 136.

222 Pour-cent des agriculteurs: Buenos-Aires 31,4\%, Rosario de Santa-Fé 32,6\%, Montevideo $12,1 \%$, Asunçion 68,3\%. Pour-cent des laitiers: Buenos-Aires 2,9\%, Rosario 3,0\%.

${ }_{223}$ D'autre part, la "Ley de la Colonizacion y del Hogar" du 30 mai 1918 favorise particulièrement la colonisation par des agriculteurs étrangers ${ }^{225}$.

22533 , page 135.

224 Pour-cent des travailleurs en bâtiment: Buenos-Aires 12,1\%, Rosario de Santa-Fé 7,5\%, Montevideo 34,6\%, Asunçion 6,7 \% ; dont à Rosario 40,5\% de maçons, menuisiers, ferblantiers, 40,5\% de serruriers et d'électriciens, $19,0 \%$ de peintres, tapissiers, vitriers; à Montevideo $66,0 \%$ de maçons, menuisiers, ferblantiers, $17,0 \%$ de serruriers et d'électriciens, $17,0 \%$ de peintres, tapissiers, vitriers.

${ }^{226}$ Pour-cent des travailleurs en industrie mécanique: Buenos-Aires 2,6\%, Rosario 25,6\%, Montevideo 3,3\%, Asunçion 5,3\%; dont à Rosario 8,4\% d'industriels et de directeurs, $10,3 \%$ de contremaîtres, 26,3\% de mécaniciens et de machinistes, 55,0\% de manœuvres industriels.

227 Pour-cent des travailleurs en technique: Buenos-Aires 14,3\%, Rosario 3,7\%, Montevideo $7,2 \%$, Asunçion 0,3\%; dont à Buenos-Aires $89,4 \%$ d'ingénieurs et de techniciens, $10,6 \%$ de monteurs, de dessinateurs; à Rosario 71,4\% d'ingénieurs et de techniciens, 28,6\% de monteurs, de dessinateurs; à Montevideo 61,5\% d'ingénieurs et de techniciens, 38,5\% de monteurs, de dessinateurs.

$22 s$ Pour-cent des commerçants: Buenos-Aires 24,4\%, Rosario 20,6\%, Montevideo 28,2\%, Asunçion $11,6 \%$; dont des employés, des sténodactylos, des vendeurs, etc.: Buenos-Aires $75,1 \%$, Rosario $56,1 \%$, Montevideo $50,0 \%$. 
part, l'offre du personnel commercial étranger est supérieure à la demande, et on préfère de plus en plus des indigènes travaillant à meilleur compte. Les formalités d'entrée et d'établissement dans le pays réduisent également les possibilités d'immigration.

Le Brésil méridional. Sur la plus grande partie des régions élevées du Brésil méridional règne un climat de savane ou de steppe, bien que chaque région présente des caractères particuliers. A Sâo-Paulo [tableau 11, No 27], le climat est chaud, sec en hiver, et sur la côte se rapproche du climat tropical ${ }^{229}$. Les précipitations, considérables sur la côte, diminuent vers l'intérieur. Dans le secteur méridional [Rio-Grande-do-Sul, No 26; Santa-Catharina, No 28; Curityba, No 24], le climat est tempéré-chaud, et il connaît des saisons chaudes et froides (ces dernières toutefois assez douces) bien tranchées. La région brésilienne la plus favorable à l'immigration, au point de vue physique, est l'État de Rio-Grınde-do-Sul, mais en dépit de ces conditions, le mouvement migratoire suisse s'est depuis plus d'un siècle dirigé particulièrement vers l'État de Sâo-Paulo, donc vers la région du Brésil méridional la plus proche du tropique du Capricorne, et actuellement encore, la circonscription de Sâo-Paulo est d'une importance numérique plus élevée que les autres circonscriptions du Brésil méridional.

Voulant échapper à la situation économique difficile dont souffrent vers 1850 à 1860 de larges couches de la population, un grand nombre de ressortissants suisses se montre sensible à la propagande du gouvernement brésilien et des agents du "fazendeiro" VERGUEIRO en faveur du travail de métayage dans les plantations de café de l'État de Sâo-Paulo. Ils y remplacent les esclaves noirs dont l'achat n'est plus profitable à cause de leur prix élevé. En 1860, il existe déjà dans l'État de Sâo-Paulo 24 colonies suisses. Celles-ci toutefois, en raison des conditions de travail peu différentes d'un véritable esclavage, se dissolvent par la suite. Le milieu physique et les conditions de travail et de vie auraient été bien plus favorables dans le Brésil méridional, parce que c'est la seule région de l'Amérique du Sud, où le fond de la population soit constitué par de véritables paysans d'origine européenne, notamment par des Allemands ${ }^{230}$.

De nos jours encore, l'immigration de Suisses dans l'État de Sâo-Paulo n'est à recommander que sous certaines conditions. Là, où des Italiens, des Polonais, des Japonais s'installent, les Suisses n'arrivent pas à subsister, habitués qu'ils sont à plus de confort, à une nourriture meilleure et plus variée. La situation est plus favorable plus au sud, dans l'État de Santa-Catharina. C'est pour cette raison que le taux des agriculteurs parmi les ressortissants suisses y est élevé231. Il est réduit dans l'État de Rio-Grandedo-Sul, où la terre est occupée par le grand nombre de descendants allemands.

Pour d'autres professions, notamment les arts et métiers, la technique et l'industrie, le Brésil méridional tout entier offre d'intéressantes possibilités. La première guerre mondiale et les commandes de matières premières et de denrées alimentaires qui en résultèrent, ont provoqué une grande extension commerciale et une rapide évolution économique. Une fois la crise de 1920 à 1923 surmontée, ce pays a joui, de 1923 à 1930, d'une assez grande prospérité. La crise économique mondiale survenant alors a entraîné une forte baisse du prix des matières premières et des denrées alimentaires et provoqué le développement de certaines industries qui rendent désormais le Brésil moins dépendant du marché mondial ${ }^{232}$. L'industrie textile, les industries du papier, du caoutchouc, d'articles électriques, des verreries, des fabriques de chaussures et de couleurs se sont installées dans les régions de Sâo-Paulo et de Rio de Janeiro. Le Brésil est donc un pays en pleine évolution, ce qui s'exprime d'ailleurs dans nos données concernant l'émigration. Le taux de l'émigration suisse dans ce pays passe, entre 1928 et 1936, de 4,3\% à 7,6\% .

En accord avec cette évolution favorable, les travailleurs suisses du bâtiment ${ }^{233}$ et de l'industrie mécanique ${ }^{234}$ sont fortement représentés dans presque toutes les cir-

229 27, page $201 . \quad 2301$, page 63.

231 Pour-cent des agriculteurs: Curityba 35,2\%, Rio-Grande-do-Sul 18,1\%, Sâo-Paulo 26,1\%, Santa-Catharina $62,5 \%$.

232 1, page 173.

233 Pour-cent des travailleurs en bâtiment: Curityba 3,2\%, Rio-Grande-do-Sul 3,4\%, Sâo-Paulo $6,0 \%$, Santa-Catharina $8,1 \%$.

234 Pour-cent des travailleurs en industrie mécanique: Curityba 37,2\%, Rio-Grande-do-Sul 22,6\%, Sâo-Paulo 12,4\%, Santa-Catharina 12,5\%; dont des mécaniciens et des machinistes: Curityba 10,4\%, Rio-Grande-do-Sul 72,5\%, Sâo-Paulo 63,8\%, Santa-Catharina 42,8\% ; pour-cent des manœuvres industriels: Curityba 72,4\%, Rio-Grande-do-Sul 17,5\%, Sâo-Paulo 25,2\%, Santa-Catharina 35,7\%; pourcent des techniciens: Curityba 3,8 \%, Rio-Grande-do-Sul 5,7\%, Sâo-Paulo 9,8\%, Santa-Catharina 0,9\%. 
conscriptions du Brésil méridiónal. Si les commerçants ${ }^{235}$ le sont moins, cela tient au fait que d'une part un tiers seulement des employés de commerce peuvent être étrangers, et que d'autre part les immigrants de cette profession sont concurrencés par les membres de la colonie germano-brésilienne qui parlent couramment le portugais.

Les conditions physiques sont donc peu favorables à l'immigration suisse dans le secteur nord du Brésil méridional, plus favorables dans son secteur sud. L'évolution économique actuelle favorise particulièrement l'immigration d'hommes des métiers, de l'industrie et de la technique.

\section{Le Chili.}

Le Chili, étroite bande de terre sur le versant occidental des Andes, du cap Horn au Pérou, s'étend de la zone de climat tropical, au nord, jusque dans la zone de climat subboréal, au sud. Il ne pleut jamais dans le nord, où règne le désert d'Atacama; dans le centre, les rosées, les brouillards et les torrents des montagnes entretiennent une humidité suffisante, le sud est inondé de pluies ${ }^{236}$.

Le Chili central est donc la contrée la plus favorable à l'établissement des hommes de race blanche, et, en effet, les deux centres de colonies suisses du Chili [tableau 11, Santiago 33, Valdivia 34] se situent dans cette zone de climat tempéré. Toutefois, le nombre de Suisses habitant la circonscription de Valdivia, est un peu plus élevé que celui des Suisses résidant dans la circonscription de Santiago; il est de 1000 individus au lieu de 900. La cause de cette différence numérique réside en partie dans l'évolution économique antérieure du district de Santiago. Cette région est colonisée par les Espagnols depuis 1540, et les terres y restent aux mains d'une aristocratie réduite de grands propriétaires. Les alentours de Valdivia, par contre, appartiennent jusqu'en 1850 aux indiens Araucans, puis ils sont colonisés par des immigrants allemands et suisses ${ }^{237}$, qui, n'étant pas gênés par le système de grandes propriétés, peuvent se développer plus librement ${ }^{238}$.

Bien que le mouvement colonisateur d'immigration suisse y ait été brusquement interrompu par l'épidémie de choléra de l'année 1887 et que l'immigration ultérieure n'ait plus qu'un caractère commercial et artisanal, les agriculteurs ${ }^{239}$ suisses de la circonscription de Valdivia occupent encore en 1939 une situation moyenne. Le taux des travailleurs de l'industrie mécanique ${ }^{240}$ et des commerçants ${ }^{2+1}$ acquiert une plus grande intensité dans la circonscription de Santiago.

Répétons donc que le Chili central, par son caractère physique, n'est pas hostile à l'établissement de Suisses, et son économie a, dans l'entre-guerres, considérablement évolué. Ainsi s'explique l'accroissement du taux de participation du Chili au mouvement migratoire suisse global, de $0,6 \%$ en 1928 à $1,2 \%$ en 1936 .

\section{$2^{\circ}$ L'Afrique}

L'Afrique du Nord. L'Égypte, la Tunisie, l'Algérie et le Maroc sont compris dans la zone des climats méditerranéens et subtropicaux. L'Égypte serait un désert, comme d'ailleurs les territoires qui l'entourent (Libye, Nubie, etc.), si elle n'était arrosée et fécondée par le Nil qui la transforme en oasis.

Les précipitations n'atteignent pas $250 \mathrm{~mm}$. par an dans le delta, et les terres fertiles n'ont que peu d'étendue. La bande cultivable n'atteint, dans la vallée, que 20 à $30 \mathrm{~km}$. de largeur, dans le delta, par contre, elle dépasse $150 \mathrm{~km}$.

235 Pour-cent des commerçants: Curityba 3,2\%, Rio-Grande-do-Sul 19,8\%, Sâo-Paulo 23,0\%, Santa-Catharina $12,5 \%$.

236 27, page 73.

237 Colonies suisses dans les provinces de Malleco et de Cautin.

238 27, page 76.

239 Pour-cent des agriculteurs: Valdivia $51,2 \%$, Santiago $11,1 \%$; pour-cent des laitiers et fromagers: Valdivia $3,5 \%$.

240 Pour-cent des travailleurs de l'industrie mécanique: Santiago 9,9\%; four-cent des techniciens: Valdivia $4,8 \%$, Santiago $4,9 \%$.

241 Pour-cent des commerçants: Valdivia $9,9 \%$, Santiago $24,6 \%$. 
L'Afrique du Nord française et espagnole, de caractère montagneux (Atlas Tellien et Saharien), est gratifiée de plus fortes précipitations, 250 à $500 \mathrm{~mm}$. à l'intérieur et bien davantage en certains endroits de la côte (jusqu'à $1500 \mathrm{~mm}$. sur la côte algérienne). La température se maintient en janvier entre $10^{\circ}$ et $20^{\circ}$ en Egypte et sur la côte de l'Afrique septentrionale française et espagnole; elle n'atteint que $0^{\circ}$ à $10^{\circ}$ à l'intérieur, sur le haut-plateau des Chotts. En été, elle est de $25^{\circ}$ à $30^{\circ}$ dans le delta du Nil en Égypte, sur la côte de la Méditerranée et de l'océan Atlantique en Afrique septentrionale. Elle dépasse $30^{\circ}$ dans la vallée du Nil et à l'intérieur du Maroc et de l'Algérie.

Pour qui supporte la chaleur, un séjour prolongé en Égypte n'est pas nuisible à la santé. La chaleur y est en général sèche, les maladies tropicales des régions humides ne s'y développent pas. Toutefois, les Européens ne peuvent pas y exercer un travail manuel intensif. Un autre facteur, d'ordre démographique, vient également interdire une immigration européenne colonisatrice: en Égypte, une grande partie du territoire n'est qu'un désert, toute la population se concentre dans la seule vallée du Nil et dans le delta, d'où une densité élevée.

Le climat de l'Afrique septentrionale française et espagnole n'oppose pas à l'adaptation des Européens de sérieux obstacles. D'autre part, certaines régions, comme la plaine de la Mitidja, se prêtent bien à la culture. Toutefois, sur la côte les Européens y sont, comme les indigènes eux-mêmes, éprouvés par le paludisme, et la chaleur accompagnée d'un état hygrométrique très élevé y produit parfois chez eux un commencement d'anémie tropicale.

Un problème bien plus grave pour la colonisation européenne est le fort accroissement des populations indigènes. C'est pourquoi le peuplement européen est particulièrement intense sur la côte, notamment dans les villes, où la population indigène s'accroît en moindre mesure. Certaines régions de l'intérieur, insuffisamment ou irrégulièrement arrosées, se montrent peu favorables à la colonisation agricole du fait d'un régime de pluies déficient; elles s'opposent particulièrement à l'immigration d'agriculteurs suisses provenant en majorité de régions de prairies (voir deuxième partie), et qui ne sont pas adaptés au système de "dry farming" pratiqué sur les hautsplateaux, ni aux cultures arbustives (olivier et vigne) caractéristiques de la côte $\mathbf{2 4 2}^{\mathbf{2 4}}$. Ainsi s'explique le faible pourcentage de nos agriculteurs dans ces circonscriptions ${ }^{\mathbf{2 4 3}}$.

Le nombre total des ressortissants suisses est assez élevé dans toutes ces colonies (il atteint près de 800 personnes au Caire et à Alexandrie, près de 2000 à Casablanca et plưs de 3000 à Alger) en raison des relations économiques multiples qui lient notre pays à ces régions d'outre-mer ${ }^{244}$. Ainsi, les travailleurs de l'industrie mécanique ${ }^{245}$ et les techniciens ${ }^{246}$ sont répandus sur toute l'Afrique du Nord; les commerçants ${ }^{247}$ acquièrent une importance particulière à Alexandrie, les employés d'hôtel ${ }^{248}$ au Caire; les travailleurs du bâtiment ${ }^{249}$, surtout à Alger et les gouvernantes ${ }^{250}$, engagées par les

242 Les immigrants suisses en Afrique septentrionale française et espagnole proviennent surtout des cantons de Fribourg, Genève, Neuchâtel, Vaud, Zurich, donc (à l'exception du dernier canton) de régions qui, par leur système agricole (production de céréales ou viticulture) ont plus de ressemblance avec l'Afrique du Nord que le reste de la Suisse pratiquant la culture des prés. La faible intensité d'émigration et le modeste pourcentage d'émigrants-agriculteurs ne leur permettent de fournir qu'un petit nombre de colons.

${ }^{243}$ Pour-cent des agriculteurs: Alexandrie 0,3\%, Alger 9,3\%, Casablanca 10,7\%.

244 En Égypte: Importation et installation de machines électriques et mécaniques, exportation de coton. En Afrique septentrionale française: Exportation de fruits, de légumes, de vin, etc.

${ }^{245}$ Pour-cent des travailleurs de l'industrie mécanique: Le Caire 12,3\%, Alexandrie 1,0\%, Alger $10,5 \%$, Casablanca $17,2 \%$.

${ }^{248}$ Pour-cent des techniciens: Alexandrie 18,1\%, Le Caire 15,5\%, Alger 8,4\%, Casablanca 10,5\%.

247 Pour-cent des commerçants: Alexandrie 46,1 \%, Le Caire 17,0 \%, Alger 19,5\%, Casablanca 28,5\%.

248 Pour-cent des employés d'hôtel: Alexandrie 0,7 \%, Le Caire 23,3\%, Alger 4,7\%, Casablanca 7,2\%.

249 Pour-cent des travailleurs en bâtiment: Alexandrie 0,7\%, Le Caire 1,5\%, Alger 10,5\%, Casablanca $4,5 \%$.

250 Pour-cent des gouvernantes: Alexandrie 10,8\%, Alger 4,0\%, Casablanca 5,8\%. 
familles de fonctionnaires ou de commerçants européens habitant ces contrées, à Alexandrie en particulier.

Il faut donc relever que les conditions climatiques de l'Afrique du Nord contrarient l'immigration colonisatrice massive, mais qu'elles ne sont pas hostiles à l'établissement d'Européens n'exerçant pas de méi ier manuel fatiguant, et que les rrultiples relations économiques entre la Suisse et ces pays sont favorables à l'immigration de travailleurs non manuels.

L'Afrique du Sud. L'Afrique du Sud, un vaste haut-plateau d'une altitude moyenne de $12 \mathrm{CO}$ à $1700 \mathrm{~m}$., à l'extrémité méridionale de l'Afrique, comporte une grande profortion de steffes et de déserts. Tout le centre et le sud-ouest sont donc impropres à la culture sans une irrigation difficile ou un dry farming coûteux, impropres à l'élevage sans nomadisme ou semi-nomadisme. Toutcfois, trois zcnes de l'A frique du Sud permettent une pratique agricole beaucoup plus rémunératrice. La zone des flissements du Cap peut fournir tous les produits méditerranéens: céréales, fruits et vins, moutons à laine et à viande. La zone du Veld offre à la fois la culture de mais dans les territoires les plus arrosés et l'élevage du bétail bovin ou du mouton. Enfin, du Sud-Est au Nord-Ouest, de Durban à Lobito-Bay, un vaste cirque de plaines et de plateaux à climat subtropical ou tropical produit la canne à sucre, les fruits tropicaux, le café, le thé, le tabac, le coton et le sisal251.

Certaines parties·de l'Afrique du Sud, telle la région du Cap et le Veld, sont favorables à l'immigration colonisatrice européenne. D'autres régions, par contre, se prêtent moins à ce genre d'immigration. Le climat de steppe ou de désert du centre et du nord-ouest demande des Blancs un tel effort, tant physique que psychique, d'adaptation à des conditions toutes différentes de celles d'Europe que l'émigration colonisatrice vers ces contrées ne peut pas être recommandée.

Le taux des agriculteurs suisses y est très peu élevé, ceux-ci ne s'habituant que difficilement, on l'a vu à propos de l'Afrique du Nord, au système agricole du «dry farming ${ }^{252}$.

Les colonies suisses sont autrement développées dans la circonscription de Johannesburg, à cause de l'évolution économique de cette région. Aujourd'hui encore, l'Afrique du Sud est un pays neuf. Elle doit compter avant tout sur ses mines, quoique ses ressources en minerais utiles soient restreintes, et sur son agriculture, plus que sur ses industries. Sa population de faible densité, sa pauvreté en capitaux l'empêchent d'être une grande puissance industrielle, cependant certaines industries trouvent leurs matières premières dans l'agriculture et l'élevage, ou encore dans les mines (industries du sucre, des céréales, industrie laitière, conserves de viande, de fruits et de légumes, raffineries d'huile comestible, biscuiterie); d'autre part, les industries textiles (dégraissage et filage de la laine) et celles du cuir (tannage, cordonnerie, etc.) se sont développées. Parmi les industries qui dépendent des mines, on trouve celle de la houille et de ses dérivés (coke, goudrons, benzol, sulfate d'ammoniaque, colorants), de l'amiante, du fer, du cuivre et de l'étain ${ }^{253}$. Ces activités multiples expliquent la proportion élevée des travailleurs de l'industrie mécanique ${ }^{254}$ parmi les Suisses des deux circonscriptions sud-africaines. Cependant, la structure économique particulière de l'industrie sudafricaine pose le problème du "poor white», du prolétariat européen auquel les travailleurs de couleur font une concurrence acharnée.

Les commerçants suisses 255 et les représentants des carrières libérales 256 sont bien moins représentés en Afrique australe, les employés de commerce n'étant jamais très

261 11, page 313.

252 Pour-cent des agriculteurs: Capetown 4,5\%, Johannesburg 4,8\%.

25311 , page 322.

254 Il s'agit surtout de mécaniciens expérimentés qui sont préférés aux ingénieurs sans grandes connaissances pratiques.

Pour-cent des travailleurs de l'industrie mécanique: Capetown 7,4\%, Johannesburg 20,2\%; dont des contremaîtres: Capetown 15,4\%, Johannesburg 1,9\%; des mécaniciens et des machinistes: Capetown $38,4 \%$, Johannesburg 5,9\%; des manœuvres industriels: Capetown $46,2 \%$, Johannesburg $92,2 \%$; des techniciens: Capetown 5,7\%, Johannesburg 4,1\%.

255 Pour-cent des commerçants: Capetown $11,4 \%$, Johannesburg 10,8\%.

${ }^{256}$ Pour-cent de l'enseignement: Capetown 2,3\%, Johannesburg 2,0\%. 
recherchés dans ce pays. D'autre part, il est difficile d'y faire d'appréciables économies $^{257}$. En outre, la demande de travailleurs commerciaux et intellectuels peut être satisfaite par les Sud-Africains eux-mêmes, et enfin la forte immigration de Juifs depuis 1933 provoque un encombrement des professions commerciales, médicales ainsi que du barreau. Un vaste champs d'activité s'ouvre, par contre, aux carrières ecclésiastiques: missionnaires et religieuses occupent dans les circonscriptions une place particulière ${ }^{258}$.

Si le milieu physique de l'Afrique du Sud n'est pas favorable à l'immigration d'agriculteurs suisses, il n'est pas hostile à l'établissement d'individus appartenant à d'autres catégories professionnelles. La structure économique y favorise l'entrée de travailleurs industriels et de techniciens, contrarie celle des commerçants et de cert aines carrières libérales.

\section{$3^{\circ}$ L'Australie et la Nouvelle-Zélande.}

L'Australie est située pour deux cinquièmes dans la zonc tropicale; les trois autres sont des régions subtropicales ou tempérées. Les vastes dimensions du pays et la présence d'une chaîne bordière à l'Est qui supprime les influences océaniques développent à l'intérieur un climat de type continental et extrême dont l'influence modifie jusque sur les côtes les effets de la latitude ${ }^{259}$.

Bien que situé pour une bonne partie sous la même latitude que l'Australie, la Nouvelle-Zélande, constituée de trois îles dont la superficie est moindre que celle de l'Italie, allongée, morcelée de massifs alpestres de plus de $3000 \mathrm{~m}$., de glaciers et de volcans, possède un climat sensiblement différent ${ }^{260}$. Tandis qu'en Australie il tend aux extrèmes, en Nouvelle-Zélande il est égalisé par l'Océan, et caractérisé l'été par des chaleurs tempérées. En Australie, l'ourlet montagneux de l'est condense l'humidité des nuages qui viennent en hiver du Pacifique. L'intérieur de relief plus uniforme et la côte occidentale, soumise à un régime de vents desséchants, reçoivent très peu d'eau et sont caractérisés par un climat aride, des déserts, des steppes broussailleuses, des bois maigres, des eucalyptus et des acacias. La NouvelleZélande, que les vents d'ouest enveloppent d'humidité, constitue, avec la Tasmanie, Victoria et la région còtière de New-South-W'ales, à l'extrémité sud-orientale de l'Australie, le domaine du climat austral, climat océanique dans l'ensemble, aux pluies en général abondantes et fréquentes, aux hivers doux et aux étés relativement frais pour la latitude, malgré des journées parfois lumineuses et brûlantes.

Les régions les plus favorables à l'immigration suisse sont donc la Nouvelle-Zélande, le district de Victoria, la zone côtière du district de New-South-Wales. En effet, le nombre de Suisses s'élève à 1000 individus dans la circonscription de Sydney [tableau 11, No 68: New-South-Wales], à près de 850 dans celle de Melbourne [67: Victoria], à près de 650 dans celle de Wellington [69: Nouvelle-Zélande]. Le reste du continent australien est complètement dépourvu de colonies suisses.

Les conditions physiques ne sont paș seules à gêner la colonisation suisse en Australie. Le problème de la distance s'y ajoute. Vues de l'Europe, l'Australie et la NouvelleZélande se trouvent à l'autre bout du monde. Ces deux pays n'ont donc jamais joué un grand rôle dans l'émigration suisse, sauf durant la période du grand "rush", après la découverte de l'or à l'intérieur du continent australien; alors l'attraction de l'Australie s'est fait sentir aussi chez nous, particulièrement dans le Tessin.

Le caractère physique des régions envisagées réagit sur la composition professionnelle des différentes colonies suisses. Tandis que le pourcentage des agriculteurs ${ }^{261}$ est très élevé parmi les Suisses habitant la Nouvelle-Zélande [Wellington: tableau 11, No 69] qui jouit de conditions climatiques favorables, il reste insignifiant dans les circonscriptions de Melbourne et de Sydney consacrées à l'élevage nomade. Les travailleurs suisses du bâtiment ${ }^{262}$ et de l'industrie ${ }^{263}$ occupent, par contre, une place relativement

${ }^{257}$ Un jeune homme ne connaissant pas bien l'anglais, peut gagner $£ 15 /-$ sud-africaines, et il doit en décompter $£ 10 /-$ pour le logement et la nourriture.

258 Pour-cent des ecclésiastiques: Capetown 13,1\%, Johannesburg 12,4\%.

250 9, page 78.2809 , page 69.

281 Pour-cent des agriculteurs: Melbourne 21,9\%, Sydney 19,8\%, Wellington 69,0\%.

${ }^{262}$ Pour-cent des travailleurs en bâtiment: Melbourne 4,3\%, Sydney 10,7\%, Wellington 20,8\%.

${ }^{283}$ Pour-cent des travailleurs en industrie mécanique: Melbourne $17,4 \%$, Sydney $13,9 \%$, Wellington 1,3\%; dont des mécaniciens et des machinistes: Melbourne $68,8 \%$, Sydney $89,2 \%$; des manœuvres industriels: Melbourne 31,2\%, Sydney 3,6\%; des techniciens: Melbourne 4,0\%, Sydney 5,7\%, Wellington 1,3\%; des commerçants: Melbourne $12,7 \%$, Sydney $18,3 \%$, Wellington $2,6 \%$. 
en vue, car les centres de Sydney et de Melbourne sont fortement industrialisés. Toutefois, même dans ces professions, les conditions de travail et de vie ne suffisent pas, pendant l'entre-deux-guerres, à encourager une forte immigration suisse. Les artisans, techniciens et spécialistes touchent un salaire de $£ 15 /-$ et doivent compter $£ 13 /-$ pour chambre et pension. D'autre part, par suite de la pression politique exercée par les syndicats ouvriers, le gouvernement australien a limité l'immigration. Pour pouvoir travailler dans l'industrie, il faut posséder l'indigénat australien qui s'acquiert après deux ans de séjour continu en Australie, pendant lesquels l'immigrant, pour gagner sa vie, est obligé de se faire enrôler dans l'agriculture comme gardien d'immenses troupeaux de moutons, sous le soleil impitoyable.

Ainsi s'explique que le taux de participation de l'Australie au mouvement migratoire suisse global ait diminué de 1924 à 1936, et que, par rapport à sa grandeur, ce continent ne soit pas habité par un plus grand nombre de Suisses.

\section{B. Pays à faible capacité d'absorption}

Moyen-Orient ${ }^{264}$. Le Moyen-Orient fait partie de l'Asie occidentale qui, d'une manière générale, présente un caractère désertique, à l'exception du nord-ouest, où le voisinage de la Méditerranée atténue un peu l'aridité du climat. Les étés y sont secs et chauds, les hivers humides et parfois rigoureux. Les inégalités de relief ne font que souligner ces contrastes, rendant plus extrêmes les températures, augmentant ou diminuant l'intensité des précipitations et déterminant leur forme, pluie ou neige ${ }^{265}$. Le haut-plateau de l'Iran, d'une altitude moyenne de 1000 à $1500 \mathrm{~m}$., n'est guère à l'intérieur qu'un ensemble de dépressions désertiques.

Toutes ces régions ne sont donc pas très favorables à l'immigration européenne. L'alternance des grandes chaleurs d'été associées à une sécheresse extrème, des hivers humides et parfois rigoureux rendent le climat difficilement supportable. En tout cas, les chaleurs d'été interdisent à l'Européen tout travail manuel pénible. Enfin, une grande partie du Moyen-Orient est vouée aux steppes ou aux déserts, et ces pays suffisent à peine à nourrir la population indigène.

Pour ces raisons, le nombre des ressortissants suisses en 1939 ne dépasse 230 en aucune des quatre circonscriptions de Jaffa, Beyrouth, Bagdad et Téhéran; il est de. 230 dans la circonscription de Jaffa, de 192 dans celle de Beyrouth en raison des conditions climatiques un peu plus favorables de la côte méditerranéenne, mais tombe à 27 dans la circonscrip:ion de Bagdad souffrant d'une chaleur d'été et d'une sécheresse extrêmes. Les mêtmes raisons excluent toute immigration agricole au Moyen-Orient, et dans la circonscription de Jaffa seulement, on trouve un pourcentage assez élevé de Suisses travaillant dans des plantations ${ }^{266}$. Il s'agit là de cultures de fruits subtropicaux, de la vigne, etc., non de véritables plantations.

Outre les conditions climatiques défavorables, des facteurs d'ordre économique contrarient une immigration de plus grande envergure. Les pays du Moyen-Orient manquent d'un marché capable d'absorber les produits suisses, car les indigènes ont un niveau d'existence très modeste. D'autre part, les autochtones travaillent à meilleur compte et connaissent plusieurs langues, les coutumes et les habitudes de la clientèle. Le coût de la vie est très élevé par rapport aux salaires: un employé de commerce parlant le français, le turc et l'arabe, gagne en 1939 dans l'Irak $£ 5 /-$ à $10 /-$ par mois et doit en compter $£ 5 /-$ au moins pour le gite et la nourriture. Les conditions d'existence sont plus favorables dans l'Iran, où un ingénieur européen touche en 1939 au service du gouvernement iranien une somme de fr. s. 600.- à 1200.-, auprès de particuliers une somme de fr. s. 550. - à 800. -, tandis que le coût de la vie (nourriture, logement, vêtements, linge) est de fr. 350.- à 400.- pour un ingénieur, de fr. 280.- à 350.- pour un technicien. Ainsi s'explique en partie le nombre plus élevé des ressortissants suisses dans la circonscription de Téhéran que dans celle de Bagdad.

Parmi nos compatriotes habitant le Moyen-Orient, les professions industrielles ${ }^{\mathbf{2 6 7}}$ (ingénieurs, techniciens, mécaniciens) occupent d'ailleurs plus de place que les commer-

${ }^{264}$ Palestine, Liban, Syrie, Irak, Iran. Des données statistiques concernant la Turquie asiatique et l'A rabie, nous font défaut.

285 7, page 1.

${ }^{206}$ Pour-cent des agriculteurs: Jaffa $15,6 \%$; des planteurs: Beyrouth $1,8 \%$.

282 Pour-cent des travailleurs de l'industrie mécanique: Beyrouth 5,4\%; des techniciens: Jaffa $10,4 \%$, Beyrouth 7,2\%, Bagdad 31,9\%, Téhéran $53,7 \%$. 
çants ${ }^{268}$, car ils trouvent facilement à s'engager dans les sociétés pétrolières ou dans les entreprises de construction de routes et de chemins de fer. Un champs d'activité assez étendu s'ouvre également à l'éducation ${ }^{269}$ (gouvernantes engagées par des fonctionnaires des sociétés pétrolières) et aux carrières ecclésiastiques ${ }^{270}$ (la mission).

Il faut donc retenir que les conditions climatiques du. Moyen-Orient ne sont pas favorables à une immigration massive. La densité démographique de la population autochtone, élevée par rapport à la surface cultivable restreinte, et l'attitude politique de ces peuples contrarie également l'établissement de nos compatriotes. Finalement, les salaires peu élevés et la concurrence des indigènes constituent un fort embarras et font que les pays du Moyen-Orient sont pour nous des zones de faible absorption. En raison de leurs conditions climatiques et économiques défavorables, ces contrées, par opposition à d'autres pays de la zone tempérée, indiquent d'ailleurs une faible proportion de femmes et d'enfants par rapport aux hommes adultes.

Extrême-Orient. Le climat de la Chine méridionale est plutôt maritime; celui de la Chine septentrionale est continental. Les côtes de Chine ont cependant des températures moyennes inférieures à celles des côtes d'Europe et d'Amérique de même latitude. La Chine méridionale (région de Canton, par exemple) est en partie située sous les tropiques, tandis que le climat de la Chine septentrionale est même boréal près de la côte.

Malgré certaines particularités inconnues en Europe (par exemple le régime des moussons) les conditions climatiques d'une grande partie de la Chine ne peuvent pas contrarier sérieusement l'immigration européenne, même colonisatrice. La même constatation peut être faite pour le Japon.

L'immigration en Chine et au Japon est limitée par des facteurs démographiques. La forte densité des populations chinoises et japonaises interdit toute infiltration étrangère, et le nombre de nos compatri stes habitant les circonscriptions de Canton [64], de Shanghaï [65], de Tokio [66] est peu élevé. Les agriculteurs et les artisans suisses y font complètement défaut: ils ne pourraient pas soutenir la concurrence indigène. Les travailleurs de l'industrie mécanique ${ }^{271}$ ne sont représentés que dans la circonscription de Tokio. Par contre, les commerçants ${ }^{272}$ y sont relativement nombreux. Il est certain que la politique de «la porte ouverte» pratiquée par les puissances étrangères, a permis à un certain nombre de commerçants de travailler en Chine. Mais la renaissance du nationalisme chinois, la guerre sino-japonaise et la situation économique troublée qui en résulta ont interdit un développement plus considérable de nos relations économiques avec ce pays, et elles y ont maintenu à un taux réduit le nombre absolu de nos co patriotes. Aussi parmi les Suisses du Japon, le pourcentage des commerçants est relativement élevé, mais les Japonais s'emparent, dans l'entre-deux-guerres, d'une grande partie du commerce et les maisons de commerce étrangères ont du mal à soutenir leur activité. Les possibilités d'y placer des commerçants suisses sont donc restreintes; les postes subordonnés sont occupés par des Japonais, des métis nipponseuropéens et des Russes blancs.

La médiocrité des établissements suisses dans ces pays d'Extrême-Orient n'est donc pas la conséquence de conditions physiques défavorables, mais de la trop forte densité démographique des peuples indigènes, de la concurrence que font ces derniers aux Européens et de la situation économique instable. Seuls les ecclésiastiques y trouvent un vaste champ d'activité et s'emploient à adoucir la misère des couches sociales inférieures. Le pourcentage des missionnaires est, par conséquent, très élevé: plus de

268 Pour-cent des commerçants: Jaffa 17,4\%, Beyrouth 9,0\%, Bagdad 18,2\%, Téhéran 7,3\%.

269 Pour-cent de l'éducation: Beyrouth 6,3\%, Bagdad 22,8\%, Téhéran 4,9\%.

270 Pour-cent des ecclésiastiques: Jaffa 13,0\%, Beyrouth 19,7\%.

271 Pour-cent des travailleurs de l'industrie mécanique: Tokio 12,1\%; des techniciens: Canton $2,9 \%$, Shanghaï 4,0\%, Tokio 4,6\%.

272 Pour-cent des commerçants: Canton 14,0\%, Shanghai 35,5\%, Tokio 47,0\% . 
43,0\% dans la circonscription de Shanghaï, 80,0\% dans celle de Canton. Bon nombre d'entre eux sont des religieuses, ce qui explique le taux de participation élevé des femmes adultes dans ces deux colonies.

\section{CHAPITRE VIII: LES ZONES DE DESTINATION: LES PAYS TROPICAUX}

Le climat tropical n'est pas salubre pour les hommes de race blanche. Les Blancs y sont sujets à certaines maladies résultant des influences physiques du milieu: troubles des secrétions internes, maladies nerveuses, intestinales, cutanées; maladies épidémiques et endémiques, malaria, fièvre jaune, typhus, dysenterie, tuberculose, maladies pulmonaires, vénériennes. Les Blancs y sont souvent sans énergie, sans goût au travail, tant physique qu'intellectuel, et de tempérament colérique. Ce sont souvent de très médiocres employés ou des chefs incapables et peu aimés. Les nouveaux-arrivés sont très facilement sujets aux maladies endémiques, jusqu'à ce que leur organisme se soit adapté et aguerri ${ }^{273}$. La nostalgie, l'isolement au milieu d'une population de mours différentes, la déception due à des échecs économiques les poussent à l'abus de l'alcool, aux excès sexuels. Pour qu'un Blanc puisse s'adapter, il ne doit pas être trop âgé. Le climat est surtout nuisible aux femmes, de constitution plus délicate que les hommes; elles succombent plus facilement et deviennent infécondes. D'autre part, il est peu recommandé de garder dans ces pays les enfants au-dessus de 12 à 13 ans, si l'on ne veut pas risquer que leur santé ne subisse de graves atteintes pendant la période de la puberté. Enfin, tout travail manuel un peu dur y est impossible aux hommes de race blanche.

Ces facteurs contribuent à rendre difficile la vie des Européens dans les pays tropicaux $\epsilon t$ à maintenir à un niveau bas le nombre des Suisses habitant ces contrées.

\section{A. L'Amérique}

L'Amérique centrale. Le Mexique, l'Amérique centrale proprement dite (Guatemala, Honduras, Salvador, Nicaragua, Panama), les Indes occidentales (Cuba, Haïti, etc.) appartiennent à la zone tropicale. Mais tandis qủe l'Amérique centrale et les Indes occidentales sont caractérisées par un climat tropical à faibles oscillations annuelles de la pression atmosphérique et de la température ${ }^{274}$, par une grande chaleur humide favorisant l'éclosion de maladies endémiques et épidémiques, on distingue au Mexique, d'après l'altitude, trois zones différentes: la tierra calida, de 0 à $1000 \mathrm{~m}$., avec $25^{\circ}$ à $30^{\circ}$ de température annuelle moyenne; la tierra templada, de 1000 à $2000 \mathrm{~m}$., avec $20^{\circ}$ à $25^{\circ}$; la tierra fria, de plus de $2000 \mathrm{~m}$. d'altitude, avec des températures inférieures. Sur le haut plateau du Mexique, les isothermes de janvier sont de $10^{\circ}$ à $20^{\circ}$, celles de juillet vont jusqu'à $35^{\circ}$, car les vents tempérés de la mer ne peuvent passer les chaînes extérieures des Cordillères. Pourtant, le climat plus sec y est plus favorable à l'établissement des Européens. Aussi la circonscription suisse de MexicoCity [tableau 11, No 16] atteint-elle en 1939 un chiffre de 680 personnes, tandis que le nombre de nos compatriotes se maintient au-dessous de 150 dans toutes les autres circonscriptions envisagées ${ }^{275}$.

Des facteurs économiques viennent également contrarier l'immigration. A Cuba, les "Public Utilities " (trusts américains) contrôlent toute l'économie du pays (chemins de fer, mines, production du sucre et du tabac). Il est, par conséquent, très difficile pour nos industries d'y prendre pied. Dans l'île de Haîti (républiques de Haîti et Dominicaine), les possibilités d'engagement sont réduites. Il n'y existe pas de maisons suisses, et les employés indigènes qui se contentent d'un salaire peu élevé constituent une forte concurrence. Dans les pays de l'Amérique centrale également, les possibilités de travail ne sont

273 15, page 87.27429 , page 9.

275 Tegucigalpa/Honduras [17], Panama [18], San-Miguel/Salvador [19], La Havane/Cuba [20], Port-au-Prince/Haïti [21], Ciudad-Trujillo/Saint-Domingue [22]. Le nombre réduit des Suisses de la circonscription de Guadalajara [15], située dans le secteur nord du haut-plateau du Mexique, s'explique par le caractère semi-désertique de cette contrée. 
pas encore très favorables. Au Panama, les lois relatives à l'immigration interdisent l'accès du pays aux artisans, ne favorisent que celui des colons agriculteurs ou des planteurs. Dans l'État de Salvador, seuls des capitalistes introduisant de nouvelles industries sont bienvenus.

Au Mexique, une loi de 1936 interdit l'immigration aux individus cherchant du travail. Même les étrangers établis depuis longtemps dans le pays ont souvent peine à trouver du travail ou à garder leur place, la loi spécifiant que $95,0 \%$ des travailleurs doivent être citoyens mexicains.

Malgré tous ces obstacles, d'ordre physique et économique, le mouvement migratoire suisse vers les pays de l'Amérique centrale s'accroît de $1,2 \%$ en 1928 à $5,5 \%$ en 1936. L'Amérique centrale est donc une zone de pays neufs qui, dans l'avenir, pourraient malgré tout devenir des débouchés intéressants pour nos industries et des zones d'absorption appréciables pour nos émigrants. Nos compatriotes habitant ces contrées appartiennent à toutes les professions, sauf à l'agriculture qui est éliminée d'office en raison des conditions climatiques défavorables. Des planteurs suisses, par exemple, se sont installés dans les circonscriptions de Tegucigalpa $(5,3 \%)$ et de San-Miguel $(35,6 \%)$. Des travailleurs du bâtiment se rencontrent à Cuba $(11,0 \%)$ et à Tegucigalpa $(21,1 \%)$, des travailleurs de l'industrie mécanique au Panama $(6,0 \%)$ et à Haîti $(15,8 \%)$, des commerçants à San-Miguel (49,0\%), Tegucigalpa $(42,2 \%)$ et Haïti $(52,6 \%)$. Le pourcentage des ecclésiastiques est très élevé $(43,0 \%$ ) au Panama à cause des religieuses provenant du couvent st-gallois de Tübach. On rencontre aussi un assez grand nombre de gouvernantes aux Indes occidentales (Ciudad-Trujillo 6,2\%).

En résumé, les conditions physiques de l'Amérique centrale sont contraires à l'immigration suisse massive; elles interdisent surtout l'immigration agricole. La structure économique de ces contrées dans l'entre-deux-guerres n'est pas favorable non plus à cette immigration. Toutefois, son évolution a atteint un degré permettant d'y envoyer des individus appartenant à des professions les plus diverses, sauf à l'agriculture, et toute l'Amérique centrale pourra acquérir pour notre économie nationale une importance accrue à l'avenir.

\section{Le Brésil tropical}

Dans la zone tropicale dü Brésil, on distingue la partie orientale, pays de montagne, des "Selvas", dépression de l'Amazone dans le nord-ouest. La dépression de l'Amazone subit le climat chaud et humide de la forêt vierge. Tout le Nord-Est du Brésil, par contre, reçoit moins de $1000 \mathrm{~mm}$. d'eau par ani, chiffre faible, étant donné la température élevée et l'intensité de l'évaporation. La zone sèche touche la côte sur $1000 \mathrm{~km}$. environ, du Maranhâo au Parahyba ${ }^{277}$; elle couvre tout l'intérieur jusqu'au bassin inférieur du Sâo-Francisco. Les pluies sont concentrées pendant une saison (inverno) qui alterne avec la saison sèche (verâo). Dans le plateau central (Goyaz et Matto Grosso) ${ }^{278}$, les pluies tombent pendant l'été austral, d'octobre à avril; la saison sèche est rigoureuse. A Cuyaba (Matto Grosso) de juin à août, les précipitations sont à peu près nulles, et le semestre d'été reçoit 82 par 100 des précipitations totales. La côte orientale est arrosée libéralement (Bahia $1876 \mathrm{~mm}$., Recife $2092 \mathrm{~mm}$., Parahyba $1763 \mathrm{~mm}$.). Mais dès qu'on s'éloigne de la côte vers l'Ouest, on pénètre dans la zone aride.

Toutes ces régions, mais particulièrement celles dont le climat est tropical et humide, sont peu propres à l'immigration des Blancs. Le nombre de Suisses habitant le Brésil tropical est peu élevé, et tandis qu'il atteint quand même près de 200 individus dans les circonscriptions de Pernambouc [tableau 11, No 25] et de Bahia [23], les Selvas et lé Matto Grosso sont complètement dépourvus de colonies suisses, les Selvas en raison de leur impénétrabilité et de leur climat malsain, le Matto Grosso à cause de son éloignement de la côte.

Aussi des facteurs d'ordre économique restreignent-ils l'établissement de nos concitoyens. Sur la côte orientale, les esclaves noirs importés d'Afrique se sont rapidement multipliés et constituent depuis longtemps pour les Blancs une sérieuse concurrence dans toutes les professions manuelles subordonnées. Mais malgré le climat défavorable et la présence des Noirs, des colons allemands et suisses se sont établis vers 1847 au sud de Bahia, au pied de la "Serra do Mar", dans les trois colonies de Santa-Isabel, do Rio Novo et Santa-Leopoldina, dans une région qui jusqu'alors était occupée par les farouches indiens ArMORÉs ${ }^{279}$. Toutefois, par la suite, ils ont dû céder la place à des Italiens, mieux adaptés au milieu physique, économique et social et au genre d'exploitation particulier de cette contrée, à l'économie des plantations.

278 14, page $89 . \quad 237$ 14, page $95 . \quad 27814$, page $130 . \quad 27927$, page 158. 
Aujourd'hui, ies ressortissants des circonscriptions consulaires de Pernambouc et de Bahia travaillent comme mécaniciens ${ }^{280}$, commerçants ${ }^{281}$ ou artisans du bâtiment ${ }^{282}$, activités où la concurrence des Noirs n'est pas sensible. La plus grande partie du Matto Grosso est encore inconnue. Dans ces régions montagneuses, qui ont été colonisées au $18 \mathrm{e}$ siècle lors de la découverte de riches mines d'or, le climat n'est pas défavorable au point d'interdire le travail du sol, mais l'agriculture ne peut pas y dépasser les limites imposées par le besoin réel en produits alimentaires de la population régionale. Elle ne pourra prendre une plus grande extension qu'au moment où l'installation de bonnes voies de communication et la garantie de frais de transport minimes permettront l'écoulement de ses produits ${ }^{283}$. Il n'y existe donc pas encore de colonie suisse, et l'immigration y restera insignifiante tant que le problème des communications ne sera pas résolu.

La dépression de l'Amazone a connu une immigration de Blancs relativement importante vers 1860 , lors de la découverte du procédé de vulcanisation du caoutchouc par Charles Nelson Goodyear permettant la mise en valeur pratique de cette matière première. La création de plantations de caoutchouc dans l'Insulinde et en d'autres pays du monde provoque la décadence de la production brésilienne, de sorte qu'aujourd'hui ces régions sont de nouveau désertes et les villes en ruines ${ }^{\mathbf{2 8 4}}$.

Les ccnditions physiques et surtout climatiques du Brésil tropical sont donc peu favorables à l'établissement massif des Suisses. Il y a quelques possibilités sur la côte orientale et au Matto Grosso; elles manquent, par contre, dans la dépression de l'Amazone. Des facteurs économiques également y embarrassent la colonisation. Certains d'entre eux, par exemple le manque de communications dans le Matto Grosso, pourront cesser d'agir dans l'avenir.

\section{Les pays andins (sauf le Chili)}

La Bolivie, le Pérou, l'Équateur, la Colombie et le Venezuela sont des pays situés entièrement dans la zone tropicale. Pourtant, les conditions climatiques y sont très complexes. La température varie selon la proximité de l'équateur et selon l'altitude. Les Llanos de l'Orénoque ont un climat tropical ${ }^{285}$, avec des températures moyennes de plus de $24^{\circ}$. Dans les Andes septentrionales, on distingue, selon l'altitude, la tierra caliente (de 0 à $1000 \mathrm{~m}$.), la tierra templada (de 1000 à $2000 \mathrm{~m}$.), la tierra fria (de 2000 à $3000 \mathrm{~m}$.) et le Paramò (de 3000 à $4000 \mathrm{~m}$. et plus suivant les régions) ${ }^{286}$. Dans les Andes centrales également, la température dépend de l'altitude. Les régions de 3000 à $4000 \mathrm{~m}$. souffrent souvent, même en été, de gelées qui détruisent les cultures, et celles de plus de $4000 \mathrm{~m}$. ne connaissent, pour cette même raison, que des pâturages.

Les grandes agglomérations humaines sont à des altitudes de 2000 à $3000 \mathrm{~m}$., dont le climat est bien supportable. Pour cette raison, le nombre de Suisses habitant ces pays est supérieur à 500 individus dans les circonscriptions de Lima [tableau 11, No 36] et de Bogotà [38], tandis qu'il se maintient entre 200 à 300 dans les circonscriptions de la Paz [35], de Guayaquil [37] et de Caracas [39]. Cependant, le pourcentage des agriculteurs suisses y est très peu élevé; il ne dépasse $11,0 \%$ du nombre total de nos compatriotes dans aucune des cinq circonscriptions ${ }^{287}$. L'air raréfié de ces régions rend pénible tout travail manuel de sorte que des facteurs d'ordre économique sont également responsables de cette participation réduite. D'autre part, les régions situées à l'intérieur des Cordillères, sont en général aux mains d'un petit nombre de grands propriétaires. Leur offre étant très réduite, la demande très grande, les prix fonciers se maintiennent

280 Pour-cent des travailleurs de l'industrie mécanique: Bahia 5,3\%; des techniciens: Pahia 1,7\%, Pernambouc $7,6 \%$.

${ }^{281}$ Pour-cent des commerçants: Bahia 70,0\%, Pernambouc 70,0\%.

282 Pour-cent des travailleurs en bâtiment: Bahia $8,8 \%$; dont $20,0 \%$ com.me maçons, menuisiers, ferblantiers, $80,0 \%$ comme serruriers et électriciens.

${ }_{283} 27$, page 187. $\quad{ }^{284} 27$, page $205 . \quad{ }^{285} 27$, page $33 . \quad{ }^{286} 27$, page 23.

287 Pour-cent des agriculteurs: $\mathrm{La} \mathrm{Paz} 7,2 \%$, Lima $5,2 \%$, Guayaquil $11,0 \%$, Bogotà 3,3\%, Caracas $1,3 \%$. 
toujours très élevés ${ }^{288}$. Par contre, l'appel aux travailleurs de l'industrie mécanique ${ }^{289}$ et aux techniciens ${ }^{290}$ suisses est fort dans toutes les circonscriptions envisagées; ces individus sont engagés en général par des sociétés minières ou pétrolières et touchent un salaire assez élevé. Ils doivent toutefois commencer très modestement, s'adapter à toute sorte de circonstances, se servir d'outils primitifs, et être physiquement sains.

La situation des commerçants ${ }^{291}$ n'est pas partout la même. Les commentaires provenant de la Bulivie sont tous enthousiastes. On n'y connaitrait pas de chômage, grâce aux besoins de main-d'œuvre des mines. Les Suisses y sont en général e.ggagés par des entreprises étrangères, GraCE, HochSCHILD, Düncan-Fox, etc. Un jeune employé de commerce y gagne $£ 20 /-$ à $25 /-$ et doit en soustraire $£ 8 /-$ pour chambre et pension; il peut donc réaliser certaines économies. Au Pérou, la situation économique est bonne en 1938. Les comptables suisses connaissant bien leur profession et sachant l'anglais sont recherchés par les grandes compagnies minières anglaises et américaines capables de leur offrir une bonne situation. Les circonstances sont moins favorables pour les employés de commerce dans l'Équateur. Il y a peu de places vacantes, et la circulation monétaire est peu intense. Le port de Guayaquil ofre plus de possibilités que Quito, à l'intérieur du pays, mais se trouve moins favorisé au point de vue climatique. Les rapports provenant de la Colombie sont assez contradictoires. Selon l'Office fédéral d'émigration, les possibilités de travail y sont fort restreintes. D'autres rapports disent que les sociétés pétrolières troublent le marché du travail en offrant à leurs employés des salaires élevés, ce qui incitérait les commerçants à abandonner leur entreprise.

L'émigration pour le Venezuela ne peut être recommandée qu'à des commerçants ayant de très bonnes connaissances professionnelles et linguistiques et disposant de ressources qui puissent leur permettre de rester quelques mois sans travail, puisqu'on n'y engage pas à distance.

La situation économique plus ou moins instable pour les employés de commerce, se reflète dans nos données statistiques. Les commerçants suisses sont nombreux en Bolivie et au Pérou, moins dans les trois autres États qui n'offrent pas d'aussi bonnes conditions d'engagement et de travail. Le pourcentage des travailleurs en bâtiment est élevé en Équateur (19,5\%), puisqu'une entreprise suisse a pu occuper plus de 100 de nos compatriotes, dont elle a dû pourtant licencier plus des quatre cinquièmes à cause de divergences survenues entre elle et le gouvernement.

D'une importance particulière sont les carrières ecclésiastiques $(42,4 \%)$ en Colombie. Le centre de religieuses suisses à Tumaco est fourni par le couvent st-gallois de Schloss Wartensee.

Notons donc que les répercussions néfastes du climat tropical sont en certaines parties des Andes neutralisées par l'altitude. Le degré d'absorption des différentes professions (sauf de l'agriculture, éliminée d'office en raison de la raréfaction de l'air) varie suivant le degré d'évolution économique.

\section{B. L'Afrique \\ L'Afrique occidentale et le Congo}

L'établissement des Blancs en Afrique occidentale (Sénégambie, Guinée) et au Congo est restreint par les faits suivants:

a) le climat, peu salubre pour les hommes de race blanche en raison des maladies tropicales et des répercussions plus graves encore sur les femmes et les enfants ${ }^{202}$;

b) les difficultés de communications avec l'intérieur de l'Afrique occidentale et le Congo, peu accessibles en raison du relief, des inondations qui interrompent les communications régulières dans le bassin du Congo et des forêts vierges hostiles à la pénétration de l'homme surtout au Congo belge.

Tous ces facteurs contra ient fortement l'immigration de Blancs et maintiennent bas le nombre des Suisses habitant les circonscriptions de Dakar [44], Accra [45: Côte

288 27, page 64.

289 Pour-cent des travailleurs en industrie mécanique: $\mathrm{La} \mathrm{Paz} 12,1 \%$, Lima 14,7\%, Guayaquil $16,4 \%$, Bogotà 11,1\%, Caracas $6,5 \%$.

290 Pour-cent des techniciens: La Paz 7,2\%, Lima 12,6\%, Guayaquil 17,2\%, Bogotà 5,2\%, Caracas $25,3 \%$.

291 Pour-cent des commerçants: La $\mathrm{Paz} 40,0 \%$, Lima 38,1\%, Guayaquil 22,7\%, Bogotà 19,4\%, Caracas $24,6 \%$.

292 15, page 151. 
d'Or] et Léopoldville [46]. Ces colonies se trouvent en général sur la côte ${ }^{293}$ plus accessible, et les Suisses sont surtout des hommes adultes. Plus de $65 \%$ des émigrants qui partent pour l'Afrique occidentale sont des jeunes gens de 20 à 30 ans. Le pourcentage de femmes adultes, d'enfants et d'adolescents est très réduit ${ }^{294}$. Les agriculteurs y font complètement défaut, par contre les planteurs suisses ${ }^{295}$ occupent, dans les circonscriptions de Dakar et de Léopoldville, une situation importante. Les techniciens ${ }^{296}$ et travailleurs de l'industrie mécanique ${ }^{297}$ sont plus rares à Dakar et à Accra, où le manque de matières premières (fer, charbon) ne justifie pas leur immigration. Seule la circonscription de Léopoldville dont fait partie la région du Haut-Katanga (située dans le secteur sud-oriental du Congo belge), riche en mines de cuivre, d'étain, de charbon et de radium, comporte des taux plus élevés.

On rencontre les commerçants ${ }^{298}$ surtout dans la circonscription d'Accra, possession anglaise, moins dans les circoncriptions de Dakar qui appartient à la France, et de Léopoldville, colonie belge. Les salaires des employés de commerce dans les entreprises anglaises et suisses ${ }^{299}$ sont, en effet, beaucoup plus élevés que les traitements versés par les sociétés commerciales françaises et belges. Ainsi; on touche, auprès d'une entreprise anglaise ou suisse de la Côte d'Or, $£ 25 /-$ par mois, plus indemnité de logement, frigidaire, lumière, etc., auprès d'une entreprise française du Sénégal fr. f. 2400.-, ou, en Livres Sterling, sur la base du mois de décembre 1938, $£ 13 / 10 /-$, sans indemnité de nourriture, auprès d'une entreprise belge de Léopoldville fr. 3500.(francs congolais) ou $£ 25 /-$, avec le logement libre, tandis que le coût de la vie s'élève, à $£ 8 / 10 /-$ au Sénégal, à $£ 8 /-$ à la Côte d'Or, à $£ 14 /-$ au Congo belge.

Un champs d'activité étendu s'ouvre aux ecclésiastiques parmi la population indigène; leur pourcentage par rapport au nombre total de ressortissants suisses dépasse $16,0 \%$ dans la circonscription de Léopoldville.

Retenons donc que le climat malsain, la mauvaise accessibilité du pays et le manque d'industries restreignent le nombre de Suisses dans ces contrées et en limitent l'accès à certaines catégories d'âge, de sexe et de profession. Les conditions d'engagement déterminent, d'autre part, le nombre de commerçants.

\section{L'Afrique orientale et Madagascar}

L'Afrique orientale doit son climat chaud à sa situation équatoriale. D'autre part, la proximité de l'Océan Indien et les contrastes accentués et brusques du relief entre les différentes régions jouent un rôle qui n'est pas négligeable ${ }^{300}$.

Dans les régions que les vents de l'Océan Indien (les alizés et la mousson) atteignent sans obstacles, la répartition des pluies au cours de l'année n'a plus un caractère nettement équatorial. A Madagascar, le climat est nettement tropical. La chaleur est élevée dans toutes les zones basses et en toute saison; mais à l'intérieur, l'altitude rafraîchit la température, et le climat de Tananarive et de Fianarantsoa est trìs supportable.

En Afrique orientale et dans l'île de Madagascar, les Européens sont sujets aux maladies tropicales dans les régions de faible altitude et sur la côte ${ }^{301}$. Dans les contrées

${ }^{283}$ Mème Léopoldville en est peu éloignée par rapport à la grandeur du bassin congolais.

204 Pour-cent des enfants et des adolescents sans distinction du sexe: Dakar 11,3\%, Accra 10,1\%, Léopoldville $11,8 \%$; des hommes adultes: Dakar $67,1 \%$, Accra $72,5 \%$, Léopoldville $68,5 \%$; des femmes adultes: Dakar 21,6\%, Accra 17,4\%, Léopoldville 19,7\%.

295 Pour-cent des planteurs: Dakar 7,1\%, Léopoldville 6,5\%. Plantations d'arachides, de sisal, de palmiers à huile à Dakar, de palmiers à huile, de hévéas au Congo belge.

298 Pour-cent des techniciens: Dakar 6,2\%, Accra 1,8\%, Léopoldville 5,2\%.

207 Pour-cent des travailleurs de l'industrie mécanique: Dakar 3,1\%, Accra 4,6\%, Léopoldville $9,5 \%$.

${ }_{298}$ Pour-cent des commerçants: Dakar 66,5\%, Accra 79,5\%, Léopoldville 44,5\%.

299 Ces dernières, par exemple "the Union Trading Company Ltd." se trouvent en territoire anglais.

300 11, page 101. 301 11, page 103. 
élevés, par contre, les travailleurs blancs pourraient vivre facilement, si la basse pression atmosphérique ne leur était néfaste, comme partout dans la zone tropicale, à ces altitudes. Des facteurs climatiques impliquent donc que le nombre de Suisses habitant ces contrées ne soit pas très élevé; il est de 430 dans la circonscription de Tanga (Tanganyika), de 88 dans celle de Tananarive. Pour la même raison, les agriculteurs suisses en sont complètement absents, par contre, nos planteurs y atteignent un nombre relativement élevé $^{302}$. Les matières premières nécessaires à l'installation d'une grande industrie (charbon, fer) y faisant défaut, le taux des travailleurs industriels et des techniciens est relativement bas ${ }^{303}$.

Le pourcentage des commerçants est plus élevé à Tananarive qu'à Tanga ${ }^{304}$. En Afrique orientale, les places commerciales subordonnées sont, en effet, de plus en plus occupées par des hommes de couleur, surtout des. Hindous. On n'engage donc plus les Européens qu'en nombre réduit, pour les fonctions de dirigeant, d'organisateur ou de surveillant. L'infiltration hindoue est moins forte dans l'île française de Madagascar, et le problème ne s'y pose pas avec la même acuité. D'autre part, les conditions de salaire sont plus favorables à Madagascar.

En Afrique orientale britannique, un employé de commerce touche $£ 22 / 10 /-$, plus le logement; il doit compter $£ 15 /-$ pour la nourriture et les autres dépenses et peut donc économiser $£ 7 / 10 /$ A Madagascar, il touche $£ 11 / 10 /-$ (fr. f. 20000 . - sur la base du mois de décembre 1938), plus la nourriture et le logement; il fait des dépenses de $£ 1 / 10 /-$ et peut réaliser des économies de $£ 10 /-$.

En Afrique orientale et à Madagascar également, les tâches des ecclésiastiques sont multiples; leur pour-cent est donc très élevé, dépassant $66,3 \%$ dans la circonscription de Tanga, se maintenant à 19,1\% dans celle de Tananarive.

Les conditions climatiques tropicales restreignent donc le nombre absolu des ressortissants suisses habitant les circonscriptions de Tanga et de Tananarive et interdisent l'immigration d'agriculteurs; le manque d'industries de transformation abaisse le nombre des techniciens et des travailleurs industriels et les conditions d'engagement et de salaire maintiennent le pourcentage des commerçants plus élevé dans la circonscription de Tananarive que dans celle de Tanga.

\section{L'Asie}

L'Inde britannique. L'Inde britannique est un pays tropical soumis aux moussons $^{305}$. Les conditions climatiques ne sont pas de nature à favoriser une immigration européenne massive. D'autre part, la forte densité de la population indigène interdit un établissement de grande envergure de Blancs. Ainsi s'expliquent la faible importance numérique des circonscriptions de Bombay [55], Calcutta [56] et Colombo/Ceylan [57], et l'absence de ressortissants suisses dans l'agriculture ou le bâtiment. Les planteurs suisses $^{\mathbf{3 0 6}}$, par contre, sont en rang honorable dans l'île de Ceylan. Les pourcentages des techniciens ${ }^{307}$ et des commerçants ${ }^{308}$ suisses sont aussi relativement élevés dans les trois circonscriptions envisagées, par le fait que l'Inde britannique offre un vaste champ d'activité à ces deux professions ${ }^{309}$. Ainsi ce pays est devenu, dans l'entre-deuxguerres, un grand fournisseur de coton (région de Bombay, partie orientale du Dekkan), de la laine (partie occidentale du Dekkan), du jute (delta du Gange), du tabac (Bombay, delta du Gange) et du sucre (dépression du Gange).

302 Pour-cent des planteurs: Tanga $10,7 \%$, Tananarive $23,5 \%$. Ils s'agit soit de planteurs indépendants, soit d'assistants de plantations d'arachides, de cocotiers, de sisal, etc.

${ }^{303}$ Pour-cent des techniciens: Tanga 8,8\%, Tananarive 4,4\%.

304 Pout-cent des commerçants: Tanga 7,5\%, Tananarive $42,7 \%$.

305 8, page 281.

306 Plantations de caoutchouc et de thé.

${ }^{307}$ Pout-cent des techniciens: Bombay 14,0\%, Calcutta 21,0\%, Colombo 5,3\%.

${ }^{308}$ Pour-cent des commerçants: Bombay 33,8\%, Calcutta 31,4\%, Colombo 58,0\%.

30924 , page 329. 
D'autre part, les gisements de charbon (bassin de la Damodar dans le Nord-Est du Dekkan) et de fer (Provinces centrales: Balaghat, Nagpour) ont permis d'installer l'industrie lourde.

Les missionnaires dont les tâches, dans ce vaste pays, sont grandes et multiples, représentent 37,8\% à Bombay, $15,7 \%$ à Calcutta de l'effectif total des immigrants, et le grand nombre de femmes missionnaires, de religieuses explique la forte participation de femmes adultes ${ }^{310}$.

L'Inde britannique, au point de vue climatique et démographique, est peu favorable à l'immigration blanche. Par contre, la politique du gouvernement anglais et l'évolution économique relativement avancée de l'Inde britannique ont permis l'établissement d'un certain nombre de commerçants et de techniciens suisses.

\section{Insulinde et Malaisie}

Comme l'Inde, l'Insulinde (Indes néerlandaises et Philippines) et la presqu'île de Malacca sont soumises au climat de mousson. Cet archipel présente la forme océanique de ce climat qui passe même au Sud au climat équatorial: la température y reste élevée pendant toute l'année $e^{311}$.

Les Européens y sont sujets aux maladies endémiques et épidémiques (malaria, dysenterie, typhus, etc.), mais échappent en général aux répercussions néfastes du climat en passant leurs vacances dans les montagnes plus tempérées.

Bien que le climat tropical de l'Insulinde réduise les colonies suisses de Singapour (Malacca), Medan (Sumatra), Batavia (Java) et Manille (Philippines), la densité des Suisses ${ }^{312}$ en pays tropical n'est nulle part aussi élevée et le gros pourcentage d'enfants et d'adolescents ${ }^{313}$ s'explique par la possibilité de se retirer à la montagne et de braver ainsi la plus mauvaise saison.

Les conditions climatiques de même que le genre d'exploitation interdisent une immigration massive d'Européens, lesquels ne peuvent exercer des travaux manuels pénibles; le pourcentage des agriculteurs suisses y est donc nul, tandis que les planteurs suisses (dirigeants de travaux) sont nombreux, et leur taux de participation dépasse $60,0 \%$ du nombre total des Suisses dans la circonscription de Medan ${ }^{314}$. Les techniciens $^{315}$. aussi occupent partout une certaine place, trouvant des engagements, soit comme surveillants de plantations ou comme spécialistes de drainage et d'irrigation de rizières, soit dans des mines de charbon (par exemple dans l'État de Selangor dans la presqu'île de Malacca) ou auprès des sociétés pétrolières hollandaises et anglaises ${ }^{\mathbf{3 1 6}}$.

Le pourcentage des commerçants ${ }^{317}$ est élevé dans les circonscriptions de Singapour et de Manille, où les possibilités d'engagement et de salaire sont favorables. A Singapour, un employé de commerce expérimenté touche jusqu'à 600 Straits Settlements Dollars; il doit en compter 300. - pour le coût de la vie et peut donc en réaliser 300.-, soit, sur la base du mois de décembre 1938, fr. s. 400.— à 450.—. Aussi les économies réalisables aux Philippines sont-elles assez élevées. Aux Indes néerlandaises, par contre, la position des commerçants est moins assurée, bien que les salaires y permettent également de faire des économies. Par contre, la concurrence des employés de commerce indigènes et surtout des

310 Pour-cent des femmes adultes: Bombay $40,2 \%$, Calcutta $38,4 \%$, Colombo $26,3 \%$.

3118 , page 478 .

312 Nombre de ressortissants suisses sur 1000 lieues angl. car.: Singapour (Straits Settlements et Malaisie britannique) 4,2, Medan (Sumatra) 1,16, Batavia (Java) 9,3, Manille (Philippines) 2,9; en comparaison: Tanga (Tanganyika, Kenya, Uganda, Mozambique) 0,44, Tananarive (Madagascar) 0,37, Léopoldville (Congo) 0,35; Accra (Afrique équatoriale française, Nigeria, Dahomey, Togo, C. d'Iv.): 0,25, Dakar (Sierra-Leone, Guinée, Gambia, Sénégal) 1,41.

${ }_{313}$ Pour-cent des enfants et adolescents, sans distinction de sexe: Singapour 24,0\%, Medan 27,7\%; Batavia 28,0\%, Manille 18,9\%.

314 Pour-cent des planteurs: Medan 60,5\%, Batavia 11,2\%, Manille 4,0\%.

315 Pour-cent des techniciens: Singapour 16,6\%, Medan 15,2\%, Batavia 16,4\%, Manille 4,5\%; des travailleurs en industrie mécanique: Medan 4,4\%, Batavia 9,2\%, Manille 4,5\%.

316 8, page 496.

317 Pour-cent des commerçants: Singapour 50,0\%, Medan 1,1\%, Batavia 18,5\%, Manille 69,0\%. 
métis indo-européens y est beaucoup plus sensible en raison de la politique coloniale plus large du gouvernement hollandais dans le domaine des mariages mixtes; d'autre part, de 1932 à 1937, les autorisations de travail n'ont été concédées, à Sumatra, qu'à des ressortissants hollandais.

La neutralisation partielle des conditions climatiques défavorables par des séjours à des altitudes plus élevées permet donc l'installation d'un nombre relativement élévé de ressortissants suisses par rapport à la superficie du pays. La structure économique et sociale particulière à ces régions a pour conséquence une participation plus ou moins forte des différentes professions à l'émigration dans les quatre circonscriptions envisagées.

L'Indochine. L'Indochine est soumise elle aussi au régime de la mousson. Son climat est tropical, chaud et humide en Birmanie et sur la côte orientale de l'Annam. Elle a un climat de savane dans sa partie centrale (Siam), un climat chaud à tempéré (sec en hiver) dans le nord (secteurs central et septent rional de l'Indochine française) ${ }^{318}$. La majorité du territoire de l'Indochine appartenant donc à la zone tropicale, le nombre de Suisses habitant ces contrées est réduit, le nombre d'agriculteurs suisses à peu près nul.

Par contre, les planteurs ${ }^{319}$ sont assez nombreux dans la circonscription de Saigon.

Des facteurs économiques impliquent des taux de participation élevés de travailleurs industriels et de commerçants suisses. L'Indochine française, pays essentiellement agricole, a été développée par la puissance protectrice. La France y a introduit des cultures nouvelles, installé des fabriques et a exploité les mines. Au Tonkin, la population très dense fournit une main-d'œuvre abondante, intelligente et adroite. Très désireux de s'instruire, lès Annamites sont de bons mécaniciens et électriciens. Servir de cadre à cette population indigène est une tâche intéressante pour des techniciens européens. Un autre facteur de prospérité, rare dans cette partie de l'Asie, est la présence de la houille, dans d'excellentes conditions de gisement et de transport. Ceci constitue une possibilité de plus pour nos ingénieurs et techniciens. L'industrie textile moderne est surtout représentée par les filatures de coton de Haiphong, et par d'importantes fabriques de nattes ${ }^{320}$. D'autres industries ont commencé à se développer: l'industrie chimique, la tannerie, la préparation scientifique du thé, du café, du sucre, du caoutchouc et des corps gras. Voilà pourquoi le taux des travailleurs industriels ${ }^{321}$ est relativement élevé dans ces circonscriptions. Les commerçants ${ }^{322}$ aussi y occupent une place exceptionnelle. Bien que les lois sur l'immigration et l'établissement en Indochine française soient très sévères et que $80,0 \%$ des travailleurs doivent être français ou indigènes, il y a 40 commerçants suisses résidant à Saigon et 120 en tout dans l'Indochine française, puisqu'un commerçant célibataire peut mettre de côté environ fr. s. 250.- par mois, s'il vit avec trois ou quatre autres Européens.

Le caractère tropical maintient donc peu élevé l'effectif global des colonies suisses en Siam et en Indochine française. Par contre, le développement industriel de ces contrées favorise l'immigration de techniciens et de commerçants. Une immigration européenne massive est, d'autre part, contrariée par la forte densité démographique.

\section{CONCLUSION}

On a constaté, au cours de cette étude, combien est complexe le problème de l'émigration suisse outre-mer et combien les facteurs dont elle dépend sont nombreux et divers. Ils résident aussi bien dans la géographie des zones de provenance que dans celle des pays de destination. La répercussion des événements internationaux y intervient à son tour, au moins dans le domaine économique et social.

Le mouvement de l'émigration entre 1850 et 1920 devient intense chaque fois que la situation outre-mer est plus prospère qu'en Suisse; elle se réduit, lorsque le phéno-

318 , page 394.

319 Pour-cent des planteurs: Saïgon $7,0 \%$.

3208 , page 46 .

321 Pour-cent des travailleurs de l'industrie mécanique: Bangkok 11,6\%, Saïgon 12,7\%; des techniciens: Saigon $7,1 \%$.

${ }^{322}$ Pour-cent des commerçants: Bangkok $73,0 \%$, Saïgon 58,0\%. 
mène inverse se produit. Dans l'entre-deux-guerres, les changements économiques prennent un caractère mondial; les possibilités de placement de main-d'œuvre et les déplacements d'individus d'un pays à l'autre augmentent chaque fois que le monde passe par une période de prospérité et diminuent en temps de crise. Il n'est plus possible, comme avant 1914, d'échapper à une situation économique précaire en quittant la Suisse pour les pays d'outre-mer.

La participation à l'émigration n'intéresse pas au même degré les différentes professions. Le nombre des émigrants-agriculteurs est beaucoup plus élevé que celui des autres catégories professionnelles. Le commerce, la technique, le tourisme, le bâtiment, l'art ménager sont de moyenne, les autres catégories professionnelles de moindre importance considérées sous l'angle de l'émigration.

L'attraction du mouvement migratoire est très forte pour certaines professions libérales et la technique, moins forte pour l'agriculture, le commerce, le tourisme, encore plus faible pour l'enseignement, le ménage, très faible pour les arts et métiers. L'émigration suisse dans l'entre-deux-guerres est donc une émigration de qualité bien que, quantitativement, le nombre des émigrants manuels, notamment des agriculteurs, soit assez élevé.

Les modifications de la situation économique agissent aussi sur la composition professionnelle du courant d'émigration. Ainsi, le pourcentage des agriculteurs est élevé en 1928 par suite des droits de douane élevés sur certains produits agricoles et à cause des besoins en main-d'œuvre de l'agriculture américaine. En 1932, la forte participation des émigrants provenant des industries d'exportation, de la technique, du commerce, du tourisme, est l'expression de la crise dont souffrent ces branches d'activité en Suisse, et, en 1936, la politique expansionniste de certaines industries suisses en vue de la reconquête des marchés d'outre-mer pousse les travailleurs appartenant à ces branches d'activité à l'émigration.

La période de prospérité (1928) et le temps de crise (1932) influent davantage sur l'émigration des personnes exerçant des activités subordonnées que sur celle des personnès à fonctions dirigeantes. De même, la catégorie des individus ayant une activité économique est, manifestement, plus sensible aux fluctuations du marché que celle des personnes sans activité économique.

Les célibataires de sexe masculin occupent, dans le mouvement d'émigration, une place prépondérante par rapport aux autres catégories de personnes, même si on compare le nombre des émigrants au chiffre de la population suisse globale. Ils paraissent émigrer de préférence durant les époques de prospérité et semblent, plus que les autres, sensibles aux difficultés économiques mondiales.

La grande majorité des émigrants s'expatrient à l'âge de 20 à 30 ans. Ces éléments jeunes participent surtout à l'émigration de l'année 1928. L'expatriation est ralentie, par contre, par la crise de l'année 1932 qui frappe en moindre mesure le déplacement outre-mer de personnes plus âgées. La structure par âge n'est pas la même pour les différentes professions. Cette différence est due aux caractères particuliers à chaque branche d'activité, certaines professions demandant une plus longue période de préparation; d'autre part, les chances de réussite dans un pays d'outre-mer ne sont pas, pour un âge donné, les mêmes pour toutes les professions.

L'intensité du mouvement d'émigration n'est pas la même non plus dans les différentes zones de départ. Des centres de forte émigration se situent en certaines parties des Alpes, d'autres dans les agglomérations industrielles ou urbaines. Les taux d'intensité sont donc supérieurs dans les Alpes et dans le Jura à ceux du Mittelland. Dans cette dernière région comme dans une grande partie des Alpes et aussi dans le Jura, les taux augmentent du Sud-Ouest au Nord-Est, en raison de conditions climatiques moins favorables. 
Aussi le courant migratoire est-il variable dans sa composition. L'émigration des agriculteurs est un phénomène propre aux régions de montagne. Les émigrants-horlogers proviennent presque tous du Jura neuchâtelois et bernois. L'émigration des travailleurs de l'industrie mécanique est caractéristique d'une bonne partie du Mittelland et du Jura, celle des techniciens provient de la Suisse septentrionale. Les travailleurs en bâtiment sont d'origine tessinoise ou grisonne. L'émigration des commerçants est un phénomène propre aux grands centres urbains, celle des personnes vivant du tourisme caractérise le secteur occidental des Alpes et la région du Léman. Les émigrants-instituteurs, les gouvernantes proviennent de la Suisse romande principalement, les ecclésiastiques de la Suisse romande protestante d'une part, de la Suisse centrale et nord-orientale catholique d'autre part.

Le milieu physique exerce une action puissante sur l'émigration. L'intensité migratoire élevée de certaines régions de montagne s'explique par l'ingratitude du climat et les mauvaises voies d'accès. Cette influence est moins manifeste, lorsque certaines industries viennent s'ajouter à l'agriculture et élargir le cadre d'existence offert aux hommes, mais elle reprend toute sa valeur, lorsque ces industries traversent une période de crise. Une grande partie du Tessin doit sa forte émigration surtout aux conditions physiques défavorables et au manque d'industries, les cantons de St-Gall et d'Appenzell à la crise de l'industrie textile. Le mouvement migratoire intense des villes, par contre, n'est qu'une manifestation toute naturelle de leur rythme économique accéléré et de leur politique de conquête de débouchés.

La participation des différentes zones de départ à l'émigration est aussi variable à travers le temps, et, en 1928, année de prospérité, les émigrants proviennent de tout autres régions de la Suisse que lors de la crise de 1932.

Le volume, la direction du courant d'émigration suisse vers les pays transocéaniques sont d'ailleurs en grande partie déterminées par le milieu physique, économique et social de ces pays eux-mêmes. Le climat interdit l'immigration massive de ressortissants suisses dans les pays tropicaux, mais favorise leur établissement en certains pays de la zone tempérée. Des raisons d'ordre économique et démographique contrarient leur infiltration dans les pays asiatiques à faible pouvoir d'absorption.

La composition du courant d'immigration suisse dépend donc des conditions physiques, économiques et sociales des différents pays transocéaniques. Le climat implique deux types différents d'exploitation du sol: l'agriculture en certaines zones tempérées, les plantations sous les tropiques. Les autres professions sont moins sujettes aux répercussions du climat. Les horlogers sont répartis un peu partout sur le globe; les travailleurs du bâtiment, nombreux dans les deux Amériques et en Australie, font complètement défaut en Afrique et en Asie. Les travailleurs de l'industrie mécanique se rencontrent également un peu partout dans les quatre continents envisagés, mais la faible absorption des pays asiatiques joue moins pour les techniciens que pour eux. C'est ainsi que l'émigration des commerçants est universellement répartie, de même celle des employés d'hôtel, sauf évidemment dans les régions tropicales de l'Afrique dépourvues de grandes agglomérations urbaines. Le nombre des instituteurs et gouvernantes est réduit dans la zone tropicale, régions néfastes à la santé des enfants blancs. Les ecclésiastiques, par contre, n'hésitent pas à affronter le climat tropical.

La répartition, dans les différents pays transocéaniques, des émigrants suisses varie toutefois au cours du temps. Le centre d'attraction, situé aux États-Unis à l'époque de prospérité de 1928, se déplace de plus en plus vers l'Amérique centrale et l'Amérique du Sud lesquelles, en 1936, à l'époque de reprise économique des industries d'exportation, sont très fréquentées par les émigrants suisses.

Nous nous sommes attaché à ne traiter que dans leurs grandes lignes les causes du mouvement migratoire. En réalité, le problème de l'émigration est beaucoup plus complexe. Certaines causes en apparence accessoires acquièrent dans certaines circons- 
tances et combinées à d'autres, une importance qui suffit à déterminer l'envergure du mouvement migratoire: une exposition peu favorable, le défaut d'eau courante ou d'électricité, l'absence d'une bonne route reliant un endroit au monde extérieur, un trop grand morcellement de la propriété foncière, des impôts trop élevés et une multitude d'autres menus faits peuvent contribuer à provoquer un mouvement d'expatriation.

Dans les pays de destination, l'abondance ou l'absence de matières premières, de denrées alimentaires, la situation géographique d'une colonie par rapport à ses débouchés, le développement des communications, la forme de l'exploitation agricole, l'attitude du gouvernement, la situation politique, des facteurs idéologiques ou religieux, l'accroissement démographique, la demande de main-d'œuvre, la situation sociale des travailleurs étrangers, les perspectives de travail et les formalités d'entrée favorisent ou contrarient l'immigration de nos ressortissants.

L'étude sur l'émigration suisse hors d'Europe que nous venons d'achever traite la période de l'entre-deux-guerres, de 1919 à 1939. Qu'en est-il aujourd'hui, en 1947, des possibilités d'émigration? Il convient de relever tout d'abord que pour des raisons politiques ou autres, de nombreux États n'admettent pour le moment aucun étranger sur leur territoire; d'autres ne les acceptent qu'avec la plus grande retenue et ne permettent tout au plus des exceptions que lorsqu'il s'agit de spécialistes introuvables chez eux. De ce fait, les pays ou régions d'outre-mer, désignés ci-après, sont, jusqu'à nouvel avis, totalement ou partiellement fermés à l'émigration suisse: en Amérique, le Canada et plusieurs États de l'Amérique centrale et du Sud; l'Egypte, pour le moment aussi le Japon, et enfin la Nouvelle-Zélande et en partie l'Australie. Dans plusieurs autres pays plus ou moins ouverts à l'émigration suisse, la situation politique et économique est encore trop confuse pour qu'on puisse recommander à des émigrants de s'y établir; souvent les possibilités de gain sont si restreintes qu'elles ne leur permettraient pas de se tirer d'affaire.

Quoi qu'il en soit, nombreux sont les États d'outre-mer - même parmi ceux qui n'ont pas pris part à la guerre ou qui en tout cas n'ont pas été dévastés - qui demandent de la main-d'œuvre étrangère. Plusieurs d'entre eux ont pu, ensuite des circonstances extraordinaires, tirer parti de possibilités économiques autrefois inutilisées et souvent même insoupçonnées. Parvenus à leurs fins, ils cherchent à conserver la situation acquise et, si possible, à l'améliorer. Mais pour cela, il leur faut plus de bras, et parce qu'ils ne les trouvent pas chez eux, ils les cherchent ailleurs.

A vrai dire, l'étude des plans que certains États ont élaborés dans le dessein d'encourager l'immigration sur une large échelle n'en est encore qu'à son premier stade. L'émigration vers ces pays ne pourra donc commencer dans un avenir rapproché. Et même si ces projets devaient aboutir, il serait difficile de prévoir quelles seraient les perspectives pour nous autres Suisses. En dépit des efforts qu'ils feront pour recruter des travailleurs étrangers, les États en question n'admettront sans doute pas indifféremment ceux qui s'offriront à eux, mais choisiront attentivement les éléments dont ils ont besoin pour développer leur économie.

Actuellement, ce sont les techniciens, les spécialistes, les ouvriers qualifiés (particulièrement les travailleurs de la métallurgie et du bâtiment) et le personnel d'hôtel qui ont le plus de chances de se faire engager à l'étranger. Les employés de commerce ne trouvent plus si facilement une place à l'étranger, la formation professionnelle ayant fait un peu partout de grands progrès dans cette branche. Les perspectives sont moins favorables surtout pour les émigrants qui exercent des professions indépendantes ou intellectuelles: ou bien ils n'obtiennent pas l'autorisation d'exercer leur profession, ou bien ils doivent, s'ils veulent en acquérir le droit, subir dans le pays de destination les examens prévus à cet effet. 
Les difficultés qui empêchent d'émigrer et de s'établir dans un pays étranger sont encore très grandes et très variées. Mentionnons comme obstacles les prescriptions d'entrée, le coût des transports aériens et maritimes, la pénurie de logements aux pays de destination, le renchérissement prononcé de leur coût de la vie et ainsi de suite.

Le problème de l'émigration suisse hors d'Europe est donc délicat. Il appartient à une organisation officielle de tenir à jour les informations d'ordre physique, économique, politique ou social et d'en tirer les conclusions pratiques.

Le mouvement d'émigration suisse répond à un besoin réel, encore que l'émigration agricole des montagnards, par exemple, semble pouvoir être évitée au prix d'une modification de la structure économique régionale. Toutefois, pour garantir le plus haut profit possible aussi bien à l'émigrant qu'à la communauté, il faut surveiller l'intensité, la composition et la direction du courant migratoire et assurer à nos ressortissants suisses d'outre-mer des conditions de travail et de vie satisfaisantes au moyen d'accords appropriés. Une émigration dirigée ou du moins contrôlée s'impose donc. C'est le seul moyen de maintenir la qualité élevée de nos colonies suisses à l'étranger, de leur procurer les forcés nécessaires pour leur permettre de reconstruire ce qui a été détruit par la guerre. Ceci contribuera à assurer à notre patrie l'estime de l'étranger, l'indépendance économique et politique, ainsi qu'un heureux avenir.

\section{ANNEXES}

Annexe 1. Les catégories professionnelles et leur participation au mouvement d'émigration. On distingue: des professions de première importance $(\mathrm{A})^{323}$ : agriculture, bâtiment, technique, commerce, tourisme, ménage; des professions de seconde importance (B): horticulture, alimentation, horlogerie, industrie mécanique, enseignement, éducation, carrières ecclésiastiques, rentiers; des professions de troisième importance $(\mathrm{C})$ : les 19 professions qui restent.

La subdivision des catégories professionnelles

Catégories professionnelles et sous-catégories

Alimentation:

Bouchers . . . . . . . . . . . . . . .

Boulangers, pâtissiers . . . . . . . . . . . . . .

Horlogerie, Bijouterie, Graphique:

Horlogers, bijoutiers, orfèvres . . . . . . . . . .

Opticiens, photographes . . . . . . . . . . . . .

Typographes, graveurs, relieurs . . . . . . . .

Bàtiment:

Construction de la maison (maçons, terrassiers, ferblantiers, vitriers) ......... . . . . . . . . .

Installations à l'intérieur (serruriers, électriciens) . . .

Travaux de finissage (peintres, tapissiers, vitriers). . .

Beaux-Arts :

Architectes, sculpteurs, artistes-peintres . . . . . . .

Musiciens, chanteurs, artistes de théâtre et de cinéma .

Agriculture:

Agriculteurs indépendants . . . . . . . . . . . .

Manœuvres agricoles.

Industrie mécanique:

Industriels, directeurs . . . . . . . . . . . . . . .

Contremaitres . . . . . . . . . . . . . . . . . . .

Mécaniciens, machinistes . . . . . . . . . . . . .

Manœuvres non qualifiés

$1924 \quad 1928$

1932

1936

33,7

65,3

22,5

77,5

17,2

82,8

15,4

84,6

66,7

8,9

26,6

81,8

5,6

12,6

65,0
5,0
20,0

89,0

0,0

11,0

75,0

5,8

19,2

$\begin{array}{rrrrr}52,4 & 40,7 & 66,6 & 42,8 & 47,0 \\ 38,6 & 36,7 & 24,2 & 42,8 & 38,0 \\ 9,0 & 22,6 & 9,1 & 14,3 & 15,0\end{array}$

$\begin{array}{lllll}56,3 & 78,7 & 66,7 & 84,6 & 72,0\end{array}$

$\begin{array}{lllll}43,7 & 21,3 & 33,3 & 15,4 & 28,0\end{array}$

96,0

\section{0,2}

97,6

95,3

4,7

93,0

$\begin{array}{lllrr}4,0 & 9,8 & 2,4 & 4,7 & 7,0\end{array}$

\section{3,0}

8,2

88,8

7,8
10,1
79,0
3,1

10,7

21,4

21,4
67,9

0,0
1,7

10,2

81,4

6,8
5,2

10,4 82,1 2,3

s23 Voir tableau 4, colonne 3. 
Industrie textile:

Entrepreneurs, directeurs. . . . . . . . . .

Techniciens textiles ....... . . . . . . .

$0,0 \quad 9,7$

15,4

$0,0 \quad 5,6$

Fileurs, tisseurs, brodeurs, apprêteurs, dessinateurs

0,0

12,9

46,1

17,6

3,4

Technique:

Ingénieurs, techniciens . . . . . . . . . . . 75,4

Monteurs, dessinateurs, géomètres.

$\begin{array}{llll}54,4 & 59,8 & 71,5 & 65,0\end{array}$

Banque:

Banquiers, directeurs, administrateurs, fondés de pouvoir

Employés ordinaires.

$\begin{array}{lllll}41,1 & 12,5 & 22,2 & 50,0 & 25,0 \\ 58,9 & 87,5 & 77,8 & 50,0 & 75,0\end{array}$

Commerce:

Avec fonction de dirigeants (commerçants, directeurs)

Avec fonction de responsabilité (gérants, réviseurs, chefs de rayon, caissiers, comptables sup., magasiniers-enchef . . . . . . . . . . . . . . .

Avec position subordonnée (employés, sténodactylos, commis, vendeurs, voyageurs) .......

Tourisme:

Hôteliers, directeurs . . . . . . . . . . . . . . . .

Maitres d'hôtel, secrétaires, employés de bureau, portiers

$81,0 \quad 62,0 \quad 78,8 \quad 81,7 \quad 73,0$

$4,4 \quad 12,2 \quad 3,3 \quad .4,9 \quad 7,5$

$14,6 \quad 25,8 \quad 17,9 \quad 13,4 \quad 19,5$

Cuisiniers, sommeliers, valets et femmes de chambre.

$\begin{array}{rrrrr}12,8 & 5,6 & 8,9 & 12,5 & 9,3 \\ 21,6 & 39,7 & 34,3 & 37,5 & 32,2 \\ 65,6 & 54,7 & 56,8 & 50,0 & 58,5\end{array}$

\section{Annexe 2 (texte voir page 24). Les districts suisses et l'émigration}

Moyenne des années 1924, 1928, 1932, 1936, en pour-mille de la population globale Région transjurassienne

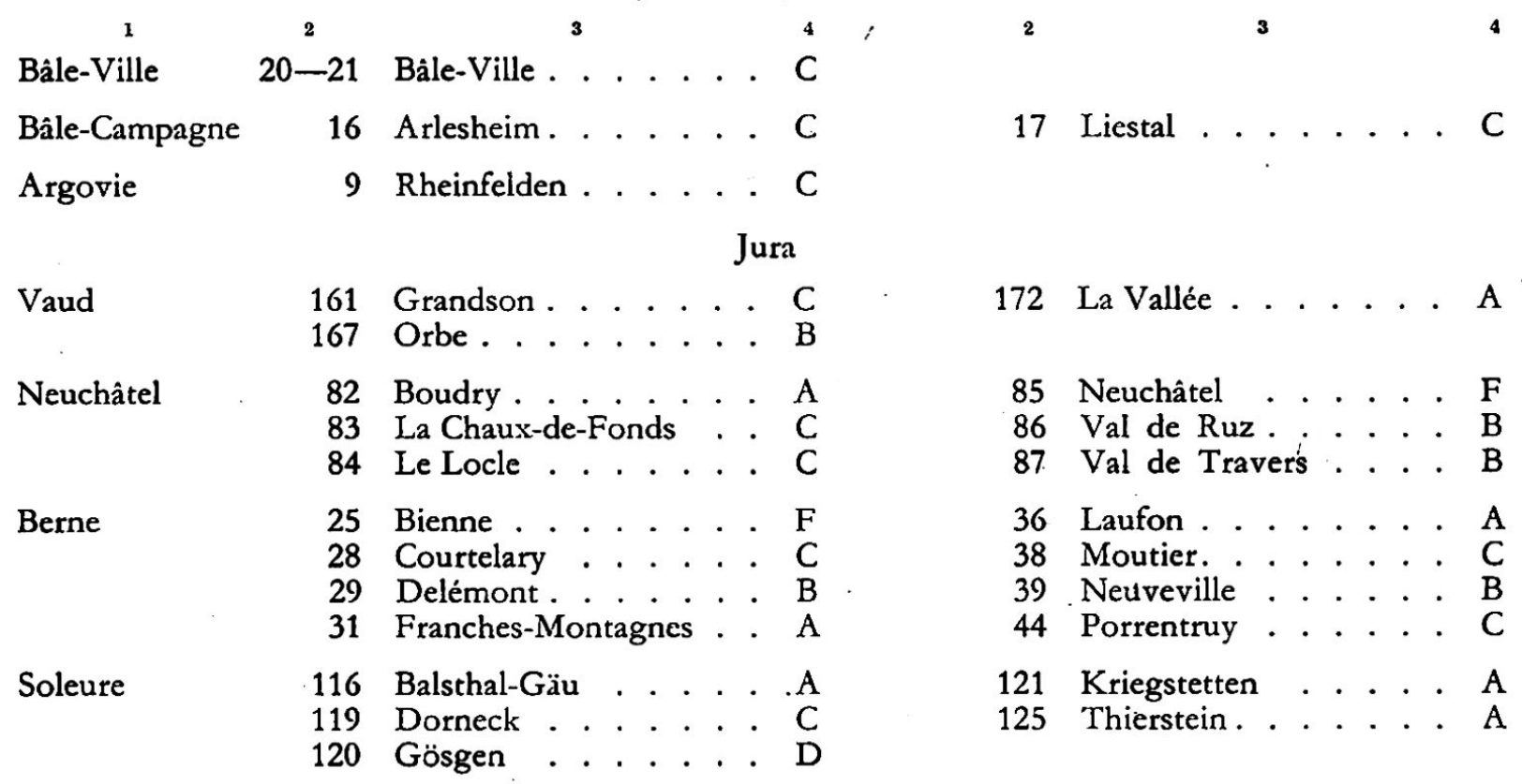

1 Cantons suisses ou la partie de leur territoire appartenant à une région déterminćc.

2 Numérotage des districts.

3 Noms des districts.

- Taux d'intensité de l'émigration, en pour-mille de la population globale:

$$
\begin{array}{ll}
A=0,00 \text { à } 0,15 \% & G=0,90 \text { à } 1,05 \% \\
B=0,15 \text { a } 0,30 \% & H=1,05 \text { a } 1,20 \% \\
C=0,30 \text { a } 0,45 \% & I=1,20 \text { à } 1,35 \% \\
D=0,45 \text { à } 0,60 \% & K=1,35 \text { a } 1,50 \% \\
E=0,60 \text { a } 0,75 \% & L=1,50 \text { a } 1,65 \% \\
F=0,75 \text { a } 0,90 \% & M=1,65 \text { a } 1,80 \%
\end{array}
$$




\begin{tabular}{|c|c|c|}
\hline Bâle-Campagne & 18 & Sissach \\
\hline Argovie & 6 & Laufenbourg \\
\hline Schaff house & $\begin{array}{l}104 \\
105 \\
106\end{array}$ & $\begin{array}{l}\text { Oberklettgau } \\
\text { Unterklettgau } \\
\text { Reiath }\end{array}$ \\
\hline
\end{tabular}

Mittelland (Haut-plateau suisse)

Genève

Vaud

Fribourg

Berne

Soleure

Lucerne

Argovie

Zoug

Zurich

Thurgovie

Fribourg

Vaud

Berne
59 Genève-Ville . . . . F

157 Aubonne . . . . . . . C

158 Avenches .... A

159 Cossonay . . . . . . . D

160 Echallens . . . . . . B

162 Lausanne . . . . . . E

163 Lavaux . . . . . . C

164 Morges . . . . . . A A

52 Broye . . . . . . A

53 Glâne . . . . . . A

55 Sarine . . . . . . A

22 Aarberg . . . . . . C

23 Aarwangen ..... B

24 Berne. . . . . . . E

26 Büren sur Aar . . . B

27 Burgdorf . . . . . . B B

30 Erlach . . . . . . . C

32 Fraubrunnen .... B

35 Konolfingen .... C

117 Balsthal-Tal . . . . . A

118 Bucheggberg . . . . . C

122 Lebern . . . . . . C

78 Hochdorf . . . . . . B

80 Sursee ..... B

1 Aarau ...... D

2 Baden ...... F

3 Bremgarten ..... C

4 Brugg . . . . . . C

5 Kulm. . . . . . C

186 Zoug. . . . . . . . . F

175 Affoltern a. A. . . . . E

176 Andelfingen . . . . . C

177 Bülach . . . . . . C

178 Dielsdorf . . . . . . . C

179 Hinwil . . . . . . . . E

180 Horgen . . . . . F

134 Arbon ... . . . . E

135 Bischofszell . . . . . . C

136 Dießenhofen .... . D

137 Frauenfeld . . . . . B

Alpes septentrionales

54 Gruyère . . . . . B

156 Aigle . . . . . B

34 Interlaken. . . . . . E

41 Niedersimmental . . D
33 Frutigen . . . . . D
19 Waldenbourg . . . D

107 Schaffhouse . . . . D D

108 Schleitheim ..... . E

109 Stein sur Rhin . . . . F

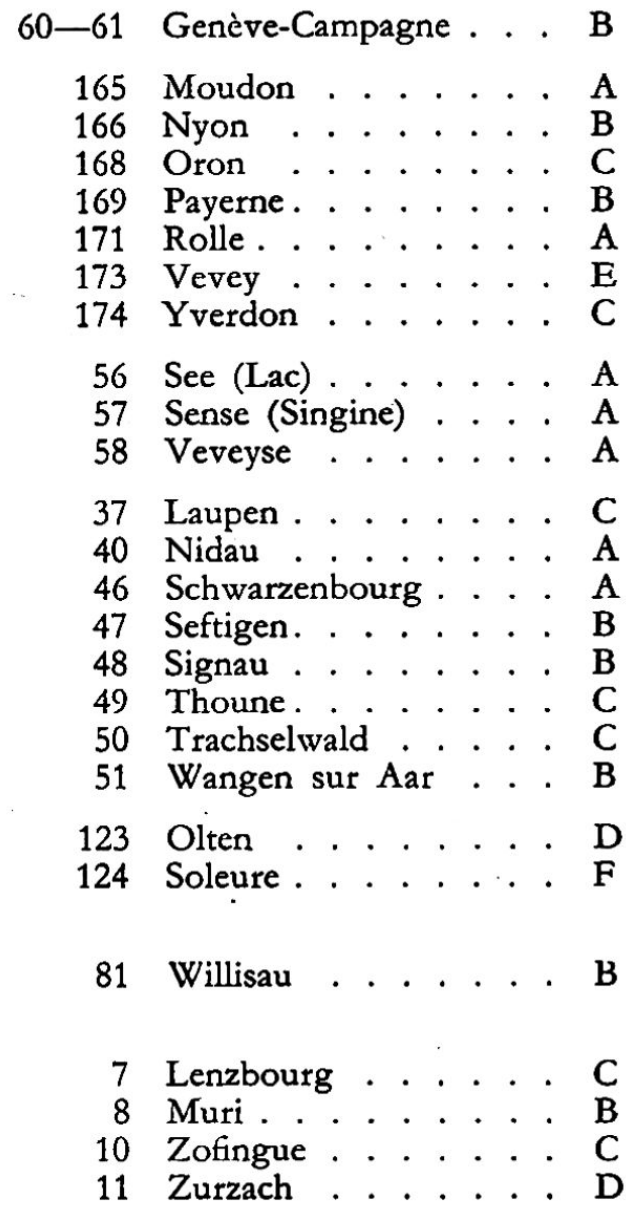

181 Meilen . . . . . . . E

182 Pfäffikon . . . C

183 Uster . . . . . . . F

184 Winterthour .... G

185 Zurich ......

138 Kreuzlingen . . . . C

139 Münchwilen. . . . . C

140 Steckborn. . . . . . . C

141 Weinfelden ..... D 
Lucerne

Obwald

Nidwald

Schwyz

Uri

Glaris

St-Gall

Valais

Appenzell R.I.

Appenzell R. E.

12

13

88 Nidwald

110 Einsiedeln. . . . . E

111 Gersau . . . . . . . C

112 Höfe . . . . . . . C

$142 \mathrm{Uri} . . . . . . \mathrm{D}$

62 Glaris ...... . D

90 Alttoggenbourg . . . C

91 Gaster . . . . . . . B

92 Gossau . . . . . . E E

93 Neutoggenbourg. . . . C

94 Oberrheintal. . . . . E

95 Obertoggenbourg . . . E

96 Rorschach. . . . . . M

15 Rhodes Intérieures . - C

Hinterland . . . . . E

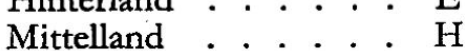

\begin{tabular}{|c|c|c|c|c|c|c|c|c|c|c|c|c|}
\hline Valais & . & $\begin{array}{l}143 \\
144 \\
145 \\
146 \\
147 \\
148 \\
149\end{array}$ & $\begin{array}{l}\text { Brigue . . . } \\
\text { Conthey . . } \\
\text { Entremont . } \\
\text { Conches (Goms). } \\
\text { Hérens . . . . } \\
\text { Loèche (Leuk). } \\
\text { Martigny . . . . }\end{array}$ & $\begin{array}{ll}\cdot & \cdot \\
\cdot & \cdot \\
\cdot & . \\
\cdot & . \\
\cdot & \cdot \\
\cdot & . \\
\cdot & .\end{array}$ & $\begin{array}{l}\dot{\cdot} \\
\dot{\cdot} \\
\dot{\cdot} \\
\dot{\cdot} \\
\dot{\cdot}\end{array}$ & $\begin{array}{ll}\cdot & \mathrm{C} \\
\cdot & \mathrm{C} \\
\cdot & \mathrm{B} \\
\cdot & \mathrm{C} \\
\cdot & \mathrm{B} \\
\cdot & \mathrm{E} \\
\cdot & \mathrm{C}\end{array}$ & $\begin{array}{l}150 \\
151 \\
152 \\
153 \\
154 \\
155\end{array}$ & $\begin{array}{l}\text { Monthey . } \\
\text { Rarogne . } \\
\text { St-Maurice . } \\
\text { Sierre. . . . } \\
\text { Sion . . . . } \\
\text { Viège (Visp) }\end{array}$ & : & $\begin{array}{l}\cdot \\
\cdot \\
\cdot \\
\cdot \\
\cdot\end{array}$ & . $\cdot$ & . \\
\hline essin & & $\begin{array}{l}126 \\
127 \\
128 \\
129\end{array}$ & 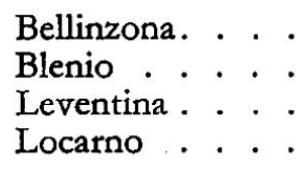 & $\begin{array}{ll}\cdot & \cdot \\
\cdot & \cdot \\
\cdot & \cdot\end{array}$ & $\dot{.}$. & $\begin{array}{ll}. & \mathrm{H} \\
. & \mathrm{C} \\
. & \mathrm{H}\end{array}$ & $\begin{array}{l}130 \\
131 \\
132 \\
133\end{array}$ & $\begin{array}{l}\text { Lugano } \cdot \\
\text { Mendrisio. } \\
\text { Riviera . } \\
\text { Vallemaggia }\end{array}$ & . & . & $\begin{array}{l}\cdot \\
\cdot \\
\cdot \\
\cdot \\
.\end{array}$ & . \\
\hline Grisons & & $\begin{array}{l}63 \\
64 \\
65 \\
66 \\
67 \\
68 \\
69\end{array}$ & $\begin{array}{l}\text { Alvaschein . } \\
\text { Bernina . . . } \\
\text { Glenner. . . . } \\
\text { Heinzenberg. . } \\
\text { Hinterrhein . . } \\
\text { Imboden . . . } \\
\text { Inn. . . . . . }\end{array}$ & $\begin{array}{ll}\cdot & . \\
\cdot & . \\
\cdot & . \\
\cdot & . \\
\cdot & . \\
\cdot & . \\
. & .\end{array}$ & $\begin{array}{l}\dot{.} \\
\dot{.} \\
\dot{.} \\
\dot{.} \\
\dot{.}\end{array}$ & $\begin{array}{ll}. & \mathrm{A} \\
. & \mathrm{F} \\
. & \mathrm{B} \\
. & \mathrm{B} \\
\cdot & \mathrm{I} \\
. & \mathrm{C} \\
. & \mathrm{C}\end{array}$ & $\begin{array}{l}70 \\
71 \\
72 \\
73 \\
74 \\
75 \\
76\end{array}$ & $\begin{array}{l}\text { Oberlandquart } \\
\text { Unterlandquart } \\
\text { Maloja. . } \cdot \text {. } \\
\text { Moësa . } \cdot \text {. } \\
\text { Münster . } \\
\text { Plessur . } \\
\text { Vorderrhein }\end{array}$ & $t$ & $\begin{array}{l}\cdot \\
\cdot \\
. \\
. \\
. \\
. \\
\text {. }\end{array}$ & & \\
\hline
\end{tabular}

79 Lucerne. . . . . . H

113 Küssnacht . . . . . G

114 March . . . . . . C

115 Schwyz....... . K

97 St-Gall . . . . . . . . I

98 Sargans . . . . . . C

99 Seebezirk . . . . . . G

100 Unterrheintal . . . . G

101 Untertoggenbourg . . . F

102 Werdenberg. . . . . C

103 Wil . . . . . . D

14 Vorderland . . . . . F

Alpes au Sud du Rhône - Rhin antérieur 
Annexe 3 (texte voir page 59). Composition par professions des colon

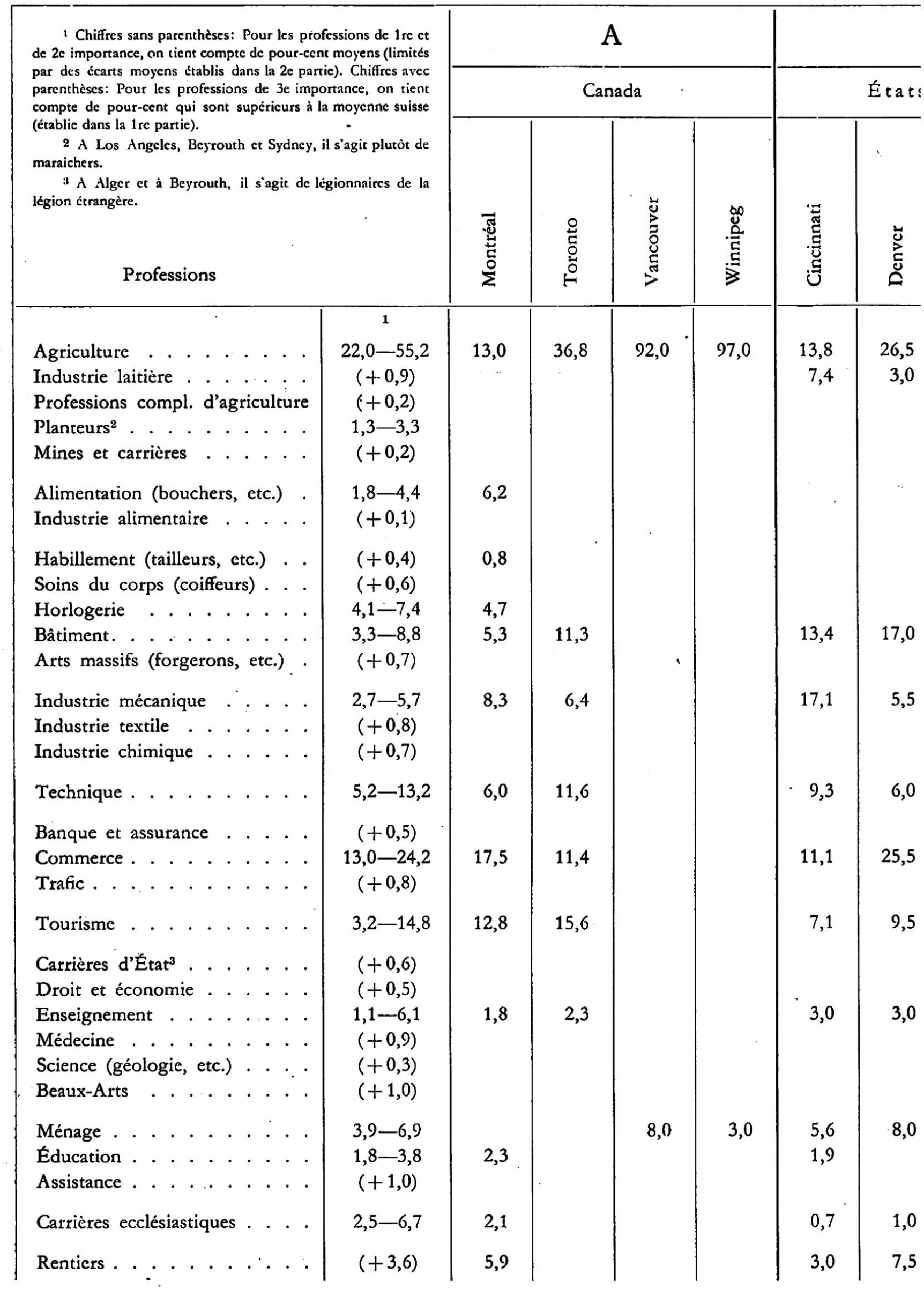


lisses d'outre-mer; en pour-cent du nombre total des ressortissants suisses

\begin{tabular}{|c|c|c|c|c|c|c|c|c|c|}
\hline \multicolumn{8}{|c|}{ B } & \multirow{2}{*}{\multicolumn{2}{|c|}{$\frac{\mathrm{C}}{\text { Mexique }}$}} \\
\hline Inis & & & & & & & & & \\
\hline 造 & 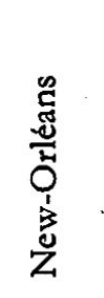 & 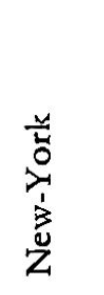 & 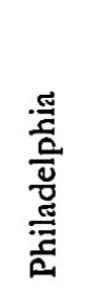 & 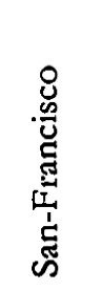 & $\begin{array}{l}\frac{n}{3} \\
\stackrel{3}{1} \\
\dot{n}\end{array}$ & · & 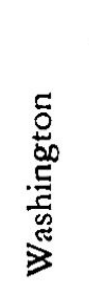 & 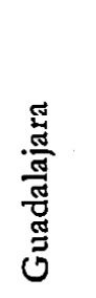 & 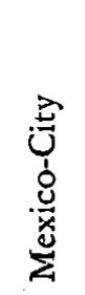 \\
\hline $\begin{array}{r}5,8 \\
18,0 \\
9,4 \\
5,8\end{array}$ & 25,0 & 5,5 & 10,4 & 49,2 & $\begin{array}{r}38,3 \\
5,5 \\
3,0\end{array}$ & 53,8 & 6,7 & 3,1 & $\begin{array}{l}4,8 \\
0,8\end{array}$ \\
\hline 4,1 & & 3,7 & 2,6 & . & $\begin{array}{l}1,9 \\
3,4\end{array}$ & 1,2 & 2,9 & & $\begin{array}{l}0,4 \\
2,4\end{array}$ \\
\hline & & 2,9 & & & & & & 50,0 & 2,4 \\
\hline 4,2 & 10,0 & 2,7 & 10,3 & 8,6 & 8,2 & 3,5 & 1,9 & & 4,4 \\
\hline $\begin{array}{c}7,3 \\
1\end{array}$ & 10,0 & $\begin{array}{l}6,1 \\
2,6\end{array}$ & $\begin{array}{r}19,0 \\
2,4 \\
1,8\end{array}$ & 8,5 & 5,1 & 3,2 & & 15,6 & $\begin{array}{l}2,8 \\
2,4 \\
6,0\end{array}$ \\
\hline 3,4 & 10,0 & 4,2 & 9,6 & 2,8 & 1,9 & 0,4 & 3,8 & 15,6 & 10,4 \\
\hline 0,6 & & 1,4 & & & & & & & 1,2 \\
\hline 7,9 & 15,0 & 16,7 & $\begin{array}{r}14,0 \\
2,2\end{array}$ & 4,6 & 3,5 & 2,5 & $\begin{array}{r}12,4 \\
1,9\end{array}$ & & 37,0 \\
\hline 11,5 & 10,0 & 14,3 & 10,4 & 6,5 & 12,2 & 2,2 & 16,2 & 9,4 & 3,2 \\
\hline 1,2 & 10,0 & 2,4 & 5,1 & 1,2 & 1,1 & 0,1 & 12,4 & 3,1 & $\begin{array}{l}1,2 \\
3,6\end{array}$ \\
\hline $\begin{array}{l}0,7 \\
3,8\end{array}$ & & & & & & & 5,7 & & 2,0 \\
\hline 5,0 & 7,5 & $6,3^{\circ}$ & & 11,6 & 11,4 & 26,8 & 12,4 & & \\
\hline $\begin{array}{l}1,1 \\
2,0\end{array}$ & & 8,2 & $\begin{array}{l}4,1 \\
3,0\end{array}$ & 1,7 & 0,7 & 0,3 & 13,4 & 3,1 & 2,4 \\
\hline 0,1 & . & 0,3 & 0,4 & & & 0,4 & 1,0 & & \\
\hline , & 2,5 & 12,9 & & 2,1 & 0,2 & 0,3 & & & 5,2 \\
\hline
\end{tabular}


1 Chiffres sans parenthèses: Pour les professions de 1re et de 2e importance, on tient compte de pour-cent moyens (limités par des écarts moyens établis dans la 2e partie). Chiffres avec parenthises: Pour les professions de $3 \mathrm{c}$ importance, on tient compte de pour-cent qui sont supérieurs à la moyenne suisse (établie dans la 1re partie).

2 A Los Angeles, Beyrouth et Sydney, il s'agit plutôt de maraîchers.

3 A Alger et à Beyrouth, il s'agit de légionnaires de la légion ćtrangère.

\begin{tabular}{|c|c|c|c|c|c|c|c|}
\hline légion ćtrangèrc. & & 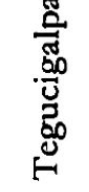 & 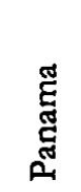 & 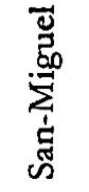 & 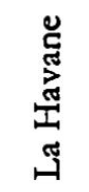 & 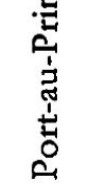 & 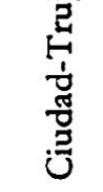 \\
\hline . & 1 & & & & & & \\
\hline Agriculture . . . . . . & $22,0-55,2$ & & 15,6 & & 15,1 & & 31,5 \\
\hline Industrie laitière..... & $(+0,9)$ & & & & 2,7 & & 12,4 \\
\hline Professions compl. d'agriculture & $(+0,2)$ & & & & & & \\
\hline Planteurs $^{2}$. . . . . . . . & $1,3-3,3$ & 5,3 & 2,4 & 35,6 & & & \\
\hline Mines ct carrières . . . . . . & $(+0,2)$ & & & & & & \\
\hline Alimentation (bouchers, etc.) & $1,8-4,4$ & 10,6 & 1,2 & & & & \\
\hline Industrie alimentaire... & $(+0,1)$ & & & & 9,6 & & \\
\hline Habillement (tailleurs, etc.) . . & $(+0,4)$ & & & 4,4 & & 5,3 & \\
\hline Soins du corps (coiffeurs). . . & $(+0,6)$ & & & & & & \\
\hline Horlogerie . . . . . . & $4,1-7,4$ & & 7,2 & & & & \\
\hline Bâtiment. . . . . . . . . & $3,3-8,8$ & 21,1 & 1,2 & 2,2 & 11,0 & & \\
\hline Arts massifs (forgerons, etc.) & $(+0,7)$ & 5,3 & & & & & \\
\hline Industrie mécanique.... & $2,7-5,7$ & & 6,0 & & & 15,8 & \\
\hline Industrie textile . . . . . & $(+0,8)$ & & & & & & \\
\hline Industrie chimique.... & $(+0,7)$ & & & & 2,7 & 5,3 & \\
\hline Technique . . . . . . & $5,2-13,2$ & & 7,2 & 4,4 & 16,5 & & \\
\hline Banque et assurance ..... & $(+0,5)$ & & & 4,4 & & & 6,2 \\
\hline Commerce . . . . . . . . & $13,0-24,2$ & 42,2 & 14,4 & 49,0 & 19,2 & 52,6 & 18,7 \\
\hline 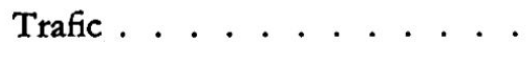 & $(+0,8)$ & & & & & & \\
\hline Tourisme . . . . . . . . & $3,2-14,8$ & 5,3 & & & 12,3 & & 12,5 \\
\hline Carrières d'État ${ }^{3} \ldots \ldots$ & $(+0,6)$ & & & & & & \\
\hline Droit et économie . . . . & $(+0,5)$ & & & & & & \\
\hline Enseignement . . . . . . & $1,1-6,1$ & & & & 4,1 & 5,3 & \\
\hline Médecine . . . . . . . . & $(+0,9)$ & & & & & & \\
\hline Science (géologie, etc.) : . . & $(+0,3)$ & & & & & & \\
\hline$\underset{,}{\operatorname{Beaux}-A r t s} \cdot \cdot \cdot \cdot \cdot \cdot \cdot \cdot$ & $(+1,0)$ & & & & & & \\
\hline Ménage . . . . . . . . & $3,9-6,9$ & & & & & & \\
\hline Éducation . . . . . . . & $1,8-3,8$ & & & & 5,5 & 5,3 & 6,2 \\
\hline Assistance . . . . . . & $(+1,0)$ & & & & & & \\
\hline Carrières ecclésiastiques . . . . & $2,5-6,7$ & 10,6 & $43 ; 1$ & & & 10,6 & \\
\hline Rentiers . . . . . . . . & $(+3,6)$ & & & & & & \\
\hline
\end{tabular}




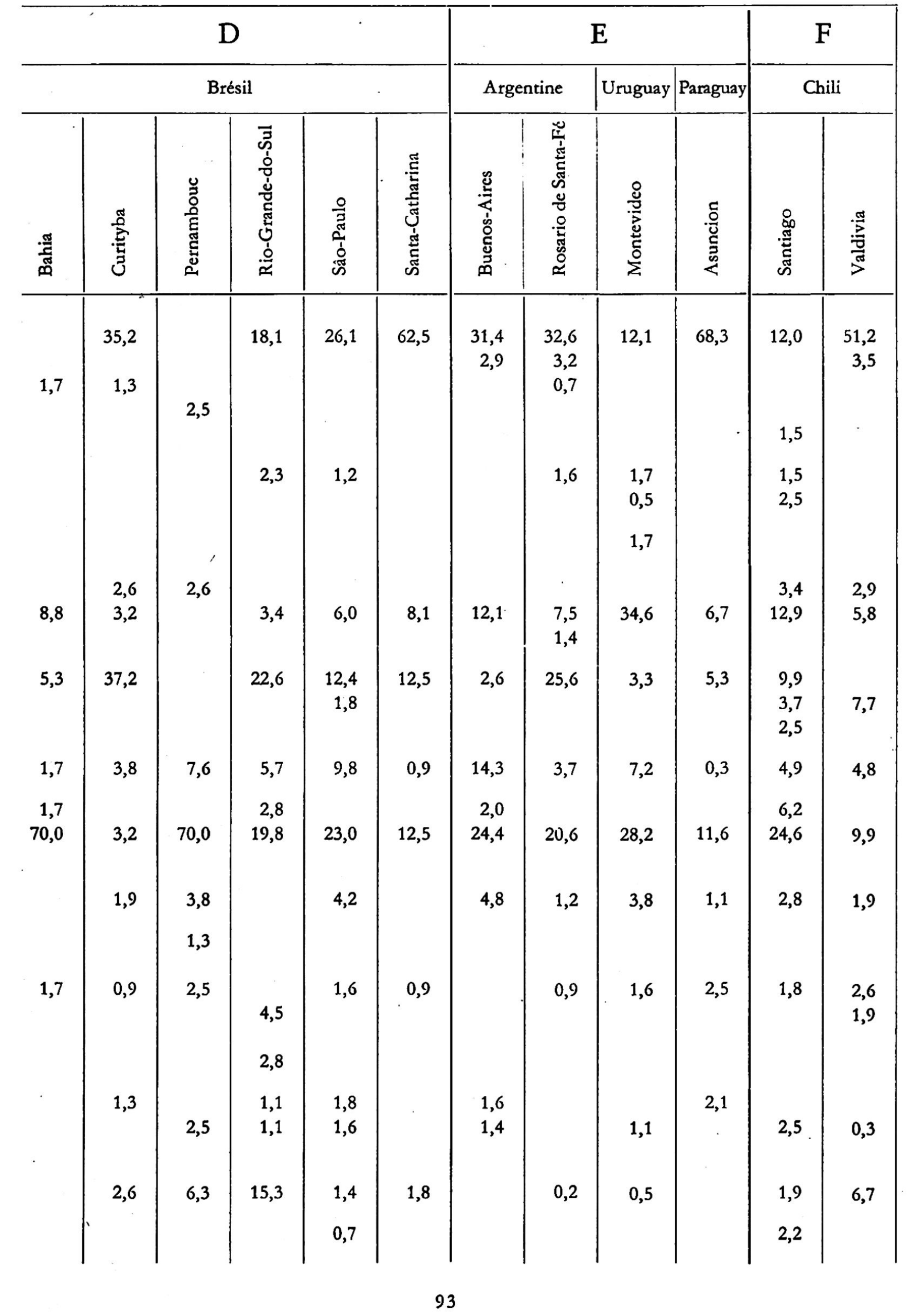




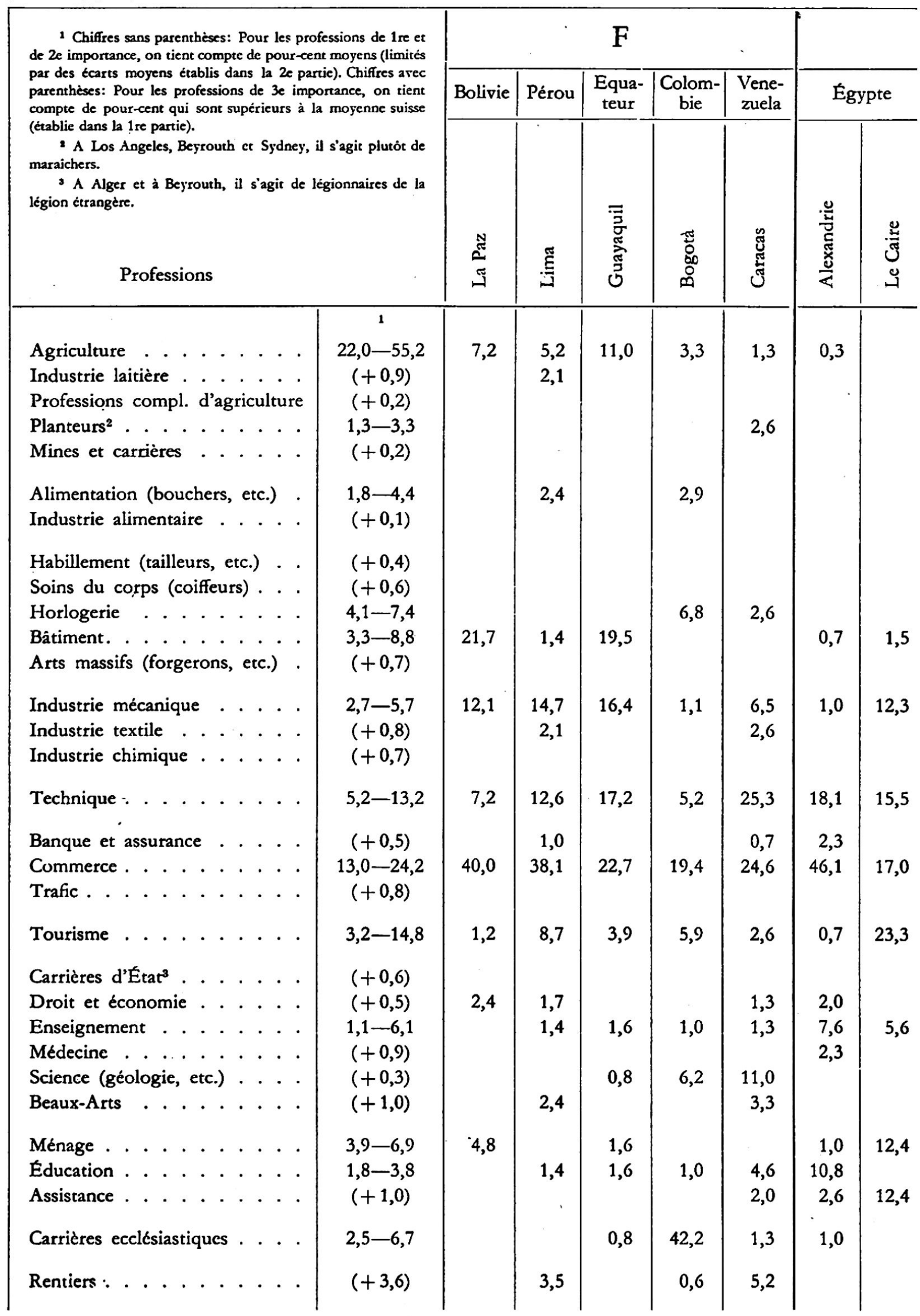




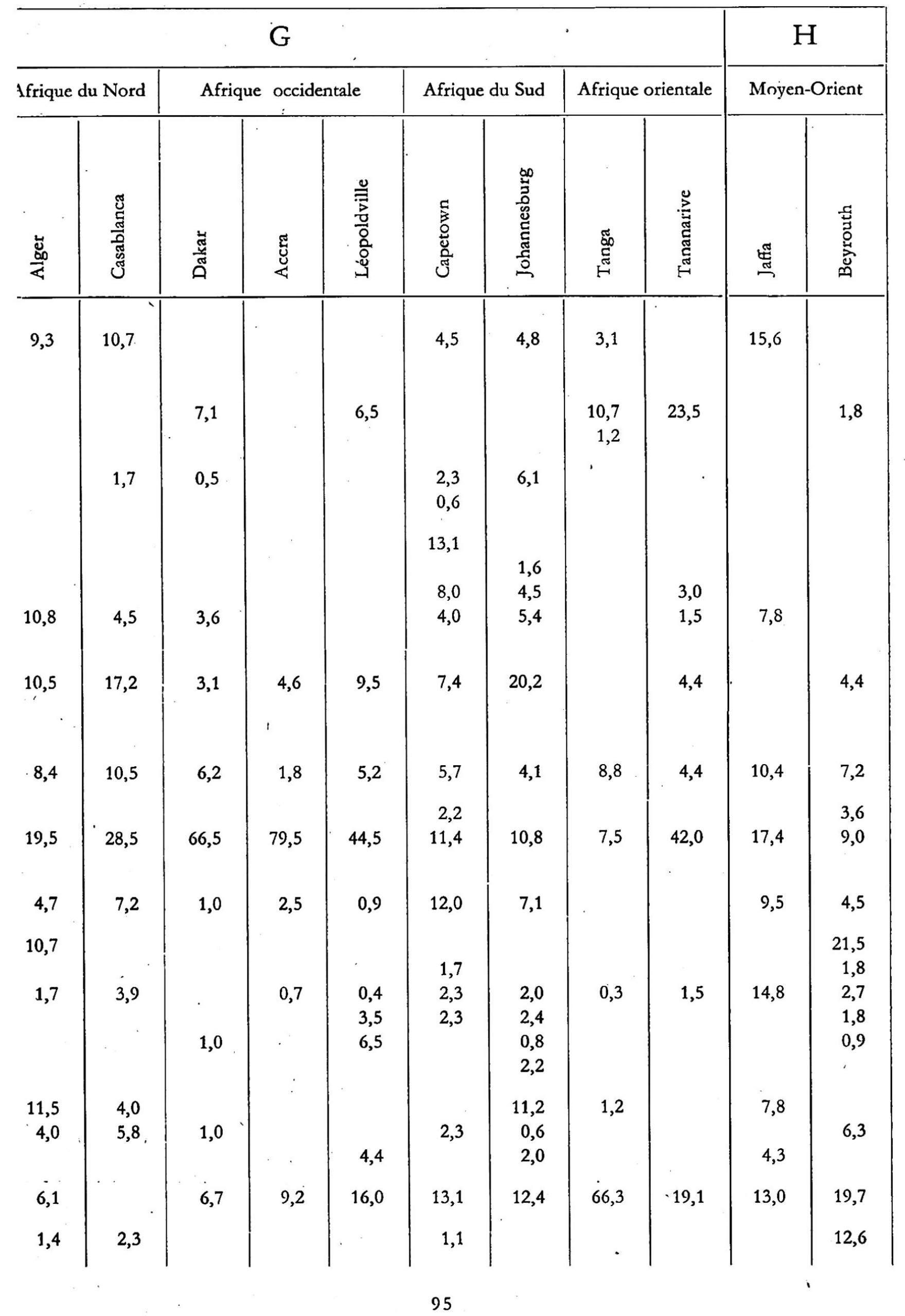


1 Chiffres sans parenthèses: Pour les professions de 1re et de $2 e$ importance, on tient compte de pour-cent moyens (limités par des écarts moyens établis dans la 2e partie). Cbiffres avec parenthèses: Pour les professions de $3 \mathrm{e}$ importance, on tient compte de pour-cent qui sont supérieurs à la moyenne suisse (ćtablie dans la 1re partie).

2 A Los Angeles, Beyrouth et Sydney, il s'agit plutôt de maraîchers.

3 A Alger et à Beyrouth, il s'agit de légionnaires de la légion étrangère.

\section{Professions}

Agriculture

Professions compl. d'agriculture

Planteurs ${ }^{2}$

Mines et carrières

Alimentation (bouchers, etc.) .

Industrie alimentaire . . . .

Habillement (tailleurs, etc.) . .

Soins du corps (coiffeurs). . .

Horlogerie . . . . . . . . .

Bâtiment. . . . . . . . . .

Arts massifs (forgerons, etc.)

Industrie mécanique . . . .

Industrie textile

Industrie chimique . . . . .

Technique . . . . . . . . . .

Banque et assurance . . . . .

Commerce . . . . . . . . . .

Trafic

Tourisme . . . . . . . . .

Carrières d'Etat ${ }^{3}$. . . . . . .

Droit et économie . . . . .

Enseignement . . . . . . .

Médecine . . . . . . . .

Science (géologie, etc.) . . . .

Beaux-Arts . . . . . . . .

Ménage . . . . . . . . .

Education . . . . . . . . .

Assistance . . . . . . . . . .

Carrières ecclésiastiques . . . $2,5-6,7$

Rentiers . . . . . . . . $(+3,6)$

$22,0-55,2$

$(+0,9)$

$(+0,2)$

$1,3-3,3$

$(+0,2)$

$1,8-4,4$

$(+0,1)$

$(+0,4)$

$(+0,6)$

$4,1-7,4$

$3,3-8,8$

$(+0,7)$

$2,7-5,7$

$(+0,8)$

$(+0,7)$

$5,2-13,2$

$(+0,5)$

$13,0-24,2$

$(+0,8)$

$3,2-14,8$

$(+0,6)$

$(+0,5)$

$1,1-6,1$

$(+0,9)$

$(+0,3)$

$(+1,0)$

$3,9-6,9$

$1,8-3,8$

$(+1,0)$

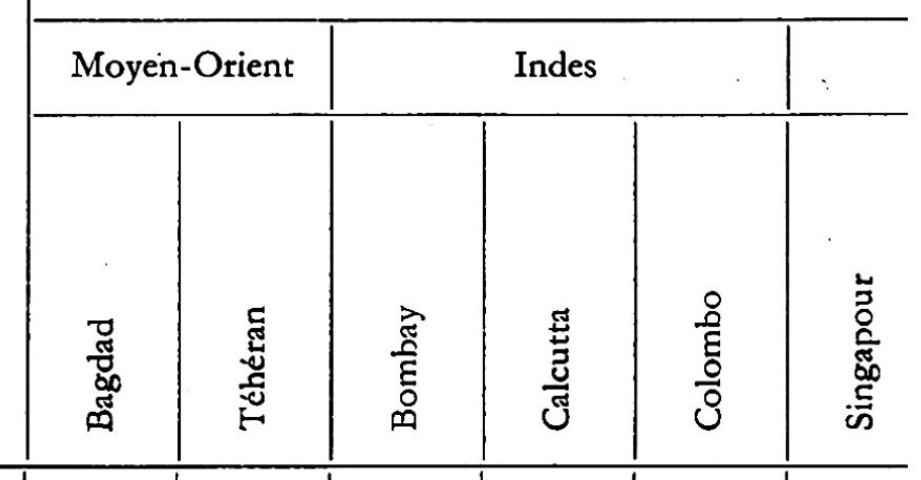

31,9

22,8

1

4,5

18,2 


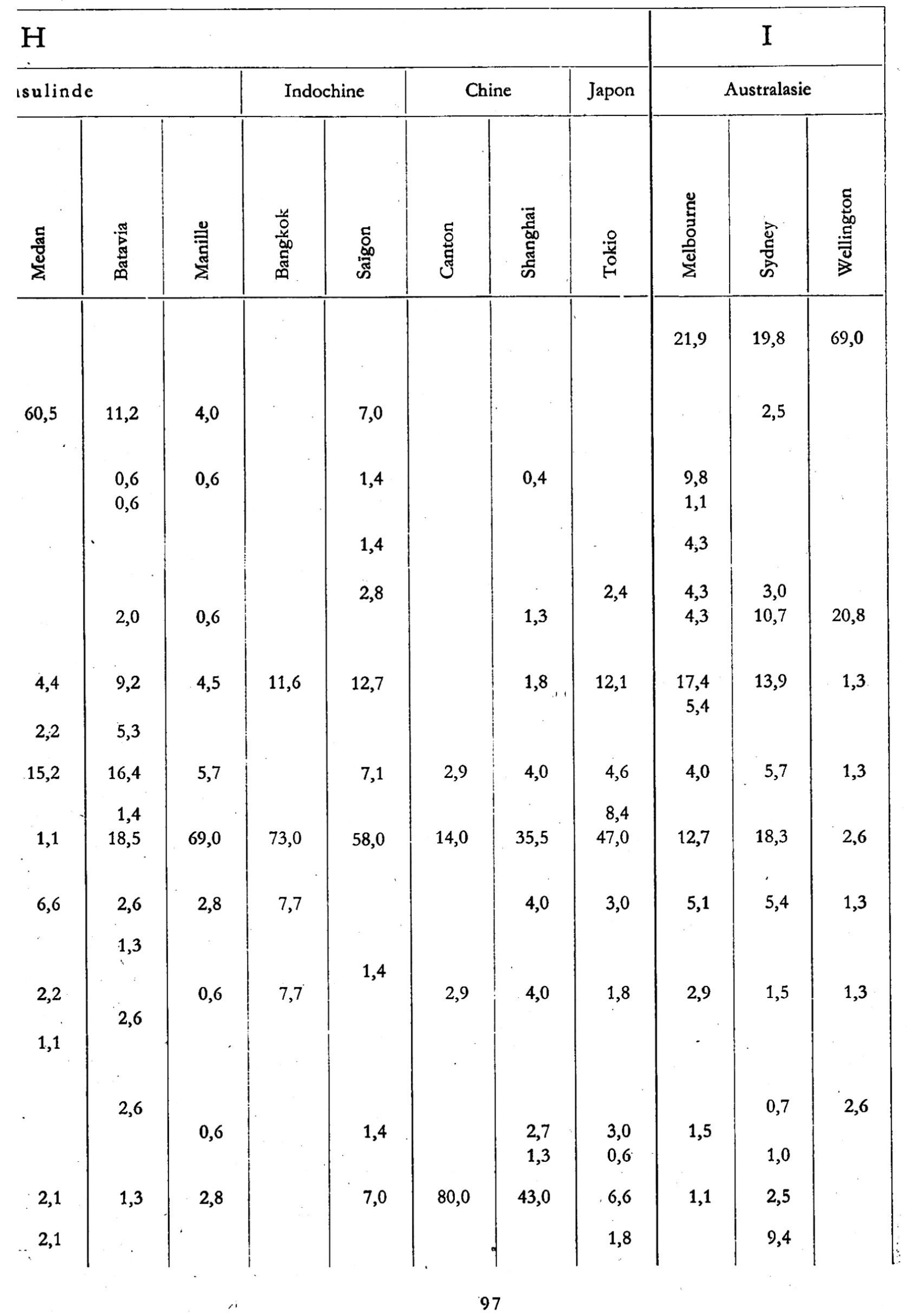




\section{Actes}

\section{BIBLIOGRAPHIE}

Fiches personnelles de 10000 émigrants suisses (partis en 1924, 1928, 1932, 1936) mises à notre disposition par l'Office fédéral d'émigration.

Réponses à ún questionnaire envoyé en 1939 à toutes les' colonies suisses de l'étranger par le Secrétariat des Suisses à l'Étranger.

Renseignements recueillis par le gérant du Service suisse de placement des techniciens, indiquant les perspectives de travail des techniciens dans les pays d'outre-mer.

Renseignements recueillis par le gérant du Service suisse de placement pour le personnel commercial, indiquant les perspectives de travail des commerçants dans les pays d'outre-mer.

\section{Statistiques}

Arealstatistik, Schweiz.: Office fédéral de statistique. Berne, Stämpfli \& Cie, 1925. $4^{\circ}, 95$ et $24 \mathrm{p}$. Annuaire statistique de la Suisse, 1930, publié par le Bureau fédéral de statistique, Berne. Kommissionsverlag A. Francke AG., $1931.8^{\circ}, 378$ p., 16 fig.

Dictionnaire géographique de la Suisse, 14e édition, par A. Jacot, Zurich. Gebr. Frey \& Kratz, 1933. $8^{\circ}, 395 \mathrm{p}$.

Statistiques de la Suisse; Bureau fédéral de statistique, Berne (1931-1945). Fascicules 28, 30, 34, $38,39,40,43,44,45,47,48,50,52,54,55,57,58,59,60,66,100,151,159$. (Recensement démographique suisse par cantons de 1930: puissance démographique, professions, état civil, etc.; recensement fédéral des entreprises du 24 août 1939.)

\section{Livres}

A. Livres mentionnés à maintes reprises:

1 Bebber, O. A., van: Südamerika; Klima, Bevölkerung und Wirtschaft, Kultur, Politik und Geschichte. Traduit de l'anglais: "The Republics of South America " (même auteur). Leipzig, Goldmann, 1939. $8^{\circ}, 343$ p., 16 pl.

2 Bernhard, H.: Grundlagen zu einer Erhebung über die schweizerische Gebirgsentvölkerung; Schriften der Schweizerischen Vereinigung für Innenkolonisation. Zurich, Vereinigung f..., Nr. 32, 1927. $8^{\circ}$, IV et 34 p.

3 Bernhard, H., Koller, A., und Caflisch, Chr.: Studien zur Gebirgsentvölkerung; Beiträge zur Agrargeographie, Nr. 4. Berne, Kümmerly \& Frey, 1928. $8^{\circ}, 286$ p.

4 Bernhard, H.: Innenkolonisation und Auswanderung. Zurich, Gebr. Leemann \& Cie, 1935. $8^{\circ}, 24 \mathrm{p}$.

5 Fuückiger, O.: Die Schweiz, Natur und Wirtschaft, 5e édition. Zurich, Schulthess \& Cie, 1934. $8^{\circ}, 234$ p., 4 cartes.

6 Früh, J.: Géographie de la Suisse. Traduction française de Charles Burky; Tome III: Géographie régionale. Lausanne, Librairie Payot \& Cie, 1944. 4², 616 p., 211 ill.

Géographie universelle, publiée sous la direction de P. Vidal DE LA Blache et L. Gallors. Paris, A. Colin. $4^{\circ}$.

7 Tome VIII: Asie occidentale, par R. Blanchard, 1929, 234 p., 48 phot. hors texte, 34 cartes et figures dans le texte.

8 Tome IX: Asie des moussons, par J. Sion, 1929, 548 p., 144 phot. hors texte, 131 cartes et figures dans le texte.

9 Tome X: L'Océanie, par P. Privat-Deschanel, 1930; Australasie:- p. 70-231, 32 phot. hors texte, 30 cartes et figures dans le texte.

10 Tome XI: Afrique septentrionale et occidentale, par A. Bernard, 1937. 518 p., 92 phot. hors texte, 131 cartes et figures dans le texte.

11 Tome XII: Afrique équatoriale, orientale et australe, par F. MAuretre, 1938. 398 p., 64 phot. hors texte, 105 cartes et figures dans le texte.

12 Tome XIII: Amérique septentrionale, par H. Baulig, 1935. 639 p., 112 phot. hors texte, 130 cartes et figures dans le texte.

13 Tome XIV: Mexique, Amérique centrale, par M. Sorre, 1928. 234 p., 48 phot. hors texte 48 cartes et figures dans le texte.

14 Tome XV: Amérique du Sud, par P. Denrs, 1927. 479 p., 84 phot. hors texte, 87 cartes et figures dans le texte.

15 Grober, J.: Der weisse Mensch in Afrika und Südamerika. Jena, Fischer, 1939. $4^{\circ}, 240$ p., 2 pl. 
16 Halkin, J.: Histoire universelle. Namur, A. Wesmael-Charlier, 1932. $8^{\circ}, 381$ p., 20 phot. hors texte.

17 Handbuch der Schweizerischen Volkswirtschaft. Vol. Ier. Berne, Benteli AG., 1939. $8^{\circ}$, p. $146-148$. Auswanderung.

18 Handwörterbuch der Schweizerischen Volkswirtschaft, Sozialpolitik und Verwaltung, par N. Reichesberg. Berne, J. Edelheim \& Cie, 1903. $8^{\circ}$, p. 380-399. Auswanderungswesen.

19 LeTsCH, E.: Leitfaden für den erdkundlichen Unterricht. Zurich, Verlag der Erziehungsdirektion, 1927. $8^{\circ}, 280$ p., 112 fig. et phot.

20 Maurer, J., Billwiller, R., und Hess, C.: Das Klima der Schweiz. 2 vol. Frauenfeld, Kommissionsverlag Huber \& Cie, 1909/10. $4^{\circ}, 302$ et 217 p., 5 pl.

21 Meyran, R.: Géographie économique de la Suisse. Lausanne, Librairie Payot \& Cie, 1943. $8^{\circ}$, IV et $120 \mathrm{p}$.

22 Mörrelr, H.: Die schweizerische Auswanderung nach Nordamerika; Thèse Berne. Langensalza, H. Beyer \& Söhne, 1920. $8^{\circ}$, VIII et 148 p.

23 NoHer, E.: Die internationalen Verträge über die Aus- und Einwanderung; Thèse Zurich. Affoltern a. A., J. Weiss, 1937. $8^{\circ}$, XIV et 195 p.

24 Oechstr, W.: Bilder aus der Weltgeschichte; 3e vol., 7e éd. Winterthour, A. Hoster, 1927. $8^{\circ}, 383 \mathrm{p}$.

25 OeChsLI, W.: Schweizergeschichte für Mittelschulen. Zurich, Verlag der Erziehungsdirektion, $1933.8^{\circ}, 448 \mathrm{p}$.

26 Office fédéral de statistique: Die Zu- und Abnahme der Bevölkerung in den Hochtälem der Schweiz; Zeitschrift für schweizerische Statistik und Volkswirtschaft, 62e an. Berne, Stämpfli \& Cie, $1926.8^{\circ}$, p. $373-383$.

27 Schmieder, O.: Länderkunde Südamerikas. Leipzig, F. Deuticke, 1932. $4^{\circ}, 252$ p., 80 phot., $4 \mathrm{pl}$.

28 Schmieder, O.: Länderkunde Nordamerikas. Leipzig, F. Deuticke, 1933. $4^{\circ}, 453$ p., 32 phot., 3 pl.

29. Schmieder, O.: Länderkunde Mittelamerikas. Leipzig, F. Deuticke, 1934. 4º, 194 p., 24 phot., 39 pl.

30 Silberschmidr, M.: Der Aufstieg der Vereinigten Staaten von Amerika zur Weltmacht. Aarau, H. R. Sauerländer \& Cie, 1941. $8^{\circ}$, XX et 498 p., 1 pl.

31 Suisses dans le vaste monde (Les); publié par la Nouvelle Société Helvétique et la Commission des Suisses à l'Étranger. Genève, Édition Sadog S.A., 1931. $8^{\circ}, 326$ p.

32 Vallière, P., de: L'émigration, ses causes, ses dangers, moyens de les enrayer; Schriften der Schweizerischen Vereinigung für Innenkolonisation, Zurich, Vereinig. f... No 10, 1920. $8^{\circ}, 31 \mathrm{p}$.

33 Zrinden, K.: Die schweizerische Auswanderung nach Argentinien, Uruguay, Chile, Paraguay; Thèse Berne. Affoltern a. A., J. Weiss, 1931. $8^{\circ}$, XXII et 209 p.

B. Livres mentionnés à une seule occasion

34 Aebixer, H.: Vorschläge zur Verbesserung der Existenzverhältnisse der Posamenterbauem im Kanton Baselland; Schriften der Schweizerischen Vereinigung für Innenkolonisation, Zurich, Vereinig. f... No 39, 1928. $8^{\circ}, 64$ p.

35 Bernhard, H.: Wirtschafts- und Siedlungsgeographie des Tösstales; Thèse Zurich. F. Lohbauer, 1912. $8^{\circ}$, IV et 185 p., 15 ill.

36 Bernhard, H.: Die Wirtschaftsprobleme des Valle Maggia; Schriften der Schweizerischen Vereinigung für Innenkolonisation, Zurich, No 36, Vereinig. f..., 1928. $8^{\circ}$, IV et $47 \mathrm{p}$.

37 BIERI, O.: Volksdichte und Besiedelung des bernischen Mittellandes; Thèse Berne. Hallersche Buchdruckerei, 1909. $8^{\circ}, 95$ p., 2 pl.

38 Biermann, $\mathrm{C}_{\text {H.: }}$ La Vallée des Conches en Valais; Thèse Lausanne. Imprimeries Réunies, 1907. $8^{\circ}, 151$ p., 24 pl.

39 Fü̈CKıger, O.: Die Wanderungen der Berner Bauern; Mitteilungen der GeographischEthnographischen Gesellschaft in Zürich. F. Lohbauer S.A., 1920. $8^{\circ}$, p. 65-74.

40 Forrer, N.: Zur Anthropogeographie des alpinen Thurtales; Thèse Zurich. Bülach, Scheuchzer \& Steinemann, 1925. $8^{\circ}$, VIII et 76 p., 2 pl.

41 FREY, H.: Das Emmental; Jahresbericht der Geographischen Gesellschaft Bern; Vol. 22. Berne, A. Francke, 1911. $8^{\circ}$, p. 29-112. 
42 HüssER, P.: Die Entvölkerung der urschweizerischen Gebirgstäler; Einsiedeln, Benziger \& $\mathrm{Cie}, 1927.8^{\circ}, 23 \mathrm{p}$.

43 KaltenbaCH, E.: Beiträge zur Anthropogeographie des Bodenseegebietes; Thèse Bâle. E. Kaltenbach, $1922.8^{\circ}, 364$ p. 25 pl.

44 LeChNer, E.: Die periodische Auswanderung der Engadiner und anderer Bündner. Samaden. Engadin-Press Cie, $1909.8^{\circ}$, IV et 116 p., 9 pl.

45 LeEmanN, E.: Wirtschafts- und siedlungsgeographische Untersuchungen im Gebiet zwischen Albis und Reuss; Thèse Zurich. Genossenschaftsdruckerei, 1926. $8^{\circ}, 84$ p., 9 pl.

46 LERCH, E.: Die bernische Auswanderung nach Amerika; Blätter für bernische Geschichte, 5e année, fasc. 4. Berne, G. Grunau, 1909. $8^{\circ}$, p. 295-325.

47 LoBsiger, G.: L'émigration de Suisse pour outre-mer de 1887 à 1938. Le Globe, LXXXV. Genève, Librairie Payot, 1946. $8^{\circ}$, p. $31-62,3$ graph., 5 cartes.

48 Nelz, W.: Das Mendrisiotto; anthropogeographisch-statistisch dargestellt. Zurich, Dynamo-Verlag, 1937. $8^{\circ}, 107$ p., 2 fig. 1 pl.

49 Nussbaum, F.: Die Landschaften des bernischen Mittellandes. Berne, K. J. Wyss, 1912. $8^{\circ}$, II et 48 p., 4 fig.

50 Oechslin, M.: Aus dem Urner Wirtschaftsleben; Zeitschrift für Schweizerische Statistik und Volkswirtschaft, 62e année, fasc. 1, Berne, Stämpfli \& Cie, 1926. $8^{\circ}$, p. $233-260$.

51 Oтr, A.: Die Siedlungsverhältnisse beider Appenzell; Thèse Zurich. F. Lohbauer, 1915. $8^{\circ}, 83$ et 39 p., 20 phot. dans le texte.

52 PESCH, A. Th.: Entvölkerung und Landflucht in der Zentralschweiz. Bâle, G. Böhm, 1926. $8^{\circ}, 43 \mathrm{p}$.

53 ReBsamen, H.: Zur Anthropogeographie der Urner Alpen; Thèse Zurich. Wetzikon, J. Wirz, 1919. $8^{\circ}, 141$ p., 8 fig., 2 pl.

54 Ringwald, F.: Wirtschaft und Besiedlung des Kantons Obwalden; Thèse Zurich. Lucerne, E. Haag, 1934. $8^{\circ}$, IV et 87 p., 20 fig., 23 phot.

55 Sсносн, A.: Beiträge zur Siedlungs- und Wirtschaftsgeographie des Zürichseegebietes; XVII. Jahresbericht der Geographisch-Ethnographischen Gesellschaft in Zürich pro 1916/17. Zurich, Beer \& Cie, 1917. $8^{\circ}, 296$ et 36 p., 10 pl.

56 Strüву, A.: Hilfe für die Gebirgsbevölkerung, 1re partie. Berne, Zimmermann \& Cie, 1928. $8^{\circ}, 99 \mathrm{p}$.

57 StUder, H.: Der Einfluss der Industrialisierung auf die Kulturlandschaft des aargauischen Mittellandes; Thèse Zurich. Horgen, Gebr. Studer, 1939. 8, 207 p.

58 Theus, A.: Systematische Untersuchungen der bündnerischen Bevölkerungsverschiebungen, deren Ursachen und Folgen; Thèse Berne. Coire, von Sprecher \& Cie, 1936. $8^{\circ}, 184$ p.

59 WiNKLER, E.: Veränderungen der Kulturlandschaft im zürcherischen Glattal; Thèse Zurich, Mitteilungen der Geographisch-Ethnographischen Gesellschaft in Zürich, Bd. 36, 1935/1936. Zurich, Aschmann \& Scheller S. A., 1936. 80, IV et 163 p., 6 pl., 1 carte.

60 Ziegler, F.: Land und Leute des Sihlplateaus; Schweizer Geograph, No 3, 2e année. Berne, Kümmerly \& Frey, $1925.8^{\circ}$, p. 33-38.

61 Zoppr, D.: L'emigrazione ticinese, sue cause e suoi effetti. Lugano, Arte grafiche, 1943, $4^{\circ}, 89$ p.

\section{TABLE DES MATIÈRES}

Introduction . . . . . . . . . . . . . . . . . . . 1

Première partie: Analyse de l'émigration suisse hors d'Europe. . . . . . . 2

Chapitre premier: L'appareil statistique . . . . . . . . . . . . . . . 2

A. Etendue de la recherche . . . . . . . . . . . . . . . . . . . . . 2

B. Les données statistiques. . . . . . . . . . . . . . . . . . . . . . . . . . . . . 2

$1^{\circ}$ Le relevé des données statistiques . . . . . . . . . . . . . . . . . . . . . . . 3

$2^{\circ}$ Le dépouillement . . . . . . . . . . . . . . . . . . . . . . . . . . . 3

C. L'évaluation de l'intensité du mouvement migratoire . . . . . . . . . . . . . . . . 3

$1^{\circ}$ Les moyennes pondérées . . . . . . . . . . . . . . . . . . . . . . . . . . . 4

$2^{\circ}$ Les écarts moyens. . . . . . . . . . . . . . . . . . . . . . . . 4 
Chapitre II : Évolution de l'émigration suisse . . . . . . . . . . . . . . . . . . 6

A. L'émigration suisse de 1800 à 1914 . . . . . . . . . . . . . . . . . . . . . . . 6

B. L'émigration suisse après $1914 \ldots \ldots$. . . . . . . . . . . . . . . . . . . . . . . 8

C. L'émigration transocéanique dans les années 1924, 1928, 1932, 1936 . . . . . . . . . . . 10

Chapitre III: La composition de l'émigration . . . . . . . . . . . . . . . . . . . . . 10

A. La structure professionnelle du courant migratoire et la participation des différentes professions à l'émigration . . . . . . . . . . . . . . . . . . . . . 10

$1^{\circ}$ Participation des diverses catégories professionnelles à l'émigration . . . . . . 10

$2^{\circ}$ L'émigration suisse rapportée à l'effectif global des diverses catégories professionnelles 14

$3^{\circ}$ L'émigration en fonction des subdivisions des catégories professionnelles . . . . . . . 14

$4^{\circ}$ Les individus avec ou sans activité économique . . . . . . . . . . . . . . . . 15

B. L'émigration suivant le sexe et l'état civil . . . . . . . . . . . . . . . . . . . . . . 17

C. L'émigration suivant l'âge. . . . . . . . . . . . . . . . . . . . . . . . . . . . 19

$1^{\circ}$ Les différentes classes d'âge et l'émigration . . . . . . . . . . . . . . . . . . . 19

$2^{\circ}$ L'activité professionnelle dans les différentes classes d'âge. . . . . . . . . . . . 20

$3^{\circ}$ L'émigration des différentes classes d'âge en fonction du sexe et de l'état civil . . . . 21

$4^{\circ}$ Emigrants avec ou sans activité économique par classes d'âge . . . . . . . . . . . 22

Deuxième partie: L'émigration transocéanique au départ de la Suisse . . . . 23

Chapitre IV: Répartition des émigrants par unités administratives . . . . . . . . . . . . . 23

A. Intensité de l'émigration transocéanique par cantons . . . . . . . . . . . . . . . 23

B. Intensité de l'émigration transocéanique dans les différentes zones de départ en 1924, 1928, 1932,1936 . . . . . . . . . . . . . . . . . 23

$1^{\circ}$ L'intensité de l'émigration par districts . . . . . . . . . . . . . . . . . . . . 23

$2^{\circ}$ L'intensité de l'émigration par cantons . . . . . . . . . . . . . . . . . . . 28

C. La composition du mouvement migratoire dans les différentes zones de départ . . . . . 29

$1^{\circ} \mathrm{La}$ participation des différentes professions à l'émigration . . . . . . . . . . . . 29

$2^{\circ}$ L'émigration en fonction du sexe et de l'état civil . . . . . . . . . . . . . . . 31

Chapitre V: L'émigration dans ses rapports avec les régions naturelles de la Suisse . . . . . . 33

A. Régions alpestres à forte intensité d'émigration . . . . . . . . . . . . . . . . 33

$1^{\circ}$ L'Oberland bernois . . . . . . . . . . . . . . . . . . . . . . 33

$2^{\circ}$ Le lac des Quatre-Cantons et ses environs . . . . . . . . . . . . . . . . 35

$3^{\circ}$. Les Alpes uranaises et glaronaises . . . . . . . . . . . . . . . . . . . . . . . . . . . . . . . . 37

$4^{\circ}$ Les Alpes thuranaises . . . . . . . . . . . . . . . . . . . . . . . . . . . . . . . . . . . . . . 38

$5^{\circ}$ Le Tessin . . . . . . . . . . . . . . . . . . . . . . . . 41

B. Régions alpestres à faible intensité d'émigration . . . . . . . . . . . . . . . . . . . 43

$1^{\circ}$ Les Grisons . . . . . . . . . . . . . . . . . . . . . . . . 43

$2^{\circ} \mathrm{Le}$ Valais . . . . . . . . . . . . . . . . . . . . . . . . . . . . . 45

$3^{\circ}$ Les Préalpes romandes. . . . . . . . . . . . . . . . . . . . . . . . . . . . 46

C. L'émigration jurassienne . . . . . . . . . . . . . . . . . . . . . . . . . . . . 47

$1^{\circ}$ Le Jura vaudois et neuchâtelois . . . . . . . . . . . . . . . . . . . . . . . . 47

$2^{\circ}$ Le Jura bernois et soleurois . . . . . . . . . . . . . . . . . . . . . . . . . . . . . . . 48

$3^{\circ}$ Le Jura bâlois et argovien . . . . . . . . . . . . . . . . . . . . . . . . . . . . . 50

D. L'émigration dans le Mittelland . . . . . . . . . . . . . . . . . . . . . . . . . 51

$1^{\circ}$ Le Plateau suisse romand. . . . . . . . . . . . . . . . . . . . . 51

$2^{\circ}$ Le Plateau bernois et soleurois . . . . . . . . . . . . . . . . . . . . . . . . 52

$3^{\circ} \mathrm{Le}$ Plateau argovien et lucernois. . . . . . . . . . . . . . . . . . . . . . 53

$4^{\circ}$ Le Plateau zurichois . . . . . . . . . . . . . . . . . . . . . . . . . . . . . 54

$5^{\circ} \mathrm{La}$ Thurgovie ......................... . . . 55

$6^{\circ}$ Les grands centres urbains . . . . . . . . . . . . . . . . . . . . 55

Troisième partie: Les zones de destination de l'émigration transocéanique . . 56

Chapitre VI: La répartition géographique de l'émigration outre-met . . . . . . . . . . . 56

A. Variations de l'intensité de l'émigration suivant la destination . . . . . . . . . . . 56

B. Variations dans la composition de l'émigration suivant la destination . . . . . . . . . . 59

$1^{\circ}$ Les professions . . . . . . . . . . . . . . . . . . . . . . . . . . . 59

$2^{\circ}$ Le sexe et l’âge . . . . . . . . . . . . . . . . . . 62 
Chapitre VII: Les zones de destination: les pays tempérćs . . . . . . . . . . . . . . . . . 62

A. Pays à économie différenciée et pays neufs . . . . . . . . . . . . . . . . . . . . . 63

$1^{\circ}$ L'Amérique ....................... 63

Les États-Unis . . . . . . . . . . . . . . . . . . . . . . . 63

Le Canada . . . . . . . . . . . . . . . . . . . . . 65

Les Etats de la Plata . . . . . . . . . . . . . . . . . . . . . . 66

Le Brésil méridional . . . . . . . . . . . . . . . . . . . . . . . 68

Le Chili . . . . . . . . . . . . . . . . . . . . . . . 69

$2^{\circ}$ L'Afrique . . . . . . . . . . . . . . . . . . . . . 69

L'Afrique du Nord . . . . . . . . . . . . . . . . . . 69

L'Afrique du Sud . . . . . . . . . . . . . . . . . . . . . . 71

$3^{\circ}$ L'Australie et la Nouvelle-Zélande . . . . . . . . . . . . . . . . . . . 72

B. Pays à faible capacité d'absorption . . . . . . . . . . . . . . . . . . . . 73

Moyen-Orient . . . . . . . . . . . . . . . . . . 73

Extrème-Orient . . . . . . . . . . . . . . . 74

Chapitre VIII: Les zones de destination: les pays tropicaux . . . . . . . . . . . . . . . . . 75

A. L’Amérique . . . . . . . . . . . . . . . . . . . . . . . . . . . . . 75

L'Amérique centrale . . . . . . . . . . . . . . . . . . . . 75

Le Brésil tropical . . . . . . . . . . . . . . . . . . . . . . . . . . . . . 76

Les pays andins $($ sauf le Chili) . . . . . . . . . . . . . . . . . . . . . . . . 77

B. L'Afrique . . . . . . . . . . . . . . . . . . . . . 78

L'Afrique occidentale et le Congo . . . . . . . . . . . . . . . . . . . . . . . . . 78

L'Afrique orientale et Madagascar . . . . . . . . . . . . . . . . . . . . . . . . . . 79

C. L'Asie . . . . . . . . . . . . . . . . . . . . . . . . . . 80

L'Inde britannique . . . . . . . . . . . . . . . . . . . . . . . . . . . 80

Insulinde et Malaisie . . . . . . . . . . . . . . . . . . . . . . . . . 81

L'Indochine . . . . . . . . . . . . . . . . . . . . . . . . . . 82

Conclusion . . . . . . . . . . . . . . . . . . . . . . . . . 82

Annexes. . . . . . . . . . . . . . . . . . . . . . 86

Bibliographie . . . . . . . . . . . . . . . . . . . . . 98

\section{Tableaux}

\section{TABLE DES TABLEAUX ET DES FIGURES}

1 Quelques moyennes pondérées d'émigrants-agriculteurs . . . . . . . . . . . . . 4

2 Quelques écarts moyens dans le mouvement d'émigration suisse . . . . . . . . . . . . 5

3 Quelques écarts moyens pondérées s'appliquant aux émigrants-agriculteurs . . . . . . . . 6

4 Les catégories professionnelles; leur participation au mouvement d'émigration . . . . . . . 11

5 Emigrants avec ou sans activité économique . . . . . . . . . . . . . . . . . . . . 15

6 L'émigration en fonction du sexe et de l'état civil . . . . . . . . . . . . . . . . . . . . 17

7 Composition des professions en fonction du sexe et de l'état civil . . . . . . . . . . . . 18

8 Participation des différentes classes d'âge à l'émigration. . . . . . . . . . . . . . . . . . . . 19

9 Participation de certaines communes suisses au mouvement d'émigration . . . . . . . . . 27

10 Le courant d'émigration en 1924, 1928, 1932, 1936 vers les différentes destinations . . . . . 57

11 Les ressortissants suisses dans les circonscriptions suisses d'outre-mer en 1939 . . . . . . 57

\section{Annexes}

1 Les catégories professionnelles et leur participation au mouvement d'émigration . . . . . . 86

2 Les districts suisses et l'émigration . . . . . . . . . . . . . . . . . . . . 87

3 Composition par professions des colonies suisses d'outre-mer . . . . . . . . . . . . . . 90

\section{Figures}

1 L'émigration suisse de 1850 à $1940^{\circ}$. . . . . . . . . . . . . . . . . . . . . . . . . 9 9

2 Participation des catégories professionnelles à l'émigration en pour-cent du nombre des émigrants 13

3 Participation des catégories professionnelles à l'émigration en pour-mille de l'effectif global de chaque catégorie 
4 Individus avec ou sans activité économique par catégories professionnelles . . . . . . . . 16

5 L'émigration en fonction du sexe et de l'état civil . . . . . . . . . . . . . . . . . . . . 17

6 Les différentes classes d'âge et l'émigration . . . . . . . . . . . . . . . . . . . . . . . 19

7 L'activité professionnelle dans les différentes classes d'âge. . . . . . . . . . . . . . . . . . 20

8 L'émigration des différentes classes d'âge en fonction du sexe et de l'état civil . . . . . . . . 21

9 Émigrants avec ou sans activité économique par classes d'âge . . . . . . . . . . . . . . 22

10 Intensité de l'émigration dans les différents districts suisses . . . . . . . . . . . . . . 25

11 Structure professionnelle du courant d'émigration par régions de départ . . . . . . . . 29/30

12 Composition du courant d'émigration (sexe et état civil) par régions de départ. . . . . . . . 32

13 L'émigration suisse en 1924, 1928, 1932, 1936 et les colonies suisses d'outre-mer en 1939 . . 60

14 Sexe et âge des ressortissants suisses habitant nos colonies d'outre-mer . . . . . . . . 62

\section{DIE SCHWEIZERISCHE AUSSEREUROPÄISCHE AUSWANDERUNG WÄHREND DER ZWISCHENKRIEGSZEIT (1919-1939)}

Während der Zwischenkriegszeit verstärkt sich die Auswanderung jeweils bei Besserung der allgemeinen Weltwirtschaftslage und vermindert sich in Krisenzeiten. Die einzelnen Berufszweige sind daran nicht alle gleich stark beteiligt. Im Verhältnis zur Zahl der Auswanderer treten die Landwirte, im Verhältnis zur Gesamtbevölkerung jedoch Techniker und liberale Berufe stark hervor. Krisenjahre verursachen eine andere berufliche Schichtung des Auswanderungsstromes als Prosperitätsjahre. Der Großteil der Auswanderer sind ledige Männer, und die Mehrzahl davon hat ein Alter zwischen 20 und 30 Jahren. Die Auswanderungsintensität ist je nach Herkunftsgebiet verschieden. Zentren starker Auswanderung finden sich in gewissen Teilen der Alpen, andere Zentren in den größeren Städten. Im Mittelland, im Jura wie auch in den Alpen wächst die Auswanderungsintensität von Südwesten nach Nordosten. Charakteristisch für die berufliche Zusammensetzung der Auswanderung ist ein starkes Úberwiegen der Landwirte in den Alpengebieten, der Kaufleute in den Städtezentren, der Techniker in den Industriekantonen der Nordschweiz, der Bauarbeiter im Tessin, der Uhrenmacher im Jura, der Hotelangestellten in den Zentrẹn des Fremdenverkehrs. Die hohe Auswanderungsintensität gewisser Berggegenden ergibt sich aus den schlechten klimatischen Bedingungen, ungenügenden Verkehrsverbindungen und dem Fehlen von Industrie. Stärke und Richtung der Auswanderung werden auch durch das physische, wirtschaftliche und soziale Milieu der überseeischen Länder mitbestimmt. Das Klima verhindert eine massive Einwanderung von Schweizern in den tropischen Gebieten, fördert sie hingegen in den Ländern der gemäßigten Zone. Wirtschaftliche und demographische Faktoren vermindern die Einwanderungsmöglichkeiten in den asiatischen Ländern. Die berufliche Zusammensetzung des schweizerischen Einwanderungsstromes desgleichen hängt von physischen und wirtschaftlichen Faktoren ab: Schweizerische Landwirte überwiegen in der gemäßigten Zone, Kaufleute in tropischen Gebieten, während Techniker mehr an die Standorte von Rohstoffen und Hauptindustrien gebunden sind.

\section{L'EMIGRAZIONE SVIZZERA FUORI D'EUROPA NELL'INTERVALLO FRA LE DUE GUERRE (1919-1939)}

Nel periodo intermedio fra le due guerre mondiali, l'emigrazione s'intensifica ognora col migliorare della situazione economica universale, e diminuisce in tempi di crise. Non ciascuno dei rami professionali vi partecipa in uguale forza. In rapporto al numero degli emigranti, più preponderanti figurano gli agricoltori, in rapporto al totale della popolazione, invece, i tecnici e le professioni libere. Anni di crisi producono una diversa stratificazione professionale di quella di anni prosperosi, nella corrente emigratoria. La più gran parte degli emigranti sono uomini celibi, e, la maggioranza di questi, hanno un' età tra i venti $\mathrm{e}$ i trent'anni. L'intensità dell'esodo è diversa a seconda della regione di provenienza. Centri di pronunciata emigrazione si trovano in certe parti delle Alpi, altri centri sono le maggiori città. Nella Svizzera centrale, nel Giura come anche nelle Alpi, cresce l'intensità dell'emigrazione da sudovest a nordest. Caratteristico, per la struttura professionale dell'emigrazione, è la forte preponderanza degli agricoltori in regione alpestre, dei commercianti nei centri urbani, dei tecnici nei cantoni industriali della Svizzera settentrionale, delle maestranze edili nel Ticino, degli orologiai nel Giura, degli impiegati d'albergo nei centri turistici. L'alta intensità d'emigrazione di certe località alpestri, risulta dalle cattive condizioni climatiche, dalle insufficienti possibilità di comunicazione, come dal manco d'industrie. Vigore e direzione dell'emigrazione viene anche condeterminata dalla struttura fisica, economica e sociale dei paesi d'oltremare. Il clima ostacola una compatta immigrazione di svizzeri nelle località tropicali, la stimola invece in paesi di zona temperata. Fattori economici e demografici diminuiscono le possibilità di immigrazione nei paesi asiatici. La composizione professionale della corrente emigratoria svizzera dipende in egual modo da fattori fisici ed economici: agricoltori elvetici preponderano nelle zone temperate, commercianti in paesi tropici, ove invece i tecnici sono più legati alla sede delle materie prime e delle principali industrie. 